\title{
Positive and gay: Safer sex by principle.
}

\author{
Citation for published version (APA):
}

van Kesteren, N. (2007). Positive and gay: Safer sex by principle. [Doctoral Thesis, Maastricht University]. Maastricht University. https://doi.org/10.26481/dis.20071026nk

Document status and date:

Published: 01/01/2007

DOI:

10.26481/dis.20071026nk

Document Version:

Publisher's PDF, also known as Version of record

\section{Please check the document version of this publication:}

- A submitted manuscript is the version of the article upon submission and before peer-review. There can be important differences between the submitted version and the official published version of record.

People interested in the research are advised to contact the author for the final version of the publication, or visit the DOI to the publisher's website.

- The final author version and the galley proof are versions of the publication after peer review.

- The final published version features the final layout of the paper including the volume, issue and page numbers.

Link to publication

\footnotetext{
General rights rights.

- You may freely distribute the URL identifying the publication in the public portal. please follow below link for the End User Agreement:

www.umlib.nl/taverne-license

Take down policy

If you believe that this document breaches copyright please contact us at:

repository@maastrichtuniversity.nl

providing details and we will investigate your claim.
}

Copyright and moral rights for the publications made accessible in the public portal are retained by the authors and/or other copyright owners and it is a condition of accessing publications that users recognise and abide by the legal requirements associated with these

- Users may download and print one copy of any publication from the public portal for the purpose of private study or research.

- You may not further distribute the material or use it for any profit-making activity or commercial gain

If the publication is distributed under the terms of Article $25 \mathrm{fa}$ of the Dutch Copyright Act, indicated by the "Taverne" license above, 
Nicole

van

Kesteren

Positive

and gay:

safer sex

by principle 



\section{Positive and gay:}

\section{Safer sex by principle}

proefschrift

ter verkrijging van de graad van doctor aan de Universiteit Maastricht, op gezag van de Rector Magnificus, prof.mr. G.P.M.F. Mols,

volgens het besluit van het College van Decanen, in het openbaar te verdedigen op vrijdag 26 oktober 2007 om 12.00 uur door

Nicole Maria Catharina van Kesteren 


\section{promotores}

Prof. dr. H.J. Hospers

Prof. dr. G.J. Kok

\section{beoordelingscommissie}

Prof. dr. H.P. Schaalma (voorzitter)

Prof. dr. L.K. Bartholomew

Dr. U. Davidovich (GGD Amsterdam)

Prof. dr. J.C.J.M. de Haes (AMC/Universiteit van Amsterdam)

Prof. dr. N.K. de Vries

\section{colophon}

Lay-out: Maarten Schrijvers, Qualisys ${ }^{\circledR}$

Cover design: Fenne Roefs ${ }^{C}$

Production: Uitgeverij Boxpress

(C) Nicole van Kesteren, Leiden, 2007

All rights reserved

ISBN 978-90-8891-010-4

The studies were funded by The Netherlands Organisation for Health Research and Development (ZonMw).

Abbott BV, Boehringer Ingelheim BV, Bristol-Myers Squibb BV, Roche Nederland $\mathrm{BV}$, and Pfizer BV financially supported the printing and distribution of this thesis. 
Voor Liesbeth en Minoes 



\section{Dankwoord}

Harm Hospers en Gerjo Kok wil ik bedanken voor de mogelijkheid en ondersteuning die ze mij hebben geboden om dit proefschrift te schrijven én tot een goed einde te brengen. Cor Blom, Peter Dankmeijer, Hanneke de Haes, Eric Kollen en Robert Witlox bedank ik voor hun deelname aan de begeleidingscommissie, goede adviezen en hulp, Jan Schippers, omdat hij de zelfhulpgids heeft geschreven, Wencke de Wildt, voor haar waardevolle bijdrage aan de ontwikkeling van het gespreksprotocol en de inspirerende wijze waarop zij de hiv-consulenten heeft getraind en Anne van Stralen, omdat zij de trainingen voor de wachtlijst-controlegroep heeft verzorgd tijdens mijn afwezigheid. In het bijzonder wil ik Bouko Bakker bedanken voor het vertrouwen dat hij vanaf het begin af aan in mij had, voor zijn hulp en steun in alle fasen van het onderzoek en voor de 'gezellige' kopjes koffie die we samen dronken als er weer eens overlegd moest worden. Gerard van Breukelen wil ik bedanken voor zijn statische begeleiding en betrokkenheid. Margaret Kavanagh heeft mij erg geholpen door alle Engelse teksten te editen, hartelijk dank hiervoor! Dirk Franssens bedank ik omdat hij ervoor zorgde dat de interventie-studie door 15 METC's werd goedgekeurd en Candy Gijssen voor haar grote inzet voor het project, ook toen ik met zwangerschapsverlof was. Verder dank ik Cheryl Roumen en Anita van Riemsdijk omdat zij met hun afstudeeronderzoek een belangrijke bijdrage hebben geleverd aan de totstandkoming van dit proefschrift en Fenne Roefs en Maarten Schrijvers voor hun creatieve uitspattingen, waardoor het proefschrift er zo mooi uitziet. Also special thanks to Kay Bartholomew, Klasien Horstman, and Nanne de Vries for inspiring me at the exact right time in the research process.

Veel dank aan alle hiv-consulenten die hebben bijgedragen aan het onderzoek en voor de prettige sfeer waarin het onderzoek heeft plaatsgevonden: Saskia Baas, Petra van Bentum, Anja van den Berg, Marjolein Bosch, Rita Deenenkamp, Aukje van Diggelen, Willemien Dorama, Sandra Faber, Bert Fledderus, Karin Grintjes, Margot Groot, Linda Hegeman, Klaas Hoeksema, Rob Korte, Betsy Kortsen, Bob Krijnen, Annette Kritsos, Nienke Langebeek, Chris Leenders, Marina Lightenberg, Narda van der Meché, Piet van der Meulen, Debbie van der Meijden, Suzanne de Munnik, Iman Padmos, Joke Patist, Hanneke Paap, Elize Prins, Daniëlle Pronk, Sylvia Rotteveel, Cora Ruissen, Rick Santegoeds, 
Jolanda Schippers, Marijke Schoemaker, Judith Tesselaar, Frieda van Truijen, Bernadette van de Ven, Ron Vergoossen, Sigrid Vervoort, Sieds Wildenbeest, Rosanna ten Wolde, Anneke van IJperen, Bert Zomer en Laura Zonneveld.

Ik wil ook mijn oud-collega's bij Experimentele Psychologie bedanken voor de leuke werksfeer en meer speciaal mijn oud-collega's van Work \& Social Psychology, ook al was ik in de laatste fasen van het project nog maar weinig in Maastricht. Anne, David, Fraukje, Madelief, Marieke (W), Pascal en Rob bedankt voor de vele gezellige momenten, swingende feestjes, en goede gesprekken, Arjan, voor je optimisme en vriendschap, Marieke (K), omdat ik me geen fijnere kamergenoot had kunnen wensen, Katy, voor alle (kranten)knipsels, ansichtkaarten en aanmoediging, Nienke, omdat je altijd geïnteresseerd en betrokken bent, Christel, möchte ich ganz herzlich bedanken für unsere innige Beziehung und das starke Gefühl von Seelenverwandtschaft en Anne-Marie voor je niet-aflatende steun en kritische blik. Ook alle andere vrienden die ik al zo lang ken wil ik bedanken voor hun steun en betrokkenheid.

Mijn ouders kan ik niet genoeg bedanken voor alles wat zij voor me hebben gedaan, evenals Marcel, mijn liefste broer. Mijn vader, voor zijn vertrouwen, trots en goede raad, mijn moeder, omdat ze mij op allerlei mogelijke manieren bijstaat, en niet alleen tijdens het schrijven van dit proefschrift (!), en Marcel, omdat hij mij ervaringen altijd vanuit een nieuwe, interessante invalshoek laat bezien. Lieve Pepijn, jou wil ik bedanken voor alle steun en inspiratie de afgelopen jaren, voor alles wat we samen delen, maar bovenal voor wie je bent. Zonder jullie had ik dit proefschrift niet kunnen schrijven!

Ten slotte, gaat veel dank gaat uit naar alle hiv-positieve mannen die hebben deelgenomen aan het onderzoek. Hopelijk dat hun bijdrage - in de vorm van dit proefschrift - zal leiden tot een verbetering van de seksuele gezondheid van mensen met hiv.

Nicole van Kesteren, juli 2007 




\section{Contents}

\section{Chapter 1:}

General overview

\section{Chapter 2:}

Sexual risk behavior: A literature review

\section{Chapter 3:}

Sexuality and sexual risk behavior

\section{Chapter 4:}

Sexual decision-making: How moral concerns and sexual motives guide intended condom use

\section{Chapter 5:}

Systematic development of a self-help and motivational enhancement intervention to promote sexual health

\section{Chapter 6:}

Evaluation of a self-help and motivational enhancement intervention to promote sexual health

References

Summary

Samenvatting 



\section{Chapter 1}

General overview

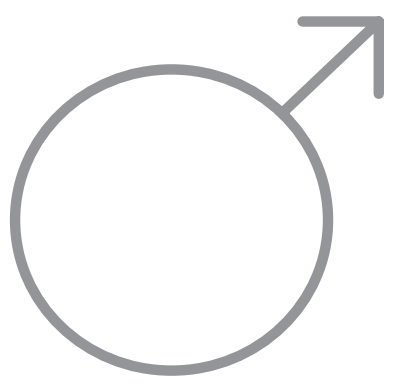




\section{INTRODUCTION}

Until recently, little attention has been paid to the prevention needs of HIV-positive men who have sex with men (MSM) in HIV-prevention research and practice. However, with the introduction of effective therapies, this has changed significantly. Widespread use of combinations of antiretroviral drugs, better known as highly active antiretroviral therapy (HAART), has resulted in significant progress in the treatment of HIV infection. Clinical data show that HAART can dramatically decrease the amount of virus in the body, and the use of more effective antiretroviral therapeutic regimens has led to a considerable increase in survival as well as in the quality of life of people living with HIV/AIDS (PLWA) (Ostrow \& Kalichman, 1999). This increased lifespan has also resulted in a prolongation of sexual activity.

In the Netherlands, as in other Western countries, AIDS first appeared in the gay community, and this group remains disproportionately affected by HIV/AIDS (Op de Coul, De Boer, $\&$ Van Sighem, 2006). Many of those who learn that they are HIV-positive subsequently modify their sexual behavior (Mikolajczak, Hospers, $\&$ Kok, 2007; Weinhardt, Carey, Johnson, \& Bickman, 1999). However, behavioral studies have consistently shown that a significant number of HIV-positive MSM engage in unprotected anal intercourse (UAI) (Hospers, Dörfler, \& Zuilhof, 2004, 2006; Kalichman, 2000). Consequently, HIV-positive MSM who do not change their sexual risk behavior may infect others and become reinfected with new viral strains or acquire other sexually transmitted diseases (STDs) (Blackard, Cohen, \& Mayer, 2002; Jost et al., 2002; Rottingen, Cameron, \& Garnett, 2001). At the same time, programs to address the sexual risk behaviors of HIV-positive MSM have been scarce. This has been the case for many years, even though evidence suggests that adoption of protected sexual practices among people who are HIV-positive leads to a significant reduction in the number of HIV infections (King-Spooner, 1999).

Thus, the challenge for the practice of HIV prevention was to fill this gap. The present thesis aims at the development of a theory-and evidence-based HIV preventive intervention for HIV-positive MSM. Specifically, attention will be directed to the factors associated with sexual risk behavior in HIV-positive MSM, as well as the development, implementation and evaluation of a self-help and motivational enhancement intervention to promote sexual health in HIV-positive MSM.

In the remainder of this chapter an overview will be given of the entire research and development process that is reported in Chapters 2 through 6 of this thesis. First, an answer will be given to the question of why behavioral programs developed for HIV-positive populations have lagged behind those developed for HIV-negative or status unknown target populations. In the next section, Intervention Mapping will be explained as a tool for systematically developing theory-and evidence-based health promotion programs (Bartholomew, Parcel, Kok, \& Gottlieb, 2001, 2006). 
Subsequently, the focus will be on the different phases of the research project. Finally, the main conclusions and the implications for future research and for HIV prevention practice will be discussed.

\section{History}

Until recently, HIV prevention interventions focused almost exclusively on individuals who were at risk of acquiring HIV. Yet, to have an impact on the sexual transmission of HIV, prevention efforts also need to reach those most at risk for transmitting HIV (King-Spooner, 1999). Thus, one might ask why HIV-infected people have been neglected in HIV prevention for such a long time. An important part of the answer relates to fear of stigmatization. Schiltz and Sandfort (2000) give a detailed historical overview of the way AIDS was dealt with, socially and politically, after the outbreak of the epidemic. According to them, the taboo around HIV prevention aimed at HIV-infected people was basically related to the terminal nature of the disease. "In this situation of preordained death, the sex life of those infected might have seemed to be a minor issue if not completely inconceivable" (Schiltz \& Sandfort, 2000, p. 1573). However, not only the terminal nature of the disease, but also its (perceived) contagiousness, which is an important determinant of fear and stigmatizing reactions toward people with HIV and AIDS (PWHA) (Dijker, Koomen, \& Kok, 1997; Herek, 1999), stressed the importance of developing HIV prevention that did not stigmatize those who have already been infected. This concern, in particular, emphasized the justification of personal responsibility for one's own health as the prominent value in HIV prevention. Hence, various prevention messages were developed in the fight against AIDS; however, HIV-positive people were excluded from the communication process.

Bayer (1996) also explains why personal responsibility for one's own health has been the underlying value promoted in most HIV prevention campaigns. Of overriding importance was the claim that a focus on the responsibility of PWHA for the protection of one's partners would lead to a further spread of the epidemic because people who are HIV-negative or do not know their status would rely on PWHA to take responsibility for safer sex and would, therefore, fail to protect themselves. Next to this pragmatic argument against an extra responsibility of HIVpositive people to practice safer sex, more philosophical and political objections also were of concern. Distinctive attention to the responsibility of those with HIV infection to practice safer sex would imbed the danger of "viral apartheid," stigmatizing, and the imposition of criminal penalties on those whose actions could result in HIV transmission. Therefore, it seemed safer to work from a common ground of self-interest, of "responsibility to oneself," rather than putting moral and psychological pressure on people who are facing a life-threatening disease and who are often doubly stigmatized already (King-Spooner, 1999). Post-HAART, the taboo around HIV prevention aimed at PWHA has been broken. Nevertheless, 
research on HIV related stigma in the Netherlands indicates that HIV-positive MSM still encounter stigmatizing responses, particularly within the gay community (Bos, 2001). Moreover, recent examples of criminal prosecutions of PWHA for transmitting HIV to others have raised considerable concern among national, as well as international, organizations working in the field of HIV prevention (International HIV/AIDS Alliance, 2003; SOA AIDS Nederland, 2004). These findings indicate that there is a need to consider the undesirable effect of stigmatization when developing HIV prevention campaigns targeting HIV-positive MSM.

\section{Framework for the present thesis}

In the present thesis, Intervention Mapping (Bartholomew et al., 2001, 2006) was used as guidance for program development, implementation, and evaluation. According to Bartholomew et al. (2001, 2006), Intervention Mapping can be thought of as a road map for making and documenting decisions in program design and development. More specifically, its purpose is to "map the path of intervention development from recognizing a need or a problem to identifying and testing solutions" (Bartholomew et al., 2006, p. xvii). Thus, Intervention Mapping is to be understood not as a theory, but rather as a planning model or conceptual framework for practice.

Intervention Mapping suggests that the development of health promotion programs can be divided into six steps: (1) conducting a needs assessment; (2) preparing matrices of change objectives; (3) selecting theory-informed intervention methods and practical strategies; (4) producing program components and materials; (5) planning program adoption, implementation, and sustainability; and (6) planning for evaluation. These steps indicate that different planning questions may be relevant at different points in the intervention development process, though movement through the steps is not considered static. Figure l provides an overview of the Intervention Mapping steps and the planning questions in the various steps.

Bartholomew et al. (2001, 2006) describe three core processes for Intervention Mapping that can be used by the professional health promoter to respond to the different planning questions. The first tool is a literature search for empirical findings, and identifies what others have reported about the causes of or solutions to a specific problem. The second tool is the discovery and use of theories that might be applied to the various decisions in the Intervention Mapping process. The third tool is new data collection, which enables the health promotion planner to answer the planning question using both qualitative and quantitative research methods.

Thus, Intervention Mapping provides a structure that gives program planners a systematic method for decision-making in each phase of intervention development. In the following sections, the application of Intervention Mapping to the development of an HIV preventive intervention for HIV-positive MSM will be described in detail. Before describing this process, however, the thesis aims will be defined in more detail. 


\begin{tabular}{|c|c|c|}
\hline$\uparrow$ & $\begin{array}{l}\text { Step } 1 \\
\text { Needs Assessment }\end{array}$ & $\begin{array}{l}\text { - Plan needs assessment with Precede model } \\
\text { - Assess health, quality of life, behavior, and environment } \\
\text { - Assess capacity } \\
\text { - Establish program outcomes }\end{array}$ \\
\hline & $\begin{array}{l}\text { Step } 2 \\
\text { Matrices }\end{array}$ & $\begin{array}{l}\text { - State expected changes in behavior and environment } \\
\text { - Specify performance objectives } \\
\text { - Specify determinants } \\
\text { - Create matrices of change objectives }\end{array}$ \\
\hline & $\begin{array}{l}\text { Step } 3 \\
\text { Theory-Based Methods } \\
\text { and Practical Strategies }\end{array}$ & $\begin{array}{l}\text { - Review program ideas with interested participants } \\
\text { - Identify theoretical methods } \\
\text { - Chose program methods } \\
\text { - Select or design strategies } \\
\text { - Ensure that strategies match change objectives }\end{array}$ \\
\hline Evaluation & $\begin{array}{l}\text { Step } 4 \\
\text { Program }\end{array}$ & $\begin{array}{l}\text { - Consult with intended participants and implementers } \\
\text { - Create program scope, sequence, theme, and materials list } \\
\text { - Develop design documents and protocols } \\
\text { - Review available materials } \\
\text { - Develop program materials } \\
\text { - Pretest program materials with target groups and } \\
\text { implementers and oversee materials production }\end{array}$ \\
\hline & $\begin{array}{l}\text { Step } 5 \\
\text { Adoption and } \\
\text { Implementation Plan }\end{array}$ & $\begin{array}{l}\text { - Identify adopters and users } \\
\text { - Specify adoption, implementation, and sustainability } \\
\text { performance objectives } \\
\text { - Specify determinants and create matrix } \\
\text { - Select methods and strategies } \\
\text { - Design interventions to affect program use }\end{array}$ \\
\hline & $\begin{array}{l}\text { Step } 6 \\
\text { Evaluation Plan }\end{array}$ & $\begin{array}{l}\text { - Describe the program } \\
\text { - Describe program outcomes and effect questions } \\
\text { - Write questions based on matrix } \\
\text { - Write process questions } \\
\text { - Develop indicators and measures } \\
\text { - Specify evaluation designs }\end{array}$ \\
\hline
\end{tabular}

Figure 1. Intervention Mapping

\section{Aims of this thesis}

The present thesis focuses on the development of an HIV preventive intervention for HIV-positive MSM. Specifically, the aim was to investigate the factors associated with sexual risk behavior in HIV-positive MSM, and the development, implementation and evaluation of an HIV preventive intervention. Thus, a series 
of specific questions were addressed that need to be answered for comprehensive program planning. In particular, the purpose of the thesis was:

$\delta$ To describe the prevalence of UAI and related risk behaviors of HIV-positive MSM (Chapter 2).

o To achieve better understanding of the psychological dynamics of (un)protected sex among HIV-positive MSM, i.e., to explain why HIV-positive MSM practice unprotected sex (Chapter 3).

o To examine determinants of HIV-positive MSM intention to use condoms for anal intercourse with steady and casual sex partners (Chapter 4).

o To describe the application of a systematic process, Intervention Mapping, to develop a theory-and evidence-based intervention to promote sexual health in HIV-positive MSM (Chapter 5).

o To evaluate the intervention for efficacy (Chapter 6).

The present study can be divided into four phases: the needs assessment (Intervention Mapping Step 1); the developmental phase of the intervention (Intervention Mapping Steps 2 to 4); implementation of the intervention (Intervention Mapping Step 5); and evaluation of the effects (Intervention Mapping Step 6).

\section{PHASE 1: NEEDS ASSESSMENT}

The needs assessment had several purposes: first, to describe the HIV prevalence rates in the Netherlands and among MSM, which are based on the most recent estimates by the Dutch HIV Monitoring Foundation and the National Institute for Public Health and the Environment (Op de Coul, Van Sighem, \& Van de Laar, 2006a), and its consequences for health and quality of life; second, to assess the prevalence of sexual risk behaviors, primarily UAI; and third, to analyze key determinants of UAI in this target population.

\section{HIV prevalence rates in the Netherlands and among MSM}

In the Netherlands, the number of PWHA monitored by the Dutch HIV Monitoring Foundation was 11,679 in January 2006, of which 10,683 currently are alive (91.5\%). However, not everyone who is HIV-positive is aware of his or her HIV infection. Based on UNAIDS methodology for producing national HIV prevalence estimates, a recent study estimated the HIV prevalence rates among different subgroups for the Netherlands, as well as the percentage of PWHA who are not aware of their HIV-positive status (Op de Coul et al., 2006a). The results indicate that the HIV prevalence in adults has increased from $0.19 \%$ in 1999 to $0.20 \%$ in 2000 . Although this figure rose to $0.23 \%$ in 2005, it was also concluded that the HIV prevalence rate would slowly stabilize in the coming years. In 2005, Op de Coul et al. (2006a) estimated the number of PLWA at 18,500, of which approximately 4,000 are living 
in Amsterdam and 14,000 in the rest of the Netherlands. Overall, about 9,000 (49\%) of the estimated number of PWHA in the Netherlands are infected through heterosexual contact; 46\% (8,500) through homosexual contact; and 1,000 (5\%) through intravenous drug use. Specifically, the HIV prevalence rate for MSM was estimated at 5.3\%. Other Dutch studies suggest higher HIV prevalence rates among MSM: 22\% in an Amsterdam study of MSM (Hospers et al., 2004) and 11\% among a national sample of MSM (Hospers et al., 2006). It should be noted, however, that these percentages are based on MSM who have ever been tested for HIV. Moreover, both samples were community-based, which has the potential for sampling bias. Despite an active HIV testing policy that was introduced by the Dutch Health Council in 1999, data show that, in compared to other Western countries, a high percentage of Dutch MSM do not know their HIV status. For example, Op de Coul et al. (2006a) estimated that 33\% of HIV-positive MSM are not aware of their HIV status, whereas Hospers et al. (2006) found that 40\% of the MSM who participated in their study had never been tested for HIV. Recent figures of STDs suggest that known HIV-positives account for $15 \%$ of all cases of rectal gonorrhea, Chlamydia and syphilis among MSM surveyed at STD clinics in the Netherlands (Op de Coul, De Boer, \& Van Sighem, 2006b).

Research on psychosocial aspects of HIV show that living with HIV is associated with high levels of strains, stress and depression (Green \& Smith, 2004). Not only must HIV-infected people live with high levels of uncertainty, they must also manage the stigma associated with HIV/AIDS, tolerate treatment with adverse side effects, deal with rejection and social discrimination, and confront the deaths of others in their social networks (Green \& Sobo, 2000). Post-HAART, there has been an increased focus on the mental health implications of HIV treatment advances for those affected by HIV/AIDS (Ostrow \& Kalichman, 1999; Weatherburn, Anderson, Reid, \& Henderson, 2002). One of the stressors PWHA need to address is the decision about when to begin taking HAART. Although HAART can produce sustained suppression of viral replication and decreased viral load at an undetectable level, concerns about the long-term detrimental effects of HAART, the patient's health status, and daily function may postpone a decision to start combination therapies (McPherson-Baker et al., 2000; Persson, Race, \& Wakeford, 2003). Further, the complexity of the regimens and the need for total adherence to the therapy places a tremendous burden on the HIV-positive individual. For many individuals, the need to constantly adhere is associated with anxiety and frustration (Adam, Maticka-Tyndale, \& Cohen, 2003; Chesney, Morin, \& Sherr, 2000). In addition, not all HIV-infected people respond well or consistently well to new combination therapies. Bogart et al. (2000) found considerable mental health issues, including feelings of depression and hopelessness, among HIV-infected men and women who do not achieve or sustain benefits from the treatment regimens. But individuals for whom new therapies are effective, are also confronted with uncertainty and other 
potential distress (Brashers et al., 1999). Stress associated with treatment response interacts with other potential sources of stress, such as concerns about employment, relationship development, sexuality and the social reactions of others (Bogart et al., 2000; Brashers et al., 1999).

\section{Sexual risk behavior in HIV-positive MSM}

The first research question that is addressed by the literature review presented in Chapter 2 (Van Kesteren, Hospers, \& Kok, 2007) concerns the prevalence of sexual risk behavior in HIV-positive MSM. Increased risk of HIV transmission among MSM is linked to the practice of UAI. At highest risk is the receptive partner, but the insertive partner also can acquire HIV through UAI (Suarez \& Kauth, 2001; Vittinghoff et al., 1999). Using condoms during anal intercourse remains one of the most effective strategies for preventing sexual transmission of STDs, including HIV infection.

Although many individuals who are HIV-positive engage in safer sexual practices, not everyone does. Indeed, a review study of sexual risk behavior of HIV-positive people, including MSM, shows that approximately one-third continue to engage in high-risk sexual behavior after learning of their HIV-positive status (Kalichman, 2000). Moreover, evidence is emerging that indicates that HIV risk among HIVpositive MSM is increasing. Therefore, a literature review was conducted in which the sexual risk behaviors of HIV-positive MSM were studied more closely. In order to get a broad overview of what has been published, 53 studies that reported on UAI in cross-sectional and longitudinal surveys of HIV-positive MSM and MSM of mixed HIV status were included. Although the different study populations and the varying recall periods for self-reports make comparisons difficult, considerable rates of sexual risk behavior in HIV-positive MSM were found. In fact, based on the studies incorporated in this review, evidence suggests that up to two in five HIVpositive MSM reported engaging in UAI, and that much of this risky behavior occurs with partners who are HIV-negative or whose status is unknown. In addition, the review study showed that the prevalence of sexual risk behavior is significantly higher among HIV-positive MSM than among MSM who are HIV-negative or whose HIV status is unknown. Furthermore, the prevalence of UAI among HIV-positive MSM has increased in recent years. Thus, the review underlines the importance of addressing HIV-positive MSM as an especially important target group for HIV prevention.

Although a substantial proportion of HIV-positive MSM are engaging in UAI, evidence was found indicating that HIV-positive MSM are employing risk-reduction strategies (cf. Elford, 2006). One such strategy is "serosorting," i.e., selecting partners who are also HIV-positive. HIV-positive MSM engage in UAI with other HIVpositive MSM more often than with partners who are HIV-negative. In addition, some evidence supports the use of "strategic positioning" (i.e., choosing to be 
the receptive partner during UAI rather than the insertive partner, based on the assumption that it is more difficult to transmit HIV as a "bottom" than as a "top"), and withdrawal before ejaculation (i.e., "pulling out" during UAI before ejaculation to lessen the likelihood of HIV through ejaculation). The use of these risk-reduction strategies remains controversial, however, mainly because the scientific evidence of their efficacy is lacking (Wolitski \& Branson, 2002). For instance, problems with the "serosorting" strategy may be that it relies largely on the individual's accurate knowledge of his own HIV status, his partner's accurate knowledge of his HIV status, and the ability of both to disclose their HIV status to each other. Lack of knowledge of a partner's HIV status may lead some HIV-positive MSM to engage in sexual risk behavior because of the incorrect assumption that their partners are also HIVpositive (Colfax \& Dawson-Rose, 2006; Wolitski \& Branson, 2002).

Additionally, our findings showed that sexual risk behavior in HIV-positive MSM varied according to partner type. Contrary to patterns of sexual risk behavior in different relationship contexts in HIV-negative MSM, HIV-positive MSM seem to use condoms less often with casual sex partners than within steady relationships. However, findings have been inconsistent: some studies showed that the rate of UAI with steady sex partners was equal to or less than rates of UAI with casual sex partners, whereas others have not found such evidence. Nevertheless, as sexual risk behavior varies by partner type, the influence of partner type was taken into account in identifying the determinants of the behavior, as well as in the program design.

\section{Analysis of determinants of sexual risk behavior in HIV-positive MSM}

In order to identify determinants of risk-taking and safer sexual behavior in HIVpositive MSM, the three earlier described core processes for Intervention Mapping were applied. First, following the issue-related approach, the literature was searched for specific evidence of determinants of risk-taking behavior in the group of HIVpositive MSM. Additionally, a concept-related approach was used, identifying useful theoretical concepts and frameworks to gain a better understanding of why HIV-positive MSM engage in safer sex or sexual risk-taking behavior. Within this context, the focus was specifically on the concepts of personal responsibility and altruistic behavior. Combining the knowledge of the first two steps with familiar theories, a sexual decision-making framework was proposed, which seemed to fit with the target group and target behavior. Finally, the third core process defined within Intervention Mapping was used, namely the collection of additional data. The following sections give a short overview of the findings derived from the evidence gathered through a mixture of strategies. 


\section{Previous research}

There is an increasingly expansive body of literature on sexual risk behavior among HIV-positive people and psychosocial determinants of safer sexual behavior. A review study of psychosocial factors and HIV risk behavior has found that UAI among HIV-positive MSM is associated with partner variables such as having HIVpositive partners, anonymous partners and a partner who is willing to engage in risky sex (Crepaz \& Marks, 2002). Further, it has been shown that higher risk-taking behavior is associated with less positive attitudes toward the use of condoms, a diminished perception of personal control over condom use, and decreased intention to use condoms. Affective states also have been shown to be important; that is, HIVpositive MSM engaging in high sexual risk behavior experience more anger and are more impulsive and sexually compulsive. Finally, it has been found that MSM who have had a greater number of previous sex partners or intercourse episodes, have engaged in more unprotected sex. Other reviews of psychosocial factors of HIV risk behavior document higher risk-taking among HIV-positive MSM who are younger and less educated. In addition, diminished coping skills, less (sexual) control, more use of alcohol and nitrate, greater feelings of mastery, less communication, and low social support were found to be related to engaging in unprotected sexual practices (Kalichman, 2000; Kok, 1999). Thus, to some extent determinants found among HIV-positive MSM seem to be similar to those that are generally found among MSM without HIV. However, to date, few studies have been designed to examine factors that may be unique to the motivations and needs of HIV-positive MSM. Therefore, additional research was conducted to investigate the existing motives of HIVpositive MSM to engage in or sustain (un)protected sex.

\section{Social cognitive approaches to the prediction of safer sexual behavior}

Well-established theoretical models, such as the Theory of Reasoned Action (TRA) (Fishbein \& Ajzen, 1975), its successor, the Theory of Planned Behavior (TPB) (Ajzen, 1991), and Social Cognitive Theory (SCT) (e.g., Bandura, 1997) emphasize the importance of the individual's attitude toward performing the behavior, the individual's subjective norms associated with the behavior, and the individual's selfefficacy expectations as precursors of the individual's intention toward performing (or not performing) a given behavior. Attitude is considered to be a function the person's overall evaluation of the advantages and disadvantages of a particular behavior, whereas subjective norms are considered to be a function of the perceived social pressure to perform the behaviors (Montano \& Kasprzyk, 2002). Self-efficacy refers to the confidence a person feels about performing a particular behavior, including confidence in overcoming the barriers to achieving that behavior (Bandura, 1986). In other words, a person who believes that positively valued outcomes will result from performing the behavior, experiences social pressure to perform the behavior, and feels confident to perform the behavior will have a positive intention 
toward the behavior. Thus, the focus of these models is on three key variables that serve as the primary determinants of any given behavior, including safer sex. Once the variables that most strongly influence one's intention to perform a given behavior have been identified, these variables should serve as the primary focus of an intervention (Fishbein et al., 2001).

Studies on sexual risk behavior are often based on these models (Albarracín, Fishbein, Johnson, \& Muellerleile, 2001; Rye, Fisher, \& Fisher, 2001; Sheeran, Abraham, \& Orbell, 1999). However, although the determinants identified may be predictive for sexual risk behavior, some researchers have argued that this approach does not provide an adequate account of the processes underlying safer sexual behavior in HIV-positive MSM (King-Spooner, 1999; Kok, 1999; Marks, Burris, \& Peterman, 1999). According to those researchers, HIV-positive MSM are primarily motivated to practice safer sex by concerns about the risks of transmitting the virus to others. That is, because HIV-positive MSM are already HIV-infected, they have minimal self-interest in avoiding HIV infection by practicing safer sex. Therefore, it is assumed that the decision of HIV-positive MSM to practice safer sex is guided by values that go beyond self-interest, and that the decision to practice safer sex "may be best understood as an act of altruism" (Nimmons, 1998, p. 78). Although there is little evidence to support this assumption, some sources provide indirect support regarding the prosocial or altruistic nature of HIV-positive MSM's safer sexual practices. The first concerns the finding that individuals who are HIV-positive respond by reducing their sexual risk behavior. The second concerns the "serosorting" strategy used by HIV-positive MSM to reduce their risk of HIV transmission to uninfected partners. The third concerns the finding that HIV-positive MSM have developed additional HIV prevention strategies to reduce the risk of transmitting HIV. Together these findings indicate that the primary motive underlying condom use for most HIV-positive MSM is altruism, not self-interest.

In research on helping and altruism, determinants of prosocial action are hypothesized as playing a key role. That is, several theoretical frameworks exist for considering why individuals engage in different forms of prosocial behavior. These include the bystander intervention model (Latané \& Darley, 1970), the arousal: costreward model (Piliavin, Dovidio, Gaertner, \& Clark, 1992), the empathy-altruism model (Batson, 1991), and Schwartz's norm activation theory (Schwartz, 1977; Schwartz \& Howard, 1982, 1984). Several studies suggest that internalized values or personal standards play an important role in the practice of safer sexual behavior in HIV-positive MSM (Godin, Savard, Kok, Fortin, \& Boyer, 1996; Keogh, Weatherburn, \& Stephens, 1999; Nimmons \& Folkman, 1999; Wolitski, Bailey, O’Leary, Gómez, $\&$ Parsons, 2003). Therefore, it was hypothesized that the decision to use condoms for anal sex largely depends on their intrinsic motivation to engage in safer sex. For this reason, the contribution of Schwartz's norm activation theory was considered an additional model to better explain the determinants of safer sex in HIV-positive MSM. 


\section{A normative model of altruism and helping}

Schwartz and Howard (Schwartz, 1977; Schwartz \& Howard, 1982, 1984) present a normative model of altruism and helping, that is, the norm-activation model. In the norm-activation model, they elaborate on the decision-making process underlying altruism and helping, proposing that such behavior is traceable to motivations related to one's internalized values. More specifically, the norm-activation theory considers how people's internalized values motivate helping by affecting both cognitive (what people think) and affective (what people feel) processes.

In explaining the underlying processes of altruistic or helping behavior, Schwartz accentuates the significant role of personal norms in relation to behavior - individuals are motivated to help to conform their own personal norms. Personal norms are defined as situation-specific behavioral expectations generated from one's own internalized values, backed by self-administered sanctions and rewards. Each person has a uniquely organized cognitive structure of values, which are activated in a specific situation. As a result, an individual will use these values as a means for evaluating his own behavior. Moreover, these values serve as a basis for rewarding or punishing himself. That is, a person asks himself whether he is morally responsible for these actions in this situation. In Schwartz's norm-activation theory, it is hypothesized that personal norms are formed through the internalization of social norms. Social norms represent the expectations of significant others, but are, in many situations, far too general and detached to guide behavior. Instead, individuals come to accept social expectations on a personal level, and as such, social norms become personal norms.

Schwartz's norm-activation theory has been applied successfully to several altruistic behaviors or behaviors in which moral considerations play a significant role, such as organ donation (Schwartz \& Tessler, 1972), blood donation (Pomazal $\&$ Jaccard, 1976) and pro-environment behavior (Black, Stern, \& Elworth, 1985; Harland, Staats, \& Wilke, 1999; Hopper \& Nielsen, 1991; Lee, De Young, \& Marans, 1995; Van Liere \& Dunlap, 1978). The determinant study reported in Chapter 4 (Van Kesteren, Hospers, Van Empelen, Van Breukelen, \& Kok, 2007) aimed to examine the predictive value of Schwartz's norm activation theory in safer sexual behavior in HIV-positive MSM.

\section{Additional data collection}

Two studies were conducted to gain further insights into the determinants of risky and safer sexual behavior in HIV-positive MSM. First, qualitative interviews were used to examine the psychological processes pertaining to sexuality and sexual risk behavior (Van Kesteren, Hospers, Kok, \& Van Empelen, 2005). Thirty HIVpositive MSM (15 in Amsterdam and Rotterdam, and 15 in the Maastricht area) were interviewed (see Chapter 3). Most HIV-positive MSM reported an overall impairment in sexual function following their HIV-positive diagnosis, which may 
interfere with the practice of safer sex. Reasons for overall impairment of sexual function included fear of transmitting HIV to sex partners, physical complaints brought on by the treatment regime or HIV itself, and negative feelings about one's own physical appearance. Personal HIV related risk seemed to play a less important role in sexual problems and safer sexual behavior. Although most respondents were aware of the risk of HIV superinfection and STDs for their own health, half reported that they did not consider HIV superinfection and STDs a serious risk. The results further indicated that feelings of personal responsibility are central to the impact of HIV on sexuality and the practice of safer sex, especially within the context of steady relationships. One of the key contributions of this study was to highlight the discrepancy between feelings of personal responsibility and actual behavior. Although most participants felt personally responsible to protect their sex partners from HIV, contextual factors (e.g., partner variables and social norms) determined whether or not their perceived norms of personal responsibility were translated into behavior. Moreover, a substantial number of men seemed to lack the skills to effectively communicate their own health interests, negotiate condom use and resist pressure to engage in sexual risk behavior. Motivation to practice safer sex in HIV-positive MSM is, therefore, best envisaged as an individual commitment (i.e., personal norm) to the practice of safer sex situated within particular social contexts in which sex occurs.

Elaborating on the results of the qualitative study, a quantitative study was conducted to gain further insights into the determinants of sexual risk-taking behavior with steady and casual sex partners among a national sample of 296 Dutch HIV-positive MSM (see Chapter 4; Van Kesteren et al., 2007). The theoretical starting point of the study was the TPB. Because the qualitative study showed that feelings of personal responsibility are influential in encouraging safer sex, constructs of the norm-activation theory were also included. A questionnaire was created to include: 1) the main components of the TPB (i.e., attitudinal beliefs, subjective norms and self-efficacy), and 2) the main components of the norm-activation theory (i.e., personal norms, awareness of the consequences for self and others, and ascription of responsibility). In addition, it was hypothesized that, depending on the context in which sex occurs, specific motives for UAI may have a negative influence on intended condom use and, as such, undermine a prosocial tendency to practice safer sex. Therefore, the influence of sexual motives for UAI on intended condom use with steady and casual sex partners was also investigated. Data from this study supported earlier study findings (e.g., Godin et al., 1996; Keogh et al., 1999), indicating that personal norms strongly influence safer sexual decision-making in HIV-positive MSM. For steady sex partners, personal norms were identified as the most proximal determinant of intended condom use. Thus, the more personally responsible HIVpositive MSM feel for safer sex, the more likely they are to intend to use condoms. In addition, personal norms were found to mediate the effects of subjective norms 
and self-efficacy on intended condom use with steady sex partners. Obviously, HIVpositive MSM need to perceive positive normative beliefs and need to feel in control over their behavior in order to feel personally responsible for safer sex. For casual sex partners, the results showed that two major paths influence intended condom use. First, intended condom use with casual sex partners was positively influenced by personal norms, whereas indirect effects of subjective norms, self-efficacy, and ascription of responsibility to self on intended condom use through personal norms were also found. Second, intended condom use with casual sex partners was found to be negatively influenced by sexual motives for UAI. This suggests that the need to engage in UAI for physical and emotional satisfaction may supersede the prosocial motivation for safer sex within casual sex encounters. Taken together, these results indicate that our proposed model of sexual decision making provides a sound theoretical basis for an understanding of antecedents of sexual risk and safer behavior of HIV-positive MSM.

\section{Conclusions and program objectives}

The needs assessment showed that approximately 40\% of HIV-positive MSM engage in UAI. If these men engage in UAI, they risk infecting others or becoming infected with new strains of HIV or other STDs. Although it was acknowledged that the program should focus on promoting safer sexual behavior (particularly condom use) in HIV-positive MSM, the needs assessment indicated that this might not be sufficient. In analyzing the health problem, it became clear that issues related to quality of life should be taken into account when targeting sexual risk behavior in HIV-positive MSM. The needs assessment indicated that a diagnosis of HIV, the illness experience, and medical treatment negatively affect physical, psychological and social functioning and can provoke stressful reactions. Moreover, HIV and its treatment may have a disruptive impact on intimacy and sexuality (e.g., reduced sexual desire and lack of arousal and orgasm) and can inhibit the ability of HIVinfected MSM to resume satisfactory sexual functioning. Although psychosexual issues form an integral aspect of quality of life, this is often neglected in interventions targeting quality of life or sexual risk behavior among HIV-positive people (Catalán, Burgess, \& Klimes, 1995; Ross \& Schonnesson, 2000). To do justice to the perceived threat of the disease to the individual's sexual existence and the complexity of sexual behavioral change, it was decided to focus not only on safer sex practices, but also on sexual function in HIV-positive MSM. Based on several studies of the relationship between sexuality and quality of life (Cove \& Petrak, 2004; Monga, 2002; Taleporos \& McGabe, 2002; Walters \& Williamson, 1998), it was assumed that HIV-positive MSM who are able to better manage sexual problems following a diagnosis of HIV are also likely to experience a better quality of life. The importance of targeting quality of life aspects in HIV-positive people in addition to risky sexual practices is underlined by several intervention studies that have shown to be effective in reducing 
sexual risk behavior (Coates, McKusick, Kuno, \& Stites, 1989; Greenberg, Johnson, \& Fichtner, 1996; Rotheram-Borus, Lee et al., 2001; Rotheram-Borus, Murphy et al., 2001).

The needs assessment made clear that social environmental conditions also play a crucial role in influencing sexual risk behavior in HIV-positive MSM. At the interpersonal level, HIV-positive MSM report a diffuse social norm with regard to condom use for anal sex. In regard to casual sex contacts, HIV-positive MSM report that other MSM do not always use a condom for anal sex and that they experience pressure to engage in UAI; within steady relationships, pressure to engage in UAI is also an important determinant of risky sexual behavior. Therefore, condom use might increase when steady and casual sex partners support condom use for anal sex. Furthermore, HIV-positive MSM are faced with stigmatization of HIV infection. Because stigmatization can interfere with help-seeking behavior, disclosure, and safer sexual practices (Brown, Macintyre, \& Trujillo, 2003; Chesney \& Smith, 1999; Marks et al., 1999), reducing stigmatization at the interpersonal and community level should be an important goal of HIV prevention.

\section{PHASE 2: PROGRAM DEVELOPMENT}

The second phase of the research project was to develop an HIV preventive intervention for HIV-positive MSM by applying Intervention Mapping Steps 2 to 4. In Step 2, the focus was the improvement of two health-promoting behaviors: satisfactory sexual function and safer sexual behavior. These behaviors were linked with selected personal and external determinants, such as attitudes and social support, to produce sets of change objectives. In Step 3, theory-informed intervention methods were identified to influence the change objectives and were translated into practical strategies. Although intervention methods were derived from various theories, self-regulation theory and a cognitive-behavioral model of behavior change provided the main framework for selecting the intervention methods. The main strategies chosen were bibliotherapy (i.e., the use of written material to help people solve problems or change behavior) and motivational interviewing. In Step 4, the theory-informed intervention methods and practical strategies were applied in a program that comprised a self-help guide, a motivational interviewing session, and a motivational telephone interviewing telephone call, both of which were conducted by specialist nurses in HIV treatment centers. For a full description of the systematic application of all Intervention Mapping steps, please see Chapter 5 (Van Kesteren, Kok, Hospers, Schippers, \& De Wildt, 2006) of this thesis. In the following section, some important decisions in and products of the Intervention Mapping process are explained. 


\section{Stating behavioral and environmental targets}

The needs assessment identified behavioral (sexual dysfunction and UAI) and environmental factors (diffuse safer sex norms in the gay community and stigmatization of HIV-positive MSM) that need to change in order to improve the health and quality of life of HIV-positive MSM. To ensure the feasibility of the program, it was decided to only focus on changing the social norm regarding condom use. Reducing stigmatization of HIV -infection was considered an important, but less changeable, environmental condition within the scope of this project. Because the program primarily focused on sexual dysfunction and UAI, it was decided to address the social norm regarding condom use as an external determinant at the individual level and to focus on social support of steady and casual sex partners regarding condom use for anal sex. Numerous studies have indicated that receiving social support has positive effects on physical, mental and social health and forms a buffer against risk-taking behavior (Heany \& Israel, 2002).

\section{Applying self-regulation theory for writing performance objectives}

Whereas the needs assessment identified behaviors that lead to reduced health and quality of life, for the purpose of intervention planning it is necessary to restate these behaviors as health-promoting behaviors (Bartholomew et al., 2001, 2006). Based on the needs assessment, it was decided to focus the program on sexual function and safer sexual behavior. After the program, HIV-positive MSM should be able to manage their sexual problems and should use condoms for anal sex. To achieve these general health-related behaviors, an essential step in the Intervention Mapping process is to break down these behaviors into sub-behaviors. The central question in doing so is: What do the participants of this program need to do to perform the health-related behaviors?

The concept-related approach was used to answer this question, expanding on the health-promoting behaviors with theories on self-regulation. Self-regulation refers to processes in which individuals try to manage or self-regulate their health (Maes \& Karoly, 2005). Over the years, several health-promoting programs based on self-regulatory processes have been implemented and proved to be effective (Danish, 1997; Miller, Toscova, Miller, \& Sanchez, 2000; Sniehotta et al., 2005). Those programs typically aim to increase participants' health by teaching them how to prevent the onset of health problems, implement health-promoting behavior, or better manage a chronic disease. Self-regulatory theory assumes that human functioning (people's emotions, thoughts and behaviors) or health behavior is influenced by personal, behavioral and environmental factors. Personal factors refer to cognitive and affective influences; behavioral factors include actions and reactions 
of an individual, and environmental influences involve both social and physical factors. Self-regulation is the process by which individuals try to manage these three influences to reach their (health) goals (Clark \& Zimmerman, 1990; Kotses, Lewis, \& Creer, 1990; Thoresen \& Kirmil-Gray, 1983).

Although different theoretical notions of self-regulation exist, generally the assumption is that people self-regulate their health through three sub-processes: a) self-observation or monitoring; b) self-judgment or comparing to personal best; and c) self-reaction or self-reinforcement. Self-observation refers to explicit attempts to perceive one's own behavior. When self-observing, a person has at his disposal several strategies for increasing his ability to self-observe. An example of an effective self-observation strategy is recording - the actual noting or keeping track of what is observed. Self-judgment involves using criteria to assess the situation or problem. For example, comparisons can be made with a medical or HIV prevention standard - goals a person sets for himself or in his dealings with others. Self-reaction is the response to self-judgment and self-observation about one's own behavior, and includes altering and maintaining one's sense of efficacy to accomplish the task and giving oneself rewards or punishments (Clark \& Zimmerman, 1990).

Finally, a specific advantage of a self-regulatory approach as a rationale for the performance objectives is that self-regulation theory takes into account individual differences. More specifically, self-regulatory theory assumes that factors that are

\section{Table 1. Performance objectives of HIV-positive MSM}

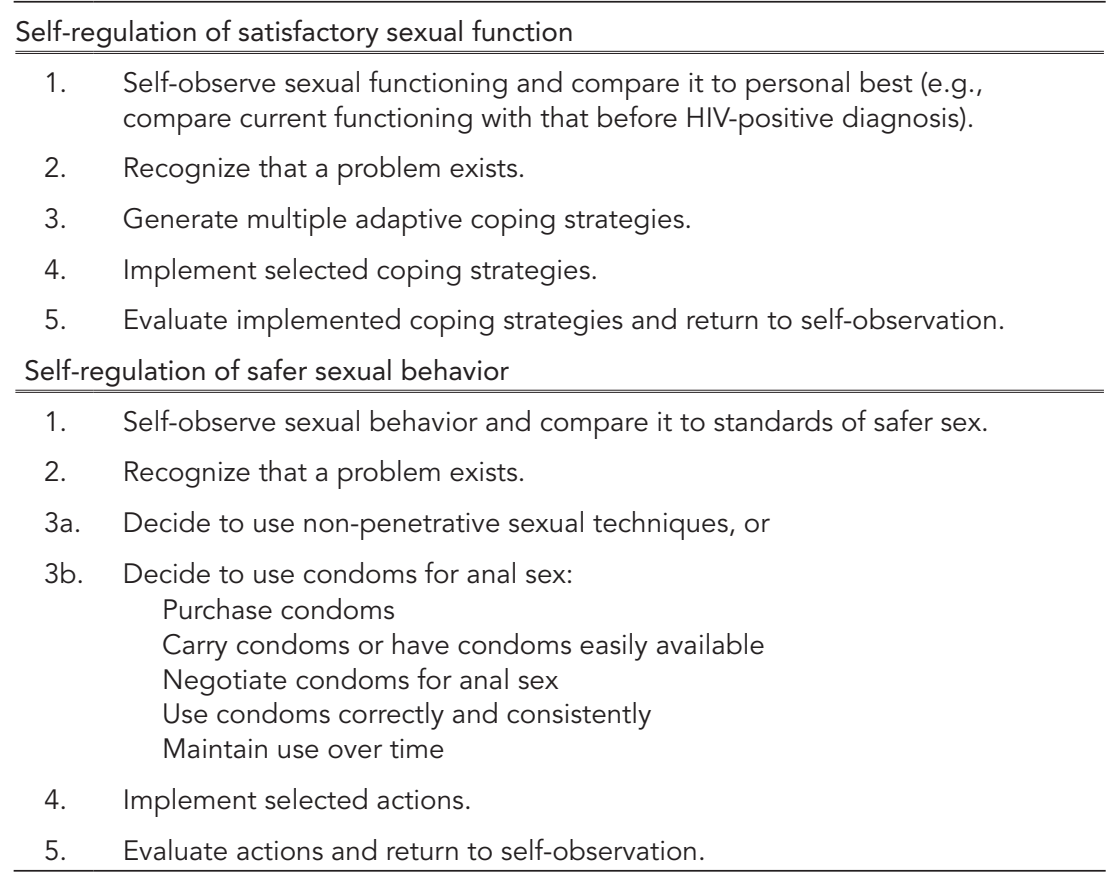


effective in the control of health and health-promoting behavior in one individual may not be effective in controlling health in another individual. As a consequence, the variables that need to be monitored may vary from person to person. Based on selfregulation theory, specific performance objectives were stated for self-regulation of satisfactory sexual function and safer sexual behavior (see Table l).

\section{Selecting determinants}

For specifying determinants of safer sexual behavior, the qualitative and quantitative study among HIV-positive MSM that are reported in Chapters 3 and 4 of this thesis, respectively, were used in combination with other empirical data and theoretical insights discussed in the needs assessment. The personal determinants (i.e., factors that lie within individuals) that were considered were: awareness, attitudes, personal norms, subjective norms, self-efficacy, skills and sexual motives. External determinants (i.e., factors that lie outside individuals) that were considered were: social support of sex partners and reinforcement by HIV nurses. Selecting determinants of satisfactory sexual function was, however, less obvious. Although a review by Catalán et al. (1995) provides a preliminary insight into psychosocial determinants of sexual (dys)function in HIV-positive MSM, not much empirical data are available on the predictors of sexual (dys)function in this target group. Therefore, the selection of important and changeable factors associated with self-regulation of sexual function was based mainly on theories of self-regulation, supplemented with the knowledge available on determinants of sexual dysfunction in HIV-positive MSM. The personal determinants for self-regulation of satisfactory sexual function that were considered were: awareness (knowledge and susceptibility), attitudes and cognitions about sexuality, self-efficacy and skills. For example, HIV-positive MSM should have at least some knowledge of the impact of HIV and its treatment on sexual function. Causative factors of sexual dysfunctions include physical or organic changes (e.g., anatomical or nerve damage, hormonal deficits, fatigue, pain), either from HIV itself or from its treatment. According to Lamba, Goldmeier, Mackie, \& Scullard (2004), there is good evidence for testicular and hormonal abnormalities in MSM with advanced HIV disease. However, causative factors of sexual dysfunctions can also be primarily psychosocial in nature. In addition to knowledge about the impact of HIV and its treatment on sexual functioning, it is important that HIVpositive MSM have some knowledge about the processes and procedures of selfregulation (Clark \& Zimmerman, 1990). This knowledge includes the self-regulation strategies for facilitating and strengthening sexual desire with which a person is familiar. Social support by significant others and reinforcement by HIV nurses were identified as the most important external determinants. 


\section{Creating matrices of change objectives}

Two matrices of change objectives were developed for the intervention: one matrix for self-regulation of satisfactory sexual function, and a matrix for self-regulation of safer sexual behavior. The performance objectives were entered in the left column of the matrix, while the personal and external determinants were entered across the top of the matrix. Then, one or more change objectives were defined for the cells that formed the intersection between performance objectives and determinants. Tables $2 \mathrm{~A}$ and $2 \mathrm{~B}$ in Chapter 5 of this thesis show a selected overview of the change objectives for satisfactory sexual function and safer sexual behavior.

\section{Overview of theory-informed intervention methods}

The theory-informed intervention methods to change the determinants of healthpromoting behaviors were based mainly on two prominent theories or models of behavior change; that is, self-regulation theory and a cognitive behavioral model of behavior change. Although self-regulation theory is particularly useful for the specification of performance objectives, the assumption that people go through several sub-processes to reach health goals is also suggestive for identifying applicable intervention methods. The primary methods within self-regulation theory are self-monitoring and self-evaluation (Clark \& Zimmerman, 1990; Thoresen \& Kirmil-Gray, 1983). Additionally, Prochaska, Redding, and Evers (2002) report that it is important that people recognize some form of need or are aware of the negative consequences of their behavior. Therefore, they suggest the use of consciousnessraising to increase awareness of the causes, consequences and cures for a particular problem behavior. Another method to increase awareness is dramatic relief, which is aimed at stimulating the experience of negative emotions, such as fear, anxiety and worry, that accompany unhealthy behavioral risks. The final outcome of dramatic relief, however, is reduced affect if appropriate action is taken. Hence, teaching problem-solving skills should be a necessary condition for behavioral interventions using dramatic relief (Bartholomew et al., 2001). Other methods described by the Transtheoretical Model (Prochaska et al., 2002) and Social Cognitive Theory (SCT) (Bandura, 1986, 1997) to stimulate self-monitoring and self-evaluation are: self-reevaluation, environmental re-evaluation, value clarification, decisional balance, imagery, modeling and feedback. Finally, Sniehotta, Schwarzer, Scholz, and Schüz (2005) suggest methods for the last sub-process of self-regulation, that is, the implementation of health-promoting behavior, namely action planning and coping planning. Both methods are based on the assumption that when individuals plan the details of action implementation and coping with obstacles in advance, it is much more likely that intended behavior is transformed into corresponding action. Action planning (very similar to implementation intentions; Gollwitzer, 1999) can help initiate action by specifying when, where and how to act. Coping planning refers to 
the mental simulation of overcoming anticipated barriers to intended action. Coping planning can help a person to overcome obstacles and to cope with difficulties by anticipating personal risk situations (i.e., situations that endanger the performance of intended behavior) and planning coping responses in detail.

The second set of theoretical concepts underlying the program was derived from a cognitive-behavioral model of behavior change. A review of the literature on the treatment of sexual dysfunction indicates that cognitive-behavioral therapy is the predominant treatment for sexual problems (Ellis, 1975; Rosen \& Leiblum, 1995; Rosen, Leiblum, \& Spector, 1994). A cognitive-behavior approach combines two models of behavior change: the behavioral model and the cognitive model. The behavior model proposes that an individual's actions (both adaptive and maladaptive) are developed and maintained largely by basic learning principles. These learning principles include classical conditioning, operant conditioning, and modeling (Bandura, 1986, 1997; Richelle, 1993). The cognitive model focuses on the potential mediating role that cognitions play in the development of sexual dysfunction. The cognitive model conceptualizes problematic behavior as resulting from dysfunctional or unhelpful thinking and hypothesizes that a decrease in symptomatic distress occurs via the reduction in these dysfunctional or unhelpful thoughts. Application of the cognitive-behavioral model to the treatment of sexual dysfunction has received significant empirical support. In addition, a number of published studies indicate the utility of a cognitive-behavioral approach to HIV risk-reduction (Belcher et al., 1998; Kelly, 1991; Van den Hoek, Kok, Van Kesteren, Hospers, \& De Zwart, 2005). The behavior and cognitive model describe several methods for changing determinants of behavior, including the use of psychoeducational information, cognitive restructuring to assist a client in identifying thought patterns that are likely to result in negative affect, relaxation training, training in problem solving skills, reinforcement, and feedback. In addition, cognitive behavioral therapy recommends various methods for the treatment of sexual dysfunction, such as sexual imaging to promote sexual arousal or reach orgasm (Ellis, 1975) and systematic desensitization and exposure in vivo, i.e. sex therapy, to reduce fear and counterbalance avoidance (Masters \& Johnson, 1970). Finally, a number of dysfunction-specific methods have been described, such as the "teasing" approach with regard to erectile disorder, the "start-stop" and "squeeze" techniques with regard to premature orgasm, and muscle relaxation training with regard to dyspareunia, including anal pain (Masters \& Johnson, 1970; Semans, 1956).

In addition to these general theoretical approaches, more specific theories suggest a variety of intervention methods. For example, theoretical insights on regret (Richard, De Vries, \& Van der Pligt, 1998; Richard, Van der Pligt, \& De Vries, 1995) and altruism (Batson, Early, \& Salvarani, 1997) suggest methods to elicit change in personal norms. Goal-setting theory was used to improve self-efficacy in HIVpositive MSM. Finally, theories about social networks and social support suggest 
methods for enhancing social support, such as assessing one's social networks, enhancing existing social networks and developing new social network linkages (Heany \& Israel, 2002).

\section{Overview of practical strategies}

At this point in the Intervention Mapping process it became necessary to specify the setting in which the intervention was to be implemented and the intended program users. After several settings were reviewed by the linkage group and pros and cons were weighted, it was decided that the intervention would be carried out in HIV treatment centers. The most important reason for choosing a hospital setting was the wish to reach as many HIV-positive MSM as possible. Thus far, prevention efforts targeting the specific needs of HIV-positive MSM were rare in the Netherlands. Moreover, the hospital setting offered an excellent opportunity to support the sex life of HIV-positive MSM and to reinforce the need to practice safer sex (Colfax $\&$ Dawson-Rose, 2006; Fisher et al., 2006).

Based on a literature search, bibliotherapy was selected as the primary strategy. A meta-analytic review has shown that bibliotherapy, often in the form of self-help guides or manuals, is effective in the treatment of sexual dysfunction (Gould \& Clum, 1993; Van Lankveld, 1998). Bibliotherapy can be defined as the use of written material to help people solve problems or change behavior, whereas self-administered bibliotherapy is a specific form of self-care behavior (Glasgow \& Rosen, 1978; Van Lankveld, 1998). A self-help intervention was thought to be worth undertaking for the following reasons. First, the idea of a self-help guide fits naturally with the starting points of self-regulation. Via various successive steps the reader can be taught how to self-observe, identify problems, search for actions, and implement them. Second, a self-help guide assures a client-centered approach, as the reader can set his own priorities regarding the areas in which he needs help. Third, although the individual is the focal point of bibliotherapy, it may function as an indirect source of social support in that it can create an awareness that others face similar problems or issues (Silverberg, 2003).

Because individuals who lack the motivation or confidence to engage in selfregulation are not accounted for in self-regulation theory, i.e., self-regulation is viewed as an autonomous, internal process (Clark \& Zimmerman, 1990), it was crucial to complement the use of the self-help guide with motivational interviewing (Miller \& Rollnick, 1991, 2002). Motivational interviewing refers to a clientcentered, directive counseling method that helps the client explore and resolve his ambivalence about change. The tone of motivational interviewing is supportive and non-moralizing. Motivational interviewing has been used extensively in the addiction field, and is known as an effective technique in the treatment of addiction, but also in facilitating a broader spectrum of health-promoting behaviors (Dunn, Deroo, \& Rivara, 2001). In motivational interviewing, the counselor provides the client with 
feedback on the possible risks of his behavior, sets the conditions to enable the client to make his own informed choices in behavioral change, and reinforces initiatives for change. Essentially, four broad guiding principles underlie motivational interviewing: express empathy (i.e., non-judgmental listening, acceptance of the client, and recognition that ambivalence about change is normal); develop discrepancy (i.e., highlighting the difference between current behavior and personal goals or values); roll with resistance (i.e., avoid arguing for change; new perspectives are invited but not imposed); and support self-efficacy. The techniques of motivational interviewing include listening reflectively and eliciting motivational statements.

\section{Overview of intervention materials}

The practical strategies and the decisions made in the previous steps were compiled in an intervention plan. It was decided to develop a program that comprised a selfhelp guide, a motivational interview session, and a motivational telephone interview, both of which were conducted by nurses whose specialty is HIV. The goal of the program was to promote self-regulation of satisfactory sexual function and safer sexual behavior over a period of three months. The participants first received the self-help guide. The motivational interview session and motivational phone interview were conducted approximately three and six weeks later, respectively. The theme of the program was for HIV-positive MSM to gain control of their sexual and social lives.

\section{Self-help guide}

The self-help guide consisted of seven chapters in which questions, problems and solutions concerning the three main topics of the self-help guide (e.g., sexuality, making contacts and safer sex) were discussed (Schippers \& Van Kesteren, 2004). The first chapter included an introduction about HIV and sex, and stated the primary goal of the self-help guide. Through the use of the reading guide, HIV-positive MSM were encouraged to identify personally relevant issues and to focus on them, but in any case, to closely read Chapters 2 and 3. The second chapter dealt with explaining the basic methods of the self-help guide, i.e. making a behavioral change plan and working on changing thoughts. Making a behavioral change plan follows the basic pattern of self-regulation and consists of four steps: increasing understanding of one's current situation (step l) $\rightarrow$ identifying goals and arranging them in order of priority (step 2) $\rightarrow$ planning when, where and how to implement possible solutions (step 3) $\rightarrow$ planning coping responses to high-risk situations (step 4). Next, a method for changing thoughts was delineated. This method generally followed the procedures for rational-emotive self-analysis as described by Ellis (1975). The third chapter aimed at expanding the men's self-awareness of the three main topics of the self-help guide. This included an examination of sexual (dys)function, making contacts, and risky sexual practices. The fourth chapter focused on the most important theoretical 
underpinning of motivation for behavior change. After having identified issues that are personally relevant, readers were encouraged to assess the importance of change to them and their level of confidence in their ability to achieve it. The purpose of the fifth, sixth and seventh chapters was to facilitate (behavior) change through suggesting solutions on how to deal with different problems, feelings and situations. The fifth chapter dealt with overcoming sexual problems. Possible solutions for change were suggested for each sexual dysfunction. For instance, respondents suffering from low libido were introduced to exercises such as self-exploration of body and genitals, exploration of potentially arousing sexual stimuli ("simmer"), and improvement of concentration on physical sensations and exploration of sexual fantasy. The sixth chapter focused on developing and keeping (sexual) contacts, while the seventh chapter covered issues related to safer sex.

\section{Motivational interview counseling sessions}

In order to enhance motivation for behavior change, a motivational interview counseling protocol for HIV specialist nurses was developed (Van Kesteren \& De Wildt, 2004). The counseling protocol was based on guidelines for behavior change consulting in healthcare settings (Rollnick, Mason, \& Butler, 1999), and consisted of one face-to-face counseling session and one follow-up counseling call. The face-toface counseling session was used to focus on a specific theme of the self-help guide identified as important by the HIV-positive MSM, and to enhance and stimulate motivation for behavior change. Typically, HIV-positive MSM are not a homogeneous group in regard to behavior change. Therefore, the first part of the face-to-face session focused on exploring the participant's priorities and tried to narrow them down to one clear objective. After selecting a particular behavior, the next step was to assess the importance of, and confidence to make, behavior change, as it helps the counselor to assess exactly how the participant feels about changing and facilitates tailoring the content and format of the encounter to the participant's readiness for change. First, participants were asked to rate on a scale of 1 to 10 (with 10 being the highest) the importance they place on behavior change and the level of confidence in their ability to do so. Second, they were asked why they had not rated it lower (to elicit positive motivational statements), and why they had not rated it higher, or what it would take to get to a 9 or 10 (to elicit barriers) (Rollnick et al., 1999). The third step of the first session focused on working through ambivalence by using the decisional balance in order to explore the costs and benefits of both staying the same and changing. However, this step was optional, and was completed only when the participant exhibited ambivalence about behavior change, i.e., scored around 5 on the assessment scale. If the score was higher, the counselors were instructed to move on to the fourth step, during which an action plan was developed. The primary purpose of the telephone call was to monitor progress. 


\section{PHASE 3: PROGRAM IMPLEMENTATION}

In the third phase of the research project several activities were undertaken to anticipate program implementation (Intervention Mapping Step 5). First, from the start of the research project, a linkage group was generated. A linkage group is used to exchange knowledge and ideas among those who are developing the intervention and those who will use the program. The linkage group was assembled early in the program planning process, because a linkage approach promotes immediate professional involvement and support for the program. Experts from several organizations working with HIV/STDs and HIV-positive MSM were part of the linkage group and served as advisors to the research project from the outset. These organizations were Schorer (Dutch Gay and Lesbian Health Foundation); SAN (Netherlands Center for HIV/AIDS and Other STDs); the Netherlands HIV patients' organization; and the Department of Medical Psychology of the Universiteit van Amsterdam, which specializes in research on quality of life among HIV-positive people. The formation of the linkage group from the start of intervention development proved to be an essential step for program adoption and implementation. For example, during the early meetings of the linkage group it appeared that the collaborating organizations had divergent views on the specific problem to address. Intervention Mapping helped to reach agreement on the goals of the intervention. The time that was taken to specify program objectives, consider different theory-based intervention methods and practical strategies, and make conscious choices about materials and activities increased acceptance of and support for the final design of the program. Second, an implementation day, hosted by the Netherlands Organization for Health, Research and Development, was held in October 2003. The implementation day brought together researchers and experienced practitioners and policy-makers working with HIV-positive MSM. The implementation day had the goals of (1) sharing information on the research project; (2) outlining the preliminary ideas on program development; and (3) exploring the possibilities for program implementation. Finally, concerted efforts were made to build support for the intervention within the HIV treatment centers. The committee of the working group of HIV specialist nurses in the Netherlands was asked to publicly support the intervention, and articles were published in their newsletter to inform HIV nurses nationwide about the progress and results of the project. In addition, several HIV treatment centers were visited to present the results of the study and discuss the program plans. Finally, the feasibility of program adoption and implementation was enhanced by conducting an implementation study (Van Riemsdijk \& Van Kesteren, 2004). This study aimed at identifying those factors that promote or inhibit the use of the self-help and motivational enhancement intervention among HIV specialist nurses. The data collected in the study were used to inform the implementation plan. Based on this implementation plan, a one-day 
course on motivational interviewing and a half-day "booster session" were developed to train the HIV nurses in the intervention protocol and to provide them with the principles and techniques of motivational interviewing.

\section{PHASE 4: EFFECT EVALUATION}

The fourth phase of the research project was to evaluate the efficacy of the self-help and motivational enhancement intervention (Intervention Mapping Step 6), the findings of which are reported in detail in Chapter 6 of this thesis (Van Kesteren, Hospers, Van Breukelen, \& Kok, 2007). The design chosen was a cluster randomized waiting list control group design. The evaluation focused on the impact of the selfhelp and motivational enhancement intervention relative to standard care (i.e., control). The primary outcome measures were sexual problems and condom use behaviors with steady and casual sex partners. The secondary outcome measures included preparatory behaviors to practice safer sex (e.g., buying condoms, carrying condoms and communicating about condoms) and action control (i.e., self-regulatory effort in implementing and maintaining behavior). Social-psychological determinants of condom use with steady and casual sex partners were also measured. Furthermore, rating scales measured self-esteem, appearance evaluation and social support.

A total of 162 participants from 15 HIV treatment centers participated in the study. Data collection took place at baseline and three-month follow-up. Evaluation was based on 135 (83.3\%) participants who completed the 3-month follow-up survey. Participants included $50(79.4 \%)$ in the intervention group and $85(85.9 \%)$ in the waiting list control group. At baseline, participants in the intervention group and waiting list did not differ at any demographics, primary or secondary outcomes. However, the intervention did not have any significant effect on the primary or secondary outcomes. Thus, it could not be concluded that the self-help and motivational enhancement intervention was effective in promoting self-regulation of sexual function and safer-sexual behavior in HIV-positive MSM. Process data helped partially explain why the program was not successful in meeting its program goals. The results showed that the HIV-positive MSM positively evaluated program components. However, implementation of the program was moderate. Although $85 \%$ of the participants reported having received the face-to-face motivational interviewing session, only $40 \%$ reported having received the motivational interviewing telephone call. With respect to use of the self-help guide, the majority of the participants (60\%) reported reading most of it, but more than half (55\%) did not apply any of the exercises outlined in the self-help guide. Additional, only a minority $(21 \%)$ of the participants reported devising a behavioral change plan, which formed the main mechanism of change of the program.

Other factors that may have contributed to the absence of intervention effects include the following: (1) The self-help guide introduced to the HIV-positive 
MSM three themes related to sexual health, i.e., sexual functioning, making and keeping contacts, and safer sex. In accordance with the principles of self-regulation, participants were encouraged to identify and focus on issues that are personally relevant. This approach may have created substantial variation in what the participants have been working on during the intervention period, making it difficult to achieve differences between the intervention group and waiting list control group. Alternatively, it may also be that the broad outline of the intervention limited its efficacy. The participants' freedom to choose goals in an array of issues related to sexuality may have made it possible to pursue personal goals that are unrelated to or too distal from the primary outcomes of the study, i.e., reducing sexual problems and UAI with steady and casual sex partners; (2) Unintended negative effects for the self-help guide could have prompted the reader's defense mechanisms (such as avoidance and denial) by producing negative emotional experiences or psychological discomfort, thus resulting in stasis or refusal to change (Silverberg, 2003; Williams, 2001, also see "Adequacy of the strategies used", p. 29); (3) The one-day course and half-day booster session in motivational interviewing may have been too limited for the HIV nurses to familiarize themselves with the principles and techniques of motivational interviewing and the counseling protocol. Although it has been suggested that practitioners can be effectively trained in motivational interviewing within the scope of short training courses or workshops (Rollnick et al., 1999), it is unclear whether the training sessions were sufficient for the HIV nurses to fully assimilate the spirit of motivational interviewing. Future research studies should monitor counseling sessions to determine the way in which HIV nurses interact with the participants and the extent to which they have achieved the necessary skills of motivational interviewing.

Despite these possible explanations, longer-term follow-up is needed to assess primary and secondary outcomes more completely. Possibly, improvement in the primary and secondary outcomes may not have taken place yet because of the short duration of the evaluation period. Follow-up data were also collected nine months after baseline, but results are not yet available.

\section{CONCLUSIONS AND FURTHER RESEARCH}

Four main conclusions can be drawn from the research in the present thesis:

1. Although evidence indicates that HIV-positive MSM have adopted riskreduction strategies, roughly two in five HIV-positive MSM continue to engage in UAI, which represents a risk for continued HIV and STD transmission (Chapter 2; Van Kesteren, Hospers, \& Kok, 2007). Therefore, developing effective HIV preventive interventions targeting HIV-positive MSM should be a priority for HIV prevention. In addition, ongoing surveillance should be undertaken to monitor trends in sexual risk behavior in HIV-positive MSM. 
2. HIV and treatment of HIV may lead to various sexual problems which might in turn facilitate sexual risk behavior (Chapter 3; Van Kesteren et al., 2005). HIVpositive MSM face the altered meaning of sexuality and the consequences of unprotected sex. Consequently, most HIV-positive MSM express fears about infecting their sex partners, and their sexual decisions take place in a complex interplay of meeting their sexual needs, meeting their sex partners' sexual needs, and several factors that have a negative effect on sexual expression and sexual function. Thus far, the focus of research into HIV prevention has been almost exclusively the physical, psychological and social functioning of those infected, and psychosexual research, especially in relation to sexual risk behavior, has been minimal. The findings indicate that the role of sexuality is an important factor to consider in understanding HIV-positive MSM's sexual risk behavior. Therefore, further research on sexual problems in HIV-positive MSM, and the relationship between sexual problems and sexual risk behavior needs to be conducted.

3. Safer sex in HIV-positive MSM is affected by feelings of moral obligation to act on one's personally held norms (Chapters 3 and 4; Van Kesteren et al., 2005; Van Kesteren et al., 2007). In Chapter 3, it was found that most HIV-positive MSM feel personally responsible for safer sex, and adhere to a style of sole or shared responsibility with regard to condom use behavior. In addition, HIVpositive MSM who feel personally responsible are more likely to have safer sex. This result was confirmed by the findings in Chapter 4. In this chapter, it was found that personal norms: (1) had a significant influence on intended condom use with steady and casual sex partners; and (2) mediated the effects of some other determinants of interest on intended condom use with steady and casual sex partners. However, the relationship between personal norms and safer sex is not straightforward (Chapters 3 and 4). Whether HIV-positive MSM ultimately adhere to these norms and have safer sex depends on situational factors (e.g., social norms and partner characteristics) (Chapter 3) and psychological processes (e.g., a conflict between the desire for sexual expression and adherence to one's norm of perceived responsibility) (Chapter 4). Overall, safer sex in HIVpositive MSM is a form of prosocial behavior, which broadens the understanding of potential motives of safer sexual behavior at work and the conditions under which HIV-positive men engage or do not engage in safer sex. Future research might expand on these findings and take into account more prosocial and affectoriented theories of condom use behavior.

4. No significant intervention effects on the primary or the secondary outcomes were identified (Chapter 6; Van Kesteren, Hospers, Van Breukelen et al., 2007). At this time, therefore, it cannot be concluded that the self-help and motivational enhancement intervention is an effective method for increasing self-regulation of satisfactory sexual function and safer sexual behavior in HIV-positive MSM. 
Longer-term follow-up is needed to assess primary and secondary outcomes more completely. Also, in-depth analysis of process data can provide more insight into what actually happened during the implementation of the program. Future HIV prevention research should focus on the development of effective interventions for HIV-positive MSM.

\section{RECOMMENDATIONS}

What can be learned from the present project? Given the limited amount of information concerning HIV-positive MSM and sexual risk behavior and the limited amount of other evaluations of interventions for these men, it is worthwhile to deduct lessons learned from the present project: aspects that are worth pursuing; aspects that were unexpected but need to be addressed in future work; and aspects that are less likely to be successful after all. In short, four specific issues that could be taken into account in future work will be discussed; it is hoped that by addressing these issues, HIV prevention efforts targeting HIV-positive MSM will be strengthened. These topics are: (1) goals and focus of the study; (2) adequacy of the strategies used; (3) implementation of the study; and (4) evaluation of the study - feasibility versus effectiveness. Each of the topics will be discussed separately, although it should be noted that topics may overlap.

\section{Goals and focus of the study}

The goal of the intervention was to improve the overall sexual health of HIV-positive MSM by targeting sexual function and safer sexual behavior. Although this may have corresponded with the problems at hand, this choice ultimately presented several challenges. First, specifying the intervention goals in such broad terms necessitated a similarly broad definition of the evaluation criteria. Nevertheless, the initial aim was to promote safer sex through the use of the intervention. Despite the selection of evaluation measures by which sexual function, condom use, and broader outcomes, such as appearance evaluation, self-esteem and social support, were assessed, it is possible that the choice of outcome measures was inadequate. This could at least partially explain the failure of the intervention to effect actual changes. Second, by giving the participants the freedom to choose goals in an array of issues related to sexuality, personal goals might have been pursued that are unrelated to or too distal from the primary outcomes of the study, i.e., reducing sexual problems and UAI with steady and casual sex partners. So what lessons can be derived from this? First, when aiming to promote sexual health at a general level, it seems to be essential to also evaluate outcomes at a broader level, for instance, in terms of quality of life and quality of sex. Moreover, if the primary focus of an intervention is on participants setting goals for sexuality that are meaningful and relevant to them, it might be important to evaluate whether participants have achieved their personal goals 
and how successful goal achievement is related to quality of life and quality of sex outcomes (e.g., Boersma, Maes, Joekes, Dusseldorp, 2006). Second, when aiming for a specific goal, such as the promotion of safer sex, the decision may be to focus on a single health-promoting behavior (e.g., condom use for anal sex) rather than the entire spectrum of sexual health. This also means that such interventions may promote a goal that is not necessarily appropriate for the personal situations of HIV-positive MSM, and is, therefore, less intrinsic than more broadly-based goals. In other words, it needs to be decided whether the aim is to address the concerns of HIV-positive MSM regarding their own sexual health, necessarily coincide with the initial goal of the project (i.e., HIV prevention), or to focus on a more extrinsic goal, which corresponds with the initial scope of the project, but may not be in line with the needs of members of the target audience. Finally, the moment at which the intervention is offered to the target population may be particularly important. Most participants were diagnosed with HIV some years ago. It is possible that the efficacy of the intervention was limited for these men since they may already have changed their behavior. Offering the intervention to recently diagnosed MSM may be more effective as this particularly is the time that they need to come to terms with the HIV-positive diagnosis and its implications for sexuality and sexual behavior.

\section{Adequacy of the strategies used}

One of the main strategies in the project was to use a self-help guide to create changes in sexual function and sexual behavior. The use of the self-help guide had several advantages. The first advantage was that the self-help guide enabled HIV-positive MSM to individualize their problem-solution decision-making. The HIV-positive MSM who participated in the intervention were allowed to select aspects from the self-help guide that they considered essential to work on. By creating this possibility, HIV-positive MSM received personalized treatment; this means that the topics they were provided were probably relevant, while simultaneously reducing the amount of information available to them. As such, it is likely that the participants would be kept motivated to deal with specific issues on sexual health. Another advantage of the self-help guide was that it could be used at the participants' convenience. The latter was also important to ensure that these men felt at ease and reassured that their confidentiality would be kept. Nevertheless, there were also some disadvantages in using the self-help guide. First, with the open approach, some participants may have been tempted to focus on issues that were of little or no concern or that they thought would be easily achievable, rather than focusing on challenging and effective issues. From goal-setting theory (Locke \& Latham, 1991), it can be gleaned that goals are likely to be achieved only if they are both challenging and achievable. Future interventions may be more effective in encouraging participants to set important, challenging goals. It is also possible within our intervention to achieve that objective, given the counseling sessions. Closer integration between the self-help guide and the 
counseling sessions might have helped to ensure that participants were motivated to improve their sexual health, while simultaneously ensuring feedback, support and reinforcement - essential elements mentioned in the goal-setting literature.

In addition, it should be mentioned that the self-help guide might have resulted in unintended adverse side effects. The original text was adapted from a pilot test of an early version of the self-help guide. Changes were made to the focus of the self-help guide; from the pretest it appeared that HIV-positive MSM were annoyed by the focus on sex as a problem. To rectify this predicament, references in the text to "having problems" were eliminated, and the focus was directed to improving or creating a more satisfactory sex life. Additional changes to the text were made in order to clarify the content of the guide. Terminology was simplified in an attempt to adapt scientific terminology to more everyday language, and a glossary of terms was added to assist readers in understanding certain concepts. Despite these changes, HIV-positive MSM still may have perceived the self-help guide as not entirely appropriate to their situations. This may have resulted in a lack of motivation on the part of participants to take note of some relevant parts of the self-help guide. The notion that the focus was too much on potential problems is also supported by process data. During intervention implementation, it appeared that HIV nurses faced significant challenges in recruiting participants for the evaluation study. One of the challenges was motivating HIV-positive MSM to take part in the study. Introducing the intervention as a vehicle for working on sexual problems or problems with safer sex emerged as an important trigger of early patient resistance. According to Rollnick and Miller (1995), imposing a diagnostic label should be considered a confrontational counseling technique. This may explain the defensive reaction of HIV-positive MSM, who may have felt pushed into making changes that they were not willing to make, which violated the essential spirit of motivational interviewing. Future efforts should address this issue directly by developing strategies to anticipate early patient resistance.

In addition to possible improvements in terms of complexity and fit with the intended audience, the user-friendliness of the self-help guide might be further improved. For instance, research in cognitive psychology (Kools, 2006) has shown that by adapting the design characteristics of written material (e.g., graphic organizers, pictures or headings), comprehension by the reader can be improved, thereby creating a significant precondition for facilitating behavior change.

\section{Implementation of the program}

For interventions to be successful, it is essential to ensure program adoption, implementation and sustainability. According to Rogers (1995), the adoption of a program depends on several factors: knowledge of the innovation; formation of an attitude about the innovation; a decision to adopt and implement the innovation; and conformity to the decision. Within this context, barriers and facilitators 
that can influence the acceptance and incorporation of a program should be anticipated (Rogers, 1995). These factors can be subdivided into six broad categories (Rubenstein, Mittman, Yano, \& Mulrow, 2000): 1) the external environment (e.g., regulations, policies); 2) the organization (e.g., staffing, regulations, scope of services, size); 3) practice mechanisms (e.g., mechanisms for the enhancement of prevention practices); 4) the individual provider (e.g., knowledge, skills, attitudes, experience); 5) the target population (e.g., health and social functioning, expectations, skills); and 6) the encounter (e.g., location, client-provider interaction). Some of these factors were addressed in the present project. An early priority was establishing a linkage group, including all essential representatives from the research and development team and key organizations in HIV-positive and gay communities. Furthermore, interviews with HIV nurses were conducted to assess perceived facilitating and hindering factors of adoption and implementation of an HIV preventive intervention for HIV-positive MSM and to generate early support (Van Riemsdijk \& Van Kesteren, 2004). These factors were addressed in the training that was provided to HIV nurses to effectively implement the intervention. During implementation, however, new inhibiting factors were identified. For example, unlike earlier conclusions drawn from the interviews with HIV nurses, it appeared that they were not always the key representatives for adopting and implementing the program. A clear barrier to program implementation was lack of time. The intervention had to be integrated within existing practices, without any additional time or resources. Consequently, the majority of the HIV nurses perceived some sort of role conflict resulting from their having to deal with multiple goals within their function as HIV nurses. Future initiatives should better anticipate contextual and organizational barriers to program implementation. Management or other representatives responsible for the allocation of resources should be included in the project to deal with the issues of personnel time and expectations. Specifically, new policies with regard to HIV nursing should be established, with specific time devoted to sexuality and HIV prevention.

\section{Evaluation of the program; feasibility vs. effectiveness}

In attempting to create an effective and feasible intervention, a combination of strategies was incorporated in the intervention, which was implemented and evaluated in several locations. Although this could be viewed as one of the project's strong points, at the same time, given the non-findings, it also may have been one of its greatest weaknesses. Often there is a conflict between demonstrating the effectiveness of a program and developing an intervention that is feasible and can be applied in practice. Recently, Michie and Abraham (2004) challenged what they called evidence-inspired programs, or programs that are assumed to be effective because of underlying theoretical notions, but without the possibility to clearly evaluated these notions. They stated that programs should first be rigorously tested on a small-scale, with each method examined individually. In the present 
project, the intervention design was based on a combination of theory-informed intervention methods and practical strategies, and was implemented on a large scale. This approach may have led to the erroneous conclusion that the intervention is not effective. In the future, specific elements or methods that seem critical to the program's effectiveness, which are put forward by the project, should be tested on their own and in a more controlled setting in order to accurately test their effectiveness.

\section{CONCLUDING REMARKS}

This thesis describes the systematic development of a self-help and motivational enhancement intervention for HIV-positive MSM. Although, the overall outcome of the project was disappointing, given that the most important purpose of the project was not accomplished, which was to promote the sexual well-being of HIV-positive MSM, the project yielded significant findings. Important HIV prevention needs of the target population were identified, which will be useful for the development of other HIV prevention programs and the development of policy aimed at the prevention of HIV risk, and specifically enhanced quality of life of people living with HIV. Moreover, the project indirectly contributed to agenda-setting of HIVpositives, sex and HIV prevention. Furthermore, the debate about responsibility has shifted to an active approach of targeting those who are HIV-positive. The issue of responsibility is no longer a barrier to HIV prevention for HIV-positive MSM. Rather, there is a discussion of how responsibility might be used in future HIV preventive efforts in such a way that it justifies the shared responsibility of people, and motivates both HIV-positive and HIV-negative people to practice safer sex. Simultaneously, it is acknowledged that criminalizing sexual risk behaviors of HIVpositive people is likely to result in adverse outcomes for the quality of life of many in the long term (International HIV/AIDS Alliance, 2003; SOA AIDS Nederland, 2004). Nevertheless, the results of the project indicate that in order to ensure that the needs of HIV-positive MSM are met, additional research must be undertaken to develop and implement effective and feasible alternative programs with the target audience within the context of current HIV care. New policies should aim at further professionalizing the context of HIV care, establishing a situation in which the combination of HIV and sex are normalized and integrated within ongoing practices. 


\section{ChAPTER 2}

\section{Sexual risk behavior:}

A literature review

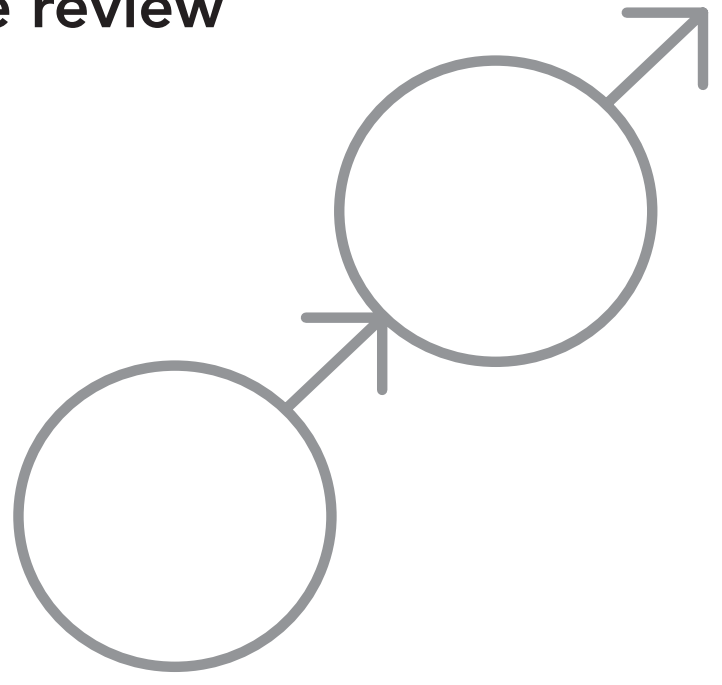

Published as:

Van Kesteren, N.M.C., Hospers, H.J., \& Kok, G. (2007). Sexual risk behavior among HIV-positive men who have sex with men: A literature review. Patient Education and Counseling, 65, 5-20 


\section{INTRODUCTION}

Evidence regarding sexual risk behavior among HIV-positive men who have sex with men (MSM) was reviewed by Kalichman in 2000 (Kalichman, 2000). The primary goal of this review was to provide an update on this issue and to summarize the factors associated with unprotected sex among different subpopulations affected by HIV/AIDS. Kalichman reviewed 22 studies, of which eight among community samples of MSM and seven among clinical or community samples of heterosexual men and women. The remaining seven studies reported on sexual risk behavior among injection drug and other substance abusers. Across populations, Kalichman estimated that approximately one-third engaged in high-risk sexual behavior. The studies among HIV-positive MSM that Kalichman included in his review indicated that sexual risk behavior occured more frequently with casual sex partners than with steady sex partners. In addition, it was found that HIV-positive MSM were more likely to engage in sexual risk behavior with HIV-positive than with HIVnegative sex partners and more likely to practice unprotected anal intercourse (UAI) as the receptive than as the insertive partner. These findings indicate that sexual risk behavior may be influenced by relationship status, partner HIV status and perceptions of risk.

Although the literature dealing with HIV prevention needs among HIV-positives is rather young, the last years are characterized by an increasingly number of studies on sexual risk behavior among HIV-positive people and its psychosocial determinants (Crepaz \& $\&$ Marks, 2002). However, studies reporting on sexual risk behavior among HIV-positive MSM have not been systematically assessed after 2000. Based on surveillance data suggesting rising rates of sexually transmitted diseases (STDs), including HIV, among MSM (Anon, 2001, 2002; CDC, 2003; Chen et al., 2002; Murphy, Charlett, Brown, Gill, \& Parry, 2004; Stolte, Dukers, De Wit, Fennema, \& Coutinho, 2001), it has been suggested that sexual risk behavior may have increased as well, which would imply a higher rate than Kalichman reported. The purpose of this review study was to assess risk behaviors for transmission of HIV. Following up on Kalichman's results, relationship status (steady vs. casual), and partner HIV status (positive, negative, unknown) were taken into account. We focused exclusively on anal intercourse because UAI poses the highest risk of viral transmission.

\section{METHODS}

To identify empirical studies addressing sexual risk behavior in HIV-positive MSM, we searched the electronic databases Medline, PsycInfo, Eric, and Online Contents using combinations of the keywords AIDS, HIV, HIV-positive, HIV-negative, sexual (risk) behavior/behaviour, MSM, gay men and bisexual men. The period covered was January 2000-October 2005. We also scrutinized the reference lists of included 
articles. Studies were included if they: 1) examined HIV-infected MSM, or general samples of MSM of whom some were HIV-positive; 2) measured UAI; and 3) reported the proportion of the sample that had UAI by HIV status. Studies were excluded if results did not show the prevalence of sexual risk behavior by HIV status. Studies were also excluded if not all HIV-positive MSM were aware of their HIV status or if they targeted seroconverting individuals before and after notification of HIV-positive status. No abstracts were included, as abstracts provide too few details of the studies' findings.

In total, 53 studies were reviewed. To enable comparisons of sexual risk behavior among the studies, we subdivided the findings of our literature review into three categories. The first category contains cross-sectional studies that focused exclusively on samples of HIV-positive MSM. The second category includes crosssectional studies that reported on sexual risk behavior in samples of MSM of mixed HIV status. The last category contains longitudinal studies that investigated changes over time in sexual risk behavior among samples of MSM who are HIV-infected or of mixed HIV status.

\section{RESULTS}

\section{Cross-sectional studies of sexual risk behavior in samples of HIV-positive MSM}

Twenty-five cross-sectional studies have reported on sexual risk behavior in HIVpositive MSM (Bingman, Marks, \& Crepaz, 2001; CDC, 2004; Colfax et al., 2004; Cove \& Petrak, 2004; Cox, Beauchemin, \& Allard, 2004; Halkitis et al., 2005; Halkitis \& Parsons, 2003; Halkitis, Wilton, Parsons, \& Hoff, 2004; Hart, Wolitski, Purcell, Gomez, \& Halkitis, 2003; Hoff et al., 2004; O'Leary et al., 2005; Parsons \& Halkitis, 2002; Parsons, Halkitis, Wolitski, \& Gómez, 2003; Parsons et al., 2005; Poppen, Reisen, Zea, Bianchi, \& Echeverry, 2005; Remor \& Ulla, 2002; Semple, Patterson, \& Grant, 2000a, 2000b, 2000c, 2003b, 2004; Stephenson et al., 2002; Theodore, Durán, Antoni, \& Fernandez, 2004; Van Kesteren, Hospers, Van Empelen, Van Breukelen, \& Kok, 2007; Vanable, Ostrow, \& McKirnan, 2003) (see Table 1 for an overview). The studies differ widely in the manner in which sexual risk behavior was assessed. A few studies focused on sexual risk behavior with HIV-positive partners, whereas others reported on sexual risk behavior regardless of the HIV status of sexual partners or exclusively included sexual risk behavior with HIV-negative or HIV status unknown partners.

\section{Sexual risk behavior regardless of partner HIV status}

We found ten cross-sectional studies that reported on the prevalence of sexual risk behavior among HIV-positive MSM regardless of the HIV status of sexual partners (CDC, 2004; Cove \& Petrak, 2004; Cox et al., 2004; Hoff et al., 2004; Poppen et al., 2005; Remor \& Ulla, 2002; Stephenson et al., 2002; Theodore et al., 2004; Van 


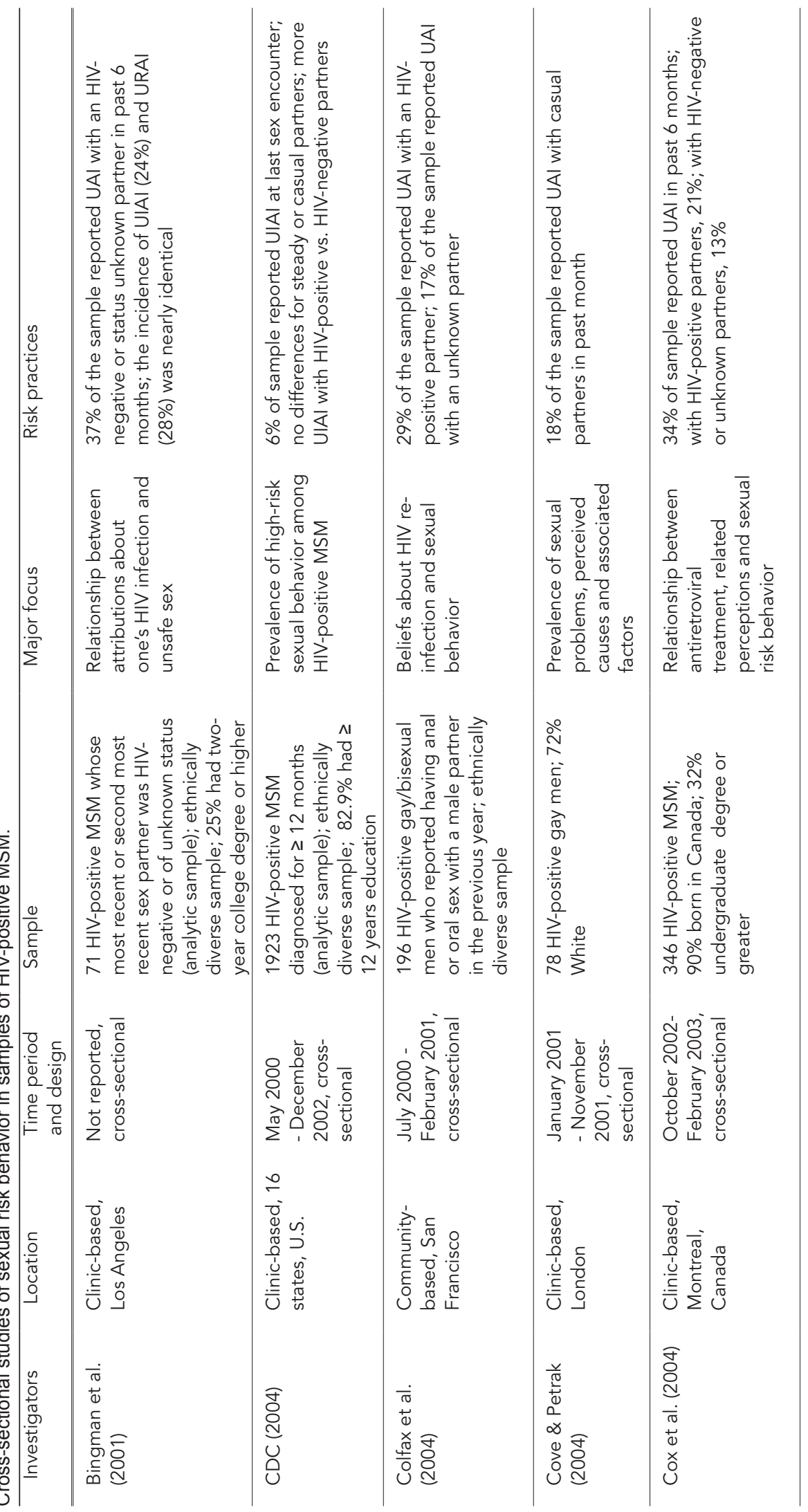




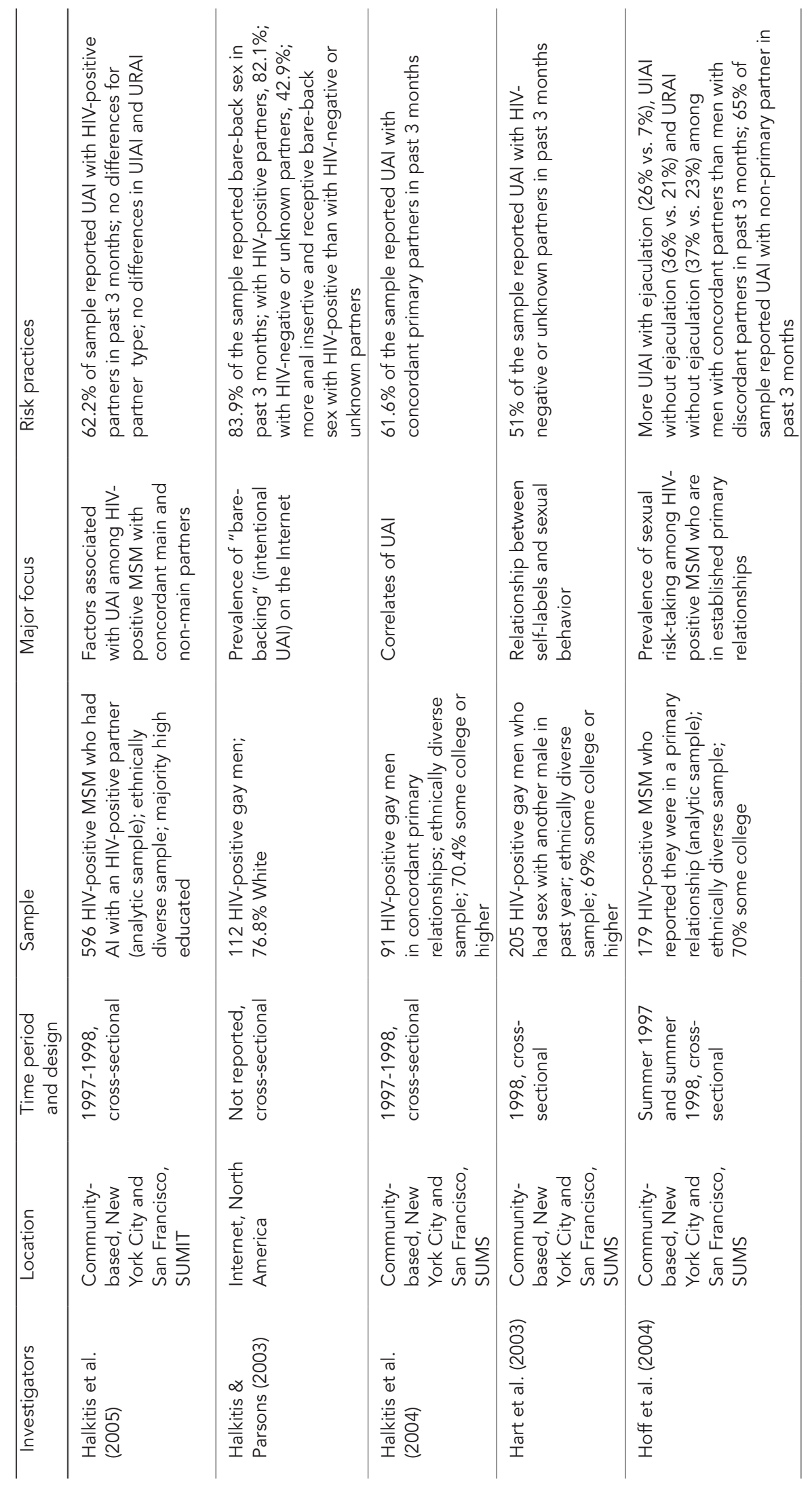

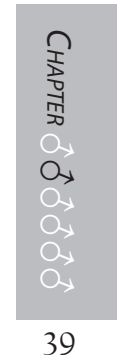




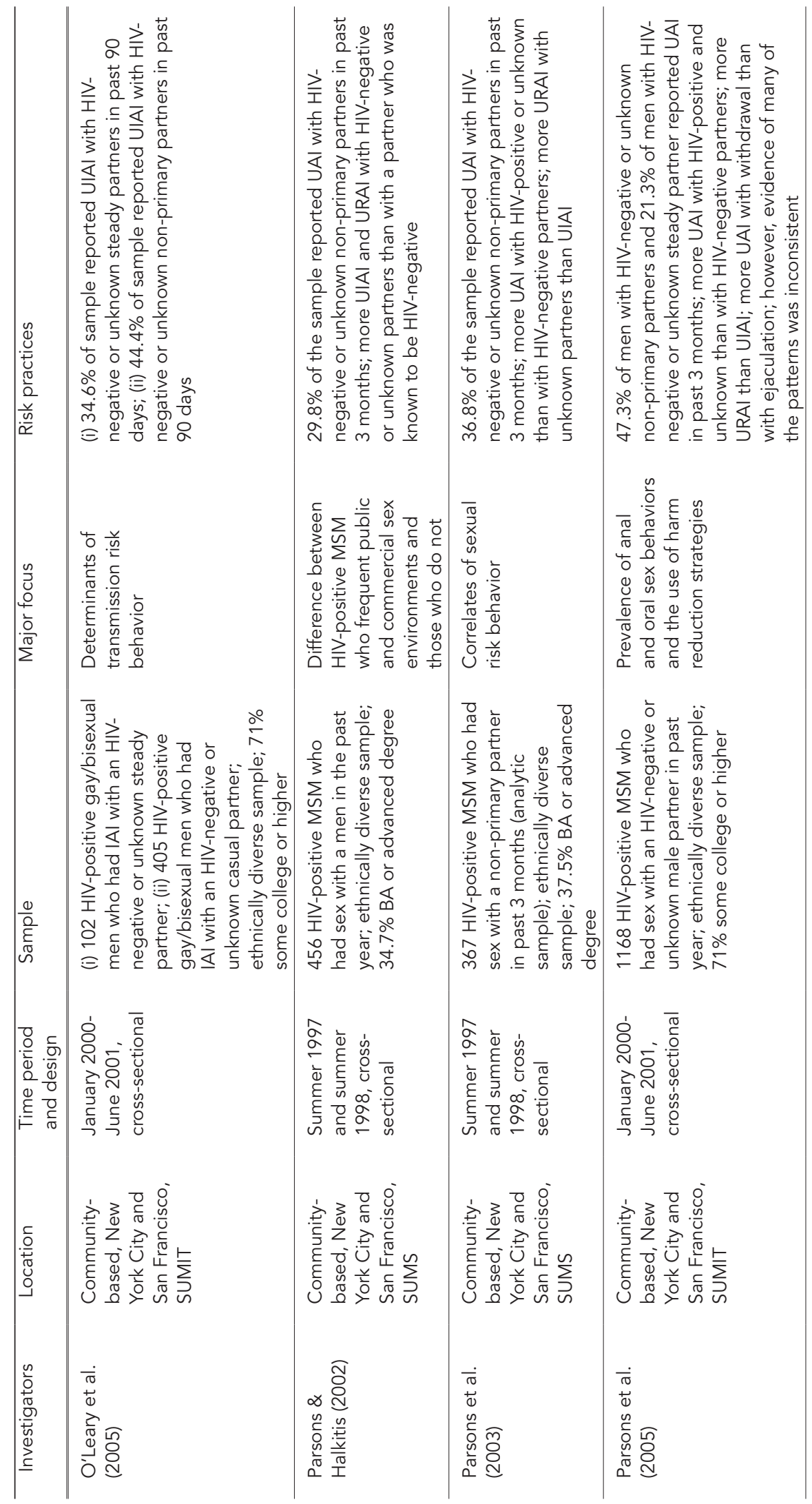




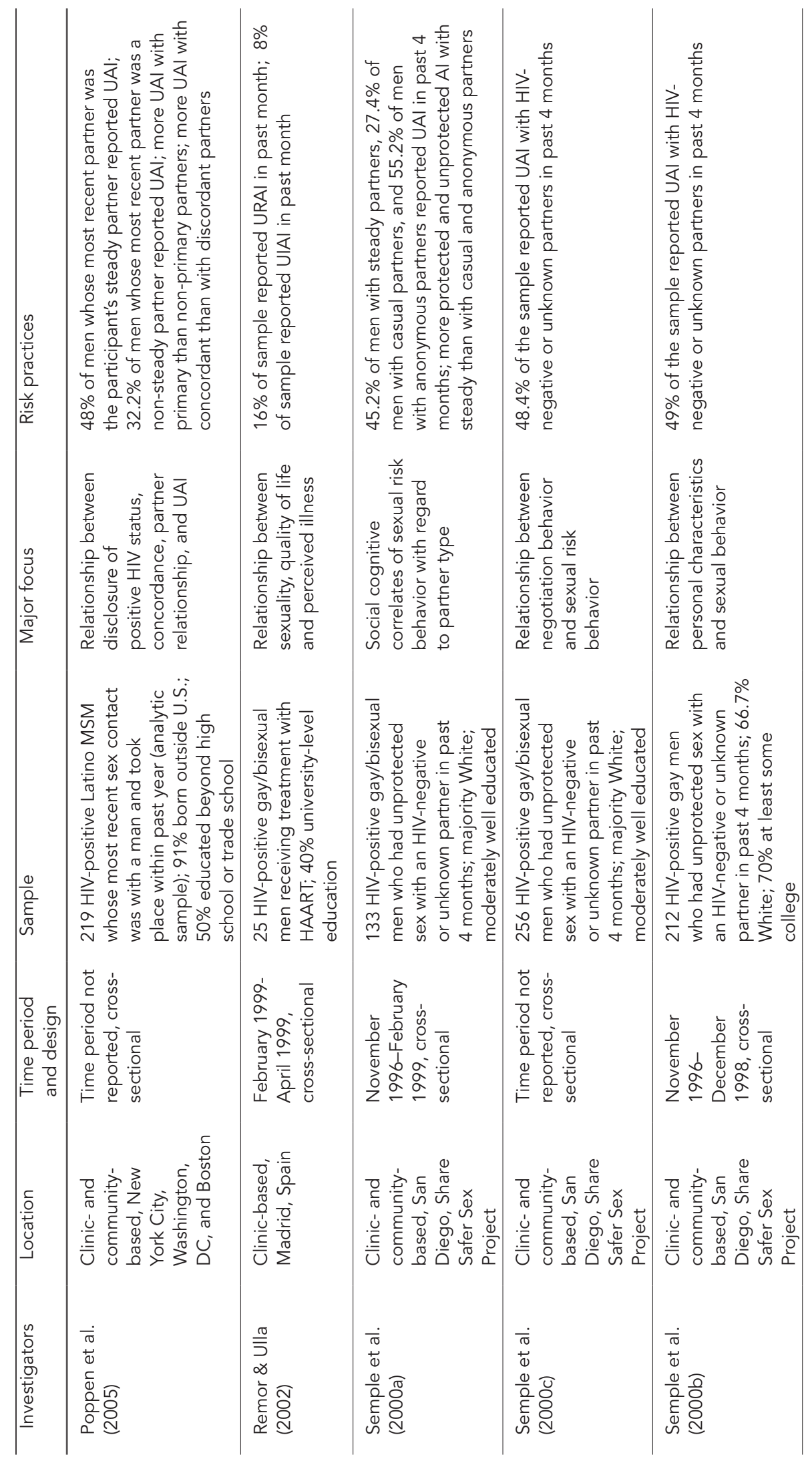

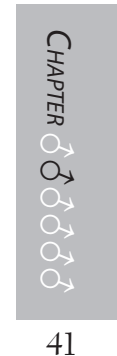




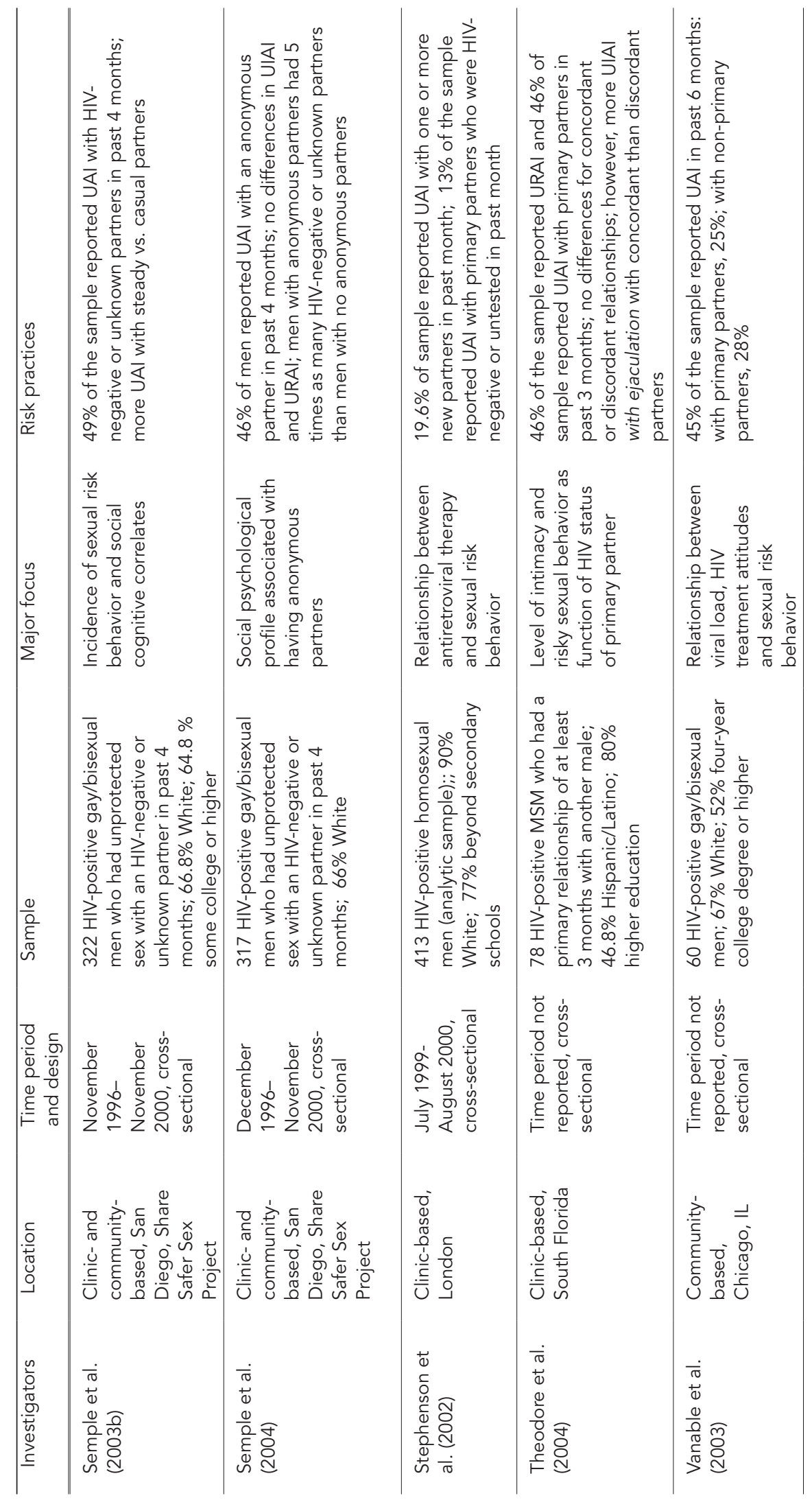


Kesteren et al., 2007; Vanable et al., 2003). Of these studies, two reported on clinic population samples in London. In one study, 18\% of respondents reported UAI with casual sex partners in the past month (Cove \& Petrak, 2004). The other survey of HIV-positive homosexual men attending a London outpatient clinic found comparable percentages of sexual risk behavior for casual sex partners (Stephenson et al., 2002). Data collected in four additional studies among clinic population samples in Europe, Canada and the U.S. also indicate that a notable minority participated in sexual risk behavior. In Spain, a survey among a small sample of HIVpositive MSM ( $\mathrm{n}=25)$ found that the proportion of men who engaged in unprotected receptive anal intercourse (URAI) and unprotected insertive anal intercourse (UIAI) was 16\% and 8\%, respectively (Remor \& Ulla, 2002). In a survey of Dutch HIVpositive MSM, Van Kesteren et al. (2007) found that $24.7 \%$ of the respondents with steady partners and $34.2 \%$ of the respondents with casual sex partners had UAI during the past six months. A study conducted in five ambulatory HIV clinics in Canada showed that $34 \%$ of the respondents had engaged in UAI in the past six months (Cox et al., 2004). Finally, relatively high levels of sexual risk behavior were found in a survey of HIV-positive MSM in South Florida, where $46 \%$ of the respondents reported URAI with their primary partners in the past three months. The same percentage had engaged in UIAI with their primary partners in the past three months (Theodore et al., 2004).

Three studies reported on sexual risk behavior in mainly community-based samples of HIV-positive MSM (CDC, 2004; Poppen et al., 2005; Vanable et al., 2003). In Chicago, Vanable et al. (2003) found that $45 \%$ of respondents recruited during a gay-oriented community street fair reported having engaged in UAI in the past six months. More specifically, the prevalence of UAI with primary partners was $25 \%$ and with non-primary partners $28 \%$. In a survey of 
Latino HIV-positive MSM, Poppen et al. (2005) found that 48\% of men whose most recent partner was the participant's steady partner had engaged in UAI, versus $32.2 \%$ of men whose most recent partner was not a steady partner. A study of HIV-positive MSM in New York City and San Francisco reported that 65\% of the respondents had engaged in UAI with non-primary partners in the past three months (Hoff et al., 2004). Finally, a study conducted by the CDC (2004) among HIV-positive MSM in 16 U.S. states reported exclusively on the prevalence of UIAI. The assumption was that this behavior comprises the greatest risk for transmitting HIV from an infected partner to an uninfected partner. In this study, the percentage of HIV-positive MSM who reported engaging in UIAI during their most recent sexual encounter was 6\%, both for steady and casual sex partners.

\section{Sexual risk behavior with HIV-negative or HIV status unknown partners}

We found 15 studies reporting on sexual risk behavior among HIV-positive MSM with either HIV-negative individuals or people whose HIV status is unknown

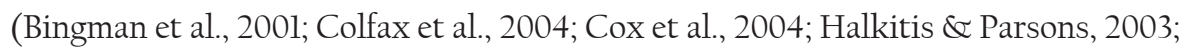
Hart et al., 2003; O'Leary et al., 2005; Parsons \& Halkitis, 2002; Parsons et al., 2003; Parsons et al., 2005; Semple et al., 2000a, 2000b, 2000c, 2003b, 2004; Stephenson et al., 2002). Findings from these studies document that a substantial percentage of HIV-positive individuals report UAI with so-called "at risk" partners. Bingman et al. (2001) reported on sexual risk behavior with partners at risk for HIV in HIV-positive gay men recruited in an outpatient HIV clinic in Los Angeles. Thirty-seven percent of their subjects had engaged in UAI with an HIV-negative or HIV status unknown partner in the past six months. In San Francisco, a survey of HIV-positive MSM at gay venues found that $17 \%$ reported UAI with HIV status unknown partners (Colfax et al., 2004). Findings from a clinic-based survey of HIV-positive MSM in London show that $13 \%$ of men reported UAI with HIV-negative or untested primary partners in the past month (Stephenson et al., 2002). In a Canadian clinic-based survey, the percentage of HIV-positive MSM who reported engaging in UAI with HIV-negative or HIV status unknown partners in the past six months was 13\% (Cox et al., 2004). Halkitis and Parsons (2003) studied intentional unsafe sex or "bare-backing" among 112 HIV-positive gay men recruited via the Internet and found that $42.9 \%$ of the respondents had engaged in intentional UAI with partners of HIV-negative or unknown status in the past three months.

Sexual risk behavior with "at risk" partners was also examined in the Seropositive Urban Men's Study (SUMS) conducted in New York City and San Francisco. In one study, Parsons and Halkitis (2002) observed that 29.8\% of the sample reported UAI with HIV-negative or status-unknown non-primary partners in the past three months. In addition, findings from this study suggest that men were less likely to practice UIAI and URAI with non-primary partners who were known to be HIVnegative than with steady partners who were HIV-negative or HIV status unknown. 
Likewise, in a sub-sample reported by Parsons et al. (2003), men were more likely to engage in UAI with HIV-positive partners or unknown HIV status partners than with HIV-negative partners. Moreover, the results showed that among those reporting UAI, men were more likely to have URAI than UIAI with HIV status unknown partners. Finally, Hart et al. (2003) found that 51\% of the respondents reported UAI with primary or non-primary partners who were HIV-negative or of unknown HIV status in the past three months. Data from the Seropositive Urban Men's Intervention Trial (SUMIT), the successor to SUMS, show that $21.3 \%$ of men whose steady partners were HIV-negative or whose HIV status was unknown reported engaging in UAI in the past three months, while $47.3 \%$ of men did so with non-primary partners who were HIV-negative or whose status was unknown (Parsons et al., 2005). In addition, O'Leary et al. (2005) found that of the men who engaged in insertive anal intercourse with HIV-negative or HIV status unknown main or non-main partners, $34.6 \%$ and $44.4 \%$, respectively, reported UIAI in the past 90 days.

Five additional studies examined the prevalence of sexual risk behavior in HIVpositive gay and bisexual men who participated in the Share Safer Sex Project. It should be noted that eligibility for participation in these studies was restricted to men who reported having unprotected vaginal, oral or anal sex with at least one HIV-negative or HIV status unknown partner during the previous four months, which may lead to an overestimation of sexual risk behavior. A first study observed that $45.2 \%$ of the respondents with steady sex partners, $27.4 \%$ of those with casual sex partners, and $55.2 \%$ of those with anonymous sex partners reported UAI in the past four months (Semple et al., 2000a). The findings further showed that men with steady sex partners reported having protected and unprotected anal intercourse more frequently than men with casual and anonymous sex partners. Another study conducted among HIV-positive gay and bisexual men reported that $48.4 \%$ of the sample had engaged in UAI with an HIV-negative or status unknown partner in the past four months (Semple et al., 2000c). Comparable findings were reported by Semple et al. (2000b) and by Semple et al. (2003b) for slightly different samples of HIV-positive gay and bisexual men. A recent study focused on differences in UAI between men who had engaged in sex with anonymous partners and men who had not (Semple et al., 2004). Although no statistical differences were found in the mean number of UAI across partners, men with anonymous partners reported significantly more HIV-negative or HIV status unknown partners and more acts of UAI. The authors concluded that this presents a continuing risk of HIV/STD transmission for both HIV-infected individuals and their HIV-negative counterparts.

\section{Sexual risk behavior with HIV-positive partners}

Four studies examined the prevalence of sexual risk behavior in the context of HIV concordant partner relationships (Colfax et al., 2004; Cox et al., 2004; Halkitis et 


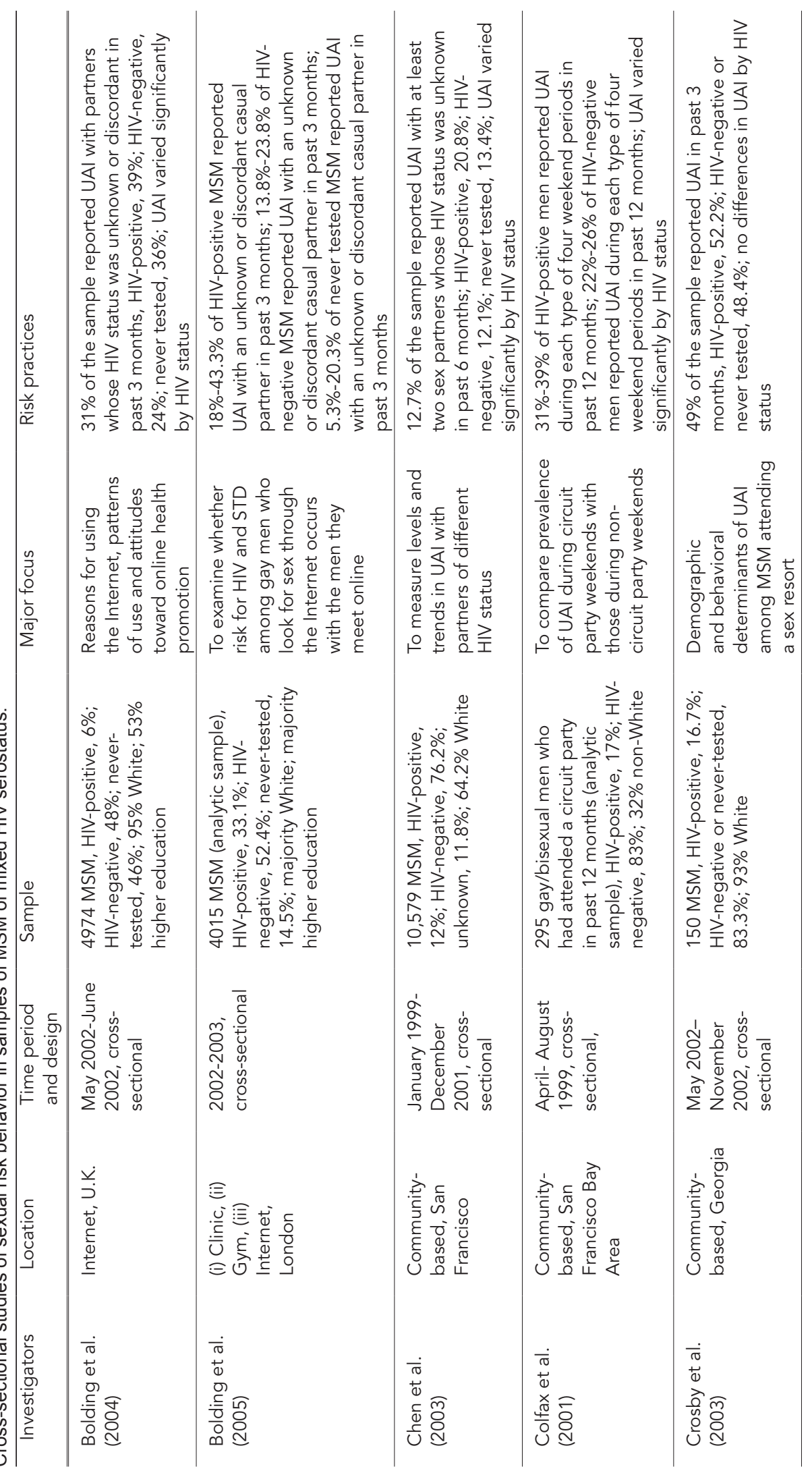




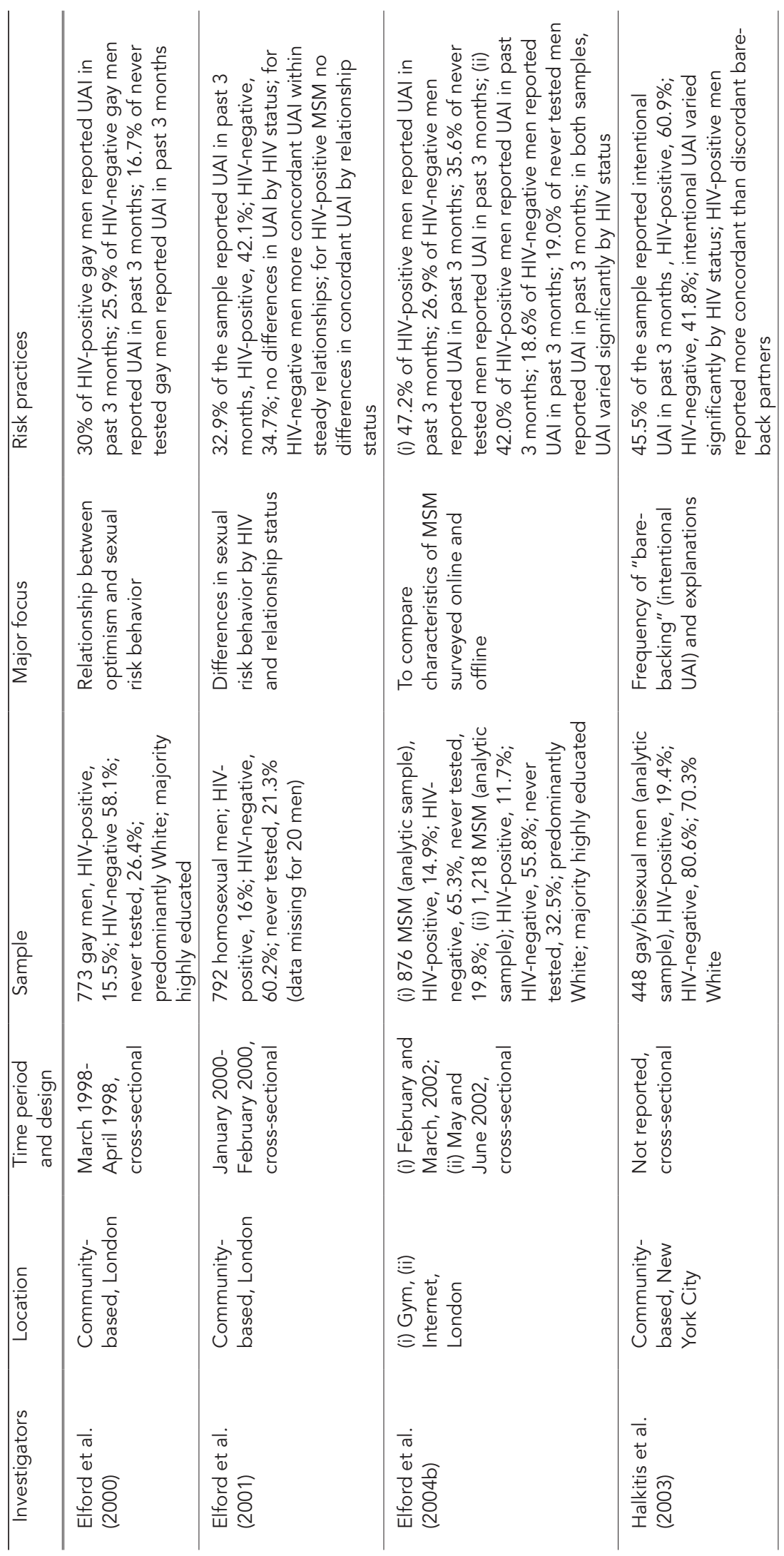

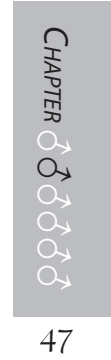




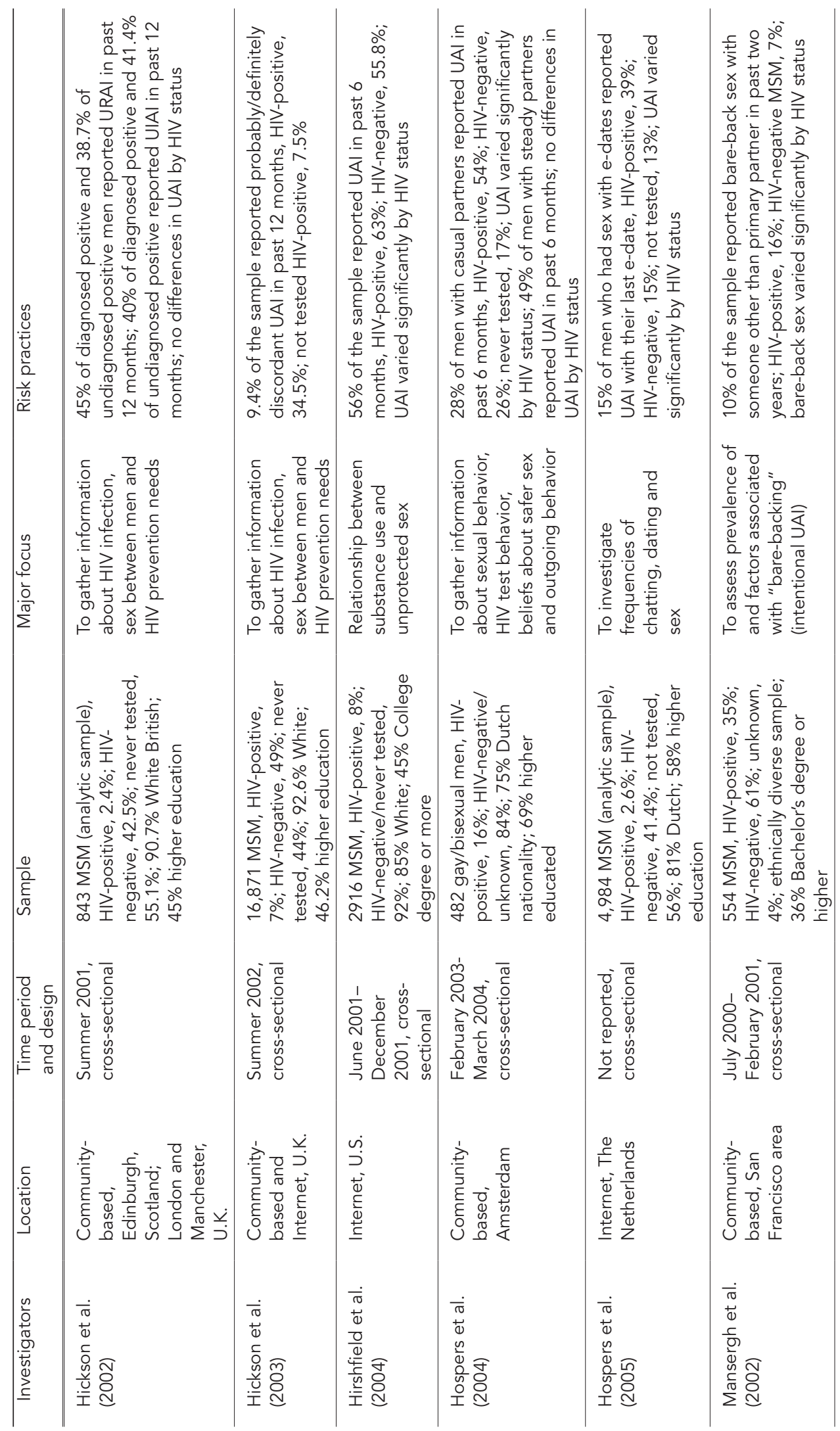




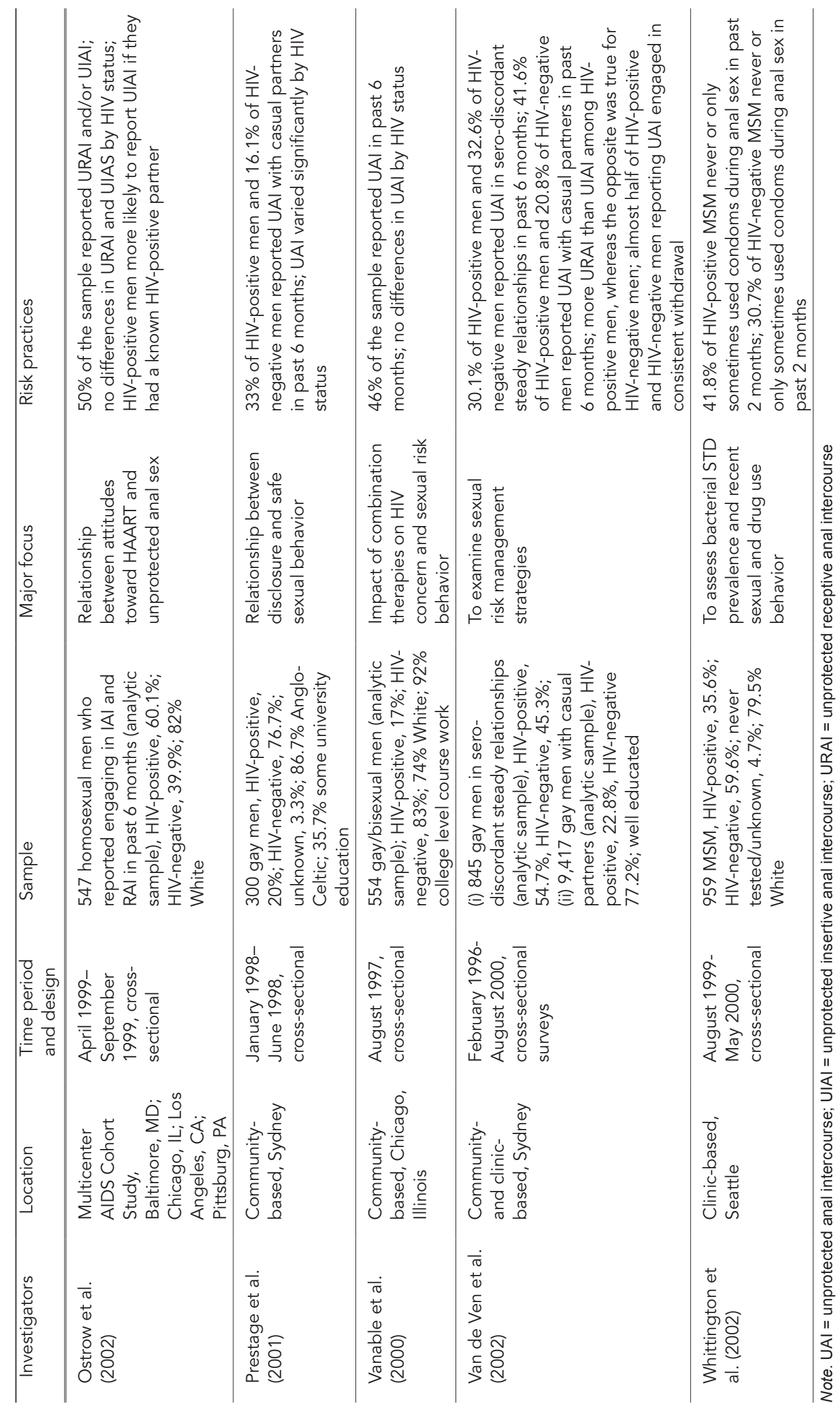

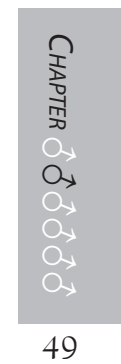

49 
al., 2005; Halkitis et al., 2004). In one study, 29\% of HIV-positive gay and bisexual men reported that they had UAI with an HIV-positive partner (Colfax et al., 2004). Likewise, Cox et al. (2004) found that 21\% reported UAI with HIV-positive partners. Relatively high rates of UAI were documented in two New York City and San Francisco studies. In one study, $61.6 \%$ of HIV-positive MSM reported engaging in UAI with their HIV-positive primary partners in the past three months (Halkitis et al., 2004). Another study showed that $62.2 \%$ of the respondents reported engaging in UAI with steady and casual sex partners in the past three months (Halkitis et al., 2005). In addition, nine studies were able to compare the proportion of men who reported having UAI with HIV concordant partners with that of men who reported having UAI with HIV discordant partners (CDC, 2004; Cox et al., 2004; Halkitis \& Parsons, 2003; Hoff et al., 2004; Parsons et al., 2003; Parsons et al., 2005; Poppen et al., 2005; Theodore et al., 2004; Van Kesteren et al., 2007). All studies found more sexual risk behavior in the context of HIV concordant sex than HIV discordant sex.

\section{Cross-sectional studies of sexual risk behavior in samples of MSM of mixed HIV status}

Twenty cross-sectional studies examined sexual risk taking behavior among diverse samples of MSM of mixed HIV status (see Table 2). Fourteen studies provide empirical evidence that the frequency of UAI is considerably higher among HIVpositive individuals compared to HIV-negative individuals (Bolding, Davis, Hart, Sherr, \& Elford, 2005; Bolding, Davis, Sherr, Hart, \& Elford, 2004; Chen, Gibson, Weide, \& McFarland, 2003; Colfax et al., 2001; Elford, Bolding, Davis, Sherr, \& Hart, 2004b; Halkitis, Parsons, \& Wilton, 2003; Hickson, Weatherburn, Reid, \& $\&$ Stephens, 2003; Hirshfield, Remien, Humberstone, Walavalkar, \& Chiasson, 2004; Hospers, Dörfler, \& Zuilhof, 2004; Hospers, Kok, Harterink, \& De Zwart, 2005; Mansergh et al., 2002; Prestage et al., 2001; Van de Ven et al., 2002; Whittington et al., 2002). Hospers et al. (2004) revealed that 54\% of HIV-positive men in an Amsterdam study of gay and bisexual men reported engaging in UAI with casual sex partners in the past six months, versus $26 \%$ of HIV-negative and $17 \%$ of untested men. No differences by HIV status were found for UAI within steady partner relationships. Another study conducted by Hospers et al. (2005) among a self-selected anonymous Dutch Internet sample showed that 39\% of the HIV-positive men versus 14\% of the HIV-negative and never tested men had engaged in UAI with their last e-date. This percentage decreased to $28 \%$ after excluding sex with HIV-positive partners, but remained higher than the rate of UAI among HIV-negative and never tested men. In the U.S., an anonymous Internet survey (Hirshfield et al., 2004) of 2,916 MSM showed that 63\% of the HIV-positive MSM versus 56\% of the HIV-negative MSM had engaged in HIV discordant UAI in the past six months. Whittington et al. (2002) investigated sexual risk behavior among a clinic population sample in Seattle and found that $41.8 \%$ of the HIV-positive MSM had never or sometimes used a condom during anal sex in the 
past two months versus $30.7 \%$ of the HIV-negative MSM. Higher rates of UAI among HIV-positive MSM than among HIV-negative or status unknown MSM were also observed in community surveys that were conducted in the U.S. (Chen et al., 2003; Colfax et al., 2001) and in U.K. studies of MSM recruited offline and online (Bolding et al., 2005; Bolding et al., 2004; Elford et al., 2004b; Hickson et al., 2003).

Additionally, data from two "bare-back" studies show that significantly more HIV-positive MSM reported intentional UAI or "bare-back sex" than their HIVnegative counterparts. Mansergh et al. (2002) found that $16 \%$ of the HIV-positive MSM had engaged in bare-back sex in the past two years versus $7 \%$ of the HIVnegative MSM, whereas Halkitis et al. (2003) found that $60.9 \%$ of the HIV-positive men had engaged in bare-back sex in the past three months versus $41.8 \%$ of the HIVnegative men. Both studies found that men had significantly more bare-back partners of the same HIV status. Van de Ven et al. (2002) examined sexual risk management strategies of gay men in Sydney. Although they found no differences in UAI between HIV-positive and HIV-negative men within HIV discordant steady relationships, with regard to casual sex partners, $41.7 \%$ of the HIV-positive MSM reported UAI in the past six months compared to $20.8 \%$ of the HIV-negative men. Findings from this study found evidence of a clear pattern of strategic positioning: among the men who had UAI that involved ejaculation inside their steady or casual sex partner, HIV-positive men tended to be receptive, whereas HIV-negative men tended to be insertive.

Other studies were unable to identify (statistical) differences in sexual risk behavior between HIV-negative and HIV-positive MSM (Crosby, DiClemente, \& Mettey, 2003; Elford, Bolding, Maguire, \& Sherr, 2000, 2001; Hickson, Weatherburn, $\&$ Reid, 2002; Ostrow et al., 2002; Vanable, Ostrow, McKirnan, Taywaditep, \& Hope, 2000). A study conducted by Elford et al. (2000) among gay men attending gyms in central London showed that $30 \%$ of the HIV-positive gay men reported UAI in the past three months versus $25.9 \%$ of the HIV-negative gay men. Comparable findings were reported in a follow-up study by Elford et al. (2001) among 792 men attending gyms in central London. Overall, 32.9\% of the sample reported UAI in the previous three months; they were unable to identify statistically significant differences by HIV status. Nevertheless, HIV-negative men were more likely to report concordant UAI in the context of a relationship, while HIV-positive men were just as likely to report concordant UAI whether or not they were in a relationship. In a more general sample of British MSM, Hickson et al. (2002) observed no differences in URAI or UIAI between undiagnosed and diagnosed HIV-positive MSM. However, the study sample was very small; therefore, interpretation of these study findings is limited. Various U.S. studies showed no differences in high-risk sex between HIVpositive and HIV-negative MSM (Crosby et al., 2003; Ostrow et al., 2002; Vanable et al., 2000). 


\section{Longitudinal studies of sexual risk behavior in samples of MSM who are HIV- positive or of mixed HIV status}

Eight studies have addressed changes over time in sexual risk behavior among HIVnegative and HIV-positive MSM (Chen et al., 2002; Denning \& Campsmith, 2005; Dukers et al., 2001; Elford, Bolding, Davis, Sherr, \& Hart, 2004a; Elford, Bolding, $\&$ Sherr, 2002; Hull et al., 2003; Stolte, De Wit, Van Eeden, Coutinho, \& Dukers, 2004; Van de Ven, Prestage, Crawford, Gruhlich, \& Kippax, 2000) (see Table 3). Of these studies, six used a repeated, cross-sectional survey design with independent convenience samples. All but one found evidence for increasing levels of UAI. A study of Elford et al. (2002) in London, showed that sexual risk-taking in HIV-positive MSM with casual sex partners who are HIV-negative or of unknown HIV status increased between 1998 and 2001 from 15.3\% to 38.8\%. This increasing trend in sexual risk behavior was confirmed in a subsequent study by Elford et al. (2004a). Between 1998 and 2003, the percentage of HIV-positive men reporting non-concordant and concordant UAI with casual sex partners increased from $15.3 \%$ to $37.2 \%$ and $6.8 \%$ to $10.3 \%$, respectively. No statistically significant increase was found for nonconcordant and concordant UAI with steady partners among HIV-positive MSM. Changes in risk behavior have also been studied in recently diagnosed men in twelve cities in the U.S. From 1995 to 2000, Denning and Campsmith (2005) interviewed MSM who had known that they were HIV-positive for more than one year, and had a steady partner with negative or unknown HIV status. Although the proportion of men reporting sexual risk behavior increased slightly over the years, this trend was not statistically significant. In contrast, findings from a San Francisco study indicate a trend toward increased risk taking. In this study, the percentage of HIV-positive MSM who reported engaging in UAI with two or more partners increased from 19\% in 1999 to 25\% in 2001 (Chen et al., 2002). In addition, Hull et al. (2003) investigated changing patterns of sexual risk behavior between 1996 and 2002 among gay men in Sydney. They reported an increase in UAI with casual and steady sex partners for HIV-positive men from $31.5 \%$ to $59.9 \%$ and $43.9 \%$ to $58.5 \%$, respectively. Van de Ven et al. (2000), who also reported on changes in sexual risk behavior among gay men in Sydney, found a significant upward trend for HIV-positive and HIV-negative men in UAI with casual sex partners. In addition, they found that HIV-positive men had significantly higher rates of concordant UAI at most data collection points.

Two studies reported on changes in sexual risk behavior among HIV-negative and HIV-positive MSM who participated in cohort studies. Dutch data from the Amsterdam Cohort Studies of 1062 gay and bisexual men younger than 35 years, showed that, compared to the time period 1992-1996, sexual risk behavior has increased among HIV-negative men after 1996 (Dukers et al., 2001). Although this significant rise in sexual risk behavior was not seen for HIV-positive men, among HIV-positive men a higher level of UAI with casual sex partners was observed after 


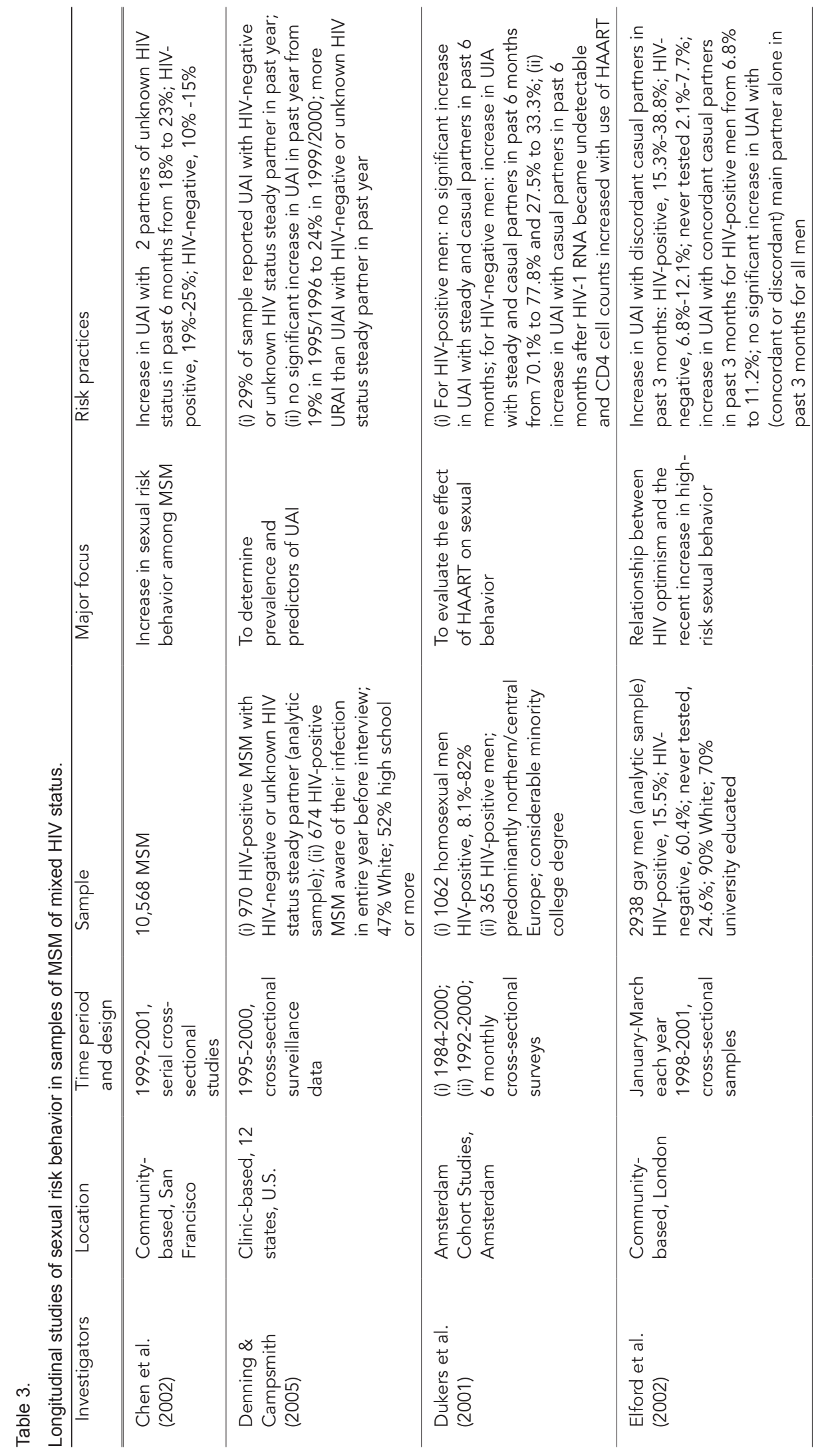

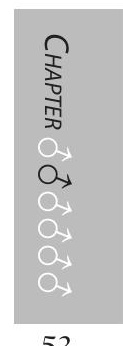

53 


\begin{tabular}{|c|c|c|c|}
\hline 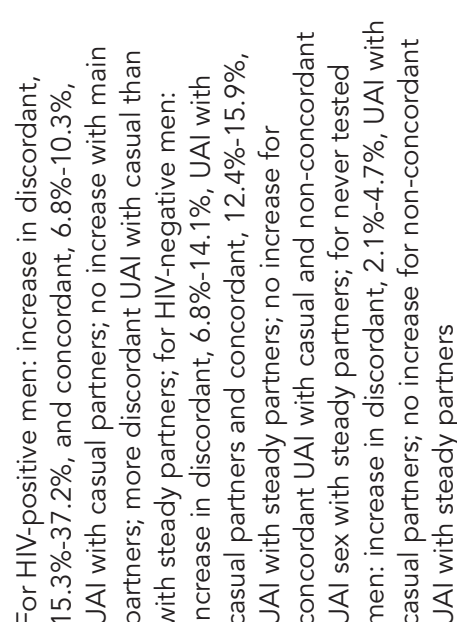 & 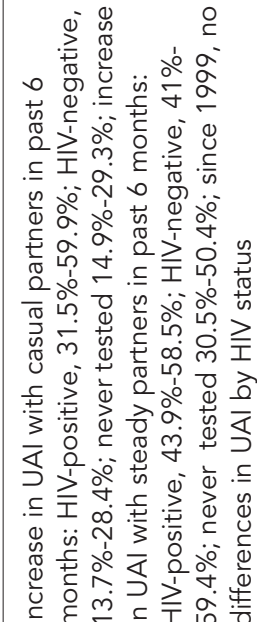 & 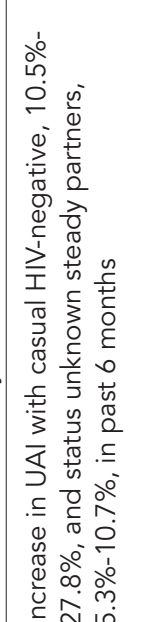 & 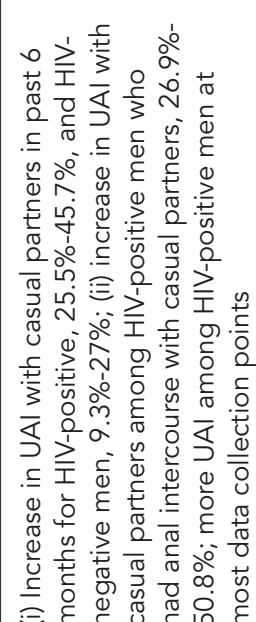 \\
\hline 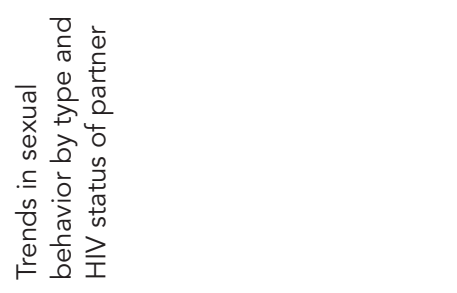 & 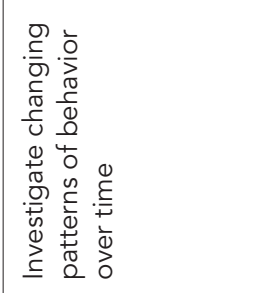 & 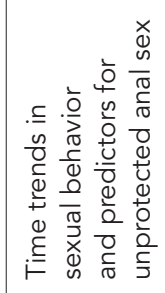 & 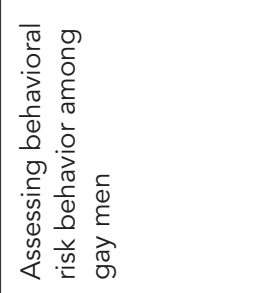 \\
\hline 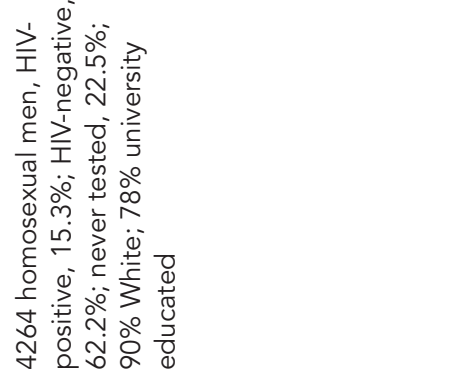 & 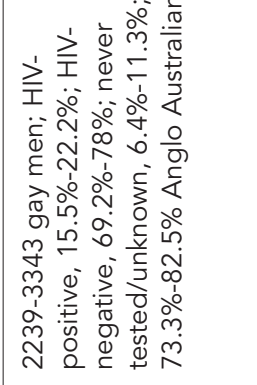 & 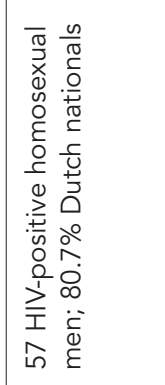 & 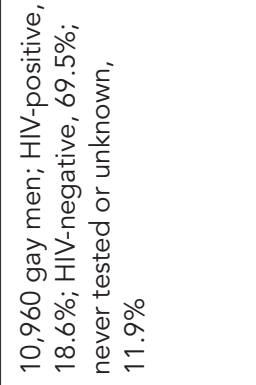 \\
\hline 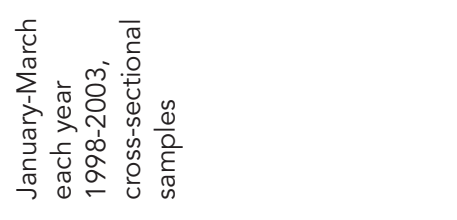 & 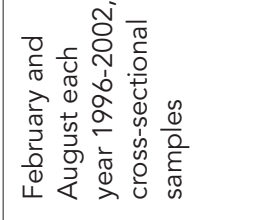 & 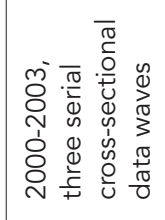 & 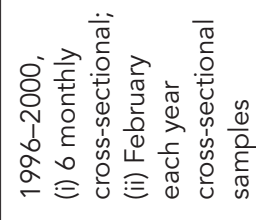 \\
\hline 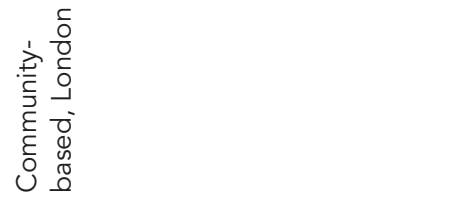 & 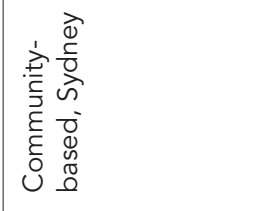 & 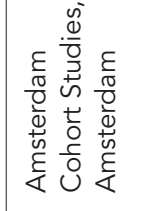 & 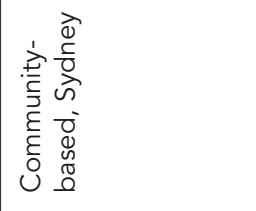 \\
\hline 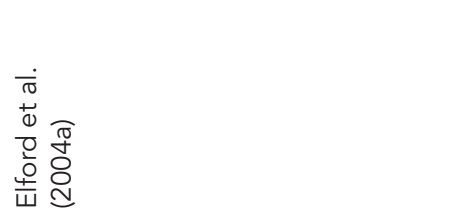 & 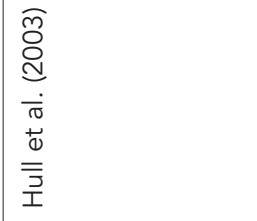 & 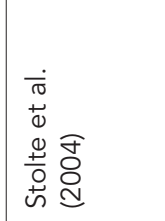 & 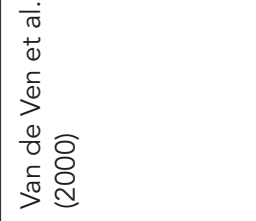 \\
\hline
\end{tabular}


viral load levels became undetectable and CD4 cell counts increased as a result of highly active antiretroviral therapy (HAART). Another study addressing the impact of HAART on sexual risk behavior among HIV-positive MSM in Amsterdam between 2000 and 2003, found an increase in UAI with casual sex partners from $10.5 \%$ to $27.8 \%$, and for steady sex partners of HIV-negative or unknown HIV status from $5.3 \%$ to $10.7 \%$ (Stolte et al., 2004).

\section{DISCUSSION AND CONCLUSION}

\section{Discussion}

In this review, we have examined the available evidence on the prevalence of sexual risk behavior in HIV-positive MSM starting in the year 2000. Following Kalichman (2000), we attempted to estimate the "average" prevalence of sexual risk behavior among HIV-positive MSM. As expected, we found evidence that the rate of UAI was bigger than the rate found across all studies reviewed by Kalichman (2000). However, inferences from this review are subject to several limitations. First, the populations studied and the way in which sexual behavior was conceptualized and assessed differed greatly among the studies reviewed, which make interpretation of and comparisons between studies difficult. Second, the timeframes over which behavior is reported vary widely, ranging from the last sexual encounter to sex in the preceding one year. The likelihood of any UAI in a one-year period is, of course, higher than in a shorter timeframe or with only the last encounter. Third, because all studies relied on self-reported sexual behavior, rates of sexual risk behavior may be underreported because of socially desirable responding. Finally, since the survey approach was used by most of the studies reviewed, the samples may not have been representative of similar cases and therefore the results may not reflect the entire population of HIV-positive MSM. However, the information presented herein was obtained from many sources, including cross-sectional and longitudinal studies of (HIV-positive) MSM, thus giving a broad overview of what has been published, and likely providing a relatively accurate account of sexual risk behavior in this target population.

Despite the limitations, we believe that our results clearly indicate that sexual risk behavior among HIV-positive MSM continues to be an issue for HIV prevention. The basis for this conclusion is that: (a) overall, our review indicates high levels of UAI among MSM who know that they are HIV-infected. Twenty-nine of the 53 studies showed UAI rates among HIV-positive MSM of over 40\% (range $6 \%-84 \%$ ); (b) the studies assessing partner HIV status show that much of this UAI occurs with partners who are HIV-negative or of unknown HIV status (range 13\%$51 \%$ ); (c) the majority of the studies assessing UAI in samples of MSM of mixed HIV status demonstrate that UAI is much higher among HIV-positive MSM than HIV-negative MSM; and (d) almost all longitudinal studies of MSM document 
increases in UAI, providing the most consistent evidence of an increase in sexual risk behavior among HIV-positive MSM. These results are consistent with reports from several Western industrialized countries on increasing rates of STDs and HIV, especially among MSM (Anon, 2001, 2002; CDC, 2003; Chen et al., 2002; Murphy et al., 2004; Stolte et al., 2001).

In line with the findings of Kalichman (2000), the evidence from the studies under review suggests that HIV-positive MSM have developed a "harm reduction approach" to reduce their risk of HIV transmission through UAI. This harm reduction approach includes sero-sorting, i.e. selecting partners who are also HIV-positive. A number of studies show that HIV-positive MSM are more likely to engage in UAI with other HIV-positive partners than with those who are HIV-negative in both primary and non-primary relationships (CDC, 2004; Cox et al., 2004; Halkitis \& Parsons, 2003; Halkitis et al., 2003; Hoff et al., 2004; Ostrow et al., 2002; Parsons et al., 2003; Parsons et al., 2005; Poppen et al., 2005; Theodore et al., 2004; Van Kesteren et al., 2007). UAI between partners who are both HIV-positive poses no health threats for HIVnegative MSM. However, the feasibility and effectiveness of this strategy has not been empirically documented (Wolitski \& Branson, 2002). Moreover, this strategy is not efficient in reducing the risk of HIV superinfection (Blackard, Cohen, \& Mayer, 2002; Jost et al., 2002) and other STDs (Kalichman, Rompa, \& Cage, 2000).

There is some evidence indicating that HIV-positive MSM have developed additional HIV prevention strategies to reduce the risk of HIV transmission. Research has found that HIV-positive MSM use HIV status to selectively engage in unprotected receptive, but not insertive, anal intercourse (so-called strategic positioning) (Van de Ven et al., 2002). However, the results are inconclusive. While five studies indicate that HIV-positive MSM were more likely to engage in URAI than UIAI (Denning \& Campsmith, 2005; Parsons \& Halkitis, 2002; Parsons et al., 2003; Parsons et al., 2005; Van de Ven et al., 2002), two did not (Hickson et al., 2002; Semple et al., 2004). In addition, research findings show that HIV-positive MSM practice withdrawal before ejaculation during anal sex (Hoff et al., 2004; Parsons $\&$ Halkitis, 2002; Parsons et al., 2005; Van de Ven et al., 2002). It could be argued, however, that the number of studies is not sufficient to draw definite conclusions about the use of these risk reduction strategies. In addition, their feasibility and effectiveness have not been critically evaluated (Wolitski \& Branson, 2002). In each case, additional research is required.

Another important question is the influence of partner type. Ten out of 14 studies showed that the rate of UAI with steady sex partners was equal to (Halkitis et al., 2005; Hospers et al., 2004; Hull et al., 2003; Vanable et al., 2003) or less than (Elford et al., 2004a; Elford et al., 2002; O'Leary et al., 2005; Parsons et al., 2005; Stolte et al., 2004; Van Kesteren et al., 2007) rates of UAI with casual sex partners, whereas the remainder of the studies found higher rates (CDC, 2004; Poppen et al., 2005; Semple et al., 2000a, 2003b). Given a recent review (Crepaz \& Marks, 2002) concluding 
that unprotected sex is not more likely to occur with primary than non-primary partners, our findings regarding the influence of partner type appear complementary. Crepaz and Marks (2002) have mentioned that this pattern of sexual risk behavior is inconsistent with the elevated rates of risky sex with primary partners observed in general MSM populations. However, further research is needed to confirm these findings.

Several explanations are given in the literature for the rise in sexual risk behavior among HIV-positive MSM. The primary focus has been on the availability of highly active antiretroviral therapy (HAART) as the direct cause of the increase in sexual risk behavior. A recent meta-analytic review indicated that the likelihood of unprotected sex was higher among HIV-positive persons who believe that HIV transmission is less likely if they are receiving HAART or have an undetectable viral load or that the availability of HAART reduces their concerns about having unprotected sex (Crepaz, Hart, \& Marks, 2004). In addition, it has been argued that HIV-positive people who are living longer as the result of the availability of HAART, are tired of always having to monitor their sexual behavior (Ostrow et al., 2002). Another explanation for the increase in unprotected sex among HIV-positive MSM is the recent phenomenon of "bare-backing" among MSM (Halkitis et al., 2003). Other publications point to the contribution of factors such as the increasing access to the Internet and the role of commercial sex environments in HIV transmission (Frankis \& Flowers, 2005; Parsons \& Halkitis, 2002). Finally, the increasing popularity of "party drugs," such as ecstasy, Special K and GHB, among MSM has been connected to the increase in high-risk sexual behavior, especially in the United

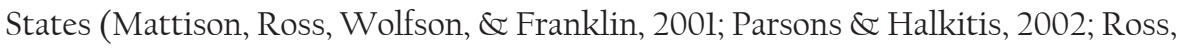
Mattison, \& Franklin, 2003; Semple, Patterson, \& Grant, 2003a).

Although we agree that it is of overriding importance that studies try to identify the contribution of the above-mentioned factors in the reported rise in UAI among HIV-positive MSM, we also believe that it is necessary to gain further insights into the psychosocial processes underlying the observed rates of sexual risk behavior in HIV-positive MSM. In recent years there has been an increase in studies of the determinants of sexual risk-taking behavior in people living with HIV (Crepaz $\&$ Marks, 2002). In addition to considering the meaning of recent trends in risk behavior among HIV-positive MSM, we should continue current efforts to investigate the variables that are associated with unprotected sexual practices of this population.

\section{Conclusion}

Assessing the overall prevalence of sexual risk behavior in HIV-positive MSM is extremely difficult because the studies varied greatly in design, sampling and measurement of sexual risk behavior. Nevertheless, the findings indicate that sexual risk behavior is highly prevalent among HIV-positive MSM, and that much of this risky behavior occurs with partners whose HIV status is HIV-negative or 
unknown. Moreover, longitudinal studies showed that rates of UAI are increasing. Considering their HIV-positive status, the risk of HIV transmission to steady and casual sex partners is substantial. In addition, UAI can pose serious health risks for HIV-positive MSM themselves if such behaviors lead to co-infection with another STD or HIV superinfection (Blackard et al., 2002; Jost et al., 2002; Kalichman et al., 2000). The need to continue to work toward a better understanding of the nature and meaning of recent trends in sexual risk behavior in HIV-positive MSM, both to better understand present sexual risk patterns and to gain better insights into the explanations for changes in sexual risk behavior, is therefore of obvious public health importance. In particular, research is needed to monitor trends in sexual behavior in HIV-positive MSM, to explore the influence of partner variables (e.g., partner HIV status and partner type) on UAI, and to examine the use and effectiveness of harm reduction strategies to reduce the risk of HIV transmission.

\section{Practice implications}

HIV prevention interventions targeting HIV-positive MSM have lagged behind those of MSM at risk of HIV infection. HIV-positive people, including MSM, were often left out of prevention efforts throughout the epidemic. Yet, to have an impact on the sexual transmission of HIV, prevention interventions also need to reach those most at risk for transmitting HIV (King-Spooner, 1999). Results from this review suggest that the prevalence of UAI is high among HIV-positive MSM. This underscores the need to intensify prevention efforts targeting HIV-positive MSM to assist them in adopting and maintaining safer sexual behaviors for reducing the transmission of HIV and other STDs. However, it is essential to bear in mind that in order to be effective, such interventions should be systematically planned, theory- and evidence-based, and appropriate to the targeted audience (Kalichman, Carey, \& Johnson, 1996; Van Empelen et al., 2003). Planning models, such as Intervention Mapping (Bartholomew, Parcel, Kok, \& Gottlieb, 2001, 2006), may provide a framework that gives planners a systematic method for decision-making in each phase of intervention development. Furthermore, HIV prevention interventions targeting HIV-positive MSM should be evaluated to ensure that they are effective. 


\section{CHAPTER 3}

\section{Sexuality and sexual}

risk behavior

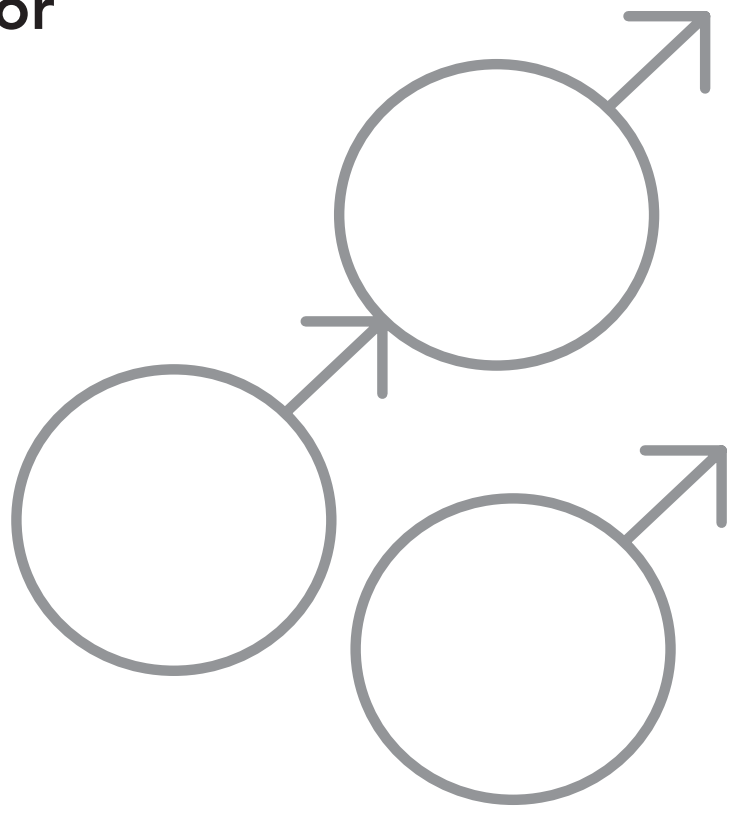

Published as:

Van Kesteren, N.M.C., Hospers, H.J., Kok, G., \& Van Empelen, P. (2005). Sexuality and sexual risk behavior in HIV-positive men who have sex with men. Qualitative Health Research, 15, 145-168 


\section{INTRODUCTION}

In attempts to prevent the further spread of HIV, HIV/AIDS prevention programs have targeted people with higher risk for HIV/AIDS, such as men having sex with men (MSM) (Flowers, Sheeran, Beail, \& Smith, 1997; Hospers \& Kok, 1995), adolescents, and heterosexuals (Sheeran, Abraham, \& Orbell, 1999). In contrast, people with HIV and AIDS (PWHA) have rarely been the specific target of prevention activities. This has been the case for many years, despite evidence suggesting that adoption of protected sexual practices among people who are HIVpositive leads to a significant reduction in the number of HIV infections (Bayer, 1996).

The reluctance to choose PWHA as a specific HIV prevention target group seems in part to be the result of concerns about focusing on the responsibility of PWHA to protect the health of others. Critics note that preventive campaigns that incorporate responsibility issues might lead to unintended negative side effects, such as placing an undue burden on the shoulders of PWHA, stigmatization and "blaming the victim" (Bayer, 1996; King-Spooner, 1999). At worst, PWHA are held responsible by society for the health outcomes of practicing unprotected sex, and prosecution and punishment might be the consequence (Guttman, 2000; Lupton, 1995). The idea of emphasizing personal responsibility of PWHA for others has also been criticized on a more practical level. It has been argued that focusing on the responsibility of PWHA would lead to a further spread of the epidemic, because people who are HIV-negative or do not know their status would rely on PWHA to take responsibility for safer sex and would, therefore, fail to protect themselves. As a result, personal responsibility for one's own health has been the underlying value promoted in most HIV prevention campaigns (Bayer, 1996; Schiltz \& Sandfort, 2000).

The introduction of combination therapy in 1996, also known as highly active antiretroviral therapy (HAART), has altered this perspective. HAART has led to beneficial results, such as a prolonged life expectancy and increased quality of life among HIV-infected individuals. Consequently, PWHA not only experience greater clinical improvement but are also likely to feel healthier and be more sexually active for more years (Blower, Gershengorn, \& Grant, 2000; Cameron et al., 1998). Although individuals who are HIV-positive report lower levels of risk-taking behavior than individuals who are HIV-negative or do not know their status, unprotected sex is prevalent among PWHA. Studies on sexual behavior of PWHA suggest that approximately one third have engaged in risky sexual practices in the previous 2 to 6 months (Kalichman, 2000; Kok, 1999). These findings confirm that promotion of safer sex methods among PWHA is an important public health challenge in reducing further transmission of HIV. Although HIV prevention aimed at PWHA is still fraught with controversy, HAART has shifted the balance of benefit in favor 
of prevention aimed at PWHA who continue to practice HIV transmission risk behaviors.

MSM are an important subgroup among the HIV-positive population for HIV prevention. Several recent studies have shown that sexual risk behavior is prevalent among HIV-positive MSM (Parsons, Halkitis, Wolitski, \&e Gómez, 2003; Semple, Patterson, \& Grant, 2000a; Semple, Patterson, \& Grant, 2003b). For example, Dukers, Goudsmit et al. (2001) reported an increase in unprotected sex among HIVnegative and HIV-positive MSM participating in the Amsterdam Cohort Studies after HAART became available in 1996. Among HIV-positive MSM, a higher level of unprotected sex with casual partners was observed after viral load levels became undetectable, and CD4 cell counts increased as a result of HAART. In addition, M. Miller et al. (2000) compared sexual risk behavior before and 6 months after the start of combination HIV therapies in a French prospective cohort study. Although they did not find an increase in overall risk behavior, there was a significant increase in sexual risk behavior among HIV-positive gay and bisexual men with partners who had a negative or unknown serostatus. Furthermore, recent figures from STD clinics in Amsterdam showed an increase in syphilis and gonorrhea in both HIV-negative and HIV-positive MSM, which might suggest a rise in unprotected sex (Cairo, Fennema, \& Maruanaya, 2001). Similar findings are reported among gay and bisexual men in London and Manchester (Browning, Blackwell, \& Joynson, 2000; Donovan, Bodsworth, Rohrheim, McNulty, \& Tapsall, 2000; Higgens, Sukthankar, Mahto, Jarvis, \& Lacey, 2000).

The reasons that HIV-positive MSM engage in unprotected sex are often very complex. A growing number of studies have been conducted better to understand the psychological determinants of sexual risk behavior among PWHA (Crepaz \& Marks, 2002; Kalichman, 2000; Kok, 1999). Although some of these determinants are similar to those found among people with a negative or unknown status, other determinants are specific to PWHA. First, their distinguishing situation has been linked to the striking mental health implications of HIV and its treatment, such as high levels of strain, stress, and depression (Alonzo \& Reynolds, 1995; Kalichman \& Ramachandran, 1999). Moreover, various studies have shown that a diagnosis of HIV negatively affects sexual expression and can even interrupt the infected man's sex life. In addition, a number of researchers have called attention to the sexual dysfunction problems resulting from combination therapies, such as erectile dysfunction and delayed or premature orgasm (e.g., Catalán, Burgess, \& Klimes, 1995). Second, an important difference between HIV-positive MSM and MSM who are HIV-negative or do not know their status is their motivation for safer sex. Whereas MSM who are HIV-negative or are not aware of their serostatus are motivated to practice safer sex primarily for "self-protection," for most HIV-positive MSM, other-oriented motives play an important role (King-Spooner, 1999; Marks, Burris, \& Peterman, 1999). Several studies have demonstrated that safer sexual behavior in PWHA is related to 
the norm of perceived personal responsibility to protect the health of sex partners (Fisher, Willcuts, Misovich, \& Weinstein, 1998; Godin, Savard, Kok, Fortin, \& Boyer, 1996; Keogh, Weatherburn, \& Stephens, 1999; Nimmons \& Folkman, 1999; Rhodes \& Cusick, 2002; Rosengarten, Race, \& Kippax, 2000). A third issue specific to PWHA is whether they disclose their serostatus to others. Some authors have regarded disclosure to be a fundamental aspect of reducing the risk of HIV transmission (e.g., Cusick \& Rhodes, 1999; Serovich, 2001). However, many people do not do not tell their sex partners about their positive status, predominantly out of fear of rejection or a negative reaction from the partners (Kalichman \& Nachimson, 1999; Marks, Richardson, \& Maldonado, 1991; Perry et al., 1994; Stein \& Samet, 1999; Wenger, Kusseling, Beck, \& Shapiro, 1994). Moreover, in these studies conflicting results have been found concerning the relationship between disclosure and safer sexual behavior.

Although the field of HIV prevention has been slow to recognize the specific need for research on sexuality and sexual risk behavior among HIV-infected individuals, this is gradually changing. The past couple of years have seen an increase in the number of quantitative studies on sexuality in HIV-positive individuals in an attempt to identify key factors that predict sexual risk behavior in HIV-positive MSM (e.g., Crepaz \& Marks, 2002). However, those studies usually do not address how HIVinfected MSM conceptualize the complex issues involved in sexuality and sexual decision making after being diagnosed HIV-positive.

In this article, we attempt to contribute to a better understanding of the psychological processes pertaining to sexuality in cases in which an individual is confronted with a HIV diagnosis of HIV. We chose qualitative research techniques, because they allow the researcher to investigate complex issues (Snape $\&$ Spencer, 2003), as is the case in sexuality in HIV-positive MSM. A qualitative research approach enables a detailed exploration of the reasons behind men's thoughts, beliefs, and behaviors regarding sexuality and being at risk. This is important, because a better understanding of sexuality issues of HIV-positive MSM is needed for the development of effective behavioral interventions for this target group.

This study addressed the following issues: (a) the influence of an HIV-positive diagnosis on participants' life and sexual behavior, (b) conceptualizations of HIV risk and infectiousness, (c) the norm of perceived responsibility for safer sex and its relationship to sexual behavior, (d) factors influencing the practice of protected and unprotected sex, and (e) reasons for HIV disclosure to sex partners.

\section{METHOD}

\section{Ethics approval}

The study was reviewed and approved by the Ethics Committee of the Maastricht University Hospital. 


\section{Procedure}

To ensure representation of HIV-positive MSM living in urbanized and suburbanized areas in the Netherlands, we recruited participants in Amsterdam and Rotterdam (urbanized, $\mathrm{n}=15$ ), and in the Maastricht area (suburbanized, $\mathrm{n}=15$ ) between May 2001 and August 2001. Several channels were used to recruit participants for the interviews. In Maastricht and the surrounding area, recruitment took place through HIV/AIDS consultants at the Maastricht University Hospital. HIV/AIDS consultants selected participants among their patient population who met the entry criteria. We subsequently approached respondents by telephone in alphabetical order and invited them to participate. This process continued until the target number had been reached. In Amsterdam and Rotterdam, we selected respondents by the so-called snowball sampling technique. Outreach workers of the Dutch Gay and Lesbian Association in Amsterdam and the municipal health service in Rotterdam approached HIV-positive MSM and asked them to participate. At our request, these men contacted their friends and acquaintances for participation in the study.

Eligibility for participation in the study was restricted to men who (a) had tested positive for HIV antibodies, (b) identified themselves as homosexual or bisexual, (c) were between the ages of 20 and 65, and (d) were Dutch nationals or spoke Dutch fluently.

At the beginning of each interview, the interviewees were provided with information about the purpose of the study, the established conditions for anonymity and confidentiality, and aftercare options. We asked the respondents whether they understood the information and if they were still willing to participate. If so, we asked them to sign an informed consent agreement to verify that they were knowingly participating in the study and were doing so of their own volition. Although Netherlands law does not compel disclosure of one's HIV status to sexual partners, there have been a limited number of prosecutions of HIV-positive people for exposing others to the risk of HIV transmission (Smit, 2002). To preserve the anonymity of the respondents, we asked them to sign only the informed consent agreement, so there would be no written record of the names of the respondents' names. Additional measures were taken to ensure confidentiality, including (a) the respondent's name was systematically replaced with a case number on the tapes and in the transcripts; (b) names, places, and other identifying characteristics were removed from the transcripts; (c) tapes were erased after transcription; and (d) the interviewers signed an informed consent agreement to keep in strict confidence everything they discussed with the interviewees.

Participants were paid 50 Dutch guilders (approximately $€ 23$ ). The first author conducted 14 interviews, and three trained interviewers who have been working in the field of HIV prevention for several years conducted the other 16. All interviewers 
were women; this was decided to avoid potential gender-of-interviewer effects (Catania, Gibson, Chitwood, \& Coates, 1990).

\section{Participants}

In total, $30 \mathrm{HIV}$-positive MSM took part in the study. The participants had a mean age of 44 years (range 28-59). The majority were Dutch nationals; one man was Scottish, and another was American. Of the 30 men, three had a low education level, 11 a medium education level, and 16 a higher education level. Ten participants were no longer employed because of their HIV infection. All participants described themselves as gay. The mean length of time these men had known they were HIVpositive was 8 years (range 1-19). Six participants were diagnosed with AIDS. All reported having had laboratory investigations of CD4 cells and viral load in the past 3 months. The most recent self-reported CD4 count ranged from 53 to 1,400 cells/ $\mathrm{mm}^{3}$. Three participants could not remember their most recent CD4 count. The most recent viral load result, if detectable, ranged from 100 to 60,000 copies $/ \mathrm{ml}$. Twelve participants reported that their viral load was undetectable; four could not remember their most recent viral load test results.

\section{The interview}

The interviews were semistructured and conducted face-to-face. We used an interview schedule to introduce participants to the different subject areas that we had specified in advance but followed up and probed further areas that arose spontaneously. The following areas were covered in each interview: impact of HIV infection on life in general and sexuality in specific, impact on steady relationships and casual sex partners, perception of HIV-related risks, feelings of personal responsibility for safer sex, disclosure of HIV-positive status to sex partners, sexual techniques, condom use, and occurrence of unprotected sex. Interviews ranged from 90 to 120 minutes. Most of the interviews were conducted at Maastricht University, the Dutch Gay and Lesbian Association in Amsterdam, and the municipal health service in Rotterdam; four participants preferred to be interviewed in their homes.

\section{Analysis}

All interviews were tape-recorded and transcribed verbatim. We analyzed the transcripts using the qualitative analysis package QRS NUD*IST 4.0 following the guidelines of Baarda, De Goede, and Teunissen (2000). In the first phase of data analysis, we grouped data into broad categories based on our research questions. In the second phase, we selected concepts, variables, and classifications using keywords that identified the most important topics in the study. Initially, we analyzed only 15 interviews, which provided the foundation for a provisional codebook. We then examined and verified the provisional codebook by analyzing the remaining 15 
interviews. After all interviews were entered and coded, we began a third phase in the data analysis process, in which we implemented selective coding. We returned to transcripts to distinguish relevant, less relevant and irrelevant issues. This procedure was followed until a definitive database was created containing all relevant information. The final interpretations and conclusions are based on this database.

Following the Dutch national guidelines (Hospers \& Blom, 1998), protected sex was defined as anal sex with the use of a condom and oral sex with the use of a condom or without ejaculation in the mouth. Unprotected sex was defined as anal sex without the use of a condom and oral sex with ejaculation in the mouth. Because we were interested in the ways the participants defined their sexual activities as protected or unprotected, the interviewers did not give any definition of protected or unprotected sex during the interviews.

\section{RESULTS}

\section{Sexual activity}

At the time of the interviews, almost all participants reported that they were sexually active. Two participants reported that they had not had sex since their positive test results, which was 5 and 8 years ago, respectively. Fifteen participants reported that they were in a steady relationship. Of these participants, 8 reported having an HIV-negative partner, 6 an HIV-positive partner, and 1 a steady partner with unknown HIV status. Of the participants who were involved in a serodiscordant relationship, 6 stated that they always practiced protected sex with their steady partner, 1 participant mentioned the occurrence of unintended unprotected sex, and 1 participant reported that he and his partner never take any precautions. Of the participants who were involved in a seroconcordant relationship, 2 reported having unprotected sex with their steady partner, 2 reported that they had agreed with their partners to have protected sex but mentioned the occasional incidence of unprotected sex, and 2 reported that they had discontinued sexual intercourse with their steady partners. The participant who had a steady partner with an unknown HIV status reported unprotected sex with his steady partner on a regular basis. Twenty-six participants reported sexual intercourse with casual sex partners. Eight reported that they always had protected sex with casual sex partners; 15 reported occasional occurrences of unprotected sex. Finally, 3 participants mentioned frequent occurrences of unprotected sex with casual sex partners.

\section{Impact of HIV-positive diagnosis}

From the interviews, it was clear that an HIV-positive diagnosis had a significant impact on well-being for the majority of the participants. Most participants reported that they were shocked at the news of their HIV-positive status. For instance, one 
man said, "I had a sinking feeling. Really, it was if my whole world collapsed." Some respondents said that they experienced total panic and started making arrangements for all kinds of practical issues, such as taking care of health insurance, writing wills, and planning funerals. One participant noted,

"I thought, this is it, I am dying. I went home and started to cry, to cry, this is it. I phoned the priest immediately, because I thought I would die within a week, and I felt really, really bad. So I phoned the priest and took care of my funeral and the lunch, the flowers I wanted and all kinds of stuff, and I collected addresses. And then, everything was arranged and then you realize you are still around, so now what? Yeah, well, and then the whole process starts. And then slowly, very slowly, you start to recover, bit by bit." (Participant aware of status for 6 years, HIV-negative partner)

Other reactions that were frequently reported in the first period after the positive test result were guilt and self-blame, anger and depression. For example,

"I was so tired the first year, really deadly tired. I couldn't take out the dog, or go upstairs. Now that I look back, I think I was so tired because I had lived to a great deal. You have to tell all kinds of people that you are HIV-positive, and I always felt very guilty. I mean, you feel guilty for the pain you cause everybody. And everybody was scared out of their wits, over and over again." (Participant aware of status for 12 years, no steady partner)

Some reported that they tried to deny their HIV infection by working overtime or by using drugs or alcohol. Not all participants, however, experienced their HIVpositive test result as a total shock. Some considered it a relief. They had suspected that they were HIV-positive, mostly because they either had a partner who was HIV-positive or because they suffered from HIV/AIDS-related symptoms for a long time. Those men noted that this suspicion had a negative impact on their emotional well-being, as they spent a lot of time thinking about the possible consequences. At last, their suspicions proved to be correct, and the positive test result meant the end of uncertainty.

To determine whether the availability of HAART had an influence on the reactions to an HIV-positive diagnosis, we compared participants who were diagnosed before HAART with those who were diagnosed after HAART. The only difference we found was that those who were diagnosed before HAART experienced stress, because they thought for a long time that they would die from HIV and had to find their way in life again.

\section{Sexuality}

Whether or not the positive test result was a shock to the participants, most reported that they needed some time to rethink or restructure several aspects of their lives. This "re-construction of life" (see Barosso, 1997; Brashers et al., 1999) was related to issues such as personal relationships, work status, financial issues, and long- 
term plans. The HIV-positive diagnosis had an impact not only on the lives of the participants in general but also on their sexuality. Most HIV-positive MSM described a diminished sexual interest in the months following diagnosis of HIV, which generally led to a break in their sex lives. For most participants, this diminished sexual interest was rooted in the knowledge that HIV is an infectious disease. The idea that they might place their sex partners at risk by means of (unprotected) sexual intercourse suppressed their sexual desire and led to a change in sexual satisfaction. Many participants who were in a steady relationship when they learned of their HIVpositive status reported that HIV had strongly influenced their sex lives with their steady partners. For instance,

"In the beginning, sex was very limited. I didn't dare anything anymore. I even didn't dare to kiss my partner. I wasn't informed at all because I didn't want to know anything about the disease. I thought, I am going to kick the bucket anyhow. At a certain point, my partner thought there should be more. So we started having sex again, and we always had very safe sex. But it wasn't good anymore. I stopped enjoying it. One has to pay attention to it continuously and it keeps running through my mind." (Participant: aware of status for 9 years; HIV-negative partner)

The possibility of infecting a sex partner was also mentioned by most participants as the reason for avoiding new sexual encounters in the first phase after the HIVpositive diagnosis. One participant, who had learned his positive test result only a year earlier, stated,

"I haven't got any casual sex partners anymore. I mean, I have kissed once in a while, but absolutely nothing further. I mean, just because of the fact that you know that you are HIV-positive, and what if you infect someone? I just can't accept it. Since I know I am HIV-positive, I find, you just cannot do that to another." (Participant aware of status for 1 year HIV-negative partner)

The decline in sexual interest that the participants faced after the diagnosis of HIV was influenced not only by anxiety about transmitting HIV to their sexual partners but also by negative physical effects resulting their HIV infection and treatment. Although some participants reported that they did not experience significant sexual problems, most of them suffered from symptoms such as fatigue, headache, stomach ache, sickness, and diarrhea. In addition, some reported erectile problems:

"I didn't feel like having sex the first months. It had also to do with problems with potency. It stiffens somewhat more nowadays. But the fact is, I'm on anti-depressants, and those inhibit the libido also." (Participant aware of status for l year, no steady partner) 
"The last year I have known no sexual awareness due to HIV and its treatment. Then they tested my testosterone, and it appeared to be extremely low. They prescribed me a testosterone and my sexual desire has returned. So at first, you think it is due to stress, but then it appears to have a clear physical cause." (Participant aware of status for 6 years, no steady partner)

In addition, some participants complained about altered body image as a result of lipodistrophy and skin rash, which had a negative influence on their sexual desire and feelings of sexual attractiveness:

"I have lost a lot of weight. For a long time, I did not consider my own body attractive. That doesn't help. I don't mean to say that I'm such an attractive person at this moment. I mean, but I am used to it now, that my body fat is disappearing. I have not got no behind anymore. I used to be a very attractive man, well, yeah, you need a while to get used to that." (Participant aware of status for 5 years, no steady partner)

A minority of the participants reported an increase in sexual activity after their HIV-positive diagnosis. Typically, those men reported primarily unprotected anal sex in this time period.

"Sex didn't become safer. I mean, I had a lot of friends who didn't practice safe sex. We all thought, well we are all infected and those that aren't infected yet will become infected any how. So, we were very a ware of what we were doing. I think they call it bare-backing these days. At a certain point, I really got a kick out of it." (Participant aware of status for 6 years, no steady partner)

Resuming sexual activity

Most participants who reported a break in their sexual activity after receiving a diagnosis of HIV said that their sexual interests returned during the course of their illness and that they started having sex again. Nevertheless, compared to the period before the HIV diagnosis, most participants reported differences in sexuality. In general, participants indicated that they experienced sexuality as emotionally charged. Contributing factors were concerns about infecting others, the pressing need to use condoms, and being constantly confronted with their illness. For instance, one participant noted,

"I have fewer sexual contacts. Significantly fewer. I believe my mentality has changed. It has become less important. I have no urgent needs anymore, only when there is a clear response. I used to have sex only to have sex often. But now, it is such a big confrontation with yourself all the time." (Participant aware of status for 5 years, no steady partner)

Although the abovementioned issues played a role in regard to both steady partners and casual sex partners, during the interviews it became clear that the impact depended on partner type. In particular, participants who had a steady 
relationship at the time of their diagnosis reported poor sexual activity with their steady partner in the long term. Certainly, when both partners worried a lot about the potential danger of sexuality, it seemed very difficult to continue an enjoyable sex life:

"At a certain point, I felt like having sex again. But fear still has the upper hand. I'm afraid of infecting him. We had to ease slowly into the whole thing, but still, even though our relationship is quite good, there is a big wall standing between us. The wall has come between us, and I can't sweep it away, and it's like iron. I mean, the fact stays that I'm infected and he isn't." (Participant aware of status for 6 years, HIV-negative partner)

One of the concerns of participants who were not in a steady relationship at the time of the interview was the potential of meeting someone with whom they could develop a serious relationship. Despite their need for the intimacy and security of a steady relationship, they feared the impact that their HIV-positive status would have on intimate relationships and the potential for infecting their partners. To avoid placing themselves in what they considered a vulnerable and uncomfortable position, some respondents reported that they preferred the "security" of casual or anonymous sex contacts.

"Nearly from the start, I feared a relationship with someone who is HIV-negative. On the one hand I'm very afraid of making love and the need to protect each other. I'm afraid that sooner or later it will go wrong anyway. And that means that you are responsible for him entering the relationship HIV-negative and quitting the relationship HIV-positive." (Participant aware of status for 5 years, no steady partner)

Risks to self: HIV superinfection and STDs

As the previous sections indicate, participants worried about the risk of transmitting HIV to sexual partners. However, when the participants were asked to what extent they worried about the risks of HIV superinfection and other STDs for their health, half of the participants reported that that was a concern. For these participants, the motivation to protect themselves was an important factor underlying the decisionmaking process concerning protected sex.

"All the time I hear HIV-positive people catching all kinds of sexually transmitted diseases due to unprotected sex - rectal gonorrhea and stuff like that. I'm really not waiting for that. Precisely because I am not on treatments, I think I can easily become ill. So that choice is not mine." (Participant aware of status for 3 years, no steady partner)

The other half of the participants hardly seemed concerned about superinfection or STDs. In general, this finding could not be attributed to a lack of awareness of the possible risks. Those participants typically argued that they did not feel the need for protecting themselves for several reasons. First, they believed that they were already 
ill, which could not get worse by superinfection or contracting a STD, something they considered beyond their control.

"In general, I worry less about catching something. I mean, the worst thing I could catch is gonorrhea and that is treatable. And with regard to superinfection, I do not worry at all. Maybe that sounds crazy, but I can't control it anyhow. So "Who cares?" I mean, if I never had sex again, and if I stayed home to watch television all the time, my viral load could increase. And if I were to fuck my brains out, then my viral load could increase as well. So to abstain from everything is a theoretical possibility, but not human at all." (Participant aware of status for 2 years, no steady partner)

Second, participants reported that practicing sex was already difficult enough because of their HIV infection. They argued that it would be easier to quit sex than to take the risk of HIV superinfection or STDs into account. Finally, some participants mentioned the lack of empirical evidence on HIV superinfection, so they did not perceive this risk as severe enough to avoid unprotected sex for their or their partners' health. For instance, one participant in a seroconcordant relationship discussed how the medical debate on HIV superinfection had influenced their decision to practice unprotected sex:

"We don't believe in HIV superinfection or other senseless terms. I think one is HIVinfected or not and I don't make a distinction any further. It's a very medical debate to me, which doesn't mean much to me in daily life." (Participant aware of status for 5 years, HIV-positive partner)

Although the effect of an undetectable viral load on the infectiousness of an HIV-infected person is still under investigation, there is some evidence that the transmission rate of HIV decreases significantly in relation to an undetectable viral load (Fideli et al., 2001; Quinn et al., 2000). When the participants were asked about this issue, it appeared that all participants had heard about the relationship between successful treatment with HAART and a decreased transmission rate of HIV. Contrary to what is generally found (Ostrow, 1999), there was consensus that a low or undetectable HIV RNA level does not mean that the risk of either transmitting HIV to a sex partner or becoming (super)infected from an HIV-positive sex partner with HIV therapy is negligible. Most interviewees argued that an undetectable viral load HIV should not be used as an indicator of decreased or nonexistent infectiousness, because the virus might still be present in the body. In their opinion, a low or undetectable viral load was no reason for not using condoms when having sexual intercourse. 


\section{Personal norms: feeling responsible}

Awareness of the risk of transmitting the virus to sex partners seemed to be closely related to feelings of personal responsibility for safer sex among the participants. Following Rosengarten et al. (2000), we could identify two types of responsibility: sole and shared. In addition to these two types of responsibility, we found a third type, which can be defined as no responsibility. Participants who adhered to the first type of responsibility were very explicit about their responsibility for protecting their sex partners from infection. In general, these participants believe that they bear 100\% responsibility for safer sex behavior. That does not necessarily imply that they do not consider their sex partners' role in safer sex behavior. However, rather than focusing on their partners' role in preventing HIV transmission, they tended to focus on the key role they themselves play in the possible health consequences of unprotected sex for their sex partners. Some participants compared being HIV positive with carrying a poisoned needle or a rifle:

"In my opinion it is the primary responsibility of the HIV-positive person to ensure that safe practices are followed. The person who is HIV positive has the weapon in his hands. Of course, the partner should make the effort to protect himself, but the HIV-infected person has the weapon. I think that he is, therefore, responsible for protecting his partner." (Participant aware of status for 11 years, no steady partner)

Typically, most participants who thought they had the sole responsibility for safer sex reported that they would have qualms about practicing unprotected sex and spoke in terms of moral conflicts with the possibility of infecting a sex partner. For example, one participant stated, "Suppose I would infect someone... that would definitively imply the end of my quality of life. It would make me sick in my head." In general, these men were highly motivated to practice safer sex.

The second type of responsibility was a type of shared responsibility. According to the participants who adhered to this type of responsibility, both sex partners are equally responsible for having safer sex, and as a consequence, both sex partners should shoulder the responsibility for not infecting others. Some participants mentioned that sex partners are equally informed about HIV-related risks. Others pointed out that they also accepted responsibility for their own illness and that they never blamed anyone else for their infection. In addition, a couple of respondents said that as there are also risks related to unsafe sex for PWHA, sex partners should also accept responsibility for safer sex. Several participants explicitly opposed the idea that they alone are accountable for unsafe sex. One participant pointed out that an extra responsibility for HIV-infected people could easily be interpreted as victim blaming and expressed his surprise about this viewpoint: 
"Suppose I had sex with you. I mean we meet and you want to fuck me. I pull off the condom and you fuck me. Who is responsible? I'm responsible, because I'm HIV-positive. However, suppose I fuck you. You pull off the condom, I put on the condom, and you pull of the condom again and I think, okay, let it be. Who is responsible? Again the answer is the HIV-positive. And I personally think that is weird. In my view the HIV-negative person was responsible. But the contrary is true; the HIV-positive is considered guilty, because he is expected to be the strongest in all circumstances. I think that is astonishing, because two people were involved." (Participant aware of status for 5 years, HIV-positive partner)

Finally, a small number of participants adhered to a type that can be identified as no responsibility. Those men denied any responsibility for protected sex, and in sexual encounters, they typically leave it to their sex partners to take the initiative for protected sex. They reasoned that everybody is responsible for his own deeds. According to them, having sex goes hand in hand with accepting HIV-related risks. As a consequence, that absolves them from protecting their sex partners.

"Responsibility for safe sex is always everybody's own responsibility. It has nothing to do with the fact that you are HIV-positive or not, nor if you are being fucked by someone or that you fuck somebody else. You can't blame somebody else. You are responsible for your own deeds and in that case it is sex, lust." (Participant, aware of status for 19 years, no steady partner)

\section{Responsibility and behavior: the role of contextual influences}

From the data, it was clear that a distinction needed to be made between feelings of responsibility and actual behavior. When the interviewees spoke about the way they handled the issue of responsibility for safer sex in sexual interactions, it appeared that they did not always act according to their beliefs of responsibility for safer sex. For example, several respondents held the opinion that both partners share responsibility for safer sex. However, in sexual encounters, they were more likely to take sole responsibility for safer sexual practices. This was expressed in changing risk behavior and the practice of protected sex (at least most of the time). One participant explained,

"In theory I'm not responsible for the HIV status of others. Others are completely responsible for their own status. But in practice, actually the fact is that I wouldn't want to have that on my conscience. And I wouldn't want someone to think he would get it from me. So I practice safe sex, at least safe for the other. So apparently in practice, I feel quite responsible for the HIV status of others. Yeah, I think there is quite a big difference between theory and practice." (Participant aware of status for 12 years, no steady partner) 
Other participants behaved in precisely the opposite way. Although they claimed to believe that sex partners share responsibility for safer sex, they also described some situations in which they were inclined toward a practice of taking no responsibility.

"Most of the time I feel very responsible for protecting sex partners, but sometimes not. Sometimes it just wears me out. I have practiced unprotected sex a couple of times. At that time the deal was not to come. In my opinion that was okay, but I thought why don't you bring up the subject; why do I always have to be the first? I mean it's also their responsibility. Of course I know the right answers, but it all happens within a few seconds." (Participant aware of status for 5 years, HIV-positive partner)

This discrepancy between feelings of personal responsibility and actual behavior is influenced by interpersonal and situational factors. Based on the interviews, we were able to identify three factors that affected feelings of personal responsibility for safer sex and its relationship with actual behavior: partner type, social norms, and sex partner characteristics.

\section{Partner type}

As previously noted, most participants who were in a steady relationship reported that HIV had a major impact on their sexual relationships. Awareness of the danger of transmitting the virus to their steady partners caused substantial stress. Consequently, most participants reported that they were highly motivated to practice protected sex. Although participants reported that HIV also had influenced their sex lives with casual partners because they might transmit the virus, the stress associated with having sex and the issue of responsibility appeared to be reduced:

"It's typical, but I don't feel as responsible to casual partners as to my boyfriend. I do feel responsible and I would behave identically, but I know that it is not the same as with my boyfriend. It's not that frustrating." (Participant aware of status for 6 years, HIVpositive partner)

The findings might be related to the sexual culture of casual and anonymous sex partners; it seemed that the anonymity of sexual encounters influenced perceptions of personal responsibility for safer sex. Casual or anonymous sex contacts were described in terms of sexual desire and enjoyment, and less in terms of the commitment and emotional involvement they described when discussing steady partners. According to the participants, they regularly had sex with men with whom they did not exchange a single word. Moreover, participants argued that everybody who is intentionally looking for casual sex contacts should be aware that those encounters are lust or sex oriented and that some risks might be involved. As a consequence, they argued, they should not bear the responsibility alone for curtailing the epidemic: 
"Well, for casual partners I don't feel responsible. That's probably also because of the places I visit when I search for partners, as they are there specifically for sex. At a party, for instance - well, those are specifically for sex. I mean, somebody has also his own responsibility for dealing with sex then." (Participant: aware of status for 3 years; no steady partner)

\section{Social norms}

The influence of social norms and rules appeared to be especially important in the context of casual and anonymous sex contacts. For many of the men who took part in the study, their views on personal responsibility were framed by the norms of the gay culture in which they have sex:

"Suppose someone says that he couldn't care less if someone else uses condoms. Subsequently, I think, well, I'm not the only one. I mean, you search for confirmation of your own norm. And the social context creates the norm. If you see that people have unsafe sex all the time, why would you have safe sex then?" (Participant aware of status for 2 years, no steady partner)

According to the participants, perceptions of responsibility for safer sex were shaped not only by their perceptions of others' behavior but also, as described below, by pressures exerted by their sex partners to participate in unprotected sex.

"It is not my intention to ejaculate in the mouth of my partner, but some men insist on it. In the beginning, I was very careful, but then I thought: Why should I be so concerned? I mean, if you see what is going on, people should determine for themselves whether or not they are willing to run the risk. After all, it is their own risk." (Participant aware of status for 19 years, no steady partner)

\section{Sexpartner characteristics}

Perceptions of responsibility among study participants were also influenced by partner characteristics. For instance, it appeared that a partner's physical attractiveness (i.e., how "gorgeous" he is) could influence perceptions of responsibility in two directions. First, when a man feels attracted to a person, and there is a possibility that a relationship could develop, he might be very keen to ensure protected sex to avoid being blamed afterward. Second, feeling attracted to a person might also increase his willingness to participate in unprotected sex, if he is "desperate" for sex (and is afraid to go home alone).

"Suppose, he's really stunning, and you would have told it [HIV-positive status] to him. And he says, I don't give a damn. And you would only see him once; then you're really put to the test." (Participant aware of status for 14 years, HIV-positive partner) 
In addition, some participants reported that they searched for clues to handle the issue of responsibility for safer sex. Assuming responsibility for safer sex might be less obvious when a sex partner seems to be able to make his own informed consent decisions concerning sexual risk behavior. Examples of such indications were age and risk-taking behavior. One participant said that he would be more willing to protect a younger partner than an older one; at the same time, he said that he would feel less personal responsibility for protecting a partner "who should have known better":

"You will check it on the most absurd things. For example, if he is a very nice boy of 18, you don't want to spoil that. So I protect him, because he is such a nice boy. But suppose it's a tourist in Amsterdam who fucks without a condom? I think: He should have known better. Suppose he is good-looking and he is interested in me? Then maybe after all I would fuck him without a condom because I might think: He travels by air tomorrow and will be gone anyhow." (Participant aware of status for 17 years, no steady partner)

\section{Negotiating safety and sexual risk behavior}

Within steady relationships

Most participants who had a steady partner at the time of the interview reported that after the HIV-positive diagnosis, they moved from unprotected sex to protected sexual behavior within their steady relationships. Having protected sex, however, included several strategies. Some participants reported that they practiced protected sex by using condoms for anal intercourse and avoiding oral sex with ejaculation. Others reported that they engaged in oral sex without ejaculation and refrained from having anal sex. Three participants (in both serodiscordant and seroconcordant relationships) described occurrences of unintended unprotected sex. Negotiating safety seemed especially difficult when they experienced pressure from their partners to engage in unprotected sex. Reasons mentioned for engaging in unprotected because of pressure from the partner were not wanting to reject the sex partner and a reduced quality of the sexual experience. For example,

"He gives me a blow job once in a while. And then he never uses a condom. For me that's frustrating, but I don't want to reject him. I mean, I don't want to hurt him. Even before, when I knew he was HIV-positive, I didn't want to reject him. And now, I have become resistant to all kind of drugs, and his therapy is very successful... It's always in the back of my mind, suppose it happens anyway [HIV superinfection]? I try to put it out of my mind." (Participant aware of status for 6 years, HIV-positive partner)

In general, participants noted that unprotected sex was more likely to occur with the passage of time. For example, one participant expressed his concerns about this and said that as a result of instances of unintended unprotected sex, he recently came to 
an agreement with his partner about not engaging in anal sex. He noted, however, that this was very difficult for him, because he likes anal sex very much:

"Let me tell you, several incidents have happened, so there have been situations in which we had sex without condoms, and I felt very uncomfortable about that. We just have talked that over and ever since we use other sex techniques that are also nice and pleasurable. But it [anal sex] is an issue that I want to bring up again because I miss it myself. I do miss it." (Participant aware of status for 16 years, HIV-negative partner)

Some participants reported that they continued to practice unprotected anal and oral intercourse. One participant reported that he and his partner decided to engage in protected sex immediately following notification of their HIV infection. However, eventually this developed into a pattern of inconsistent condom use.

"It is actually very odd. In the beginning we really had safe sex, but at a certain moment we started having unprotected sex. I participated too. I must say that I'm the one who is penetrated and that is not as unsafe as when I would fuck him. But actually, it is all some kind of excuse. I began to feel really uncomfortable about that. But we have spoken about it and without a condom you have more intimacy, for sure. Within a relationship you want to be close." (Participant aware of status for 16 years, HIV-negative partner)

When both partners are HIV-positive, other reasons might lead to the practice of unprotected sex. For example, two participants reported that they had chosen to practice unprotected sex within their steady relationships because they did not consider HIV superinfection to be a serious risk to their health.

\section{With casual or anonymous sex contacts}

Eight respondents reported that they always practiced protected sex with casual partners. Most of these men said that they were concerned that they might infect their partners and that they just could not have sex without using condoms. Some of them, however, reported that they avoided the risk of HIV transmission by engaging in oral sex without ejaculation or that they just kissed with casual partners or engaged in mutual masturbation. Several participants reported that they "negotiated safety" by selecting seroconcordant partners. Having sex with a person who is also HIV-positive results in less worry about the risk of transmitting the virus. Interviewees reported that as a consequence, they felt more comfortable and could enjoy sex more, regardless of whether they practiced safer sex during those sexual encounters. Some used this strategy specifically to facilitate unprotected sex. For example, 
"I don't want a relationship with somebody who is HIV-negative, partly out of fear of having sex and the need to protect him... I mean it is very practical if the other is infected too. You don't have to deal with the fact that you can transmit the virus to the other person - and then condoms are no longer an issue." (Participant aware of status for 6 years, no steady partner)

In general, however, incidents of unprotected sex within the context of casual and anonymous sex were described as accidents rather than as calculated risk taking, and were attributed primarily to willingness of the sex partner not to use condoms.

"It has happened, although not very often, that someone insists on doing it without using a condom. I was very horny at that time. And I thought if it doesn't happen right now, I go home alone. So at that time I did it without a condom and hoped for the best." (Participant aware of status for 14 years, HIV-positive partner)

Other accounts of unprotected sex were attributed to intense feelings of falling in love, feelings of desire, or "change of a lifetime." Not having condoms on hand and embarrassment about proposing condom use were also mentioned. For example, one participant explained that he feared that he would immediately be labeled as having HIV and would be rejected:

"It's easier for me when the other person proposes condom use. Because if it depends on me... I have more difficulties doing so. Because once someone said to me: Oh I hope you don't have AIDS. So, for me, it's very hard to bring up the issue of condom use." (Participant aware of status for 7 years, HIV-positive partner)

\section{Disclosure}

To gain further insight into the ways in which participants coped with the issue of disclosure, we asked them if they shared their serostatus with sexual partners. The responses suggested that a distinction should be made between disclosure to a steady sex partner or someone with whom a long-term relationship might develop and, on the other hand, casual or anonymous sex contacts. With regard to casual and anonymous sex contacts, most participants reported that they avoided disclosure of their HIV status because they feared rejection. In addition, participants reported a concern for their anonymity if they were to disclose their HIV status, because PWHA are still stigmatized. Arguments for nondisclosure were also linked to the typical culture of casual and anonymous sex. First, communication about HIV related risks and condom use rarely occurs. Second, because most of those contacts are once only or short term, they often lack trust and emotional intimacy. Both aspects make disclosure more problematic, as is illustrated by the citations below. 
"Yeah, well, you know what it is - anonymity has its own character. It's so odd, I mean... It's about sexuality and it's a very open atmosphere, but there is a code. It would be a letdown if I met someone and I think: Oh gee, he looks gorgeous and he thinks the same of me and something happens. You know? What if I said: Listen, we have to watch out a little, because I'm HIV-infected... lust will go out totally". (Participant aware of status for 1 year, HIV-negative partner)

"When you meet someone you're interested in, for sex I mean, and you would mention that you're HIV-positive, lust will soon come to an end." (Participant aware of status for 12 years, no steady partner)

Some participants reported that they had disclosed their HIV-positive status to casual sex contacts a couple of times. However, because they had been rejected after disclosure of their status, they decided to stop disclosing. Other participants argued that disclosure was unnecessary because they made sure of safer sex practices:

"I used to mention that I'm HIV-positive, but now I look after protected sex." (Participant aware of status for 7 years, HIV-positive partner)

Exceptions were made for sexual contacts with whom participants might become closely attached (for example, when having sex repeatedly with the same partner or when feelings of friendship begin to develop). Particularly in these encounters, it seems to be important not to delay disclosure too long, because it might be perceived as dishonest and might also raise the risk of rejection by a partner.

"Sometimes I have one-night stands; sometimes I have sex with them more often. And when I have sex with them more often, I have to tell them that I'm HIV-positive. Because when it's the second or third time, there's more confidentiality, the anonymity is gone. Then I think it should be clear; it should be transparent." (Participant aware of status for 5 years, no steady partner)

All participants agreed that they would disclose their HIV-positive status as soon as possible to a new steady partner. Informing a steady partner of their serostatus was unanimously seen as necessary for developing a trusting and satisfying relationship.

Only a few participants reported that they (nearly) always disclosed their serostatus to casual or anonymous sex partners. For these men, disclosure offered the opportunity to negotiate safer sex with their sex partners. Typically, it gave them a feeling of greater control over the situation. In addition, disclosure provided the opportunity to shift the responsibility for practicing safer sex to the partner. After disclosing HIV status to sexual partners, it was easier to argue that it is the responsibility of the potential sex partner to practice safer sex. 
"When I meet an attractive person, I always try to communicate in one way or the other that I am HIV-positive. Then he knows immediately what is going on. When he is sure that he can handle the situation, then he can make his first move." (Participant aware of status for 8 years, no steady partner)

\section{DISCUSSION}

This study shows that confrontation with an HIV-positive diagnosis had far-reaching implications for general well-being and sexual functioning. The initial diagnosis of HIV was often met with shock and denial. Participants reported feelings of shame, self-blame, and depression, emotions that are well documented in the literature (e.g., Alonzo \& Reynolds, 1995). In addition, most HIV-positive MSM reported significant changes in sexual behavior, such as curtailing sexual activity and having fewer sex partners, for several reasons. First, most participants struggled with the altered meaning and consequences of unprotected sex. Whereas unprotected sex before diagnosis was directly related to risks to their own health, after diagnosis unprotected sex is mainly associated with the risk of transmitting the virus during sexual intercourse. This realization diminished the enjoyment of sex for most participants and left them feeling anxious and tense. Second, many participants suffered from sexual problems because of physical complaints brought on by the treatment regime or HIV itself. Third, some participants reported that sexual problems were related to negative feelings about their physical appearance (see

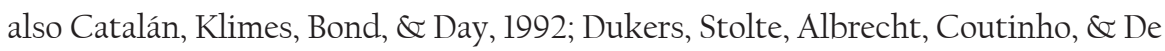
Wit, 2001; Gochros, 1992; Quadland, 1992; Sherr, 1995). Personal HIV-related risk seemed to play a less important role in sexual problems experienced by the study participants. Although most were aware of the risk of HIV superinfection and STDs for their own health, only half of the respondents reported that they were motivated to practice safer sex to protect themselves. The other half did not consider HIV superinfection and STDs as a serious risk to their own health. It should be noted that at the time of the interviews, there was little evidence concerning the possibility of HIV superinfection. However, this has changed recently, as several studies have been published indicating that HIV superinfection is, in fact, possible (e.g., Jost et al., 2002; Ramos et al., 2002). Future researchers should investigate the relationship between concerns about HIV superinfection and sexual risk behavior among HIVpositive MSM.

Despite the impact of HIV on life in general and sexual life in particular, over time most participants found a way to express their sexuality. Nevertheless, it was found that HIV still has a significant impact on sexuality and intimacy in the long run and can generate all kinds of emotional difficulties. Coping with the negative impact of HIV on sexuality seemed to be especially difficult within steady relationships, in which both partners are insecure about the dangers implicit in sex. 
The results of this study confirm previous research findings that feelings of personal responsibility are central to the impact of HIV on sexuality and the decline in sexual risk behavior (Fisher et al., 1998; Godin et al., 1996; Keogh et al., 1999; Nimmons \& Folkman, 1999; Rhodes \& Cusick, 2002; Rosengarten et al., 2000). It was glaringly apparent that the majority of participants not only worried about the possibility of transmitting the virus to their sex partners but also felt responsible for the health of their sex partners. It seemed that both moral concerns ("unprotected sex is wrong") and social concerns (avoidance of blame by others) played a key role in their resolve to practice safer sex with both steady and casual or anonymous sex partners. Only a small minority of participants claimed to take no personal responsibility for safer sex and reported that engaging in safer sex practices depended on what a sex partner wants.

The relationship between feelings of responsibility and engaging in safer sexual practices documented in this study warrants further investigation. Although feelings of personal responsibility and safer sex seem to be closely related, in some situations there appeared to be a discrepancy between feelings of personal responsibility and behavior. First, it was found that partner type influenced feelings of personal responsibility. In general, the strain of sexuality and feelings of personal responsibility were found to be less burdensome within the context of casual or anonymous sex partners than within steady relationships. This finding can be explained by feelings of closeness and the recognition of common interests. In research on prosocial behavior, both factors have been found to induce feelings of social or personal responsibility (De Cremer \& Van Dijk, 2002; Messick \& Brewer, 1983; Schroeder, Penner, Dovidio, \& Piliavin, 1995). The results suggest that with casual or anonymous sex partners, the feelings of responsibility are influenced by the nature of sexual encounters. The men who took part in this study described a shared understanding of sex with casual or anonymous partners as primarily lust oriented. Casual and anonymous sex partners were perceived to be aware of the risks they might be taking, which diminished feelings of personal responsibility for safer sex. A second factor that influences the relationship between feelings of personal responsibility and behavior is the perception of the behavior of others. When others are not using condoms, this provides a standard for the participants' behavior. Moreover, direct pressure from sex partners to engage in unprotected sex was viewed as a barrier that affects their decisions regarding protected sex. Third, the results suggest that partner characteristics also affect feelings of responsibility and the likeliness that protected sex might occur. For example, attractiveness might both enhance long-term ("We might develop a steady relationship") and inhibit short-term ("I don't want to risk this sexy person walking out on me") feelings of personal responsibility. Furthermore, respondents seem to negotiate feelings of personal responsibility by searching for clues that indicate the level of equivalence between the two. The more similar the sex partner is with regard to appearance and 
background, for example, the less likely one is to assume responsibility for practicing safer sex. Recently, Wolitski, Bailey, O'Leary, Gómez, and Parsons (2003) found comparable factors that influenced beliefs about personal responsibility for safer sex among HIV-positive MSM.

In addition, our data show that the majority of the participants have adopted safer sex practices since their HIV diagnosis. Nevertheless, many reported the occasional occurrence of unprotected sex. In some cases, unprotected sex within steady relationships might be a deliberate choice when both partners are HIV-positive. In addition, this study suggests that the occurrence of unprotected sex within the context of steady relationships might increase over time and could be attributed to emotional arguments, such as feeling the need to be intimate with each other and not wanting to reject the partner. Moreover, because of the reduced quality of sexuality within a steady relationship, the ability to negotiate condom use might decline (Hankins, Gendron, Tran, Lamping, \& Lapointe, 1997).

The most frequently cited reason for the occurrence of unprotected sex within casual or anonymous sex contacts was the willingness of the sex partner to engage in unprotected sex. Other reasons mentioned were feelings of passion and desire. Similar reasons for the incidence of unprotected sex have frequently been reported in research on sexual risk behavior among MSM (Offir, Fisher, Williams, \& Fisher, 1993). Yet, another explanation for the occurrence of unprotected sex with casual or anonymous sex contacts was "serosorting." Some respondents reported that they "negotiated safety" by selecting partners who are also HIV-positive. Moreover, in accordance with other studies (Kalichman \& Nachimson, 1999; Marks et al., 1991; Perry et al., 1994; Stein \& Samet, 1999; Wenger et al., 1994), it was found that most participants were reluctant to disclose their HIV-positive status to casual or anonymous sex partners. Reasons for not disclosing their serostatus were fear of and actual stigmatizing and rejection by sex partners. Only a few participants reported that they informed their sex partners about their positive status or that they asked their sex partners about their status. Based on this strategy, they avoided unprotected sex or shifted the responsibility for safer sex to the sex partner.

Although this study offers valuable information on sexual risk behavior among HIV-positive MSM, it should be noted that there are limitations to our sampling method. The study sample was self selected, which might have led to a bias in the presentation of the study results. However, by using several sampling methods supplementary to each other, we have attempted to reduce the possible bias arising from selecting a sample on the basis of convenience (Ritchie, Lewis, \& Elam, 2003). Nevertheless, generalizations to the total population of Dutch HIV-positive MSM and other HIV-positive populations should be treated with caution. 


\section{IMPLICATIONS FOR PRACTICE}

The results of this study offer several important implications for HIV preventive activities for HIV-positive MSM. First, because many participants reported sexual problems after diagnosis with HIV, it is crucial that HIV preventive interventions for HIV-positive MSM not only target the health-promoting behavior of using a condom every time during anal intercourse but also address the broader area of sexual health. In this respect, more attention should be given to assessing and treating sexual dysfunction in HIV-positive MSM (Catalán et al., 1995). Moreover, HIV prevention programs should include clear and specific information about the medical findings regarding the risk of HIV superinfection and the relationship between undetectable viral load and HIV transmissibility. Failure to meet the information needs of HIVpositive MSM might result in continued confusion about HIV-related risk and might lead some people to discount the relevance of prevention messages (Wolitski $\&$ Branson, 2002). In addition, specific attention should be paid to the issue of personal responsibility for safer sex. Several researchers have argued that prevention programs should incorporate methods that promote feelings of responsibility for safer sex. However, overemphasizing personal responsibility might increase feelings of guilt and shame, and could interfere with the well-being of HIV-positive MSM (Guttman \& Ressler, 2001; Tangney \& Dearing, 2002). Moreover, this study shows that most respondents feel personally responsible but are faced with several complex challenges. HIV preventive interventions should provide HIV-positive MSM with support to face the dilemma of personal responsibility and to cope with these challenges. It seems essential to enhance skills and self-efficacy to handle risk pressure and to negotiate condom use by means of, for example, instruction and modeling (Bandura, 1997). A possible way to address sexuality and safer sexual behavior in practice are brief counseling techniques that have been effective in improving sexual functioning in cancer patients. Typically those interventions focus on (a) assessing sexual problems; (b) providing information on the impact of the illness on sexual drive, behavior, body functioning and body image; and (c) giving reassurance to the participant (and his partner), improving their communication and finding alternative ways for expressing affection (Tan, Waldman, \& Bostick, 2002). The techniques of motivational interviewing described by Miller and Rollnick (1991, 2002) can be useful to target safer sexual practices of HIV-positive MSM.

In addition, it seems imperative to make protected sex practices (e.g., condom use) more acceptable within the gay community. Recently, Flowers, Marriott, and Hart (2000) demonstrated the importance of locale and location on gay men's sexual behavior. In accordance with this finding, Prieur (1990) reported that the lack of a social network and supportive environment were the most important factors underlying the continued practice of unsafe sex. Stimulating the development of social networks by encouraging helpful relationships that enhance safer sex norms 
might be a very powerful tool in promoting safer sexual behavior (Prochaska, DiClemente, \& Norcoss, 1997). For example, Kelly et al. (1992) showed that trained patrons of gay bars can be effective in changing behavior and norms.

In conclusion, the current study provides a valuable basis for future research, by offering new insights that clearly distinguish HIV-positive MSM from other atrisk groups for HIV prevention. In addition, to gain more profound knowledge on the factors that influence sexual behavior, the results of this study deserve further investigation. 


\section{CHAPTER 4}

Sexual decision-making: How moral concerns and sexual motives guide intended condom use

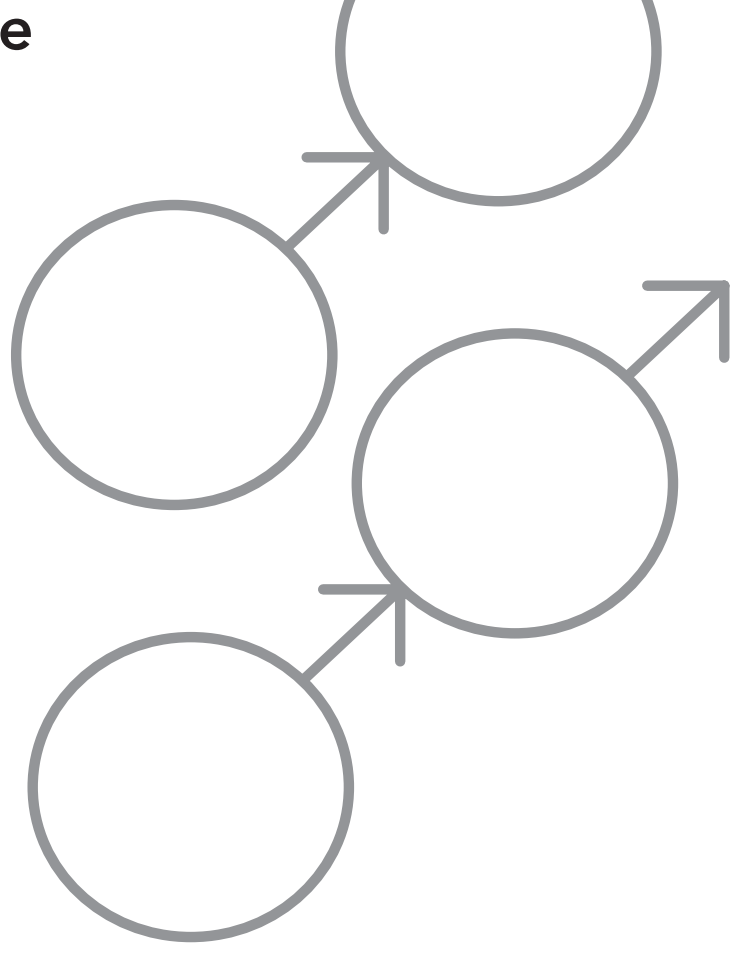

Published as:

Van Kesteren, N.M.C., Hospers, H.J., Van Empelen, P., Van Breukelen, G., \& Kok, G. (2007). Sexual decision-making in HIV-positive men who have sex with men: How moral concerns and sexual motives guide intended condom use with steady and casual sex partners. Archives of Sexual Behavior, 36, 437-449. 


\section{INTRODUCTION}

Studies on the effects of HIV counseling and testing show that most individuals who are tested HIV-positive respond by reducing their sexual risk behavior (Weinhardt, Carey, Johnson, \& Bickman, 1999). Nevertheless, it has been found that approximately one third of HIV-positive men who have sex with men (MSM) engaged in unprotected anal sex in the last two to three months (for a review, see Kalichman, 2000). Moreover, increased prevalence rates of gonorrhea and syphilis have been reported among HIV-positive and HIV-negative MSM in several western regions (Anon, 2001, 2002; Browning, Blackwell, \& Joynson, 2000; Donovan, Bodsworth, Rohrheim, McNulty, \& Tapsall, 2000; Higgens, Sukthankar, Mahto, Jarvis, \& Lacey, 2000; Van de Laar \& Op de Coul, 2004). These findings suggest a rise in unprotected anal sex among HIV-negative and HIV-positive MSM. Given that at least a subgroup of HIV-positive MSM, for various reasons, engage in risky sexual behavior, an understanding of why this occurs remains a matter of significant public healthy concern.

Studies have been conducted that examined possible antecedents of (un)safe sexual behavior in HIV-positive MSM (Crepaz \& Marks, 2002). One of the factors that has been identified as promoting sexual behavior change is perception of risk, i.e., awareness that unprotected sex increases the risk for HIV infection and STDs. Accordingly, studies have indicated that HIV-positive MSM who believe that HIV superinfection and other STDs may have negative consequences for their own health are more likely to use condoms for anal sex (McConnell, Grant, \& Greenwood, 2002). However, other studies suggest that a person's own risk of HIV superinfection and STDs is not a key concern. Of great importance is the finding that safer sex in HIV-positive MSM is primarily motivated by concerns about the risks for the other and that concerns about one's own risks are subordinate (Keogh, Weatherburn, \& Stephens, 1999; Van Kesteren, Hospers, Kok, \& Van Empelen, 2005).

The notion that HIV-positive MSM engage in safer sex because of concerns about the welfare of sex partners can be characterized as a form of prosocial behavior. Prosocial behavior "represents a broad category of acts...that are defined as generally beneficial to other people" (Penner, Dovidio, Piliavin, \& Schroeder, 2005, p. 366). If HIV-positive MSM indeed engage in safer sex to benefit others, or more specifically, are motivated to prevent harm to others, it is of particular importance to understand why this is the case and to determine which factors promote such behavior. The literature offers several explanations to account for prosocial behavior. One explanation for a wide range of moral and prosocial behaviors, which has received considerable attention, is the so-called personal standards approach (e.g., Manstead, 2000). This approach emphasizes how internalized, self-reinforced standards, such as altruism, can promote prosocial behavior as people strive to maintain a positive selfimage or achieve their ideals (Penner et al., 2005). 
Indeed, some qualitative studies suggest that internalized values or personal standards play an important role in the practice of safer sexual behavior. For example, Nimmons and Folkman (1999) showed that HIV-positive MSM described moral and altruistic values in regard to the need to practice safer sex. A study by Wolitski, Bailey, O'Leary, Gómez, and Parsons (2003) found that many HIV-positive MSM perceived that they had a particular responsibility for protecting their partners and that this perception influenced safer sexual decision-making. Participants cited altruism and self-imposed standards as the motivations underlying their beliefs about personal responsibility. Similarly, Van Kesteren et al. (2005) found that a greater concern about potential HIV transmission to sex partners was related to enhanced feelings of personal responsibility for safer sex.

While these studies have contributed greatly to a preliminary understanding of the role of intrinsic motivation in safer sexual behavior, the factors that may motivate HIV-positive MSM to adopt safer sex practices for the protection of others warrants further examination. This study represents such an attempt, examining socialpsychological factors of condom use in the context of steady and casual sex. For this reason, we combined the Theory of Planned Behavior (Ajzen, 1991), a well-established framework used to understand behavior in a broad range of contexts, with the normactivation theory (Schwartz, 1977; Schwartz \& Howard, 1981, 1982), a framework specifically developed to understand prosocial behavior. In spite of the supposed importance of prosocial motivation in safer sexual behavior, it is possible that other motivations (e.g., sexual motives) for unprotected anal sex may have a negative influence on intended condom use in certain circumstances (Cooper, Shapiro, \& Powers, 1998). Therefore, for both steady and casual sex partners, we examined the extent to which sexual motives for unprotected anal sex negatively affect intended condom use.

\section{Theory of Planned Behavior}

The Theory of Planned Behavior (TPB) (Ajzen, 1991) is one of the most important social psychological theories for predicting and understanding behavior. The TPB posits that the most proximal determinant of whether or not a person performs a behavior is his intention to do so. According to the theory, behavioral intention is determined by attitude, subjective norm, and perceived behavioral control. Attitude is the person's overall evaluation of the advantages and disadvantages of a particular behavior whereas subjective norms are determined by the perceived social pressure to perform the behavior. Perceived behavioral control is the person's conviction about whether or not the required skills and resources to perform the behavior are at his disposal and is closely related to Bandura's (1986) concept of self-efficacy. The TPB has received significant support from research on the adoption of many health-related behaviors (Godin \& Kok, 1996), including safer sex behavior (Albarracín, Fishbein, 
Johnson, \& Muellerleile, 2001; Rye, Fisher, \& Fisher, 2001; Sheeran, Abraham, \& Orbell, 1999).

Essentially, the TPB stresses the importance of cognitive, information processing mechanisms in explaining behavior. However, not every act of safer sex is necessarily the result of deliberate thought processes. Of particular interest are the growing number of studies that suggest that HIV-positive MSM are motivated by concerns about the effect that their sexual behavior may have on others; that is, that they feel personally responsible for protecting their partners from HIV. Although we agree that the TPB provides a valuable framework for predicting safer sex practices, we argue that this perspective is too narrow and may not fully account for feelings of personal responsibility that may promote safer sexual behavior. More specifically, we believe that safer sexual behavior in HIV-positive MSM is based on concerns that go beyond a purely rational weighing of personal advantages and disadvantages, i.e., that safer sex is simply the right thing to do. One theory that may help explain why HIV-positive MSM are motivated to adopt safer sexual practices for the protection of others is Schwartz' (1977) norm-activation theory.

\section{Norm-activation theory}

The norm-activation theory (Schwartz, 1977; Schwartz \& Howard, 1981, 1982) seeks to predict and understand prosocial or altruistic behavior. According to norm-activation theory, personal norms are the immediate determinant of behavior. Personal norms are considered as strong intrinsic motivators, as they trigger an individual's internal value system and are tied to one's self-concept. In the case of sexual behavior, these aspects reflect the feeling of moral obligation to practice safer sex because of concern about the welfare of sex partners. That personal norms may play an important role in safer sexual behavior in HIV-positive MSM was shown in a study by Godin, Savard, Kok, Fortin, and Boyer (1996). Their study showed that personal norms, in addition to perceived behavioral control, are important predictors of intended condom use for anal sex.

The important relationship between personal norms and condom use intention underscores the assumption that safer sexual behavior is influenced by feelings of moral obligation. However, Schwartz argued that there will be no moral motivation unless: (1) an individual is aware of the specific action that is needed and the consequences of action or inaction to oneself and others (awareness of need); (2) an individual ascribes responsibility to himself for the consequences of the action or inaction (ascription of responsibility); (3) a person identifies actions that might be effective in handling the specific situation (efficacy); and (4) a person believes that he is capable of performing the required actions or behavior (ability). As such, we expect that, in predicting safer sex, awareness of need and ascription of responsibility may be important determinants of behavioral intention to use condoms for anal sex with steady and casual sex partners. Note that in this context, efficacy and ability are not 
differentiated because both concepts seem to be covered by the theoretical paradigm of the TPB (i.e., attitude and self-efficacy, respectively).

\section{Sexual motives for unprotected anal sex}

Notwithstanding our argument that personal norms play a central role in sexual decision-making, we expect that, depending on the social context in which sex occurs, strong motives to engage in unprotected sex may conflict with one's personal norm for safer sex. For instance, Cooper et al. (1998) have demonstrated that sexual behaviors, whether risky or safe, may serve a range of psychological functions that have little to do with health protection and disease avoidance. Indeed, the study by Van Kesteren et al. (2005) indicated that the extent to which HIV-positive MSM acted in accordance with their feelings of personal responsibility to practice safer sex depended, in part, on their sexual motives for engaging in unprotected anal sex. Typically, HIV-positive MSM reported having engaged in unprotected anal sex to express emotions related to love or because they were "sexually turned-on" by their sex partners. Thus, sexual motives appear to have a negative influence on intended condom use, which may undermine a prosocial motivation to practice safer sex. However, it can be argued that a conflict such as this may play a role more in casual sex encounters than in steady sexual relationships, as it is likely that the benefits of unprotected sex are more salient in the context of casual sex (i.e., when one does not necessarily know one's sex partner and is less likely to be confronted with the potential adverse longer term social consequences of having engaged in unprotected sex) than with steady partners (i.e., when one is emotionally involved with a partner and committed to an ongoing relationship) (Flowers, Marriott, \& Hart, 2000; Van Kesteren et al., 2005). It has been shown that when people perceive increased benefits of a specific behavior (unsafe sex), it leads to a more favorable affective impression, resulting in lower judgments of risk (so-called affect-heuristic; Finucane, Alhakami, Slovic, \& Johnson, 2000). Therefore, we expect that sexual motives may have a negative impact on intended condom use, particularly in casual sex encounters.

\section{Proposed model of sexual decision-making}

Safer sex in HIV-positive MSM can be seen as a prosocial behavior, making it vital to integrate variables specific to the TPB with variables specific to the norm-activation theory. In accordance with the TPB, we propose a model (see Fig. 1) in which intention is the most proximal determinant of behavior. However, in line with the norm-activation theory, we assume that the decision to use condoms for anal sex largely depends on one's intrinsic motivation to engage in safer sex. Accordingly, we expect personal norms to be the most direct determinant of intention, thereby mediating the effects of the other determinants specific to the TPB and the norm- 
activation theory. Following Cooper et al. (1998), we further assume that sexual motives for unprotected anal sex may have a direct and negative impact on intended condom use and, as such, may compete with a prosocial tendency to engage in safer sex. However, due to the social context in which sex occurs, we hypothesize that sexual motives will contribute to the explanation of intended condom use with casual sex partners, whereas this is unlikely to be the case in the context of steady sex partners.

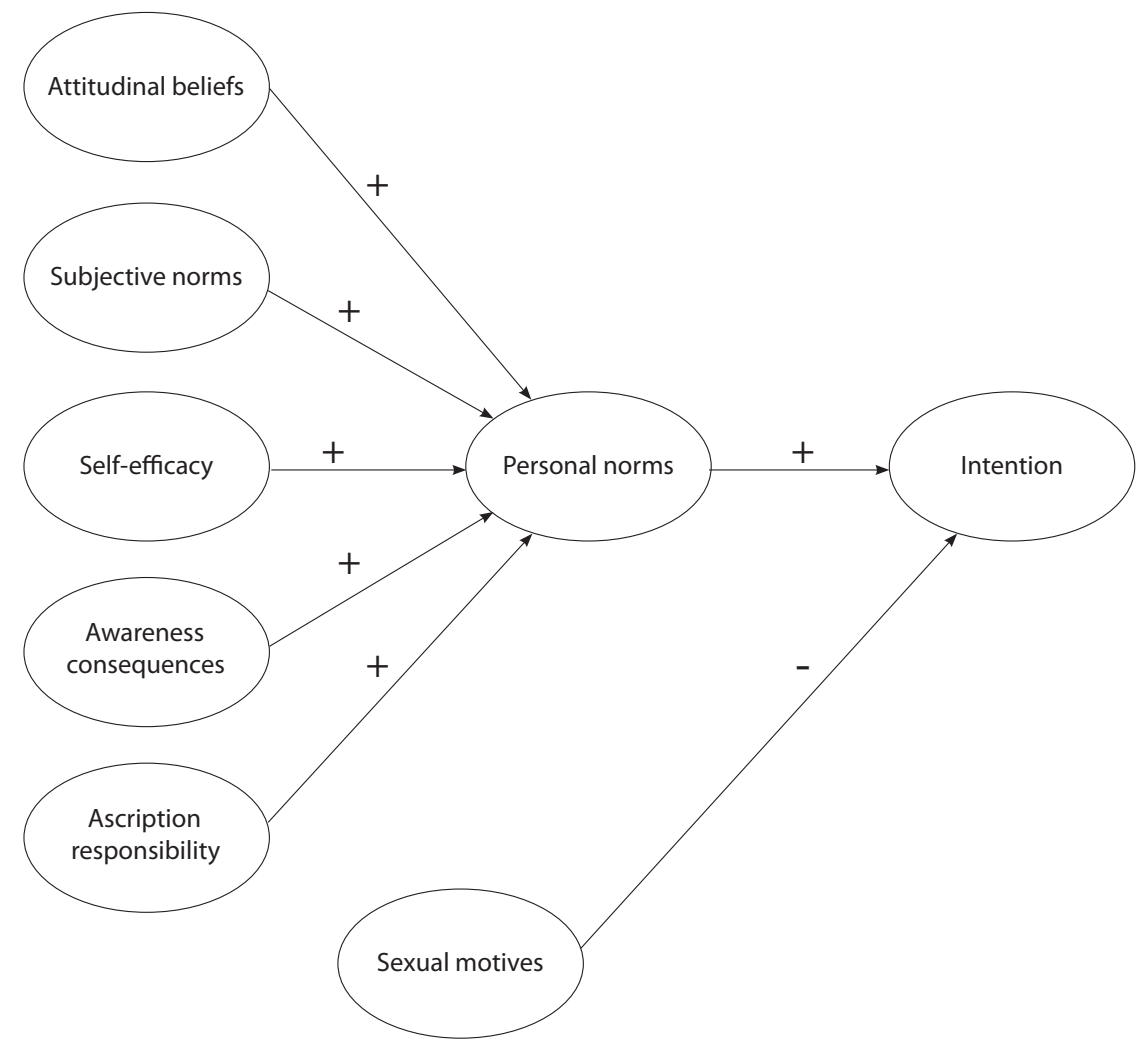

Figure 1. Proposed model of sexual decision-making

\section{METHOD}

\section{Participants}

Data was obtained by means of a self-administered questionnaire between July 2002 and April 2003. Participants were recruited through AIDS consultants working in 15 Dutch hospitals. Participants were asked to fill out the questionnaire at home and return the questionnaires directly to the research institution by means of a stamped, pre-addressed envelope. Consequently, no information was available about the response rate per hospital. Participation was on a voluntary and anonymous basis. 
A pilot study indicated that completion of the questionnaire took about 30 to 45 minutes. Participants received no compensation for filling out the questionnaires. Approval for the study was obtained from the Ethics Committee of Maastricht University Hospital.

Participants who met the following criteria were included in the study: (1) tested positive for HIV antibodies; (2) identified themselves as homosexual or bisexual; (3) aged between 20 and 65 years; and (4) were sufficiently fluent in Dutch to complete the questionnaire. A total of 1,050 questionnaires were distributed, of which 296 were completed and returned (response rate $=28.2 \%$ ).

Table 1 summarizes the demographic characteristics of the participants. Participants were predominantly Dutch nationals, were mainly from the Western part of the Netherlands, including Amsterdam, and ranged in age from 25 to 59 years, with a mean age of 42.1 years. Most participants had a medium or high level of education and were employed full-time or part-time. Most participants identified themselves as exclusively homosexual. More than half of the men had known themselves to be HIV-positive for 6 years or less. The majority of men was aware of their CD4 counts and viral load and indicated that they were currently on some form of HIV antiretroviral therapy.

\section{Measures}

The questionnaire was based on earlier studies (Hogeweg \& Hospers, 2000; Van Kesteren et al., 2005) and consisted of several questions on determinants for explaining condom use behavior: attitudinal beliefs, subjective norms, self-efficacy, personal norms, awareness of consequences, ascription of responsibility, sexual motives, intention and demographic variables. Separate scales were used for condom use with steady and casual sex partners for all determinants. The questionnaire was pre-tested among a group of $12 \mathrm{HIV}$-positive MSM for comprehension and completeness.

Attitudinal beliefs were measured through 16 items drawn from interviews with HIV-positive MSM (Van Kesteren et al., 2005) and from an earlier quantitative study among MSM (Hogeweg \& Hospers, 2000). Four items were used to assess response efficacy (e.g., "By using condoms when having anal intercourse, I protect my steady partner/casual sex partners against the AIDS virus/HIV superinfection"). In addition, seven possible pros (e.g., "By using condoms during anal sex with my steady partner/ casual sex partners, I worry less about his/their well-being"), and five possible cons of condom use behavior (e.g., "Using condoms for anal sex with my steady partner/ casual sex partners reminds me of HIV/AIDS") were included in the questionnaire. Items were indexed on 5-point scales ( 1 = totally disagree, $5=$ totally agree), and had an alpha of .81 for steady and .76 for casual sex partners.

Subjective norms were measured through the use of three items on 5-point scales. Two items assessed the perception of participants of the opinions of other important 
Table 1. Socio-demographic characteristics of the sample (maximum $N=296$ ).

\begin{tabular}{|c|c|c|}
\hline Characteristics & $N$ & $\%$ \\
\hline \multicolumn{3}{|l|}{ Nationality } \\
\hline Dutch & 251 & 85.7 \\
\hline Surinam/Antillean & 5 & 1.7 \\
\hline Other & 37 & 12.6 \\
\hline \multicolumn{3}{|l|}{ Geographic area of the Netherlands } \\
\hline Amsterdam & 73 & 25.3 \\
\hline West (excluding Amsterdam) & 110 & 38.0 \\
\hline South & 67 & 23.2 \\
\hline Northeast & 39 & 13.5 \\
\hline \multicolumn{3}{|l|}{ Age } \\
\hline $25-35$ & 55 & 18.9 \\
\hline $36-45$ & 136 & 46.7 \\
\hline $46-55$ & 82 & 28.2 \\
\hline$>56$ & 18 & 6.2 \\
\hline \multicolumn{3}{|l|}{ Education } \\
\hline higher vocational education or university & 124 & 43.1 \\
\hline secondary vocational training or high school & 120 & 41.7 \\
\hline primary school or basic vocational training & 34 & 11.8 \\
\hline other & 10 & 3.5 \\
\hline \multicolumn{3}{|l|}{ Employment status } \\
\hline full-time & 117 & 43.5 \\
\hline part-time & 80 & 29.7 \\
\hline unemployed & 72 & 26.8 \\
\hline \multicolumn{3}{|l|}{ Self-identification } \\
\hline homosexual & 244 & 82.4 \\
\hline more homosexual than heterosexual & 38 & 12.8 \\
\hline bisexual & 8 & 2.7 \\
\hline more heterosexual than bisexual & 4 & 1.4 \\
\hline other & 2 & 0.7 \\
\hline \multicolumn{3}{|l|}{ Years knowing HIV-positive status } \\
\hline$<2$ yrs & 59 & 20.1 \\
\hline $2-6$ yrs & 116 & 39.6 \\
\hline $7-11 \mathrm{yrs}$ & 71 & 24.2 \\
\hline $12-16$ yrs & 37 & 12.6 \\
\hline$>16$ yrs & 10 & 3.4 \\
\hline \multicolumn{3}{|l|}{ Self-reported CD4+ } \\
\hline$<200$ & 33 & 11.1 \\
\hline $200-500$ & 120 & 40.5 \\
\hline$>500$ & 92 & 31.1 \\
\hline don't know & 51 & 17.2 \\
\hline \multicolumn{3}{|l|}{ Self-reported viral load } \\
\hline detectable [median $=10.000$, range $50-2.080 .000$ ] & 72 & 25.9 \\
\hline undetectable & 176 & 63.3 \\
\hline don't know & 30 & 10.8 \\
\hline \multicolumn{3}{|l|}{ Antiviral treatment } \\
\hline no & 59 & 20.1 \\
\hline yes & 234 & 79.9 \\
\hline
\end{tabular}


people on whether or not they should use condoms when having anal intercourse ( 1 = certainly not, 5 = certainly). Following Schwartz (1973), one item assessed perceived social sanctions regarding not using condoms during anal intercourse and was expressed as follows: "How do you think important others would react if you told them that you don't use condoms when having anal intercourse with your steady partner/casual sex partners?" ( 1 = very approving, 5 = very disapproving). Alpha for steady and casual sex partners was .76 and .63 , respectively.

Self-efficacy was measured with seven items based on Van Kesteren et al. (2005) and Hogeweg \& Hospers (2000) (e.g., "Suppose you want to use condoms when having anal intercourse, will you be able to discuss condom use with your steady partner/casual sex partners?"). Items were measured on 5-point scales ( 1 = certainly not, 5 = certainly), and had an alpha of .89 for steady and .87 for casual sex partners.

Personal norms were measured by means of three items on 5-point scales (Godin et al., 1996; Parker, West, Stradling, \& Manstead, 1995), such as: "As a matter of principle, I use condoms every time I have anal intercourse with my steady partner/ casual sex partners." Items were rated on 5-point scales ( 1 = totally disagree, 5 = totally agree) and had an alpha of .96 and .90 for steady and casual sex partners, respectively.

Both awareness of consequences for self and awareness of consequences for others were assessed separately for condom use with steady and casual sex partners by a single item on a 5-point ( 1 = totally agree, 5 = totally disagree) scale. Awareness of consequences for self measured the participant's view about whether the consequences for his health were negligible when not using condoms during anal sex. Awareness of consequences for others measured the participant's views about whether the consequences for the health of his partner were negligible when not using condoms during anal sex.

Ascription of responsibility to self was measured by means of four items on 5-point scales concerning responsibility for condom use behavior and one item concerning transmission of HIV. For example: "How responsible are you yourself for negotiating condom use?" ( 1 = not at all, 5 = completely). Alpha for steady and casual sex partners was .91 and .89 , respectively.

Sexual motives for unprotected anal sex were measured using seven affective states on 7-point scales ( 1 = considerably less, 7 = considerably more), such as lust, love, excitement, and feeling good. Following Nelissen, Dijker, and De Vries (in press), participants were asked to indicate the extent to which they would feel a particular emotion when engaging in unprotected anal sex with steady $($ alpha $=.89)$ and casual sex partners (alpha $=.85)$.

Intention to use condoms when having anal intercourse was measured by the following three items on 5-point scales: "I intend to use a condom when having anal intercourse with my steady partner/casual sex partners"; "I will try to use a condom when ..."; and "I plan to use a condom when ..." (1 = certainly not, 5 = certainly). Alpha for both steady and casual sex partners was .93. 
With respect to sexual risk behavior, participants were asked whether or not they had engaged in receptive and insertive oral sex with ejaculation and in receptive and insertive anal sex in the past six months (separate for steady and casual sex partners). For each sexual behavior they had engaged in, the frequency of condom use ( 1 = never, 5 = always) was assessed.

\section{RESULTS}

\section{Sexual behavior}

Table 2 shows that about $60 \%$ of the participants reported a male steady partner in the preceding six months. Among these, about one third (30.3\%) reported that they had not had oral or anal sex with their steady sex partner. Among those who had had oral sex with ejaculation with their steady partners (23.6\%), only one person reported that he consistently had used a condom. Among those who had had anal sex with their steady sex partners (51.1\%), about half (48.4\%) reported that they had not used condoms consistently. Approximately $72 \%$ of the participants reported male casual sex partners in the preceding six months. When oral intercourse was considered, none of the men who had engaged in oral sex with ejaculation (31.8\%) reported consistent condom use. When anal sex was considered, about half (45.6\%) of the participants who had engaged in anal intercourse with casual sex partners $(74.8 \%)$ had not consistently used condoms.

Table 2. Descriptives of sexual behavior and disclosure in casual sex encounters of the sample HIV-positive MSM $(N=296)$.

\begin{tabular}{lrr}
\hline & $N$ & $\%$ \\
\hline Steady partner(s) in the preceding 6 months & 178 & 60.1 \\
Anal or oral sex with steady sex partner & $124(178)$ & 69.7 \\
Oral intercourse with ejaculation with steady sex partner & $42(178)$ & 23.6 \\
$\quad$ Unprotected oral intercourse with steady sex partner & $41(42)$ & 97.6 \\
Anal intercourse with steady sex partner & $91(178)$ & 51.1 \\
$\quad$ Unprotected anal intercourse with steady sex partner & $44(91)$ & 48.4 \\
& & \\
& 214 & 72.3 \\
Casual partner(s) in the preceding 6 months & $167(214)$ & 78.0 \\
Anal or oral sex with casual sex partners & $68(214)$ & 31.8 \\
Oral intercourse with ejaculation with casual sex partners & $68(68)$ & 100.0 \\
$\quad$ Unprotected oral intercourse with casual sex partners & $160(214)$ & 74.8 \\
Anal intercourse with casual sex partners & $73(160)$ & 45.6 \\
$\quad$ Unprotected anal intercourse with casual sex partners & & \\
Disclosure of HIV status in casual sex encounters & $177(214)$ & 82.8 \\
Has never/rarely informed casual sex partners about HIV- & & \\
positive status & $189(214)$ & 88.3 \\
Was never/rarely informed about HIV status of casual sex & & \\
partners & &
\end{tabular}


Among men who had anal sex with their steady sex partner, unprotected sex occurred more often within the context of HIV seroconcordant relationships than within HIV serodiscordant relationships: 23.3\% (7 out of 30) of the men with an HIV-positive partner reported consistent condom use in the preceding six months compared to $61.0 \%$ (25 out of 41 ) of the men with an HIV-negative partner and $73.7 \%$ (14 out of 19) of the men with a partner whose HIV status was unknown, $\chi^{2}(2)=14.7$, $p<.01$.

Although no data were available on the HIV status of casual sex partners, participants were asked two questions regarding disclosure of HIV status. The majority of the participants $(82.8 \%$ ) reported that they never or rarely had informed casual sex partners about their HIV status in the preceding six months. Similarly, most participants (88.3\%) reported that casual sex partners had never or rarely informed them of their HIV status (see Table 2). Thus, accurate knowledge of each others HIV status appears to be minimal, which makes the use of effective partner selection strategies (i.e., "serosorting") as an explanation for the occurrence of unprotected sex within casual sex encounters less likely.

\section{Descriptive statistics and correlations}

Means, SD, and correlations for the determinants of condom use for anal sex are provided in Table 3. A missing value analysis was conducted for independent variables relating to condom use with steady and casual sex partners. Participants with missing values exceeding $10 \%$ of all items were excluded from further data analyses. For participants with less than $10 \%$ missing values, the item score was replaced with the mean of the remaining participants for the respective item. As a result, analyses of intention to use condoms were conducted among 149 out of 178 participants who reported a steady sex partner and 188 out of 214 participants who reported casual sex partners in the preceding six months. Of the participants who were included in the analyses with steady and casual sex partners, there were 22 and 24 , respectively, who had one or more missing items (range 1-4). In both samples, however, the majority was missing only one of the questionnaire items.

The descriptive statistics indicates that, in general, participants' intentions to use condoms during anal sex with steady and casual sex partners were high. In addition, the means of most of the other determinants were on the positive side of the scale. The exception was for sexual motives for unprotected anal sex, where participants scored negative with regard to both steady and casual sex partners. Consistent with our proposed model (see Fig. 1), attitudinal beliefs, subjective norms, self-efficacy, personal norms, awareness of consequences for self and others, and ascription of responsibility to self were all positively correlated with behavioral intention, with the exception of sexual motives for unprotected anal sex. As expected, the correlation between sexual motives for unprotected anal sex and intended condom use was negative for both steady and casual sex partners. 


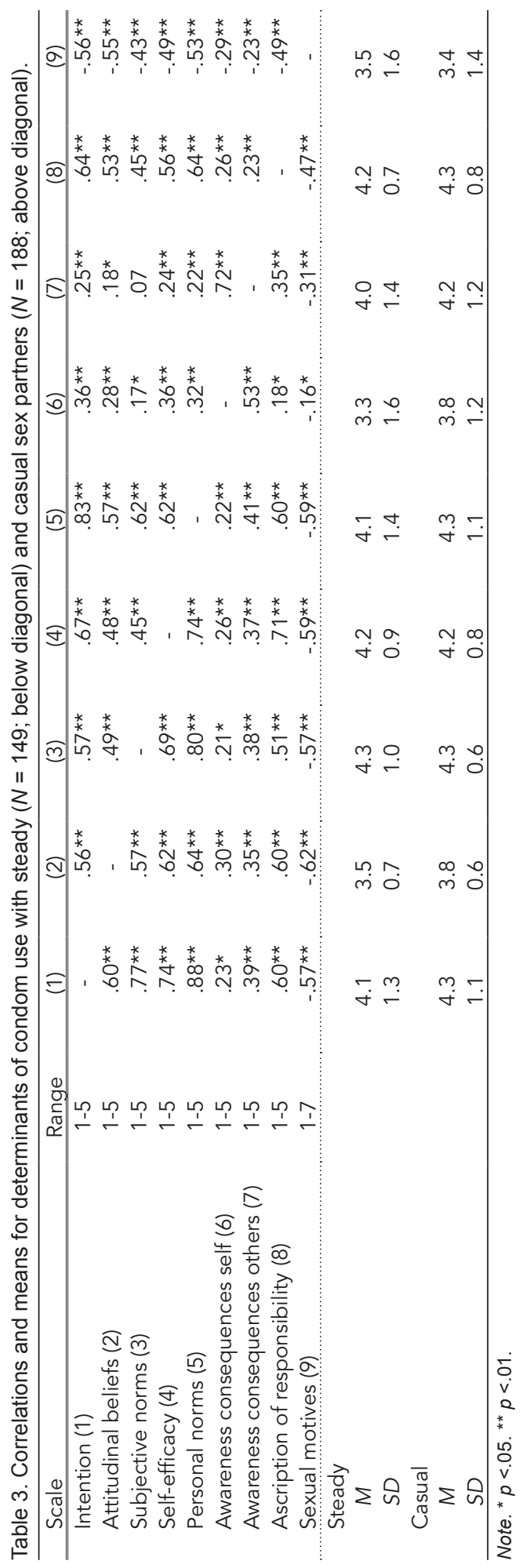

\section{Predictors of intended condom use}

Because intention for both steady and casual sex partners was positively skewed (more than $50 \%$ of the sample scored 5 on a 5 -point scale), intended condom use with steady and casual sex partners was dichotomized on its median into high versus low intention. To test our proposed model (see Fig. 1), two hierarchical logistic regression analyses were conducted with intended condom use with steady and casual sex partners as the outcome variables. Personal characteristics and partner variables were controlled in both analyses and were entered first. In order to examine the relative contribution of the TPB variables (i.e., attitudinal beliefs, subjective norms and self-efficacy), these variables were entered in the second step. Awareness of consequences for self and others and ascription of responsibility were entered in the third step, followed by sexual motives for unprotected anal sex in the fourth step. Personal norms were entered in the final step of the regression analyses. In addition, we examined the mediating role of personal norms following the standard procedure specified by Baron and Kenny (1986).

Prior to analyses, collinearity between all variables in the regression analyses was checked by computing the Variance Inflation Factor (VIF) of each variable. Values above 10 were regarded as an indication of near-collinearity (Kleinbaum, Kupper, Muller, \& Nizam, 1998). 
With respect to steady and casual sex partner variables, all VIFs were $<5$ and $<3$, respectively. Additionally, initial regression analyses were conducted to minimize the number of potential personal characteristics and partner variables used in the logistic regression. Only those personal characteristics and partner variables making significant contributions to prediction of intended condom use with steady or casual sex partners were included in subsequent analyses.

\section{Steady sex partners}

First, a regression of intended condom use with steady sex partners on personal characteristics (age, education, antiviral treatment, and years knowing HIVpositive status) and partner variables (steady partner only versus casual partners as well and HIV-negative or unknown status partner versus HIV-positive status) showed education level and partner HIV status to be the only significant predictors. Therefore, these variables were entered in the first step of the subsequent regression analysis, yielding an explained variance of $13 \%$ (see Table 4 ). When the TPB variables were entered in the second step, a further $40 \%(p<.001)$ of variance was explained, with self-efficacy as a significant predictor. Subjective norms were borderline significant $(p=.05)$. As shown in Table 4 , there was no significant increase in variance explained with the addition of awareness of consequences for self and others and ascription of responsibility in Step 3, or with sexual motives for unprotected anal sex in Step 4. At this stage of the analysis, self-efficacy significantly contributed to the prediction of intention, whereas a marginally significant effect was found for subjective norms $(p<.10)$. When personal norms were entered in the final step of the analysis, a further $9 \%(p<.001)$ of variance was explained. In this model, the effect of personal norms was significant; however, the effects of subjective norms and selfefficacy dropped below significance, which suggested that the effects of subjective norms and self-efficacy were mediated through personal norms.

Testing this suggestion required that three conditions be met (see Baron \& Kenny, 1986). The first condition-that subjective norms and self-efficacy be related to intended condom use-was assessed in the above analysis (see Step 4, Table 4). The second condition requires that the mediator (i.e., personal norms) predict intended condom use and that subjective norms and self-efficacy have weaker effects when controlling for personal norms. This was also confirmed in the above analysis (see Step 5, Table 4). The third condition requires that subjective norms and self-efficacy significantly predict the mediator. To test this condition, personal norms were regressed on subjective norms and self-efficacy, while controlling for educational level and partner HIV status. Results revealed that subjective norms (OR = 4.6, $p<$ $.001)$ and self-efficacy $(\mathrm{OR}=16.3, p<.001)$ were significantly related to personal norms. Thus, there was evidence that personal norms mediated the effects of self-efficacy on intended condom use. In addition, there was evidence that personal norms mediated the tentative influence of subjective norms. 


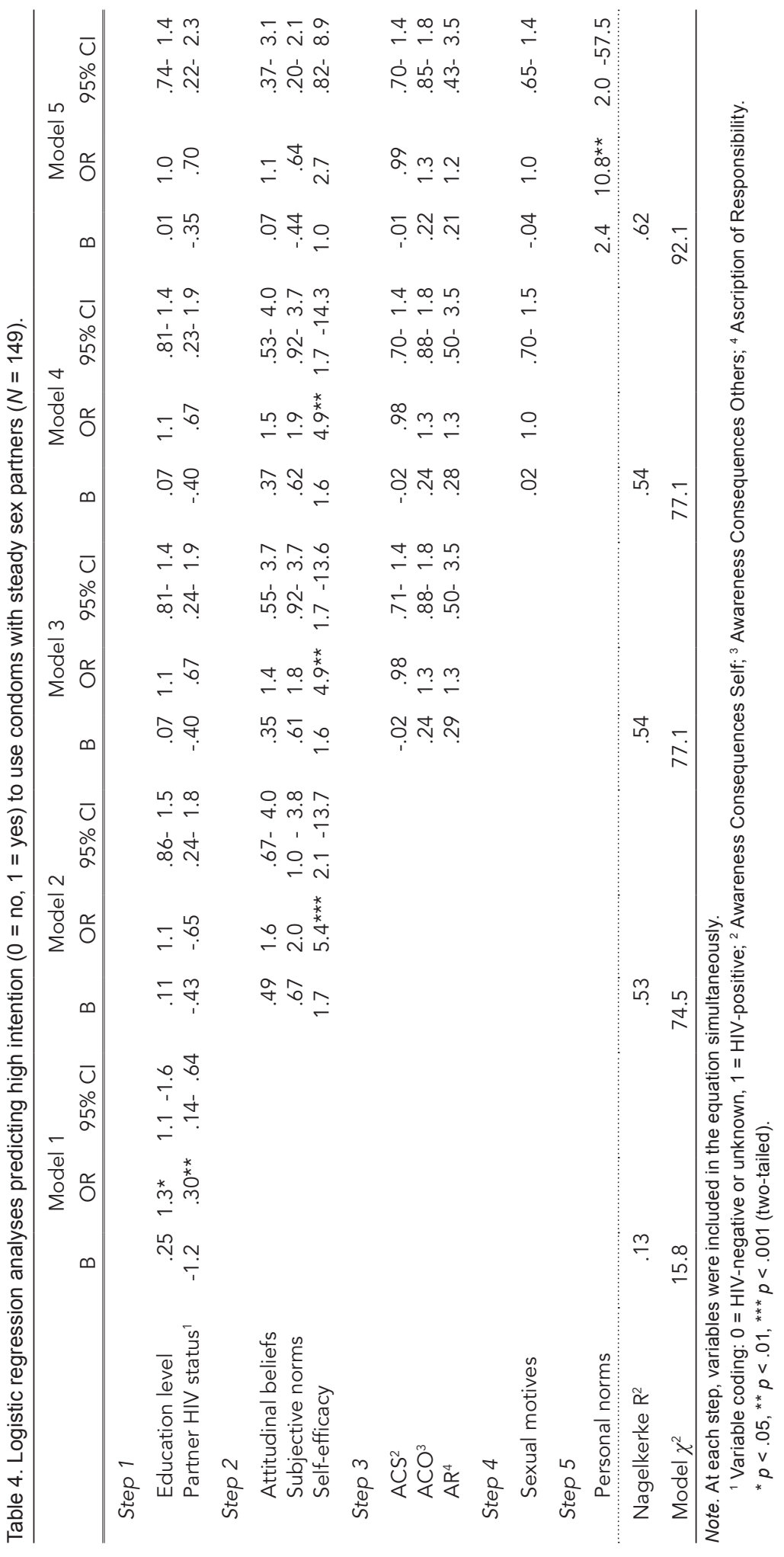




\section{Casual sex partners}

Initially, a regression of condom use intention with casual sex partners on personal characteristics (age, education, antiviral treatment, and years knowing HIVpositive status) and partner variables (casual partners only versus steady partners as well) showed antiviral therapy to be the only statistically significant predictor. Therefore, only this variable was subsequently entered in Step 1 of the logistic regression analysis, yielding an explained variance of 6\% (see Table 5). When the TPB variables were entered in the second step, a further $46 \%(p<.001)$ of the variance was explained. Attitudinal beliefs, subjective norms and self-efficacy significantly predicted intention, whereas a marginally significant effect was found for antiviral therapy. The entry of awareness of consequences for self and others and ascription of responsibility in Step 3 led to a further 8\% ( $p<.001)$ of explained variance. Step 4 also accounted for a significant increase of variance explained with 3\% ( $p<.01)$. In this step of the analysis, antiviral therapy, self-efficacy, ascription of responsibility and sexual motives significantly contributed to the prediction of intention, whereas a marginally significant effect was found for subjective norms ( $p<10)$. When personal norms were entered in the final step, a further $5 \%(p<.001)$ of variance was explained. As shown in Table 5, antiviral therapy and personal norms positively and sexual motives negatively predicted behavioral intention. Furthermore, the effects of subjective norms, self-efficacy and ascription of responsibility became nonsignificant, which suggested that these variables were mediated through personal norms.

To test this notion, we again assessed the three conditions specified by Baron and Kenny (1986). First, the analysis above revealed that self-efficacy and ascription of responsibility significantly predicted intended condom use, whereas a marginally significant effect was found for subjective norms (see Step 4, Table 5). Second, the above analysis showed that adding personal norms gave a significant regression coefficient for personal norms, and non-significant regression coefficients for subjective norms, self-efficacy, and ascription of responsibility (see Step 5, Table 5). Finally, in an analysis predicting personal norms while controlling for antiviral therapy, subjective norms $(\mathrm{OR}=2.7, p<.05)$, self-efficacy $(\mathrm{OR}=3.0, p<.01)$, and ascription of responsibility $(\mathrm{OR}=10.5, p<.001)$ emerged as significant predictors. Taken together, these results provided evidence that personal norms were a mediator of the self-efficacy-intention and ascription of responsibility-intention relationships. In addition, evidence was found that personal norms mediated the tentative influence of subjective norms. 


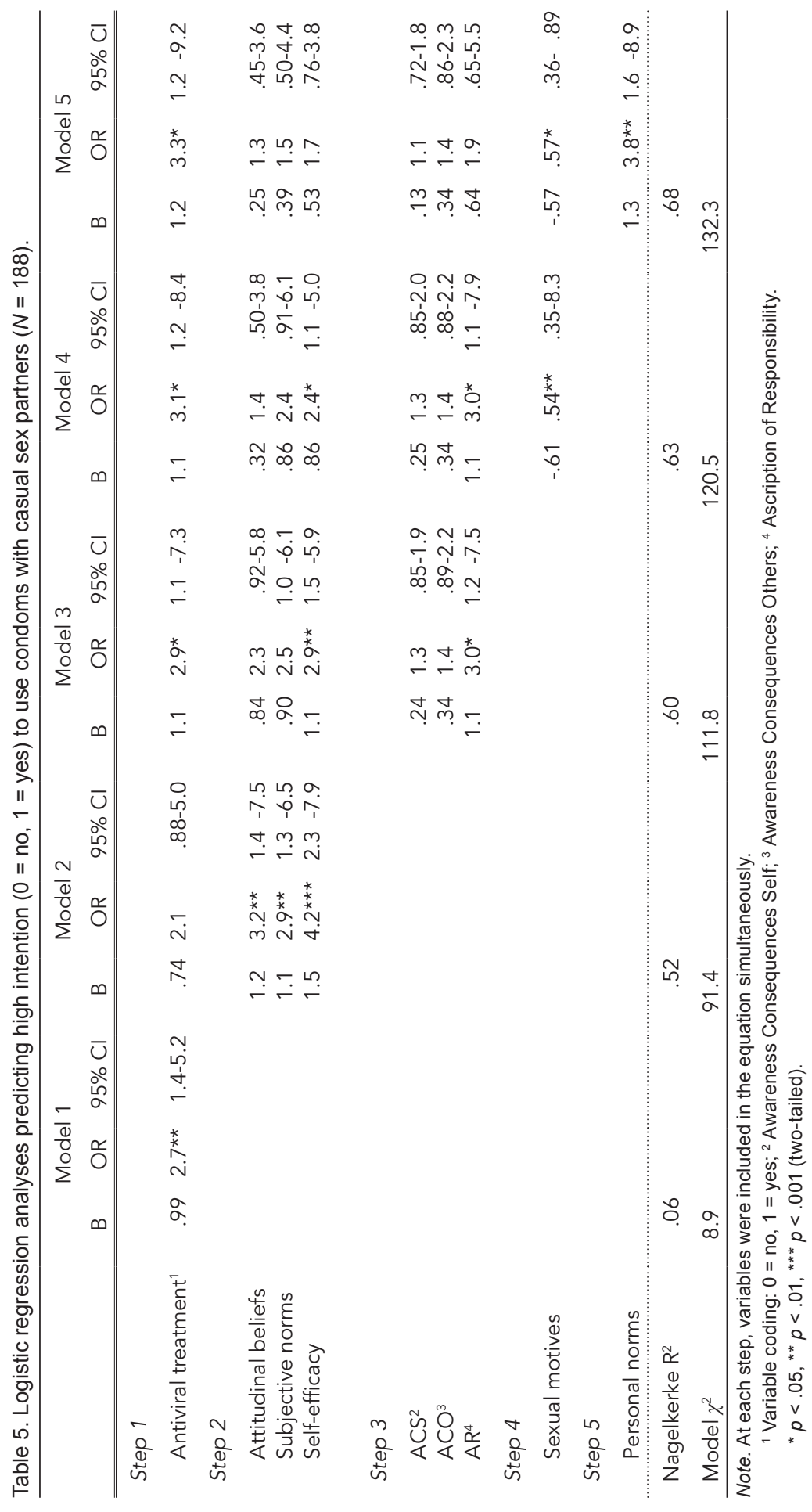




\section{DISCUSSION}

The present study showed that the majority of HIV-positive MSM reported engaging in safer sexual behavior either though abstinence or consistent condom use for anal sex. Nonetheless, a high number of men who had had anal sex reported that they had not used condoms consistently with steady and casual sex partners. Results further indicated that HIV-positive MSM were more likely to engage in unprotected anal intercourse in the context of casual sex encounters than in steady sexual relationships (overall $34.1 \%$ and $24.7 \%$, respectively). This finding was consistent with patterns of sexual risk behavior observed in other populations of HIV-positive MSM (cf. Crepaz \& Marks, 2002).

In this study, we tested a model of factors that influence intended condom use for anal sex with steady and casual sex partners. The results showed that, compared with the TPB (Ajzen, 1991), our proposed model of sexual decision-making led to a significant increase of explained variance from $53 \%$ to $62 \%$ for steady sex partners and from $52 \%$ to $68 \%$ for casual sex partners. Furthermore, evidence was obtained for the mediating role of personal norms on intended condom use with both steady and casual sex partners, suggesting that moral issues play an important role. However, the study also showed that sexual motives may undermine the influence of personal norms on intended condom use in the context of casual sex, with the likelihood of unprotected sexual intercourse. Taken together, the results revealed strong support for our model of sexual decision-making.

In this study, the finding that personal norms appeared to exert a strong direct effect on intention to use condoms with both steady and casual partners was consistent with results of earlier studies that suggest that safer sex in HIV-positive MSM is largely determined by moral concerns or feelings of personal responsibility (e.g., Godin et al., 1996). Moreover, this finding lends further indirect support to the proposition that condom use behavior among HIV-positive MSM is a form of prosocial behavior (King-Spooner, 1999; Kok, 1999; Nimmons, 1998). For steady partners, personal norms were identified as the most proximal determinant of intended condom use, whereas an indirect effect was found for self-efficacy on intended condom use through personal norms. Furthermore, some evidence that personal norms mediate the tentative effect of subjective norms on intended condom use with steady sex partners was found. Similar results were found for intended condom use with casual sex partners. However, we also found an additional indirect effect of ascription of responsibility on intended condom use through personal norms. These findings are important because they underscore the need to take into account the role of social expectations, self-efficacy expectations, and attributions about responsibility for condom use in promoting feelings of moral obligation-a process that has not been identified in previous research on sexual risk behavior in HIVpositive MSM. 
Furthermore, in the case of casual sex partners, condom use intention was not only directly related to personal norms, but was also negatively influenced by sexual motives for unprotected anal sex. Thus, the findings from this study suggest that the need to engage in unprotected anal sex for physical and emotional satisfaction may supercede the prosocial motivation for safer sex. The fact that sexual motives contributed toward explaining intended condom use in casual sex encounters but not in steady relationships does not imply that sexual motives are not important in the context of steady sex. More likely, there are some differences between steady and casual sex that encourage HIV-positive MSM to suppress sexual motives within the context of steady relationships but not within casual sex encounters. As discussed previously, a possible explanation may lie in the so-called affect-heuristic. In the context of casual sex, the benefits of unprotected sex may be more salient, thus resulting in a decreased assessment of risk. It is worth noting that the affect-heuristic is especially likely to color judgments under time pressure, which may play a more important role in the context of casual sex (Finucane et al., 2000). The "Coolidge effect" may also explain why sexual motives play a role in the casual sexual context, but not in steady sexual relationships. The Coolidge effect refers to enhanced sexual arousal that is felt when sexual stimuli and partners are novel (Gregoire, 1999). A final explanation may be the greater ambivalence that HIV-positive MSM experience in casual sex encounters as opposed to steady relationships. Greater ambivalence is likely to result in a reduction in both behavioral intention and actual behavior. In addition, people who experience ambivalence are more easily persuaded (Conner $\&$ Armitage, 1998). It may be that pointing out the potential for casual sex partners to become steady partners in the future could increase the perceived benefits of safer sex, thus facilitating prosocial motivation to engage in protected sex. Indeed, the study by Van Kesteren et al. (2005) suggests that such a mechanism exists. Further, the results of this study demonstrated that the use of antiviral therapy was associated with a greater intention to use condoms with casual sex partners. To date, inconclusive evidence exists regarding the association between the use of antiviral therapy and unprotected sex (for a meta-analysis, see Crepaz, Hart, \& Marks, 2004).

Some study considerations and limitations and implications for practice should be mentioned. First, as Ajzen and Fishbein (1970) held, it may be argued that the important role of personal norms as a predictor of intention can be attributed to a certain amount of overlap between the measures of personal norms and intention. In this study, high correlations were found between personal norms and intention. On theoretical grounds, however, it seems imperative to distinguish personal norms from intentions. As Manstead (2000) argued, holding the belief that something is morally "right" or "wrong" is not the same as the perceived likelihood of performing certain behaviors. Consequently, an individual may feel a personal obligation to act in a certain way, but intend to behave in a way that is contradictory to his personal norm because the personal or social advantages of acting inconsistently with his 
personal norm outweigh the personal or social advantages of acting consistently with the norm. Second, it should be noted that the data were cross-sectional, which hampers conclusions about causality. Due to the cross-sectional design we did not specifically address the relationship between the psychosocial factors and behavior. It should be noted, however, that tentative support for our model was found in an additional analyses when intention was examined as a mediator of the personal norms-behavior relationship, both for steady and casual sex partners. Yet, longitudinal studies are needed to determine causative relationships between the measured constructs. A third limitation of the present study concerns the use of a single-item approach to measure awareness of consequences, as single-item measures are known to be less reliable. This issue merits attention in future research. Finally, the sample used in this study warrants some concern. More than $70 \%$ of those who received questionnaires did not respond. This raises the question as to whether these participants were predominantly more aware of the need to practice safer sex and, as such, are not a representative sample of Dutch HIV-positive MSM. On the other hand, Swanborn (2002) found that 30\% is a common response rate for this type of research in the Netherlands. It is possible that the sensitivity of the subject and the fact that the participants suffer from a chronic disease may create barriers to participation. Moreover, substantial efforts were made to recruit HIV-positive MSM from throughout the Netherlands. Although this approach did not ensure that the sample was representative, it did enhance its diversity and therefore strengthens the external validity of the study results.

The findings reported in this study carry several implications for HIV prevention efforts to promote safer sexual behavior among HIV-positive MSM. When addressing condom use behavior with steady and casual sex partners, it seems particularly crucial to enhance feelings of moral obligation to use condoms for anal sex. Feelings of moral obligation could be addressed by inducing HIV-positive MSM to reflect on their own personal risk and personal standards for safer sex (Kalichman, 1998). The findings of this study further suggest that desirable changes in subjective norms and self-efficacy expectations might lead to corresponding changes in personal norms and intentions (e.g., Deci \& Ryan, 2000; Van Empelen, Kok, Jansen, \& Hoebe, 2001; Van Empelen, Schaalma, Kok, \& Jansen, 2001). Therefore, preventive interventions should focus on helping HIV-positive MSM to cope with an unsupportive social environment and to encourage them to build the skills and confidence required for communicating and negotiating condom use. For the promotion of condom use with casual sex partners, personal norms may be further increased by urging HIVpositive MSM to accept responsibility for safer sexual behavior. Moreover, especially within casual sex encounters, it is imperative to help HIV-positive MSM to deal with feelings that may conflict with the goal of safer sex. Possible methods that can help HIV-positive MSM to identify and control high risk situations are, for example, action planning and coping planning (Sniehotta, Schwarzer, Scholz, \&\& Schüz, 2005). 
Action plans and coping plans are detailed plans of what a person needs to do when a specific situation occurs. When such situation arise, it is likely to function as a cue for the execution of those precise plans of implementation. Additionally, stimulating HIV-positive MSM to imagine how they would feel if they were in their sex partners shoes (i.e., perspective taking) may evoke a mixture of egoistic and altruistic motivation and, as such, lead to more protected sex (Batson, Early, \& Salvarani, 1997). That such an approach is feasible has been shown in a study by Van Kesteren, Kok, Hospers, Schippers, and De Wildt (2006), in which the above-mentioned methods have been integrated in an intervention to promote sexual health in HIVpositive MSM. 


\section{CHAPTER 5}

\section{Systematic development of a self-help and motivational}

enhancement intervention to promote sexual health

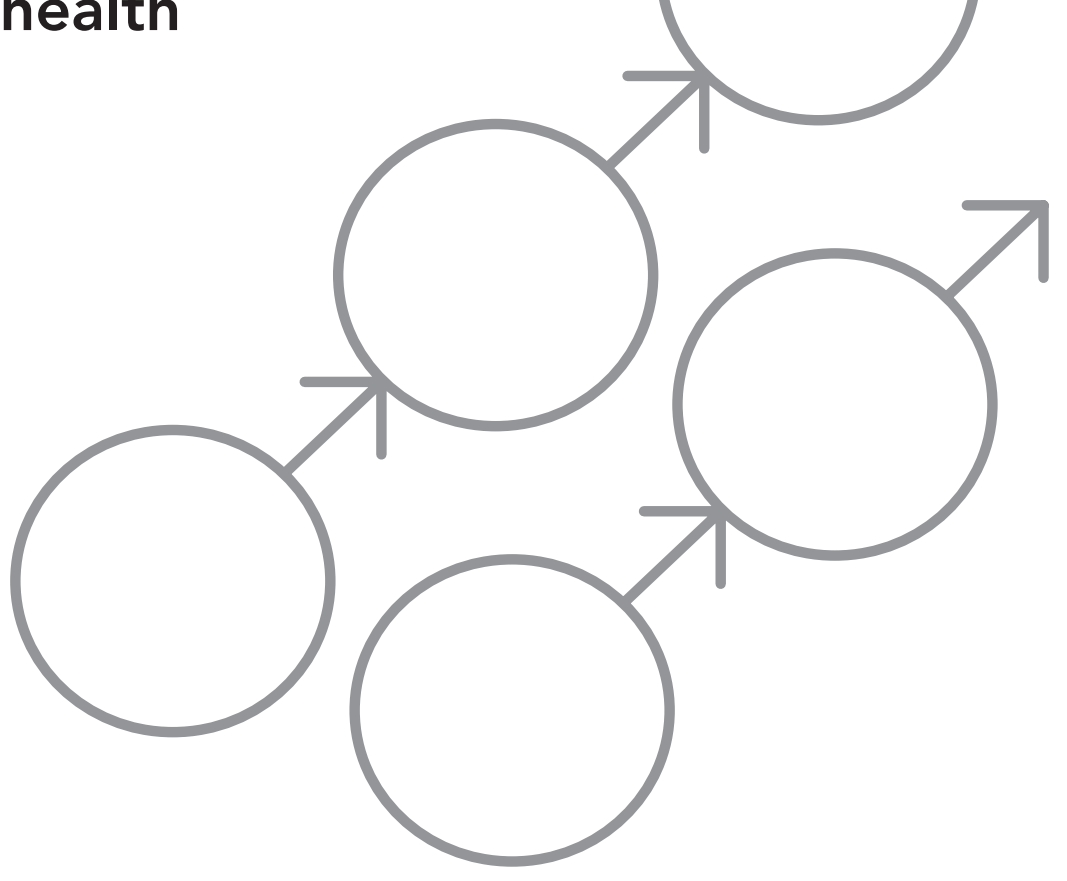




\section{INTRODUCTION}

Sexual risk behavior among HIV-positive men who have sex with men (MSM) is a serious problem, and may be more common than was previously believed. Across a wide range of studies of HIV-positive MSM, the prevalence of unprotected anal intercourse ranges from 6\% to 84\% (Van Kesteren, Hospers, \& Kok, 2007). HIVpositive MSM who engage in unprotected anal sex are at risk for acquiring sexually transmitted diseases (STDs) and HIV superinfection (Blackard, Cohen, \& Mayer, 2002; Jost et al., 2002), but can also pose clear risks to uninfected partners. Therefore, there is an urgent need for behavioral interventions that promote safer sex practices in HIV-positive MSM as a means of preventing further spread of HIV and STDs.

In most Western industrialized countries, MSM have been disproportionately affected by HIV since the beginning of the epidemic. In the Netherlands, more than 10,000 people have been diagnosed with HIV and, of these, about 53\% became infected via homosexual contact (Gras, Van Sighem, Zaheri, \& De Wolf, 2005). Moreover, the rate of HIV infection among MSM is rising. In the period 2000-2004, the estimated number of MSM newly diagnosed with HIV increased from 326 to 455 per year. The Dutch HIV Monitoring Foundation (Gras et al., 2005) reports that the majority $(74.1 \%)$ of these HIV-positive MSM are of Dutch origin; the median age at diagnosis is 38.8 years.

Traditionally, HIV prevention programs have targeted uninfected MSM to prevent them from becoming infected with HIV (Herbst et al., 2005; Kegeles \& $\leftarrow$ Hart, 1998; Kelly, 2000). Yet research suggests that adoption of protected sexual practices among people who are HIV-positive leads to a significant reduction in the number of HIV infections (King-Spooner, 1999). Despite the substantial gains in targeting sexual risk behavior in people with HIV, only a few interventions designed or adapted specifically for HIV-positive MSM have been identified, and even fewer have been evaluated for their efficacy (Coates, McKusick, Kuno, \& Stites, 1989; Rutledge et al., 2001).

The purpose of this paper is to describe the development of a program aimed at promoting satisfactory sexual functioning and safer sexual behavior in Dutch HIV-positive MSM, which was implemented by specialist nurses in HIV treatment centers. In designing our program we used the Intervention Mapping framework for systematically developing theory-and evidence-based health promotion programs (Bartholomew, Parcel, Kok, \& Gottlieb, 2001, 2006). A description of the process of intervention development offers insights into general principles and procedures in intervention design and can be used as an example for designing coherent health promotion interventions. In addition, a description of how our intervention was developed might assist prevention program planners to improve the lives of HIVpositive MSM. 


\section{Intervention Mapping}

Review studies on the effectiveness of HIV prevention programs have convincingly demonstrated that in order to be effective, HIV preventive interventions should be systematically planned, theory-and evidence-based, and appropriate to the targeted audience (Kalichman, Carey, \& Johnson, 1996; Van Empelen, Kok, Van Kesteren et al., 2003). A planning model currently used to guide the process of intervention development is Intervention Mapping (Bartholomew et al., 2000; Cullen, Bartholomew, Parcel, \& Kok, 1998; Heinen, Bartholomew, Wensing, Van de Kerkhof, $\&$ Van Achterberg, 2006; Tortolero et al., 2005; Van Empelen, Kok, Schaalma, \& Bartholomew, 2003). Intervention Mapping provides a framework that gives planners a systematic method for decision-making in each phase of intervention development (Bartholomew et al., 2001, 2006). In Intervention Mapping the process of intervention design can be divided into five steps: (1) preparing matrices of proximal program objectives; (2) selecting theory-based methods and practical strategies; (3) producing program components and materials; (4) planning for program adoption, implementation and sustainability; and (5) planning for evaluation. The steps of Intervention Mapping are followed in an iterative way. Each step, in turn, comprises several tasks. By completing the tasks in each step, a product is created that forms the foundation for the subsequent step. As such, the intervention map is the result of the completion of all tasks for each of the steps and can be seen as a blueprint for the planning, development, implementation and evaluation of an intervention program.

\section{Preliminary research}

Prior to beginning the Intervention Mapping process, qualitative (Van Kesteren, Hospers, Kok, \& Van Empelen, 2005) and quantitative (Van Kesteren, Hospers, Van Empelen, Van Breukelen, \& Kok, 2007) methods were used to gain further insight into the determinants of risky and safer sexual behavior in HIV-positive MSM. In brief, the qualitative study suggested that many HIV-positive MSM suffer from sexual problems after being diagnosed with HIV, including a temporary cessation of sexual activity and overall impairment in sexual function. In general, sexuality was dominated by fear of transmitting HIV to sex partners and feelings of personal responsibility for safer sex, especially within the context of steady relationships. One of the key contributions of this study was highlighting the discrepancy between feelings of personal responsibility and actual behavior. Although most participants felt personally responsible to protect their sex partners from HIV, contextual factors (e.g., partner variables and social norms) determined whether or not their perceived norms of personal responsibility were translated into behavior. Moreover, a substantial number of men appeared to lack the skills to effectively communicate their own health interests, negotiate condom use and resist pressure to engage in sexual risk behavior. The subsequent quantitative study generally confirmed the 
results of the qualitative study. Results showed that personal norms (i.e., feelings of personal responsibility) were the most important determinant of intended condom use with both steady and casual sex partners. It was also found that sexual motives (i.e., the need to engage in unprotected anal sex for physical or emotional satisfaction) negatively influenced intended condom use with casual sex partners but not with steady sex partners. Based on these preliminary studies, it was concluded that an HIV prevention program for HIV-positive MSM should not only enhance intrinsic motivation to use condoms for anal sex, but also teach HIV-positive MSM how to plan, initiate and maintain sexual behavior change.

\section{Intervention Mapping Step l: preparing matrices of proximal program objectives}

The first step in Intervention Mapping is specifying proximal program objectives. Proximal program objectives are the most immediate objectives that need to be achieved in order to accomplish the more general behavioral program outcomes. Five tasks underlie the specification of proximal program objectives. The first task is to state health-promoting behaviors by defining what the program intends to accomplish. This is followed by specifying the performance objectives or subbehaviors that we want to encourage the target group to 'do' as a result of the program and the important and changeable personal and external determinants of health-promoting behaviors. The fourth task is to differentiate the target population. Finally, the performance objectives were crossed with their determinants, resulting in matrices of proximal program objectives.

\section{Task 1.l Stating health-promoting behaviors}

Specifically, the goal of the program was to reduce unprotected anal sex among HIV-positive MSM. This was to be attained by promoting the consistent and correct use of condoms for anal sex with both steady and casual sex partners. Although the program did not ignore other sexual risk behaviors/sexual risk reduction strategies (e.g., oral sex, "sero-sorting," strategic positioning, withdrawal prior to ejaculation, and assessing viral load), focusing on the riskiest behavior practiced by HIV-positive MSM (i.e., unprotected anal sex) was considered essential in order to more effectively improve health and quality of life. In addition, the qualitative study showed that HIV and its treatment may have a disruptive impact on intimacy and sexuality and can inhibit the ability of HIV-positive MSM to resume satisfactory sexual function (Van Kesteren et al., 2005). Managing sexual problems, or even improving sexual function following a diagnosis of HIV, can be essential for the well-being of HIV-positive MSM and possibly for the adoption and maintenance of safer sexual behavior. Therefore, we also elected to focus on promoting satisfactory sexual functioning in HIV-positive MSM.

1 Following the national guidelines (Hospers \& Blom, 1998), protected oral sex was defined as oral sex with the use of a condom or without ejaculation in the mouth. 


\section{Task 1.2 Specifying performance objectives}

Theories on self-regulation are helpful in specifying performance objectives. These theories are particularly useful because they afford greater precision in understanding what people are doing or need to do to reach health goals (Aspinwall, 2001; Clark $\&$ Zimmerman, 1990; Kotses, Lewis, \& Creer, 1990; Thoresen \& Kirmil-Gray, 1983). Although there are diverse theoretical notions on self-regulation, it is generally believed that people self-regulate their health through three sub-processes: (a) self-observation; (b) self-judgment; and (c) self-reaction. Self-observation refers to explicit attempts to perceive one's own behavior. Self-judgment involves using criteria to assess the situation or problem. For example, comparisons can be made with a medical or HIV prevention standard, goals a person sets for himself or with the performance of others. Self-reaction is a response to self-judgment and selfobservation about one's own behavior and includes altering and maintaining one's ability to accomplish the task and giving oneself rewards or punishments (Clark $\&$ Zimmerman, 1990). Based on theories on self-regulation, specific performance objectives were formulated for satisfactory sexual functioning and safer sexual behavior (see Table 1).

Table 1. Performance objectives of HIV-positive MSM

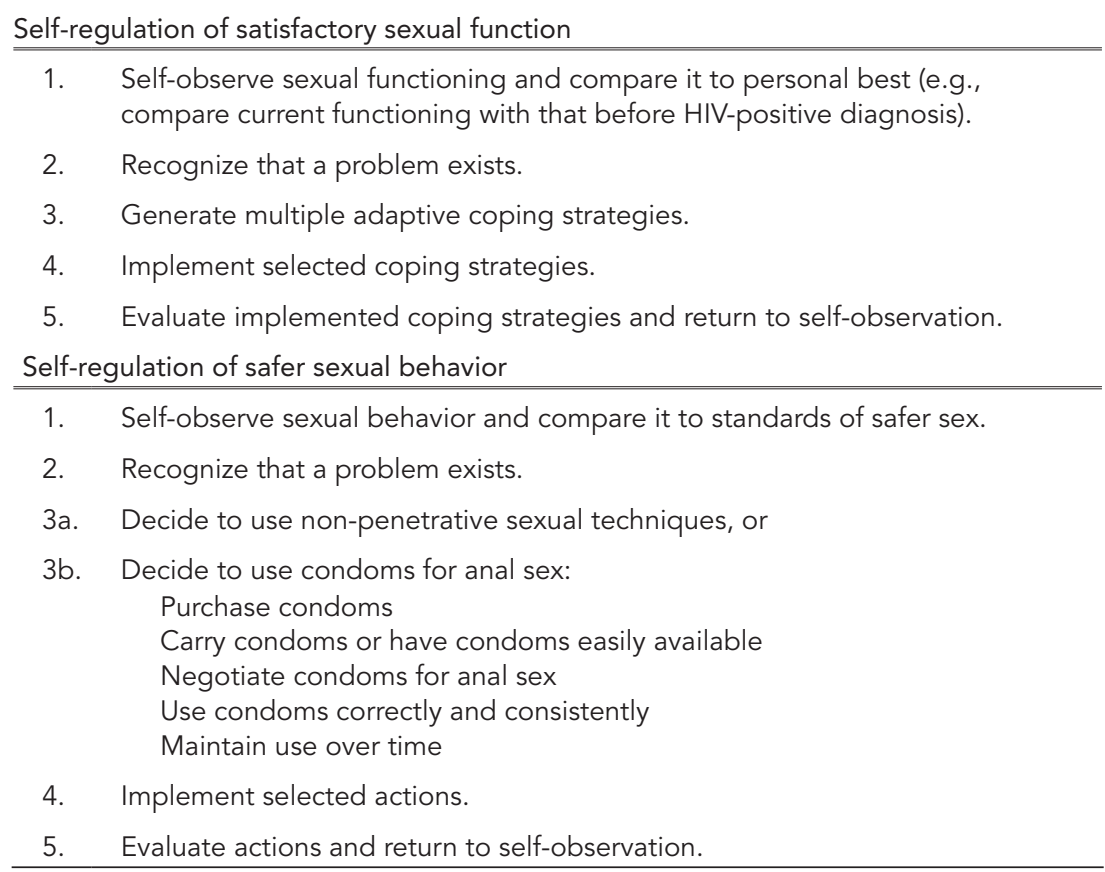




\section{Task 1.3 Selecting personal and external determinants}

Personal and external determinants of self-regulation of satisfactory sexual function and safer sexual behavior were identified based on our own studies of sexuality and safer sexual behavior in HIV-positive MSM, as well as on reviews of existing literature and studies of HIV-positive MSM (Crepaz \& Marks, 2002; Kok, 1999; Schiltz \& Sandfort, 2000) and applicable theories and methods (Clark $\&$ Zimmerman, 1990; Kotses et al., 1990; Thoresen \& Kirmil-Gray, 1983). Personal determinants are those factors that rest within individuals and are subject to their direct control, whereas external determinants are those factors outside the individual, which can directly influence their behavior (Bartholomew et al., 2001). The personal determinants for self-regulation of satisfactory sexual function that we considered were awareness (knowledge and susceptibility), attitudes and cognitions about sexuality, self-efficacy and skills. Social support by significant others and reinforcement by HIV nurses were identified as the most important external determinants. For self-regulation of safer sexual behavior, the personal determinants considered were awareness, attitudes, personal norms, subjective norms, self-efficacy, skills and sexual motives. Alcohol and drug use in itself may increase sexual risk behavior (Stall \& Purcell, 2000) and was addressed within the context of selfefficacy expectations and skills to use condoms. Considering the aim of our program (promotion of sexual health), it is important to note that the use of Viagra ${ }^{\mathrm{TM}}$ has been shown to be related to sexual risk-taking behavior in HIV-positive MSM (Cachay, Mar-Tang, \& Mathews, 2004; Swearingen \& Klausner, 2005). Therefore, attitudinal and behavioral norms for safer sex were reinforced regarding the use of these medications for the treatment of erectile dysfunction. The most important external determinants considered were social support of sex partners and reinforcement by HIV nurses.

\section{Task 1.4 Differentiate the target population}

In order to adapt the health-promotion program to the target group of HIV-positive MSM, it is necessary to consider whether the health-promoting behaviors or determinants of the health-promoting behaviors are different for subgroups of the population. If so, the development of specific programs for the various subgroups needs to be considered. First, we differentiated on ethnicity, and decided to focus the intervention on the Dutch population of HIV-positive MSM. A demographic description of HIV-positive MSM in the Netherlands revealed that this is the largest group of HIV-positive MSM (Gras et al., 2005). Moreover, when we began developing the program, there were few HIV prevention efforts targeting this population. We also had to decide which category of HIV-positive MSM we wanted to reach. In general, MSM is seen as a wider category that covers both self-identified gay men and other men who engage in same-sex activity but do not necessarily consider themselves "gay" or "bisexual." The international literature demonstrates 
that the social and contextual determinants of condom use differ between these subgroups (Brooks, Etzel, Hinojos, Henry, \& Perez, 2005), so we chose self-identified gay or bisexual men as the target population for our intervention.

\section{Task 1.5 Developing matrices of proximal program objectives}

Matrices of proximal program objectives were created by crossing the performance objectives with the determinants of health-promoting behaviors (see Table $2 \mathrm{a}$ and $2 b$ ). As a general rule, the performance objectives were entered in the left column of the matrix; the personal and external determinants were entered across the top of the matrix. Then, one or more learning or change objectives were defined for the cells that were formed at the intersection between performance objectives and determinants. Learning objectives were written for the personal determinants and answer the question: What do the participants in the program need to learn (related to the determinant) to accomplish the performance objective? For example, at the intersection between the performance objective self-observe sexual function and compare to personal best and the determinant awareness in Table 2a, answers to this question included that HIV-positive MSM should consider the meaning of sexuality and sexual function and the impact of HIV on their sexual lives. Change objectives are written for the external determinants and answer the question: What needs to change in the environment in order for the target group to accomplish the performance objective? For example, at the intersection between the performance objective decide to use condoms for anal sex and the determinant reinforcement in Table $2 \mathrm{~b}$, the answer to this question was that HIV nurses reinforce the importance of condom use for anal sex. The product of Intervention Mapping Step l was a detailed list of specific statements referring to individual- or environmental-level change. The matrices of proximal program objectives provided the foundation both for developing intervention components and planning the program evaluation.

\section{Intervention Mapping Step 2: selecting theory-based methods and practical strategies}

The second step in Intervention Mapping was the selection of theoretical methods and practical strategies. First, based on the matrices of proximal program objectives, we searched for theoretical change methods. In order to find theoretical methods, the learning and change objectives were ordered by determinants. Second, we translated these methods into practical strategies and then matched the strategies with the proximal program objectives to ensure full coverage of the most important program objectives. 
Table 2a. Proximal program objectives matrix (selected) - Self-regulation of satisfactory sexual function

\begin{tabular}{|c|c|c|c|c|c|}
\hline \multirow[b]{2}{*}{$\begin{array}{l}\text { Performance } \\
\text { Objective }\end{array}$} & \multicolumn{3}{|c|}{ Individual determinants } & \multicolumn{2}{|c|}{ External determinants } \\
\hline & $\begin{array}{c}\text { Awareness } \\
\text { (Knowledge and } \\
\text { susceptibility) }\end{array}$ & $\begin{array}{l}\text { Attitudes and } \\
\text { cognitions about } \\
\text { sexuality }\end{array}$ & $\begin{array}{l}\text { Self-efficacy/ } \\
\text { skills }\end{array}$ & $\begin{array}{c}\text { Support from } \\
\text { significant others }\end{array}$ & $\begin{array}{c}\text { Reinforcement by } \\
\text { HIV nurses }\end{array}$ \\
\hline $\begin{array}{l}\text { 1.HIV+ MSM } \\
\text { self-observe } \\
\text { sexual function } \\
\text { and compare to } \\
\text { personal best. }\end{array}$ & $\begin{array}{l}\text { A1.1 Describe what } \\
\text { is meant by sexuality } \\
\text { and sexual function. } \\
\text { A1.2 Describe how } \\
\text { HIV and its treatment } \\
\text { may affect sexuality. } \\
\text { A1.3 Relate sexual } \\
\text { problems to a variety } \\
\text { of factors. }\end{array}$ & $\begin{array}{l}\text { Att1.1 Accept HIV as } \\
\text { the medical diagnosis. } \\
\text { Att1.2 Recognize the } \\
\text { need for psychological } \\
\text { and sexual adjustment } \\
\text { to a diagnosis of HIV. } \\
\text { Att1.3 Consider the } \\
\text { meaning of sexuality } \\
\text { for one's own life. } \\
\text { Att1.4 Identify } \\
\text { dysfunctional thoughts } \\
\text { about sexuality and } \\
\text { create alternative } \\
\text { and more realistic } \\
\text { thoughts. }\end{array}$ & $\begin{array}{l}\text { S1.2 Say to be } \\
\text { able to analyze } \\
\text { one's own sexual } \\
\text { function and to } \\
\text { recognize sexual } \\
\text { problems. }\end{array}$ & $\begin{array}{l}\text { SSO1.1 } \\
\text { Significant others } \\
\text { support self- } \\
\text { observation of } \\
\text { sexual function. }\end{array}$ & $\begin{array}{l}\text { R1.1 HIV nurses } \\
\text { encourage HIV+ } \\
\text { MSM to explore } \\
\text { sexuality issues. } \\
\text { R1.2 HIV nurses } \\
\text { reinforce the } \\
\text { need for self- } \\
\text { observation to } \\
\text { regain satisfactory } \\
\text { sexual function. }\end{array}$ \\
\hline $\begin{array}{l}\text { 3.HIV+ MSM } \\
\text { generate multiple } \\
\text { adaptive coping } \\
\text { strategies. }\end{array}$ & $\begin{array}{l}\text { A3.1 Have insight } \\
\text { into multiple } \\
\text { adaptive coping } \\
\text { strategies to deal } \\
\text { with sexual problems. } \\
\text { A3.2 Describe coping } \\
\text { strategies directed } \\
\text { at resolving sexual } \\
\text { problems. } \\
\text { A3.3 Describe coping } \\
\text { strategies directed } \\
\text { at changing the way } \\
\text { one thinks about } \\
\text { sexual problems. }\end{array}$ & $\begin{array}{l}\text { Att3.1 Have positive } \\
\text { expectancies with } \\
\text { regard to multiple } \\
\text { adaptive coping } \\
\text { strategies. }\end{array}$ & $\begin{array}{l}\text { S3.1 Say to be } \\
\text { able to generate } \\
\text { multiple coping } \\
\text { strategies to } \\
\text { deal with sexual } \\
\text { problems. } \\
\text { S3.1 Say to } \\
\text { be able to } \\
\text { implement } \\
\text { selected coping } \\
\text { strategies. }\end{array}$ & $\begin{array}{l}\text { SSO3.1 } \\
\text { Significant others } \\
\text { express to be } \\
\text { convinced of } \\
\text { the importance } \\
\text { of generating } \\
\text { multiple adaptive } \\
\text { coping strategies. }\end{array}$ & $\begin{array}{l}\text { R3.1 HIV nurses } \\
\text { discuss the } \\
\text { effectiveness of } \\
\text { multiple coping } \\
\text { strategies to } \\
\text { deal with sexual } \\
\text { problems. }\end{array}$ \\
\hline $\begin{array}{l}\text { 5.HIV+ MSM } \\
\text { evaluate } \\
\text { implemented } \\
\text { coping strategies } \\
\text { and return to } \\
\text { monitoring. }\end{array}$ & $\begin{array}{l}\text { A5.1 Explain the } \\
\text { importance of self- } \\
\text { evaluation skills } \\
\text { (set realistic goals, } \\
\text { evaluate personal } \\
\text { action, and reward } \\
\text { own efforts) for self- } \\
\text { regulation. }\end{array}$ & & $\begin{array}{l}\text { S5.1 Say to be } \\
\text { able to evaluate } \\
\text { implemented } \\
\text { coping strategies } \\
\text { and return to } \\
\text { monitoring. }\end{array}$ & $\begin{array}{l}\text { SSO5.1 } \\
\text { Significant } \\
\text { others support } \\
\text { evaluation of } \\
\text { implemented } \\
\text { coping strategies. }\end{array}$ & $\begin{array}{l}\text { R5. } 1 \text { HIV nurses } \\
\text { reward effective } \\
\text { efforts. }\end{array}$ \\
\hline
\end{tabular}

Task 2.1 Selecting theoretical methods

Two prominent theories or models of behavior change served as the foundation

for the development of our intervention. The first was self-regulation theory.

Although this theory is particularly useful for specifying performance objectives, the

assumption that people go through several sub-processes to reach health goals can

also be used for identifying applicable intervention methods. The primary methods

within self-regulation theory are self-monitoring and self-evaluation (Clark \&

Zimmerman, 1990; Thoresen $\&$ Kirmil-Gray, 1983). In addition, the Trans-theoretical

Model (Prochaska, Redding, \& Evers, 2002) and Social Cognitive Theory (Bandura, 

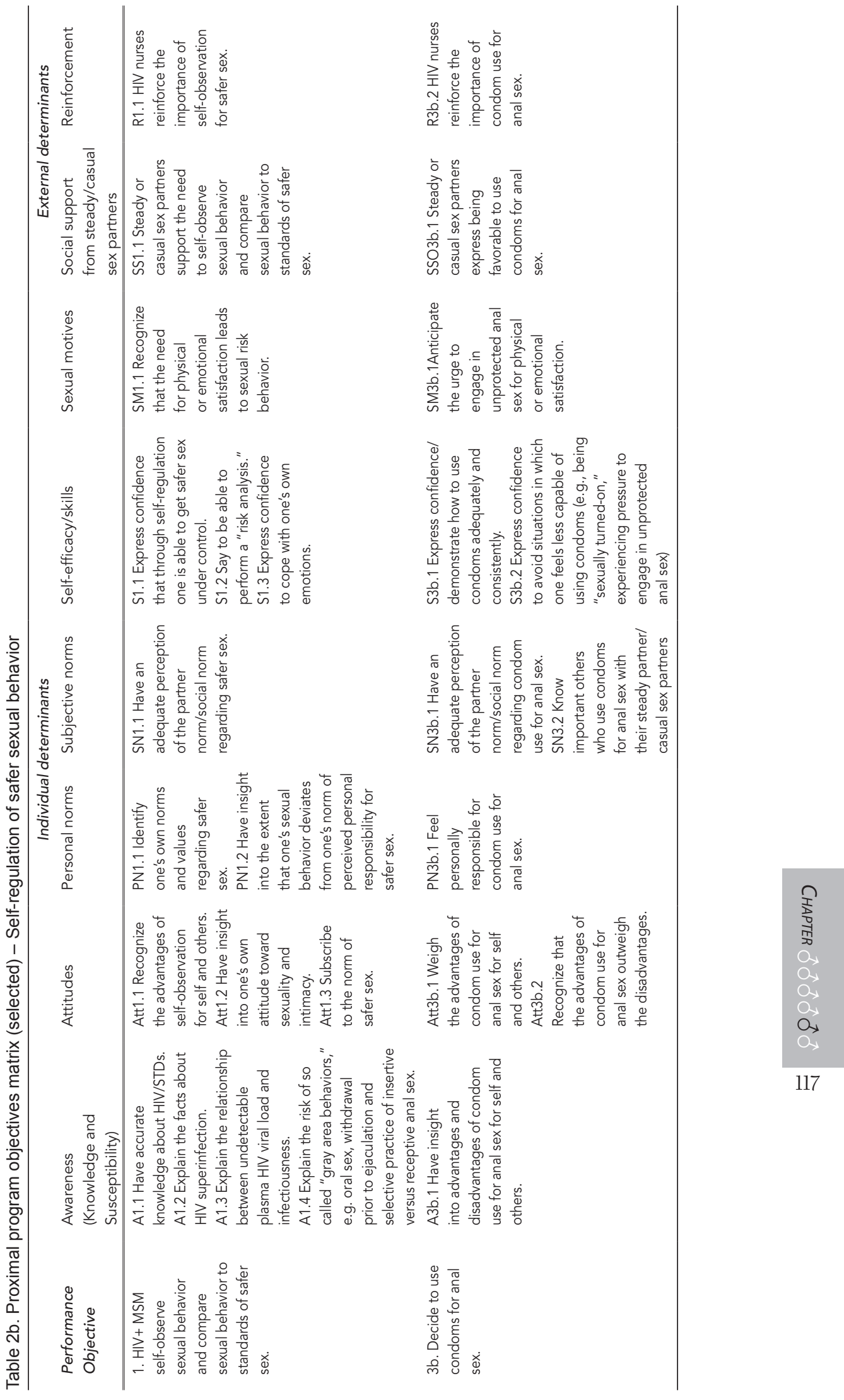
1986, 1997) describe several methods of stimulating self-monitoring and selfevaluation: consciousness raising, dramatic relief, self-re-evaluation, environmental re-evaluation, decisional balance, modeling, guided practice and feedback. Finally, based on the last stage of self-regulation, we used action planning and coping planning to support the implementation of health-promoting behavior (Sniehotta, Schwarzer, Scholz, \& Schüz, 2005).

The second set of theoretical concepts underlying our program was derived from a cognitive-behavioral model of behavior change. A review of the literature on the treatment of sexual dysfunction indicates that cognitive-behavioral therapy is the predominant treatment for sexual problems (Ellis, 1975; Rosen \& Leiblum, 1995; Rosen, Leiblum, \& Spector, 1994). In addition, several studies indicate the utility of a cognitive-behavioral approach to HIV risk-reduction (Belcher et al., 1998; Kelly, 1991; Van den Hoek, Kok, Van Kesteren, Hospers, \& De Zwart, 2005). The cognitivebehavioral model describes several methods for changing the determinants of behavior, including giving psycho-educational information, cognitive restructuring to assist a client in identifying thought patterns that are likely to result in negative affect, relaxation training, training in problem-solving skills, reinforcement and feedback (Blagys \& Hilsenroth, 2002; Crowther \& Zeiss, 1999). Further, cognitivebehavioral therapy recommends various methods for the treatment of sexual dysfunction, such as sexual imaging to promote sexual arousal or reach orgasm (Ellis, 1975) and systematic desensitization and exposure in vivo, i.e. sex therapy, to reduce fear and counterbalance avoidance (Masters \& Johnson, 1970).

In addition to these general theoretical approaches, more specific theories suggest a variety of intervention methods. Table 3 gives an overview of selected methods, theories and considerations for use. Considerations for use are the conditions under which the methods are shown to be effective and are essential to keep in mind when translating methods into practical strategies and program components.

\section{Task 2.2 Translating methods into practical strategies}

We selected self-administered bibliotherapy and motivational interviewing as our primary strategies because they were expected to be effective in covering all methods described (see Table 3). A review of the literature suggests that the use of bibliotherapy, often in the form of self-help guides or manuals, is an effective treatment for sexual dysfunction (Gould \& Clum, 1993; Van Lankveld, 1998).

Bibliotherapy can be defined as the use of written material to help people solve problems or change behavior, whereas self-administered bibliotherapy is a specific form of self-care behavior (Glasgow \& Rosen, 1978; Van Lankveld, 1998). As this is behavior that a person deliberately initiates to improve his health or to solve a health problem, this approach fits naturally with the basis of self-regulation. Moreover, bibliotherapy offers the opportunity to receive sexual support in the privacy of one's own home. In addition, it is important to note that although bibliotherapy 


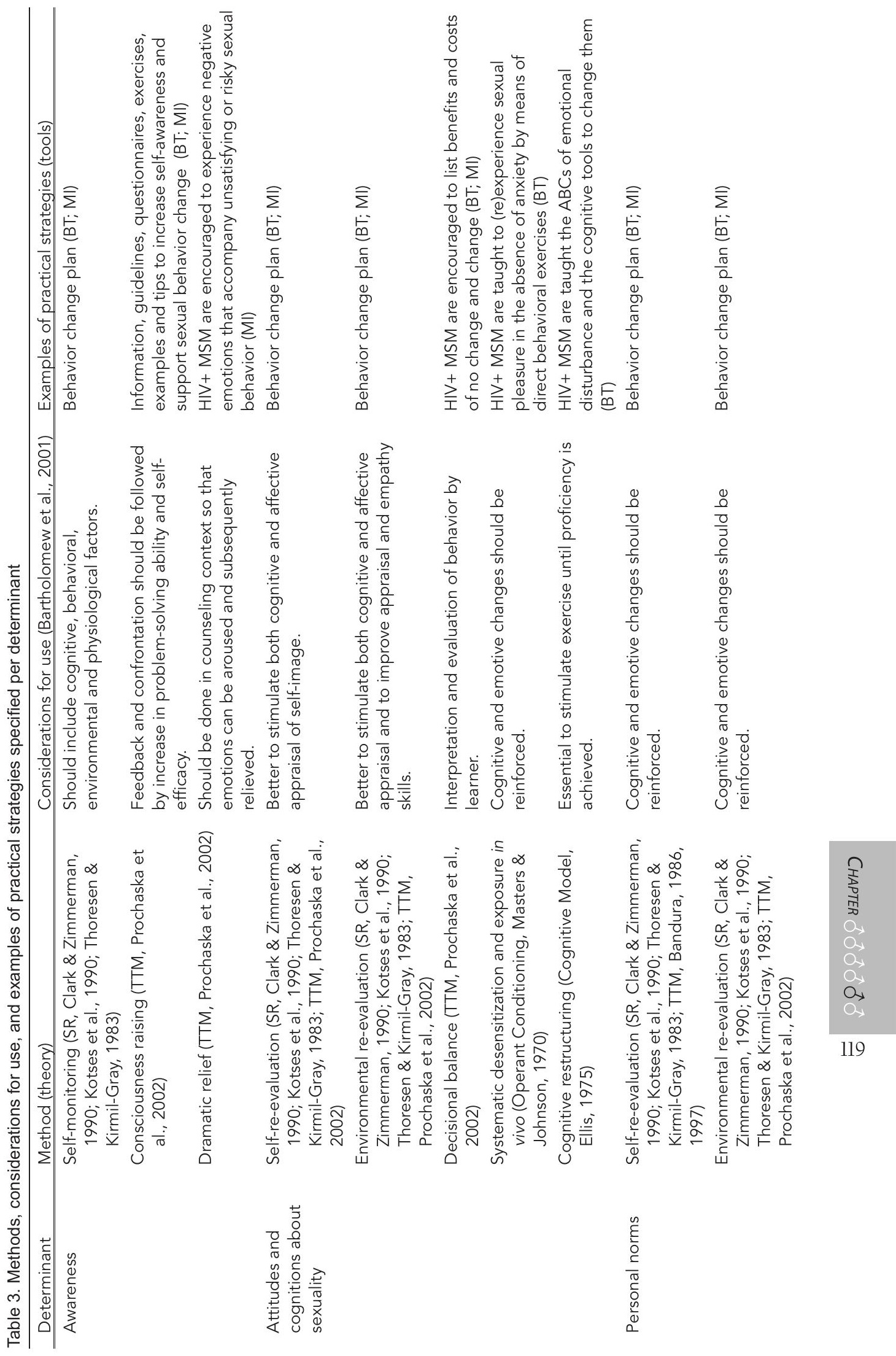




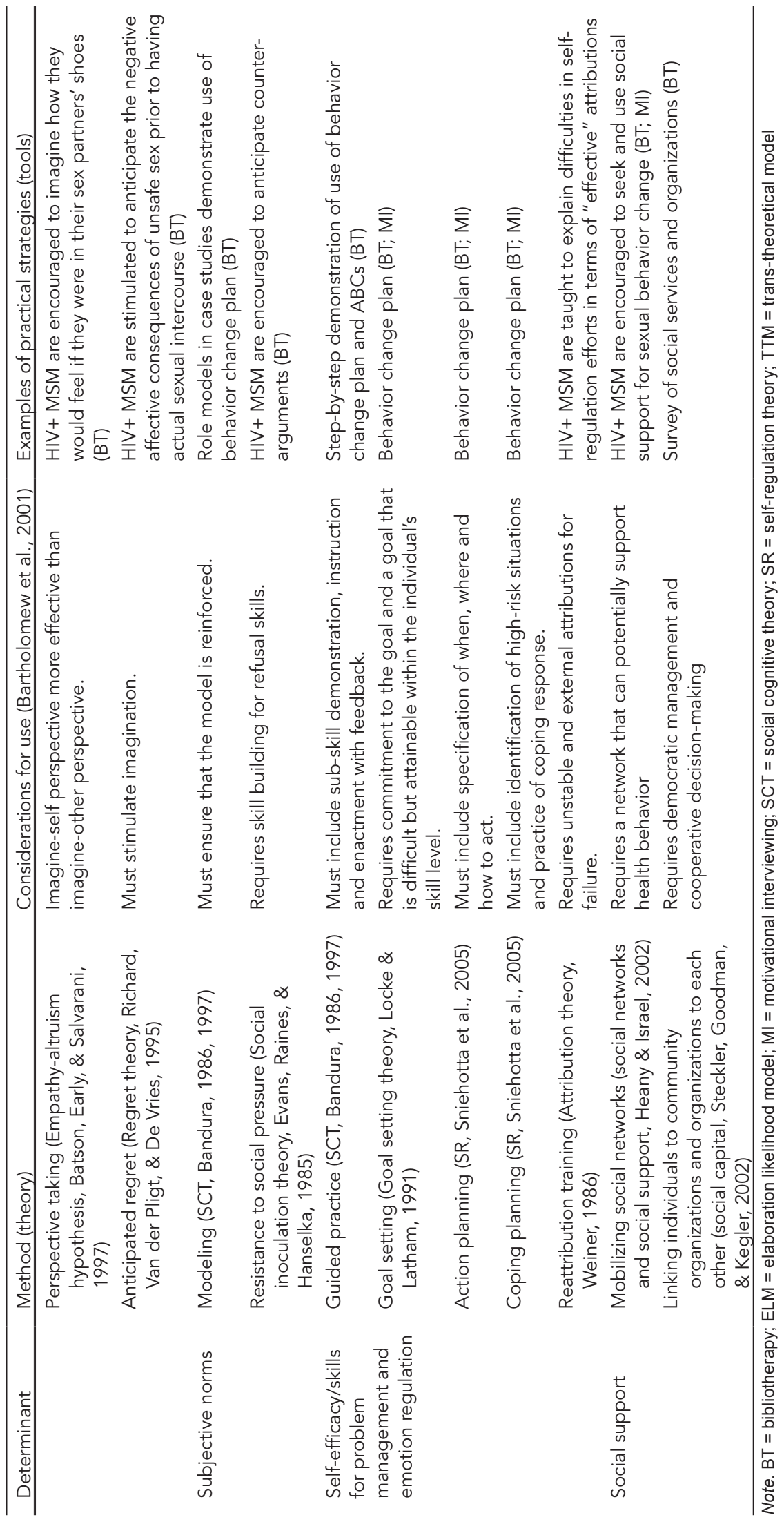


emphasizes the individual, it may function as an indirect source of social support because it can create an awareness that others are dealing with similar problems or issues (Silverberg, 2003).

Although bibliotherapy offers obvious advantages and empirical support with all kinds of behaviors, there are some important limitations to its use and the assumptions of self-care behavior, or more specifically, self-regulation. In essence, theories of self-regulation assume that it is an autonomous, internal process (Clark \& Zimmerman, 1990). This might be problematic, especially when HIV-positive MSM have low motivation or lack the confidence to engage in self-regulation of satisfactory sexual function or safer sexual behavior. Therefore, the use of the self-help guide was complemented with motivational interviewing (Miller \& Rollnick, 1991, 2002). Motivational interviewing refers to a direct, client-centered style of counseling that helps clients to explore and resolve their ambivalence about changing, and might be especially appropriate because it is neither moralistic nor judgmental. Essentially, four broad guiding principles underlie motivational interviewing: (1) express empathy (i.e., non-judgmental listening, acceptance of the client, and recognition that ambivalence about change is normal); (2) develop discrepancy (i.e., highlight the difference between current behavior and personal goals or values); (3) roll with resistance (i.e., avoid arguing for change; new perspectives are invited but not imposed); and (4) support self-efficacy. The techniques of motivational interviewing include listening reflectively and eliciting motivational statements.

\section{Intervention Mapping Step 3: producing program components and materials}

Intervention Mapping Step 3 was the actual design of the program. This involved organizing strategies into a deliverable program, taking into account the context in which the program will be used. As part of this task, we had to determine the program structure (i.e., scope and sequence), theme, and channels for delivery. In the second task of Intervention Mapping Step 3, program materials were developed. The last task in this step was to pre-test the program materials with the target group and implementers before the final materials were produced.

Task 3.1 Organize strategies into a deliverable program, considering implementers and sites Based on Intervention Mapping Step 2, we decided to develop a program that comprised a self-help guide, a motivational interviewing session and a motivational interviewing telephone call; both delivered by nurses specialized in HIV. The goal of the program was to promote self-regulation of satisfactory sexual function and safer sexual behavior over a three-month time period. The participants first received the self-help guide. The motivational interviewing session and motivational interviewing call were delivered approximately three and six weeks afterwards, respectively. The theme of the program was for HIV-positive MSM to gain control of their sexual and social lives. 
An important challenge in this step was to ensure that the program would fit within the context in which the program would be delivered. Nurses employed in HIV treatment centers represent a potentially effective channel for delivering HIV prevention tools to HIV-positive MSM. A recent study among $400 \mathrm{HIV}$-positive people in the Netherlands showed that $58 \%$ visited an HIV treatment center at least once every three months (Verdult, 2005). In addition, it was found that $71 \%$ had seen an HIV nurse during their last visit, so a major advantage in using HIV nurses to implement the program is that many HIV-positive MSM can be reached. Moreover, HIV nurses have an excellent opportunity to systematically address sexuality and related issues with their patients (Mayer, Safren, \& Gordon, 2004; Ross \& Schonnesson, 2000). To increase program fit with the HIV nurses, additional research was conducted to better understand how to implement our program (see Intervention Mapping Step 4).

In order to develop, pre-test, and eventually produce the program materials, a group of researchers, HIV prevention specialists, HIV nurses, and a sexologist was assembled. Developing the self-help guide involved working with a professional text writer, designer, and publisher. Developing the counseling protocol involved working with a motivational interviewing professional. Although program development is preeminently a creative process, it is important not to lose track of the proximal program objectives and to ensure that the methods and strategies are adequately implemented. Therefore, the matrices of proximal program objectives and the selected methods and strategies formed the basis for developing the program materials.

\section{Task 3.2 Developing program materials}

The self-help guide developed for this program, entitled HIV and Sex, focused on self-regulation of satisfactory sexual functioning and safer sexual behavior (Schippers $\&$ Van Kesteren, 2004). The self-help guide consisted of seven chapters. The first chapter included an introduction about HIV and sex and stated the guide's primary goal. The second chapter explained the basic methods of the self-help guide, i.e. devising a behavior change plan and working on changing thoughts. Devising a behavior change plan follows the basic pattern of self-regulation and consists of four steps: (1) increasing understanding of one's current situation; (2) identifying goals and arranging them in order of priority; (3) planning when, where and how to implement possible solutions; and (4) planning coping responses to high-risk situations. Next, a method for changing thoughts was delineated. This method generally followed the procedures for rational-emotive self-analysis as described by Ellis (1975). The third chapter was aimed at expanding self-awareness into the three main topics of the self-help guide. This included an examination of sexual (dys)function, making contacts and risky sexual practices. The fourth chapter focused on the most important theoretical underpinnings of motivating behavior 
Table 4. Structure and content self-help guide

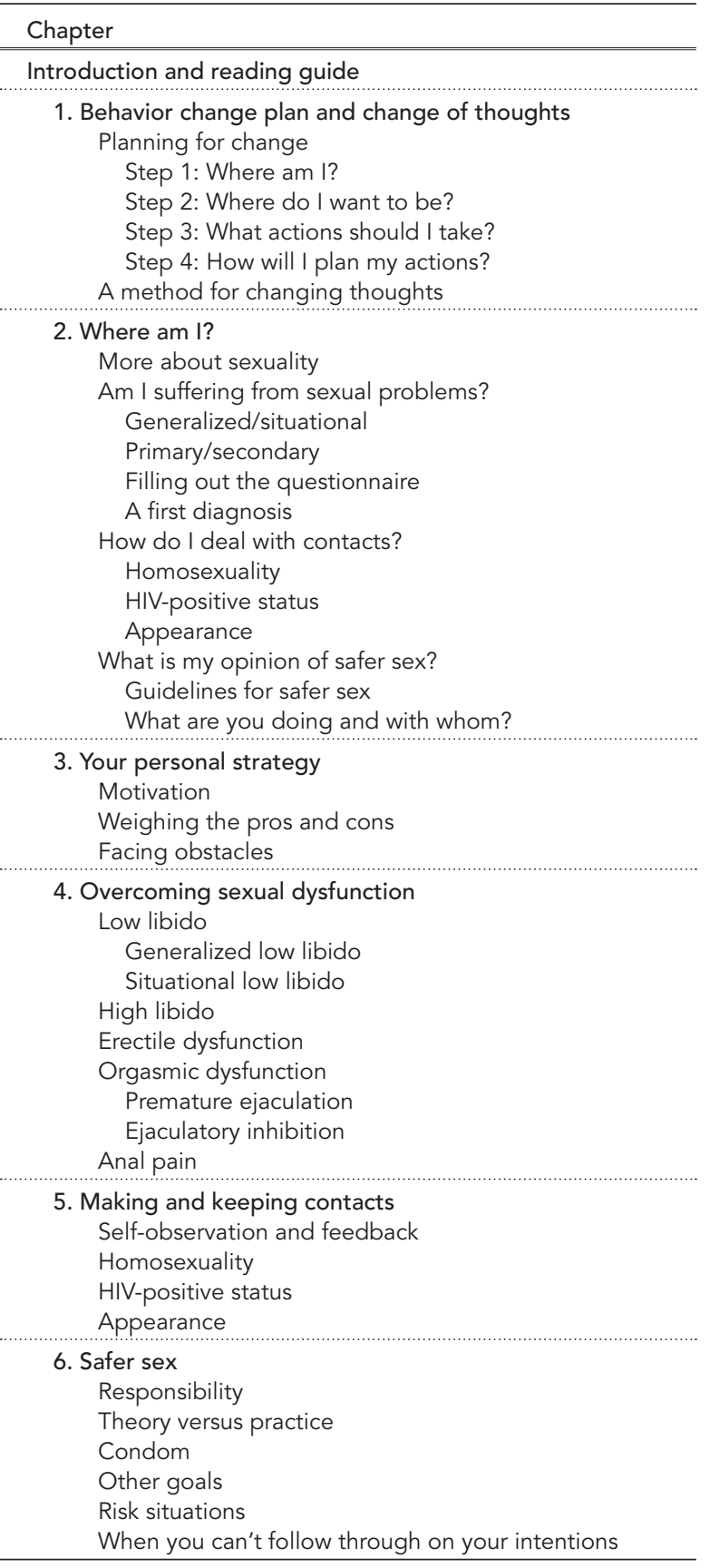

change. The purpose of the fifth, sixth and seventh chapters was to facilitate (behavior) change. The fifth chapter covered overcoming sexual problems; the sixth chapter focused on developing and keeping (sexual) contacts; and the seventh chapter covered issues of safer sex. The structure and contents of the self-help guide are summarized in Table 4. 
In order to increase motivation for behavior change, we developed a twosession motivational interviewing counseling protocol for HIV specialist nurses. The counseling protocol was based on guidelines for behavior change consultation in a health care setting (Rollnick, Mason, \& Butler, 1999). The aims of the face-toface counseling session were to help participants work through their ambivalence and to support self-efficacy for behavior change. Assessing the importance of, and confidence to make, behavior change formed an important focus of this counseling session. First, participants were asked to rate on a scale of 1 to 10 (with 10 being the highest) the importance they placed on change and their level of confidence in their ability to do so. Second, they were asked why they had not rated it lower (to elicit positive motivational statements), and why they had not rated it higher, or what it would take to get to a 9 or 10 (to elicit barriers) (Rollnick et al., 1999). The aim of the counseling phone interview was to monitor progress. After reviewing homework assignments and assessing barriers to implementation, participants were reinforced to stay motivated and to use the methods for change they had learned in the self-help guide. The structure and contents of the counseling protocol are summarized in Table 5 .

\section{Task 3.3 Pre-testing program materials}

Nine HIV-positive MSM, who had a mean age of 41 years (range 29-63), and had known they were HIV-positive for a mean length of time of 10 years (range 2-20), were interviewed to evaluate the self-help guide. Specific questions were asked regarding the content (i.e., whether the guide was interesting, recognizable, contained information new to the respondent, excluded any relevant information or included irrelevant information) and design (i.e., whether it was easy to read, understand and use, and whether they liked the composition). The main outcome was that the respondents evaluated the self-help guide positively; most of the respondents appreciated the broad approach to sexual health and the fact that the self-help guide was written specifically for HIV-positive MSM. However, three men objected to the guide's problem-centered approach; they felt that the focus on HIV-related worries or problems was disproportionate and thus a barrier to their using the guide. As result of this outcome, the word 'problem' was deleted from the text wherever possible and replaced by a phrase that leaves more room for a positive approach to pursuing change. For example, the original title of a section: "Problems with contacts" was replaced with the title: "How do I deal with contacts?" (chapter 3; see Table 4). Other changes to the self-help guide were: improvement of the layout (including a more relevant arrangement of exercises) and simplification of the text.

The counseling protocol was developed in close cooperation with a team of four HIV specialist nurses. Early in the development process, the nurses were asked to evaluate the objectives of the counseling protocol and to provide preconditions 
Table 5. Structure and content of motivational interviewing protocol

\begin{tabular}{|c|c|}
\hline \multicolumn{2}{|c|}{ Session 1: facilitate change (face-to-face counseling session) } \\
\hline $\begin{array}{l}\text { 1. Assess patient's level of concern about sexual } \\
\text { function, making contacts and safer sex }\end{array}$ & $\begin{array}{l}\text { Introduce counseling session } \\
\text { Discuss homework assignment (Chapter } \\
1-3 \text { self-help guide) } \\
\text { Set agenda in consultation with patient } \\
\text { Explore/solidify patient's concerns } \\
\text { Summarize }\end{array}$ \\
\hline 2. Assess readiness to change & Introduce assessment \\
\hline Explore importance & $\begin{array}{l}\text { Assess importance } \\
\text { Explore and increase importance }\end{array}$ \\
\hline Build confidence & $\begin{array}{l}\text { Assess confidence } \\
\text { Support and reinforce confidence }\end{array}$ \\
\hline 3. Optional: decisional balance & $\begin{array}{l}\text { Explore pros and cons of no change } \\
\text { Explore pros and cons of change } \\
\text { Discuss contradictions in beliefs and } \\
\text { behavior } \\
\text { Provide objective information and } \\
\text { encourage reaction }\end{array}$ \\
\hline 4. Determine goals and action plans & $\begin{array}{l}\text { Set (sub)goals for change } \\
\text { Develop action plan } \\
\text { Set homework assignment in consultation } \\
\text { with patient } \\
\text { Make an appointment for phone call }\end{array}$ \\
\hline \multicolumn{2}{|l|}{ Session 2: monitor behavioral change (phone call) } \\
\hline 1. Assess progress & $\begin{array}{l}\text { Introduce counseling session } \\
\text { Discuss homework assignment } \\
\text { Set agenda in consultation with patient }\end{array}$ \\
\hline 2. Reinforce progress/attempts & $\begin{array}{l}\text { Demonstrate understanding } \\
\text { Normalize failure while being sensitive to } \\
\text { patient's feelings }\end{array}$ \\
\hline 3. Conclusion & $\begin{array}{l}\text { Discuss options for maintaining progress } \\
\text { Evaluate counseling sessions }\end{array}$ \\
\hline
\end{tabular}

regarding the content and layout. Subsequently, the nurses were asked to give feedback on the draft counseling protocol, which led to several changes.

\section{Intervention Mapping Step 4: planning for program adoption, implementation and sustainability}

Effective health promotion programs will have little impact if they are not used or if they are not sustained while still needed to create the desired health impact (Bartholomew et al., 2001, 2006). Therefore, it is essential to plan for program use from the outset. The first task was to develop a linkage system, a board that enables the exchange of knowledge and ideas between those who are developing the intervention and those who will use the program. Second, an implementation plan was created that specified program objectives for implementation, methods and strategies. 


\section{Task 4.1 Develop a linkage system}

At the beginning of program planning, key organizations in HIV-positive and gay communities were approached and asked to participate in the linkage group. All of the organizations agreed, resulting in a linkage group with representatives of the research and development team, Schorer (Dutch Gay and Lesbian Health Foundation), SAN (Netherlands Center for HIV/AIDS and Other STDs), the Netherlands HIV patients' organization, and the Department of Medical Psychology of the Universiteit van Amsterdam, which specializes in research on quality of life among HIV-positive people. During the process of intervention development the linkage group met five times. These meetings were used to give feedback on the progress and results of the Intervention Mapping process. In addition, an implementation day was organized in cooperation with the funding agency to enlist early professional involvement and to answer some important implementation questions, such as which channels should be used to deliver the intervention. In October 2003, participants from 10 different professional groups working with HIVpositive MSM (e.g., primary health care providers, social workers, sexologists) met to learn more about the intervention and to develop a united vision for the program. Finally, concerted efforts were made to build support for the intervention within the HIV treatment centers. The committee of the working group of HIV specialist nurses in the Netherlands was requested to publicly support the intervention, and articles were published in their newsletter to inform HIV nurses nation-wide about the progress and results of the project. In addition, we visited several HIV treatment centers to present the results of the study and discuss the program plans.

\section{Task 4.2 Develop an implementation plan}

From our implementation activities, it became clear that the HIV nurses were the key adopters as well as the implementers of our program. The performance objectives for the nurses were based on the Diffusion Theory (Rogers, 1995): (1) decide to adopt the program; (2) implement the program; and (3) continue to use the program. A qualitative study among 16 HIV nurses was conducted to gain insights into the determinants of adoption and implementation of the intervention (unpublished data). One finding was that HIV nurses were very positive about the program. The nurses indicated a desire to systematically address sexuality and safer sex, but were inhibited by the belief that HIV-positive MSM would feel uncomfortable discussing sexual behaviors. Moreover, some of the nurses anticipated time constraints. The respondents suggested factors that might assist in implementing the program, including a better understanding of the homosexual lifestyle, training in motivational interviewing skills, and assistance from colleagues. Based on these findings, we decided to focus on the following determinants of program adoption and implementation: knowledge of the homosexual lifestyle; knowledge of principles and techniques of motivational interviewing; attitudes toward the program; self-efficacy 
and skills to implement the program as designed; and social support from colleagues. Theoretical methods to address the determinants were derived from Social Cognitive Theory (Bandura, 1986, 1997) and applied in a one-day course on motivational interviewing. Additionally, HIV nurses were provided with a half-day "booster session" six months later. The following tools were used to apply the methods: literature on motivational interviewing, demonstrations, videotaped role-playing, discussions and skills practice with feedback.

\section{Intervention Mapping Step 5: planning for evaluation}

The fifth step is to plan for the evaluation of the process and its effectiveness based on the products from previous Intervention Mapping steps. Process evaluation entails analyzing the target group's and implementers' acceptance of the program's use, format and content. We relied on Intervention Mapping Step 2, 3 and 4 to evaluate the process. The process evaluation data will seek to answer questions such as: To what extent did the HIV nurses implement the program as intended? and How did they evaluate the program? Primary and secondary endpoints to test whether or not the intervention is effective were identified based on Intervention Mapping Step 1: proximal program objectives and determinants, performance objectives and behaviors, and quality-of-life outcomes. Since the intervention is currently being evaluated, the results will be reported elsewhere.

\section{DISCUSSION}

This paper presents the process by which a theory-and evidence-based intervention was developed to promote sexual health in HIV-positive MSM. Intervention Mapping, a tool for planning and developing health promotion interventions, was used as a guide in developing the intervention (Bartholomew et al., 2001, 2006). Intervention Mapping not only explicates the processes involved in intervention development, it also guides the application of both theory and empirical evidence to all phases of intervention development. Intervention Mapping has been shown to contribute to well-considered choices and transparency both in the process of intervention development and in anticipation of its implementation.

An assessment of the target population was of great value in developing our intervention. Based on our qualitative study (Van Kesteren et al., 2005) and other research reports on sexual risk behavior among HIV-positive MSM, we decided not to focus solely on the health promoting behavior of consistent use of condoms during anal intercourse. It was thought that optimal results would more likely be achieved if an HIV preventive intervention targeting HIV-positive MSM was not narrowly focused on preventing transmission of HIV and STDs, but more broadly on managing the influence of HIV and its treatment on sexual health. We believe that in doing so we succeeded in addressing the perceived threat of HIV to the men's sexuality and 
the complexity of sexual behavior change, and were thus better able to direct the intervention to the specific needs of the target group.

In Intervention Mapping Step 1, self-regulation theory provided a useful framework for specifying performance objectives. Self-regulation is an ongoing process in which people strive to achieve various health objectives (Aspinwall, 2001). This makes possible an individually-tailored approach to sexual behavior change. Moreover, self-regulation theory recognizes that people need to develop the means to exert control over their motivation for health-enhancing behavior, as well as over the implementation and maintenance of such behavior (Bandura, 2005). As such, the intervention stimulates HIV-positive MSM to monitor sexual behaviors, set goals that are not only high, but realistic and specific, and to evaluate their reactions.

Based on the performance objectives and selected determinants, the specification of proximal program objectives provided an anchor throughout the Intervention Mapping process. For example, in Intervention Mapping Step 2, the determinants and proximal program objectives were used to identify appropriate intervention methods, such as self-monitoring, self-evaluation, action planning, coping planning and cognitive restructuring. Critical to the translation of methods into strategies was the need to consider considerations for use. Methods may fail because the considerations for use are not taken into account, resulting in inappropriate theoretical assumptions by program planners.

Ensuring a coherent program that relies on the planning as outlined in Intervention Mapping Step 1 and 2 is undeniably one of the major challenges of Intervention Mapping. Using proximal program objectives, theoretical methods and practical strategies to structure the organization of the program as well as the production of the program materials was crucial to the development of our program. Finally, the evaluation plan was specified within the learning and change objectives formulated in the matrices of proximal program objectives. Moreover, the results of the planning in the previous Intervention Mapping steps will provide feedback on the feasibility of our program in everyday practice. These results will help to determine whether or not the intervention is effective in improving sexual function and safer sexual behavior, while meeting the subjective needs of HIV-positive MSM.

Another important element highlighted by Intervention Mapping is how the intervention is implemented among program users. Key elements we considered included collaboration, increasing ownership, and promoting motivation and mutual support among program users. The formation of the linkage group from the start of intervention development proved to be an essential step for program adoption and implementation. For example, during the early meetings of the linkage group it appeared that the collaborating organizations had divergent views on the specific problem we should address. Intervention Mapping helped us to reach agreement on the goals of the intervention. The time we took to specify program objectives, consider different theory-based intervention methods and practical strategies, and 
make conscious choices about materials and activities increased acceptance of and support for the final design of the program. Involving the target population and program users in program planning and development was particularly useful in ensuring that the program materials were appropriate and acceptable to the intended audience.

Despite the many advantages of Intervention Mapping, applying the Intervention Mapping protocol may seem elaborate, expensive and time-consuming. However, reviews of health promotion intervention studies have shown that the quality of planning is the best predictor of success (Kalichman et al., 1996; Van Empelen, Kok, Van Kesteren et al., 2003). By working with Intervention Mapping, we focused on stating explicit program goals, guaranteeing effective methods, developing practical strategies to produce the desired objectives, planning for adoption and implementation, and creating an evaluation plan. As such, Intervention Mapping may provide a manageable tool to guide the process in designing health promotion programs.

\section{Limitations}

It is important to emphasize that the intervention described in this paper was developed specifically for Dutch HIV-positive MSM; therefore, it is unclear whether or not the intervention would be appropriate for other subgroups of HIV-positive MSM, particularly HIV-positive MSM of color. Studies of ethnic HIV-positive MSM suggest that their sexual behavior is different from that of Caucasian MSM and that many social and cultural factors may be involved in sexual risk-taking and risk-reduction behavior (Díaz, 1998). In addition, there is evidence that HIV-related stigma and discrimination is particularly pervasive in ethnic populations of MSM and that their manifestation is closely linked to the prevalence of homophobia (Brooks et al., 2005). Those who fear becoming stigmatized may not be able or motivated to take part in HIV preventive interventions or may be frightened to disclose their HIV status. Although motivational interviewing provides HIV nurses with a means of working with patients who are ambivalent about or not ready for change, it may be particularly difficult to effectively address sexual health when HIV-positive MSM deny their sexual orientation, avoid discussing their sexual health, or avoid utilizing HIV treatment services. Therefore, it might be essential to explore new methods and strategies for behavior change or channels for delivering prevention efforts. Moreover, intervention programs targeting ethnic HIV-positive MSM should be embedded among other problems and needs of these subgroups. Within this context, Intervention Mapping suggests additional research is needed to better serve the target population. 


\section{ChAPTER 6}

\section{intervention to promote sexual health}

Evaluation of a self-help and motivational enhancement

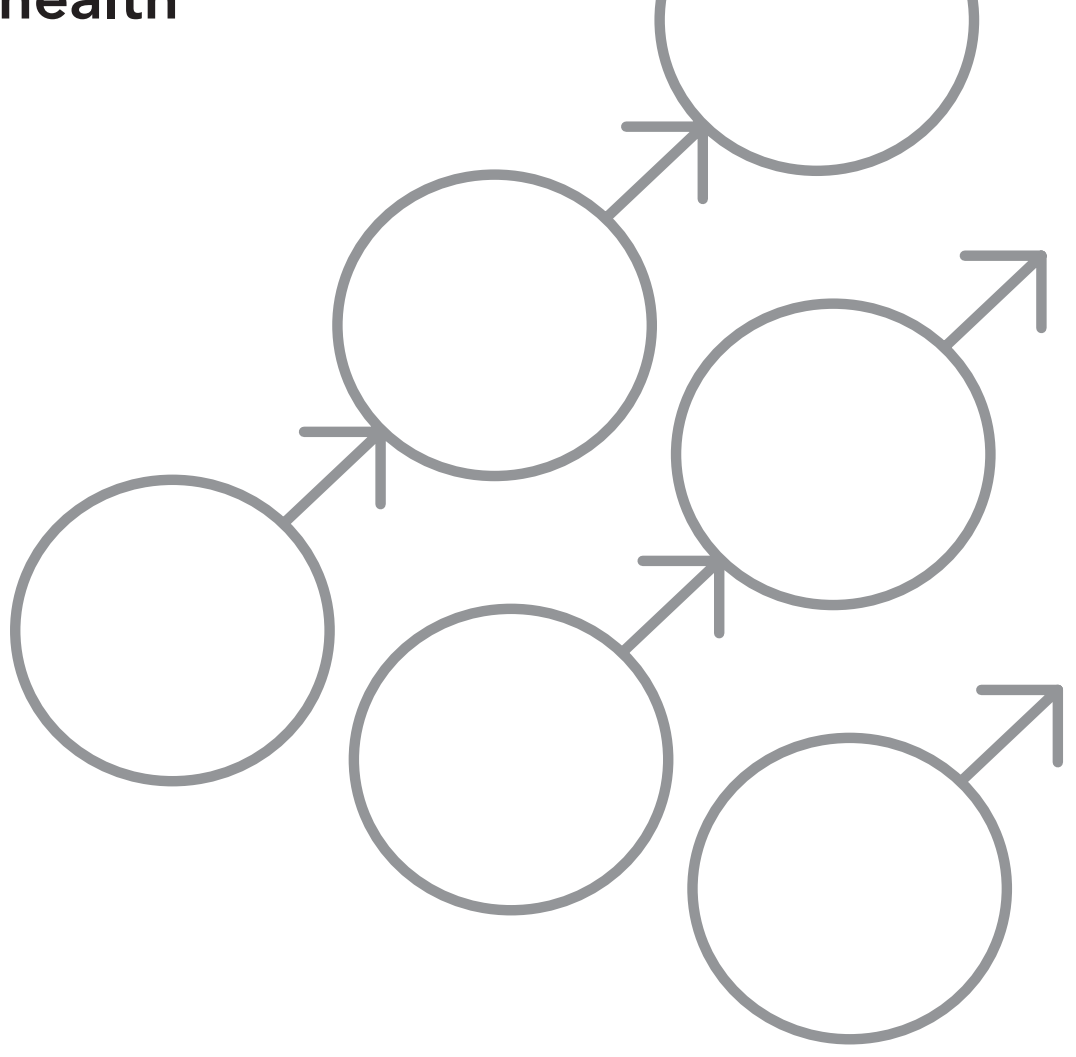

In submission as:

Van Kesteren, N.M.C., Kok, H.J., Van Breukelen, G., \& Kok, G. (2007). Evaluation of a self-help and motivational enhanvement intervention to promote sexual health in HIVpositive men who have sex with men. 


\section{INTRODUCTION}

The prevalence of unprotected anal intercourse (UAI) is increasing among HIVpositive men who have sex with men (MSM) (Van Kesteren, Hospers, \& Kok, 2007). UAI in HIV-positive MSM may not only result in transmission of HIV to their uninfected sexual partners, but may also facilitate the evolution and spread of drug resistance (Little et al., 2002; Richman et al., 2001; Sterling, Chaisson, \& Moore, 2001). Moreover, HIV-positive MSM are at risk of HIV superinfection and other STDs through UAI, which might progress at an accelerated pace to full-blown AIDS and death (Blackard, Cohen, \& Mayer, 2002; Jost et al., 2002). Thus, there is an urgent need to develop, implement, and evaluate interventions to support HIVpositive MSM to reduce UAI.

The research reported here investigated the short-term effects of an HIV preventive intervention for HIV-positive MSM based on motivational interviewing (Miller \& Rollnick, 1991, 2002) and self-help principles (Glasgow \& Rosen, 1978; Gould \& Clum, 1993). To guide the development of our intervention, we made use of a planned approach for the development of health promotion programs (Bartholomew, Parcel, Kok, \& Gottlieb, 2001, 2006). Existing evidence, theory, and new research (i.e., one-on-one in-depth interviews and questionnaires) were used to inform the process of program development (Van Kesteren, Kok, Hospers, Schippers, \& De Wildt, 2006). The primary goals of the intervention were to promote satisfactory sexual function and safer sexual behavior (primarily condom use for anal intercourse). Self-regulation theory (see Maes \& $\&$ Karoly, 2005 for a review) and a cognitive behavioral model of behavior change, i.e., cognitive behavioral therapy (Hobbis \& $\&$ Sutton, 2005), were chosen as the predominant theories underlying our intervention. The mechanisms of change included self-monitoring, self-evaluation, cognitive restructuring, skills performance, reinforcement, and feedback. The intervention consisted of a self-help guide, supported by a motivational interviewing session and a motivational telephone interviewing telephone call; both of which were conducted by HIV specialist nurses at HIV treatment centers. A linkage group, comprised of representatives of the research and development team and key organizations in HIV-positive and gay communities, was formed to help provide ideas and give feedback on the process of program development. A more detailed description of the intervention is provided in Van Kesteren et al. (2006); however, several features of the intervention are considered essential.

One feature of the intervention reflects the finding that sexual problems are frequent among HIV-positive MSM. For example, in an earlier qualitative study, HIV-positive MSM were found to report overall impairment in sexual function (e.g., reduced sexual desire and lack of arousal and orgasm) after their HIV-positive diagnosis (Van Kesteren, Hospers, Kok, \& Van Empelen, 2005). In addition, Cove and Petrak (2004) found that 69\% of HIV-positive MSM reported one or more 
sexual problems, whereas other studies indicated that HIV-positive homosexual men were more likely to experience sexual problems compared to those who are HIVnegative (Jones, Klimes, \& Catalan, 1994; Lamba, Goldmeier, Mackie, \& $\&$ Scullard, 2004; Meyer-Bahlburg et al., 1991; Orr, Catalán, \& Longstaff, 2004). Sexual problems have a negative impact on quality of life (Laumann, Paik, \& Rosen, 1999), and can, as such, interfere with healthy practices (Wenzel, Glanz, \& Lerman, 2002). Because people are generally ill-prepared to deal with the sexual aspects of a chronic disease, it might be expected that managing sexual problems and related psychosocial issues may restore satisfactory sexual function and enhance the quality of life in HIVpositive MSM (Gochros, 1992; Remor \& Ulla, 2002; Tan, Waldman, \& Bostick, 2002). Moreover, increased confidence in one's sexual response may promote condom use for anal sex (Catalan \& Meadows, 2000; Cove \& Petrak, 2004). Therefore, the purpose of our intervention was to enhance satisfactory sexual function, in addition to promoting safer sexual behavior. We were not able to identify any previous HIV-preventive interventions that addressed the role of sexual dysfunction in HIVpositive men.

Second, most HIV-preventive interventions focus on the individual's self-interest to protect his own health. However, a number of researchers have argued that otheroriented motives are the essential factor that distinguishes HIV-positive MSM from MSM who are HIV-negative or are not aware of their HIV status (King-Spooner, 1999; Marks, Burris, \& Peterman, 1999). Indeed, a growing number of studies suggest that feelings of personal responsibility to use condoms for anal sex are strong predictors of intentions to use condoms for anal sex (Godin, Savard, Kok, Fortin, \& Boyer, 1996; Van Kesteren, Hospers, Van Empelen, Van Breukelen, \& Kok, 2007). That is, HIV-positive MSM who feel more personally responsible for safer sexual behavior tend to practice safer sex. Underlying feelings of personal responsibility are considered to be internalized, self-reinforced standards, such as altruism (Penner, Dovidio, Piliavin, \& Schroeder, 2005). This is why HIV preventive interventions targeting HIV-positive MSM should incorporate a strong motivational component to internalize the regulation of safer sexual behavior (Deci, Eghrari, Patrick, \& Leone, 1994). We have attempted to enhance internalization for sexual behavior change, primarily by encouraging HIV-positive MSM to assume more responsibility for their health-related behavior. The importance of identifying with the value of health behavior change (i.e., safer sex) and accepting full responsibility for doing so is advocated in the technique of motivational interviewing (Miller \& Rollnick, 1991, 2002).

Third, motivation may not be the only, and perhaps not the most important, aspect to be considered in altering one's behavior. After all, accumulated research shows that "good" intentions may not always translate into protective behavior (Orbell \& Sheeran, 1998; Sheeran, 2002). Succeeding in the complex task of adopting safer sexual behavior includes efforts to control one's behavior, performing diverse 
preparatory actions, and actually achieving the goal (Abraham, Sheeran, \& Johnson, 1998). Theories on self-regulation explain such action control processes. These theories emphasize the involvement of sequences of actions across time in the achievement of many health-related behaviors (Gollwitzer \& Sheeran, 2006; Maes $\&$ Karoly, 2005), and can thus provide a valuable framework for modeling an HIV preventive intervention (Van Kesteren et al., 2006). Furthermore, interventions developed on the basis of self-regulation theory have been shown to be capable of supporting improvements in health-promoting behaviors. For example, there is evidence that self-regulation interventions are effective in developing and maintaining positive life skills in adolescents (Danish, 1997), reducing alcohol and drug use in university students (Miller, Toscova, Miller, \& Sanchez, 2000), and improving exercise adherence in coronary heart disease patients (Sniehotta et al., 2005).

Fourth, it is recognized that imbedding HIV prevention within the HIV clinical care setting may be a promising avenue for targeting sexual risk behavior in HIV-positive MSM. HIV care providers can play an important role in helping their patients to reduce sexual risk behaviors by adopting and maintaining safer sexual practices with a reasonable level of effort (Fisher et al., 2006). Moreover, a Dutch implementation study suggested that most HIV care providers include HIV prevention as part of their job responsibilities (unpublished data). Another advantage of working with HIV clinical care settings is their relatively easy access to people with HIV and AIDS, as many in this population now make use of the clinical care delivery system and receive regular HIV care (Verdult, 2005).

The objective of the study was to test the relative effectiveness of the self-help and motivational enhancement intervention (i.e., the intervention group) versus standard care (i.e., the waiting list control group). We hypothesized that HIV-positive MSM who receive counseling based on self-help principles and motivational interviewing would exhibit significantly less sexual dysfunction, fewer sexual risk behaviors, and increased preparatory behaviors to actually practice safer sex behaviors (e.g., buying condoms, carrying condoms and communicating about condoms) than HIVpositive MSM in the waiting list control group. In addition, it was expected that the experimental group would score higher in action control (i.e., self-regulatory efforts to implement and maintain behavior) compared to the waiting list group. With regard to social-psychological determinants, more favorable outcomes were expected for HIV-positive MSM receiving the self-help and motivational enhancement intervention. Because the intervention targeted the broader domain of sexual health, it was also expected that the intervention would lead to higher self-esteem and appearance evaluation. Furthermore, increased social support was expected for the HIV-positive MSM receiving the self-help and motivational enhancement intervention. 


\section{METHODS}

\section{Design}

This was a cluster-randomized waiting list control group trial of a self-help and motivational enhancement intervention versus usual care (no intervention). HIV treatment centers, stratified by region (Amsterdam, west, south and northeast) and HIV-positive patients served, were randomly assigned to one of the two study groups. The HIV-positive population served ranged from 86 to 900 per center. Participants in the intervention group first received a self-help guide. Approximately, three and six weeks later, they participated in a motivational face-to-face interview and a motivational telephone interview. Data collection took place at baseline and three-month follow-up. The waiting list control group received the self-help and motivational enhancement intervention after data collection was completed.

All 22 HIV treatment clinics in the Netherlands were invited to participate, of which $16(73 \%)$ agreed. Reasons for refusal included time constraints $(n=3)$; participation in another, concurrent study $(n=2)$; and concerns about the limited scope of the study's target population $(n=1)$. Eight HIV treatment centers were randomly assigned to the intervention group and eight to the waiting list control group. One HIV treatment center dropped out of the intervention group before commencement of the intervention. Consequently, a total of 15 HIV treatment centers participated in the study.

\section{Participant selection criteria and recruitment}

Participants were recruited through specialist nurses working in 15 HIV treatment centers. All specialist nurses were trained in a standardized recruitment procedure. Criteria for inclusion in the study included: tested positive for HIV antibodies at least half a year ago or longer; identified themselves as homosexual or bisexual; age 18 years or older; and sufficiently fluent in Dutch to provide written informed consent, complete the questionnaire, and read the self-help guide. The sole exclusion criterion was current treatment for psychological problems.

Interested and eligible candidates received a description of the purpose of the study and signed an informed consent document. To maximize participant convenience and reduce potential response biases, participants were asked to complete a pre-intervention questionnaire in their homes; the questionnaire took about 20 minutes to complete. Participants were assured that any information they gave to researchers was strictly confidential and that refusal to participate would not adversely affect their relationships with the clinicians or nurses. Following receipt of the baseline questionnaire, the specialist nurses sent the self-help guide to the participants' home addresses and scheduled a follow-up appointment for the motivational face-to-face interview and motivational phone interview. Participants 
received no compensation for participating in the study. The study protocol was approved by the review boards of the participating HIV treatment centers.

\section{Participants}

Between October 2004 and August 2005, 171 HIV-positive MSM participated in this study across clinics. The number of participants per center averaged 9 (range 3-32). Because of exclusionary data and missing data (> 15\%) at baseline, seven and two participants, respectively, were excluded from the analyses. The final study sample consisted of $162 \mathrm{HIV}$-positive MSM. Of that sample, 135 (83.3\%) were assessed at the three-month follow-up. Follow-up numbers for the intervention group and waiting list group were $50(79.4 \%)$ and 85 (85.9\%), respectively.

\section{Measures}

Primary outcome measures were possible sexual dysfunction and sexual risk behaviors. Sexual dysfunctions were determined by the Eleven Questions on Sexual Functioning Survey (ESF; Vroege, 1998), which is comprised of four primary dimensions of sexual functioning (i.e., libido, erectile dysfunction, orgasmic dysfunction, and genital pain) and one overall score for satisfaction with one's sex life. A sum score of nine out of eleven items gives an index of possible sexual problems (scoring range 0-9). Higher scores indicate more sexual complaints. The reliability and validity of the ESF were found to be sufficient (Vroege, 1998). Sexual risk behavior items included questions about anal intercourse and condom use. Participants were asked whether or not they had engaged in receptive and insertive anal sex with their steady sex partners and with casual sex partners over the previous six-month period. For each sexual behavior in which they had engaged, the frequency of condom use ( 1 = never, 5 = always) was assessed. Data were re-coded as "safer sexual behavior" (1) (i.e., no anal intercourse or consistent condom use for anal sex) or "sexual risk behavior" (0) (i.e., UAI). In addition, the number of casual sex partners was assessed by asking the number of casual sex partners with whom the participants had sex in the past six months. To get some insight into the phenomenon of "serosorting" and UAI, we included questions on the HIV status of both steady sex partners and casual sex partners. For steady sex partners, participants were asked about their steady sex partners' HIV status (i.e., HIV-positive, HIV-negative, don't know). For casual sex partners, participants were asked whether they had engaged in UAI in the past six months: (1) with a casual sex partner they knew at the time was HIV-positive; (2) with a casual sex partner they knew at the time was HIV-negative; and (3) with a casual sex partner whose HIV status they did not know.

Secondary outcome measures included preparatory behaviors for condom use and action control. Preparatory behaviors were measured by asking how often the 
participants had bought, carried and discussed condoms with steady and casual sex partners in the last six months (Van Empelen \& Kok, 2006). Action control for satisfactory sexual function and safer sexual behavior was assessed separately with four items measuring self-regulatory effort. Examples of questions include "How often in the preceding six months have you evaluated your satisfaction with your sex life?" and "How often in the preceding six months have you made a detailed plan to improve your sex life?" In addition, separate rating scales were constructed to measure determinants of condom use with steady and casual sex partners. Most of these scales were modeled after a survey conducted by Van Kesteren and colleagues (2007). These scales assessed the following determinants: attitudinal beliefs (e.g., "I protect my steady partner/casual sex partners against the AIDS virus/HIV superinfection by using condoms when having anal intercourse."); subjective norms (e.g., "Do you think your closest friends expect you to use condoms when having anal intercourse with your steady partner/casual sex partners?"); personal norms (e.g., "As a matter of principle, I use condoms every time I have anal intercourse with my steady partner/casual sex partners."); self-efficacy (e.g., "Suppose you want to use condoms when having anal intercourse, will you be able to discuss condom use with your steady partner/casual sex partners?"); and intentions to use condoms when having anal intercourse (e.g., "I intend to use a condom when having anal intercourse with my steady partner/casual sex partners."). Sexual motives (i.e., the extent to which participants feel particular emotions, such as lust or excitement, when having unprotected anal sex) were measured only for casual sex partners. Furthermore, rating scales measured self-esteem, appearance evaluation, and social support. Self-esteem was measured with a 10-item scale called the Rosenberg SelfEsteem Scale (RSE; Rosenburg, 1965). Items are scored on a 4-point scale. The scores for the 10 items are totaled; a higher score indicates more positive self-esteem (scoring range 10-40). Scores below 21 indicate low self-esteem (Rosenburg, 1979).

The seven-item Appearance Evaluation sub-scale of the Multidimensional Body Self Relations Questionnaire (MBSRQ; Cash \& Pruzinsky, 1990) assesses satisfaction with one's appearance; higher scores reflect greater satisfaction. Finally, the MOS (Medical Outcomes Study) Social Support Survey (Sherbourne \& Stewart, 1991) was used to assess social support. The following sub-scales were selected for this study: emotional/informational support; affectionate support; and positive social interaction. Higher scores indicate greater support.

\section{Intervention description}

The self-help guide developed for this intervention, entitled HIV and Sex, addressed three topics related to sexual health (i.e., sexual function, making contacts, and safer sexual behavior) and was based on self-regulation theory and a cognitive-behavior approach to facilitate sexual behavior change (Schippers \& Van Kesteren, 2004). Via various successive steps, participants were taught how to self-observe, set standards 
and goals, plan for action, and cope with obstacles. For each topic, exercises were given to increase understanding of one's current situation. These exercises included filling out questionnaires or listing and evaluating one's own (sexual) activities. Next, information on how to improve one's own situation was provided. For instance, participants suffering from low libido were given exercises such as self-exploration of body and genitals, exploration of potentially arousing sexual stimuli ("simmer"), and improvement of concentration on physical sensations and exploration of sexual fantasy. Participants were then asked to plan the details of carrying out these actions by specifying when, were and how to act, and to anticipate possible barriers by identifying personal risk situations and planning detailed coping responses (Sniehotta, Schwarzer, Scholz, \& Schüz, 2005). In addition, participants were taught to reward themselves for performing the intended behavior. Case examples of fictional individuals were used throughout the self-help guide to illustrate the application of the sub-processes of self-regulation.

The face-to-face motivational interview and motivational phone interview were based on motivational interviewing, an empirically validated, client-centered strategy for promoting behavior change in healthcare settings (Rollnick, Mason, \& Butler, 1999). During the face-to-face session, HIV nurses verbally explored the issues most salient to the participants and sought agreement to focus on one clear objective. Next, the importance of, and confidence to make, behavior change were evaluated. This gave the nurse a clearer idea about how the participant felt about change, which enabled her/him to tailor the content and format of the encounter to the participant's readiness for change. The nurse and participant then negotiated an individual action plan that served as a guide for behavioral self-regulation of his sexual health. The telephone call was used mainly for monitoring progress. Once the agenda had been set, the HIV nurse checked the participant's progress since the counseling encounter. The nurse then reviewed the homework assignments and assessed barriers for implementation.

\section{HIV specialist nurses' training}

To promote the standardization of implementation, intervention activities were described in a detailed protocol for HIV nurses. All HIV nurses who took part in the intervention participated in a one-day course on motivational interviewing to learn the protocol and to practice their interviewing techniques. Training aids included literature on motivational interviewing, videotaped role-playing, discussions and skill-building activities. A half-day "booster session" was provided six months later. HIV nurses were provided with a complete intervention manual and had access to an online "Yahoo! Groups" for peer coaching. 


\section{Statistical analyses}

Data entry was first checked for obvious errors. Discordant data were discarded or corrected. Sum scores for baseline assessment and three-month follow-up were then analyzed for possible statistical outliers. Values were replaced by the highest nonoutlier plus 1, or the lowest non-outlier minus 1, if they lay outside the range of Mean $+/-3$ SD. All variables treated this way had a range of at least 5 points. Next, the total number of missing values was calculated for all primary and secondary predictors and outcomes for each participant for each assessment (baseline and 3-month follow-up). A total number of less than $15 \%$ missing values was accepted for the analyses. Finally, dependent variables were examined for skewness and dichotomized on the median if the variable showed extreme skewness; in particular, a strong ceiling effect (> 50\% of the sample having the highest possible value) or floor effect ( $<50 \%$ of the sample having the lowest possible value).

Chi-square analyses and independent sample $t$-tests were used to test for pre-intervention differences between groups. Logistic regression analyses for dichotomous outcomes and linear regression analyses for continuous outcomes were conducted to test for differences between the intervention and waiting list control group. The pre-intervention measure of each dependent variable was always used as a covariate, just like age, education, years since HIV-positive diagnosis, antiviral treatment, and steady sex partner (no/yes) and casual sex partner (no/yes). Variables found to differ between groups at pre-intervention assessment were also used as covariates (see Table 1). In addition, all analyses included region and number of HIVpositive patients served as covariates in line with the sampling design. The variable "region" was transformed into three dichotomies by dummy coding. "Amsterdam" was the reference group and was compared to "west," "south," and "northeast." Note that this analysis ignores nesting of patients within clinics, thereby underestimating standard errors of effects if clinics are treated as a random sample. Therefore, if significant intervention effects were found, they were checked with a more advanced analysis (i.e., multilevel analysis), taking a random clinic effect into account.

\section{RESULTS}

\section{Baseline differences between intervention group and waiting list}

We compared HIV-positive MSM assigned to the intervention group $(n=63)$ with those assigned to the waiting list $(n=99)$ on all demographics, primary and secondary outcomes collected at baseline. Comparisons revealed that the only difference between groups was that a higher percentage of participants assigned to the waiting list $(69 \%)$ reported having a steady sex partner compared to participants assigned to the intervention group $(46 \%), \chi^{2}(1)=8.23, p<.01$ (see Table 1$)$. 
Table 1. Baseline characteristics in percentages or mean (SD) by study group

\begin{tabular}{|c|c|c|c|c|}
\hline & $\begin{array}{l}\text { Intervention } \\
\quad(n=63)\end{array}$ & Missing & $\begin{array}{r}\text { Waiting-List } \\
(n=99)\end{array}$ & Missing \\
\hline Age $(M, S D)$ & $42.4(9.02)$ & & $43.9(8.14)$ & \\
\hline Dutch & $87.1 \%$ & 1 & $90.4 \%$ & 5 \\
\hline $\begin{array}{l}\text { Education } \\
\text { High } \\
\text { Medium } \\
\text { Low }\end{array}$ & $\begin{array}{l}39.7 \% \\
37.9 \% \\
22.4 \%\end{array}$ & 5 & $\begin{array}{l}43.5 \% \\
39.1 \% \\
17.4 \%\end{array}$ & 7 \\
\hline $\begin{array}{l}\text { Employment status } \\
\text { full-time } \\
\text { part-time } \\
\text { unemployed }\end{array}$ & $\begin{array}{l}54.8 \% \\
19.4 \% \\
25.8 \%\end{array}$ & 1 & $\begin{array}{l}42.7 \% \\
26.0 \% \\
31.3 \%\end{array}$ & 3 \\
\hline $\begin{array}{l}\text { Self-identification } \\
\text { homosexual } \\
\text { bisexual }\end{array}$ & $\begin{array}{r}92.1 \% \\
7.9 \%\end{array}$ & & $\begin{array}{l}85.7 \% \\
14.3 \%\end{array}$ & 1 \\
\hline $\begin{array}{l}\text { Mean years since HIV-positive } \\
\text { diagnosis }(M, S D)\end{array}$ & $5.7(4.7)$ & 2 & $6.6(4.7)$ & 1 \\
\hline $\begin{array}{l}\text { Self-reported CD4+ } \\
\quad<200 \\
\quad \geq 200 \\
\text { don't know }\end{array}$ & $\begin{array}{r}1.7 \% \\
88.1 \% \\
10.2 \%\end{array}$ & 4 & $\begin{array}{r}6.3 \% \\
80.2 \% \\
13.5 \%\end{array}$ & 3 \\
\hline $\begin{array}{l}\text { Self-reported viral load } \\
\text { detectable } \\
\text { undetectable } \\
\text { don't know }\end{array}$ & $\begin{array}{l}65.6 \% \\
23.0 \% \\
11.5 \%\end{array}$ & 2 & $\begin{array}{l}65.3 \% \\
22.4 \% \\
12.2 \%\end{array}$ & 1 \\
\hline $\begin{array}{l}\text { Antiviral treatment } \\
\text { yes } \\
\text { no }\end{array}$ & $\begin{array}{l}80.3 \% \\
19.7 \%\end{array}$ & 2 & $\begin{array}{l}74.0 \% \\
62.0 \%\end{array}$ & 3 \\
\hline Steady sex partner & $46.0 \% * \star$ & & $68.7 \% * \star$ & \\
\hline Status steady sex partner & & 2 & & 2 \\
\hline HIV-positive & $3.7 \%$ & & $4.5 \%$ & \\
\hline HIV-negative & $48.1 \%$ & & $53.0 \%$ & \\
\hline HIV status unknown & $48.1 \%$ & & $42.4 \%$ & \\
\hline Casual sex partners & $73.0 \%$ & & $65.7 \%$ & \\
\hline
\end{tabular}

${ }^{* \star} p<.01$ for difference between intervention group and waiting-list.

\section{Baseline sample characteristics}

As shown in Table l, the majority of HIV-positive MSM were of Dutch origin, average or higher educated, employed, identified themselves as exclusively homosexual, and indicated that they were currently on some form of HIV antiretroviral therapy. As reported above, the study groups did not differ in regard to any of the variables listed in Table l, except that those on the waiting list had more steady sex partners than those in the intervention group. 


\section{Baseline sexual problems}

Table 2 shows the proportion of participants reporting sexual problems at baseline. Sexual problems related to sexual arousal (i.e., diminished penis stiffness, and shorter duration of penis stiffness) and orgasm (absence of orgasm, delayed orgasm, and accelerated orgasm) were most frequently reported. Other sexual problems, such as "masturbated several times per day," "never, once or several times per day feel like having sex," and "regularly painful genitals" were less frequently reported. Almost one-third (29\%) of the participants reported that they were dissatisfied with their current sex life. On average, participants reported 1.5 (range 1-5) sexual problems. A total of $27 \%$ of the participants reported one sexual problem; 14\% had two sexual problems; $8 \%$ had three sexual problems; $12 \%$ had four sexual problems; and 4\% reported five sexual problems. Sixty-five percent of the participants reported at least one sexual problem.

\section{Baseline UAI}

Sexual risk behaviors with steady and casual sex partners reported in the sample during the six months before baseline assessment are listed in Table 2. When steady sex partners were considered, $23.5 \%$ of the participants reported having had UAI,

Table 2. Sexual problems and UAI at baseline

\begin{tabular}{|c|c|c|c|}
\hline Variable & $\begin{array}{r}\text { Total } \\
(N=162)\end{array}$ & $\begin{array}{r}\text { Intervention } \\
(n=63)\end{array}$ & $\begin{array}{l}\text { Waiting-list } \\
\quad(n=99)\end{array}$ \\
\hline Masturbated several times per day & $5.0 \%$ & $8.1 \%$ & $3.0 \%$ \\
\hline $\begin{array}{l}\text { Never or several times per day feeling like } \\
\text { having sex }\end{array}$ & $5.6 \%$ & $8.1 \%$ & $4.0 \%$ \\
\hline Regularly diminished stiffness of penis & $25.3 \%$ & $21.3 \%$ & $27.8 \%$ \\
\hline Regularly shorter duration of penis stiffness & $25.9 \%$ & $21.3 \%$ & $28.9 \%$ \\
\hline Regularly absence of orgasm & $29.3 \%$ & $31.7 \%$ & $27.8 \%$ \\
\hline Regularly delayed orgasm & $13.4 \%$ & $5.0 \%$ & $18.6 \%$ \\
\hline Regularly accelerated orgasm & $10.9 \%$ & $5.0 \%$ & $14.6 \%$ \\
\hline Regularly painful genitals & $4.5 \%$ & $5.0 \%$ & $4.1 \%$ \\
\hline Dissatisfied with current sex life & $29.4 \%$ & $34.9 \%$ & $25.8 \%$ \\
\hline Number of sexual problems ( $M, S D)$ & $1.48(1.52)$ & $1.36(1.49)$ & $1.56(1.54)$ \\
\hline \multicolumn{4}{|l|}{ UAI with } \\
\hline Steady sex partner & $23.5 \%$ & $22.1 \%$ & $24.2 \%$ \\
\hline Casual sex partners & $27.8 \%$ & $33.3 \%$ & $24.2 \%$ \\
\hline Number of casual sex partners ${ }^{\mathrm{a}}(M, \mathrm{SD})$ & $13.6(15.0)$ & $15.9(17.4)$ & $12.0(13.0)$ \\
\hline
\end{tabular}


thus indicating that $76.5 \%$ reported consistent safer or protected sex, either through abstinence $(21.6 \%)$, consistent condom use for anal sex $(14.8 \%)$, or because they had not had a steady sex partner in the six months prior to the baseline assessment (40.1\%). When casual sex partners were considered, 27.8\% reported having had UAI, thus indicating that $72.2 \%$ reported consistent safer or protected sex, either through abstinence (16.6\%), consistent condom use for anal sex $(24.1 \%)$, or because they had not had casual sex partners in the six months prior to the baseline assessment $(31.5 \%)$. Finally, study participants reported a mean number of nearly $14(\mathrm{SD}=8.8)$ casual sex partners in the preceding six months (Table 2).

At baseline assessment, among participants who had had a steady sex partner in the previous six months, UAI was observed more often within the context of HIV seroconcordant relationships than within HIV serodiscordant relationships: $63.4 \%$ (26 out of 4l) of the men with an HIV-positive partner reported UAI compared to $20.8 \%$ (10 out of 48 ) of the men with an HIV-negative partner, and $0 \%$ (0 out of 4 ) of the men with a partner whose HIV status was unknown to them; $\chi^{2}(2)=19.5, p<.001$. Among participants who had had casual sex partners in the previous six months, 25.5\% (28 out of 111 ) reported UAI with casual sex partners who were HIV-positive, and $33.3 \%$ (37 out of 1ll) with casual sex partners who were HIV-negative or whose HIV status was unknown.

\section{Baseline preparatory behaviors}

Table 3 shows preparatory behaviors at baseline. The baseline means for buying and talking to steady partners about condoms were low, i.e., below the midpoint of the 5-point scale, suggesting that these behaviors, on average, were inconsistently

Table 3. Preparatory behaviors and number of casual sex partners at baseline

\begin{tabular}{|c|c|c|c|c|}
\hline & & $\begin{array}{c}\text { Total } \\
(N=162)\end{array}$ & $\begin{array}{l}\text { Intervention } \\
\quad(n=63)\end{array}$ & $\begin{array}{l}\text { Waiting-list } \\
\qquad(n=99)\end{array}$ \\
\hline Variable & Ranges & $M(S D)$ & $M(S D)$ & $M(\mathrm{SD})$ \\
\hline Bought condoms & $1-5$ & $2.19(1.30)$ & $2.18(1.36)$ & $2.20(1.27)$ \\
\hline Carried condoms & $1-5$ & $3.78(1.58)$ & $3.80(1.57)$ & 3.77 (1.59) \\
\hline $\begin{array}{l}\text { Talked to steady sex partner } \\
\text { about condoms }\end{array}$ & $1-5$ & $2.23(1.16)$ & $2.25(1.23)$ & $2.21(1.14)$ \\
\hline $\begin{array}{l}\text { Talked to casual sex partners } \\
\text { about condoms }^{\text {b }}\end{array}$ & $1-5$ & $3.28(1.63)$ & $3.38(1.56)$ & $3.22(1.70)$ \\
\hline $\begin{array}{l}\text { Disclosed HIV-positive status } \\
\text { to casual sex partners }\end{array}$ & $1-5$ & $2.02(1.46)$ & $1.96(1.43)$ & 2.06 (1.49) \\
\hline $\begin{array}{l}\text { Casual sex partners disclosed } \\
\text { HIV status to participant }{ }^{b}\end{array}$ & $1-5$ & $1.69(1.26)$ & $1.70(1.23)$ & $1.69(1.30)$ \\
\hline
\end{tabular}

a Limited to participants who reported having a steady sex partner in the 6 months prior to the baseline assessment $(n=97)$.

${ }^{b}$ Limited to participants who reported having casual sex partners in the 6 months prior to the baseline assessment $(n=111)$. 
performed by the participants. Scale scores for talking to casual sex partners about condoms were somewhat higher. Participants scored highly in condom carrying. Further, participants reported that they rarely had informed casual sex partners about their HIV status, and that they themselves were rarely informed about their casual sex partners' HIV status. Thus, disclosure of HIV status within casual sex encounters appears to be minimal.

\section{Baseline determinants and overall outcomes}

At baseline assessment, participants reported moderately positive levels of action control regarding safer sexual behavior, whereas the levels of action control regarding sexual function were considerably lower (see Table 4). For steady and casual sex partners, participants' attitudinal beliefs, subjective norms, personal norms, selfefficacy, and behavioral intentions were generally positive. The exception was for sexual motives for unprotected anal sex with casual sex partners, in which

Table 4. Internal consistency and means (SD) for action control, condom-related social-psychological determinants, appearance evaluation, self-esteem and social support at baseline

\begin{tabular}{|c|c|c|c|c|c|c|}
\hline & & & & $\begin{array}{c}\text { Total } \\
(N=162)\end{array}$ & $\begin{array}{l}\text { Intervention } \\
\quad(n=63)\end{array}$ & $\begin{array}{l}\text { Waiting list } \\
\quad(n=99)\end{array}$ \\
\hline Scales & $\begin{array}{l}\text { No. of } \\
\text { items }\end{array}$ & $\begin{array}{c}\text { Internal } \\
\text { consistency }\end{array}$ & Ranges & $M(\mathrm{SD})$ & $M(\mathrm{SD})$ & $M(\mathrm{SD})$ \\
\hline Action control sexual function & 4 & 0.76 & $1-5$ & $2.40(0.77)$ & $2.42(0.80)$ & $2.39(0.75)$ \\
\hline Action control safer sex & 4 & 0.86 & $1-5$ & $3.48(1.17)$ & $3.51(1.07)$ & $3.47(1.22)$ \\
\hline \multicolumn{7}{|l|}{ Steady sex partners ${ }^{a}$} \\
\hline Beliefs & 12 & 0.79 & $1-5$ & $3.38(0.76)$ & $3.39(0.69)$ & $3.37(0.80)$ \\
\hline Subjective norms & 3 & 0.75 & $1-5$ & $3.92(1.12)$ & $3.81(1.00)$ & $3.96(1.17)$ \\
\hline Personal norms & 2 & 0.87 & $1-5$ & $3.66(1.63)$ & $3.45(1.60)$ & $3.75(1.64)$ \\
\hline Self-efficacy & 7 & 0.95 & $1-5$ & $3.71(1.30)$ & $3.89(1.02)$ & $3.64(1.40)$ \\
\hline Intention & 3 & 0.99 & $1-5$ & $3.74(1.63)$ & $3.61(1.58)$ & $3.80(1.66)$ \\
\hline \multicolumn{7}{|l|}{ Casual sex partners ${ }^{b}$} \\
\hline Beliefs & 12 & 0.67 & $1-5$ & $3.71(0.61)$ & $3.66(0.57)$ & $3.22(1.70)$ \\
\hline Subjective norms & 3 & 0.65 & $1-5$ & $4.13(0.69)$ & $4.03(0.62)$ & $4.20(0.74)$ \\
\hline Personal norms & 2 & 0.87 & $1-5$ & $4.15(1.28)$ & $4.02(1.45)$ & $4.34(1.14)$ \\
\hline Self-efficacy & 7 & 0.90 & $1-5$ & $4.11(0.84)$ & $4.03(0.83)$ & $4.15(0.85)$ \\
\hline Intention & 7 & 0.97 & $1-5$ & $4.37(1.04)$ & $4.35(1.14)$ & $4.39(0.97)$ \\
\hline Sexual motives & 3 & 0.92 & $1-7$ & $3.02(1.56)$ & $3.32(1.43)$ & $2.80(1.62)$ \\
\hline Appearance Evaluation & 7 & 0.90 & $1-5$ & $3.85(0.83)$ & $3.83(0.89)$ & $3.85(0.80)$ \\
\hline Rosenburg Self-Esteem & 10 & 0.89 & $10-40$ & $26.6(2.98)$ & $26.2(2.41)$ & $26.8(3.29)$ \\
\hline Emotional/informational support & 8 & 0.95 & $1-5$ & $4.00(0.80)$ & $3.99(0.83)$ & $4.01(0.79)$ \\
\hline Affectionate support & 3 & 0.90 & $1-5$ & $4.00(1.01)$ & $3.87(1.14)$ & $4.08(0.91)$ \\
\hline Positive social interaction & 3 & 0.87 & $1-5$ & $4.07(0.83)$ & $3.95(0.94)$ & $4.15(0.74)$ \\
\hline
\end{tabular}


participants scored below the midpoint of the 7-point scale. With respect to the other outcome measures, the results show that participants evaluated their appearance positively, had moderate levels of self-esteem, and experienced high levels of social support.

\section{Drop-out analyses}

Logistic regression analyses of dropout $(1=$ yes, 0 =no) with the intervention group, age, nationality, education, employment status, self-identification, years since HIVpositive diagnosis, having a steady sex partner or not, and having casual sex partners or not showed that none of the predictors were significantly related to dropout (all p's > .10)

\section{Delivery, use and evaluation of the intervention}

Table 5 shows means data on the delivery, use and evaluation of intervention components. All participants in the intervention group were sent the self-help guide, and over 60\% reported reading most of it. However, more than half (55\%) did not do any of the exercises outlined in the self-help guide. In addition, only $21 \%$ reported that they devised a behavioral change plan. A comparably small percentage reported devising a plan for changing thoughts. In general, participants rated the self-help guide as interesting, understandable, useful, clear and recognizable. Participants were least positive about the newsworthiness of the self-help guide. On a scale of 1 to 10 , the self-help guide received a mean score of 6.7 . A total of $85 \%$ of those in the intervention group took part in a motivational interview. However, only $40 \%$ received a follow-up phone call. Participants who received the motivational sessions evaluated them very positively. According to the participants, the motivational sessions were pleasant, encouraging, helpful and useful.

\section{Intervention outcome analyses}

Table 6 shows the regression analyses of the primary endpoints at 3-month followup, comparing the intervention group against the waiting list. No significant effects of the intervention were found, either in regard to sexual problems or condom use behavior for anal sex with steady and casual sex partners ${ }^{1}$. Results for secondary outcomes were comparable with those for primary outcomes. There were no significant effects of the intervention on preparatory behaviors or number of sex partners (see Table 7). In addition, the intervention effects were not significant for action control, social-psychological determinants of condom use with steady and casual sex partners, appearance evaluation, self-esteem, or social support (see Table 8), thus indicating that the participants were unaffected by the intervention (all p's > $.10)$.

1 Intention to treat analyses (last observation carried forward) of sexual problems and condom use behaviors for anal sex with steady and casual sex partners did not lead to different conclusions. 
Table 5. Delivery, use and evaluation of intervention materials, intervention group only $(n=50)$

\begin{tabular}{|c|c|}
\hline \multicolumn{2}{|l|}{ Self-help guide } \\
\hline \multicolumn{2}{|l|}{ Amount read } \\
\hline Most & $60.0 \%$ \\
\hline Some & $20.0 \%$ \\
\hline None & $20.0 \%$ \\
\hline \multicolumn{2}{|l|}{ Exercises applied } \\
\hline Most & $15.0 \%$ \\
\hline Some & $30.0 \%$ \\
\hline None & $55.0 \%$ \\
\hline \multicolumn{2}{|c|}{ Devised a behavior change plan } \\
\hline Yes & $21.3 \%$ \\
\hline No & $78.7 \%$ \\
\hline \multicolumn{2}{|c|}{ Devised a plan for changing thoughts } \\
\hline Yes & $22.9 \%$ \\
\hline No & $77.1 \%$ \\
\hline How new? & $M, 3.18 ; S D, 1.17 ;$ range, $1-5$ \\
\hline How interesting? & $M, 3.49 ; S D, 1.08 ;$ range, $1-5$ \\
\hline How understandable? & $M, 3.76 ; S D, 1.21 ;$ range, $1-5$ \\
\hline How useful? & $M, 3.38 ; S D, 1.30 ;$ range, $1-5$ \\
\hline How clear? & $M, 3.69 ; S D, 1.84 ;$ range, $1-5$ \\
\hline How attractive? & $M, 3.68 ; S D, 1.14 ;$ range, $1-5$ \\
\hline How recognizable? & $M, 3.47 ; S D, 1.20 ;$ range, $1-5$ \\
\hline Overall & $M, 6.70 ; S D, 1.52 ;$ range, $1-10$ \\
\hline \multicolumn{2}{|l|}{ Motivational session } \\
\hline Received & $85.1 \%$ \\
\hline Not received & $14.9 \%$ \\
\hline How pleasant? & $M, 4.35 ; S D, 0.74 ;$ range, $1-5$ \\
\hline How encouraging? & $M, 3.77 ; S D, 1.06$; range, $1-5$ \\
\hline How helpful? & $M, 3.92 ; S D, 1.04 ;$ range, $1-5$ \\
\hline How useful? & $M, 3.69 ; S D, 1.20 ;$ range, $1-5$ \\
\hline \multicolumn{2}{|l|}{ Motivational session } \\
\hline Received & $40.4 \%$ \\
\hline Not received & $59.6 \%$ \\
\hline How pleasant? & $M, 4.24 ; S D, 0.70 ;$ range, $1-5$ \\
\hline How encouraging? & $M, 3.76 ; S D, 1.04 ;$ range, $1-5$ \\
\hline How helpful? & $M, 3.76 ; S D, 1.26$; range, $1-5$ \\
\hline How useful? & $M, 3.48 ; S D, 1.40 ;$ range, $1-5$ \\
\hline
\end{tabular}

Table 6. Intervention effect $(0=$ waiting list, $1=$ intervention group) on primary outcomes at three-month follow-up $(N=135)$

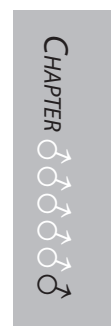

145

\begin{tabular}{lcccccr}
\hline & & \multicolumn{3}{c}{ Linear } & \multicolumn{3}{c}{ Logistic } & \\
\cline { 3 - 5 } Outcome & $N$ & $\mathrm{~B}$ & $95 \% \mathrm{Cl}$ & $\mathrm{OR}$ & $95 \% \mathrm{Cl}$ & $\mathrm{p}$-value \\
\hline \hline Sexual problems (range 0-5) & 116 & -0.41 & -0.91 to 0.08 & & & 0.10 \\
UAl with steady sex partners & 120 & & & 0.45 & 0.05 to 3.78 & 0.46 \\
UAl with casual sex partners & 118 & & & 0.94 & 0.25 to 3.60 & 0.93 \\
\hline
\end{tabular}

Note. Totals may be less than expected because of missing data. Statistically controlling for the dependent variable at baseline, region, HIV-positive patients served, age, education, years since HIV-positive diagnosis, antiviral treatment, having a steady sex partner, and having casual sex partners. 
Table 7. Intervention effect ( 0 = waiting list, $1=$ intervention group) on preparatory behaviors and number of casual sex partners at three-month follow-up $(N=135)$

\begin{tabular}{|c|c|c|c|c|c|c|}
\hline \multirow[b]{2}{*}{ Outcome } & \multirow[b]{2}{*}{$n$} & \multicolumn{2}{|l|}{ Linear } & \multicolumn{2}{|c|}{ Logistic } & \multirow[b]{2}{*}{$p$-value } \\
\hline & & $\mathrm{B}$ & $95 \% \mathrm{Cl}$ & OR & $95 \% \mathrm{Cl}$ & \\
\hline Bought condoms $s^{a, b}$ & 118 & & & 0.57 & 0.18 to 1.81 & 0.43 \\
\hline Carried condoms $\mathrm{s}^{\mathrm{a}, \mathrm{b}}$ & 116 & & & 0.63 & 0.22 to 1.78 & 0.39 \\
\hline $\begin{array}{l}\text { Talked to steady sex partner } \\
\text { about condoms }{ }^{c}\end{array}$ & 53 & 0.05 & -0.61 to 0.71 & & & 0.88 \\
\hline $\begin{array}{l}\text { Talked to casual sex partners } \\
\text { about condoms }{ }^{d}\end{array}$ & 69 & -0.52 & -1.31 to 0.27 & & & 0.19 \\
\hline $\begin{array}{l}\text { Disclosed HIV-positive status to } \\
\text { casual sex partners }{ }^{\mathrm{a}, \mathrm{d}}\end{array}$ & 66 & & & 2.04 & 0.43 to 9.69 & 0.37 \\
\hline $\begin{array}{l}\text { Casual sex partners disclosed } \\
\text { HIV status to participant } t^{a, d}\end{array}$ & 66 & & & 0.21 & 0.02 to 1.81 & 0.16 \\
\hline Number of casual sex partners ${ }^{d}$ & 64 & 0.79 & -3.18 to 4.76 & & & 0.69 \\
\hline
\end{tabular}

Note. Totals may be less than expected because of missing data.

a Outcomes were dichotomized on their median due to extreme skewness (see statistical analyses).

b Statistically controlling for the dependent variable at baseline, region, HIV-positive patients served, age, education, years since HIV-positive diagnosis, antiviral treatment, having a steady sex partner, and having casual sex partners.

c Limited to participants who reported having a steady sex partner at baseline and three-month follow-up $(n=70)$. Statistically controlling for the dependent variable at baseline, region, HIV-positive patients served, age, education, years since HIV-positive diagnosis, antiviral treatment, steady sex partner only versus casual sex partners as well, and steady sex partner with HIV-negative or unknown status versus steady sex partner with HIV-positive status.

d Limited to participants who reported having casual sex partners at baseline and three-month follow-up $(n=72)$. Statistically controlling for the dependent variable at baseline, region, HIV-positive patients served, age, education, years since HIV-positive diagnosis, antiviral treatment, and casual sex partners only versus steady partner as well.

We performed additional analyses of the effects, focusing on participants' use of different intervention components. Participants who had received the intervention and had made a behavioral change plan (intervention group, more compliant; $n=10$ ) were compared with those who had received the intervention and had not made a behavioral change plan (intervention group, less compliant; $n=37$ ) and with those who had received no intervention components (waiting list; $n=85$ ). No significant differences in primary or secondary outcomes were found among those who received the intervention and were more compliant and those who received the intervention and were less compliant, or those who received no intervention components (all p's > .06). Note that even if outcome differences had been found in the additional analyses, they would have required confirmation by a more advanced analysis to rule out selection bias, which may occur as a result of sub-grouping based on compliance.

To explore the possibility that the intervention was effective for certain subgroups only, we tested interaction of treatment with each of the following baseline variables: education, years knowing HIV-positive status, and antiviral treatment, for each of the following outcomes: sexual problems, UAI with steady sex partners, UAI with casual sex partners, appearance evaluation, self-esteem, and social support. For 
Table 8. Intervention effect ( 0 = waiting list, 1 = intervention group) on action control, condomrelated social-psychological determinants, appearance evaluation, self-esteem and social support at three-month follow-up $(N=135)$

\begin{tabular}{|c|c|c|c|c|c|c|}
\hline \multirow[b]{2}{*}{ Outcome } & \multirow[b]{2}{*}{$n$} & \multicolumn{2}{|l|}{ Linear } & \multicolumn{2}{|c|}{ Logistic } & \multirow[b]{2}{*}{$p$-value } \\
\hline & & B & $95 \% \mathrm{Cl}$ & OR & $95 \% \mathrm{Cl}$ & \\
\hline Action control sexual function ${ }^{a}$ & 123 & 0.13 & -0.10 to 0.36 & & & 0.27 \\
\hline Action control safer sex ${ }^{a}$ & 118 & -0.09 & -0.51 to 0.34 & & & 0.69 \\
\hline \multicolumn{7}{|l|}{ Steady sex partners } \\
\hline Beliefs $^{b}$ & 65 & 0.06 & -0.19 to 0.30 & & & 0.65 \\
\hline Subjective norms ${ }^{b}$ & 63 & 0.18 & -0.25 to 0.61 & & & 0.41 \\
\hline Personal norms ${ }^{\mathrm{b}, \mathrm{c}}$ & 64 & & & 4.00 & 0.20 to 80.6 & 0.37 \\
\hline Self-efficacy ${ }^{b}$ & 64 & -0.11 & -0.43 to 0.21 & & & 0.51 \\
\hline Intention ${ }^{b, c}$ & 60 & & & 0.50 & 0.01 to 24.8 & 0.73 \\
\hline \multicolumn{7}{|l|}{ Casual sex partners } \\
\hline Beliefs $^{d}$ & 67 & 0.06 & -0.20 to 0.33 & & & 0.63 \\
\hline Subjective norms ${ }^{d}$ & 69 & -0.01 & -0.26 to 0.24 & & & 0.94 \\
\hline Personal norms $s^{c, d}$ & 65 & & & 1.03 & 0.12 to 8.69 & 0.98 \\
\hline Self-efficacy ${ }^{d}$ & 64 & -0.10 & -0.40 to 0.21 & & & 0.51 \\
\hline Intention ${ }^{c, d}$ & 65 & & & 1.08 & 0.13 to 8.68 & 0.94 \\
\hline Sexual motives ${ }^{d}$ & 61 & -0.58 & -1.33 to 0.17 & & & 0.13 \\
\hline Appearance evaluation ${ }^{\text {a }}$ & 120 & 0.18 & -0.05 to 0.41 & & & 0.12 \\
\hline Rosenburg Self-Esteem ${ }^{a}$ & 120 & -0.43 & -1.34 to 0.48 & & & 0.35 \\
\hline Emotional/informational ${ }^{a}$ & 123 & -0.09 & -0.33 to 0.16 & & & 0.49 \\
\hline Affectionate support ${ }^{a}$ & 124 & -0.09 & -0.36 to 0.20 & & & 0.55 \\
\hline Positive social interaction ${ }^{a}$ & 124 & 0.00 & -0.26 to 0.27 & & & 0.99 \\
\hline
\end{tabular}

Note. Totals may be less than expected because of missing data.

a Statistically controlling for the dependent variable at baseline, region, HIV-positive patients served, age, education, years since HIV-positive diagnosis, antiviral treatment, having a steady sex partner, and having casual sex partners.

b Limited to participants who reported having a steady sex partner at baseline and three-month followup $(n=70)$. Statistically controlling for the dependent variable at baseline, region, HIV-positive patients served, age, education, years since HIV-positive diagnosis, antiviral treatment, steady sex partner only versus casual sex partners as well, and steady sex partner with HIV-negative or unknown status versus steady sex partner with HIV-positive status.

c Outcomes were dichotomized on their median because of extreme skewness (see statistical analyses).

d Limited to participants who reported having casual sex partners at baseline and three-month follow-up $(n=72)$. Statistically controlling for the dependent variable at baseline, region, HIV-positive patients served, age, education, years since HIV-positive diagnosis, antiviral treatment, and casual sex partners only versus steady sex partner as well.

sexual problems, UAI with steady sex partners, and UAI with casual sex partners, we also tested interaction of treatment with baseline assessments. Finally, we tested interaction of treatment with partner HIV status for UAI with steady sex partners ${ }^{2}$. No interaction was found (all p's >.10), indicating that sub-group analyses were useless and might only lead to type I errors as a result of multiple testing.

2 Because we had no information on the number of HIV-positive, HIV-negative, or HIV status unknown casual sex partners with whom participants had safer sex, we did not test interaction of treatment with partner HIV status for UAI with casual sex partners. 


\section{DISCUSSION}

Our hypotheses regarding the positive effects of our intervention were not confirmed; the self-help and motivational enhancement intervention was not effective in decreasing sexual problems or UAI with steady or casual sex partners. Nor were there significant effects for our secondary outcomes; that is, the intervention was not effective in improving preparatory behaviors or self-regulatory efforts. Additionally, we did not find any intervention effects for social-psychological determinants of intended condom use with steady or casual sex partners or for appearance evaluation, self-esteem or social support.

The lack of significant effects of our intervention is disappointing, particularly in light of the substantial effort that was expended on systematic program development. Previous reviews have convincingly demonstrated the critical role of a systematic approach to developing effective health promotion programs (Crepaz et al., 2006; Van Empelen et al., 2003). Apparently, however, this is no guarantee of program success. Thus, the main question to emerge is: why did the study fail to detect positive effects of the self-help and motivational enhancement intervention versus usual care?

One explanation for the failure of the motivational enhancement and self-help intervention to significantly affect the program outcomes may lie in the broad outline of the intervention. The self-help guide introduced to the HIV-positive MSM three themes related to sexual health, i.e., sexual functioning, making and keeping contacts, and safer sex. In accordance with the principles of self-regulation, participants were encouraged to identify and focus on issues that are personally relevant. This approach can result in a wide variety of goals and sub goals that participants address during the intervention period and may have had the effect of reducing the sensitivity of the study design to detect differences between groups. However, it may also be that the broad approach of the intervention limited its efficacy. Because of the participants' freedom to choose goals in an array of issues related to sexuality, personal goals might have been pursued that are unrelated to or too distal from the primary outcomes of the study, i.e., reducing sexual problems and UAI with steady and casual sex partners. A second explanation concerns the short duration of the evaluation period. The evaluation took place three months after the intervention began. Therefore, improvement in the primary and secondary outcomes may not have taken place yet. A third explanation involves this sample's generally high motivation to use condoms with steady and casual sex partners. Consequently, "ceiling" effects might have come into play, possibly preventing the demonstration of sizeable intervention effects on those outcomes. For these reasons, it is difficult to determine the true cause of the lack of significant effects.

Process data may provide some insights into these findings. The results indicate a generally positive evaluation of the various components of the intervention by the participants. However, data on the delivery of the program components showed that 
only $40 \%$ of the participants reported having received the motivational follow-up phone call. Moreover, data on the use of the self-help guide revealed that although $60 \%$ of the participants read most of the self-help guide, and $45 \%$ did some or most of the exercises, only about $20 \%$ devised a behavioral change plan. This latter finding may be of great significance in explaining the apparent ineffectiveness of the program, as the program's intention was to operate via the behavioral change plan to achieve its objectives.

The fact that relatively few participants developed a behavioral change plan seems to suggest low motivation on the part of the participants, though this notion runs counter to the aforementioned "ceiling effect." The low rate of participants' devising a behavioral change plan may be the result of negative effects of bibliotherapy. Some researchers have suggested that bibliotherapy may not only promote change in a reader, but also prompt the reader's defense mechanisms (such as avoidance and denial) by producing negative emotional experiences or psychological discomfort, thus resulting in stasis or refusal to change (Silverberg, 2003; Williams, 2001). Furthermore, the usability of the self-help guide may account for the low rate of participants' devising a behavioral change plan. In general, the participants were positive about the design of the self-help guide. However, it was quite lengthy. Perhaps more thought should have gone into the design of the guide so that the reader was able to find personally relevant information more easily. A recent study by Kools, Ruiter, Van de Wiel, and Kok (in press) on the ease with which people are able to find relevant information in a "health education" self-help guide, suggests that improving the accessibility of written materials may enhance the clarity of the material, which might facilitate behavior change.

Another important factor that may have limited the effectiveness of the intervention is the extent to which the HIV-specialist nurses familiarized themselves with the principles and techniques of motivational interviewing and the counseling protocol. Although it has been suggested that practitioners can be effectively trained in motivational interviewing within the scope of short training courses or workshops (Rollnick et al., 1999), it is unclear whether the one-day course and half-day booster session were sufficient for the HIV nurses to fully assimilate the spirit of motivational interviewing. Research has suggested that obtaining an accurate assessment of the way in which counselors interact with the participants requires that the counseling sessions be observed, recorded, and evaluated (Dunn, Deroo, \& Rivara, 2001). However, observing and recording can be intrusive, and provides little more than a snapshot of the program's implementation (Davis et al., 2000). Moreover, the study participants took part under a guarantee of anonymity and, because of the delicate nature of the subject matter, it was considered essential that this guarantee be honored. Consequently, we cannot comment on the way in which the motivational interviews were conducted. Future research studies should monitor counseling 
sessions to determine the effectiveness of counselors in conducting motivational interviews.

Because this study found no support for positive effects of our self-help and motivational enhancement intervention, the recommendations for HIV-prevention practice are limited. Additional research is needed to determine why the intervention showed no effect and to find ways to promote sexual health in HIV-positive MSM. To date, few HIV preventive interventions have been directed at HIV-positive MSM. Moreover, other programs targeting HIV-positive MSM have also yielded disappointing results (Crepaz et al., 2006; Johnson, Carey, Chaudoir, \& Reid, 2006). Thus, the challenge faced by HIV prevention researchers and practitioners is to increase the efficacy of behavioral interventions for HIV-positive MSM. 


\section{References}

Abraham, C., Sheeran, P., \& Johnson, M. (1998). From health beliefs to self-regulation: Theoretical advances in the psychology of action control. Psychology $\sim$ Health, 13, 569-591.

Adam, B. D., Maticka-Tyndale, E., \& Cohen, J. J. (2003). Adherence practices among people living with HIV. AIDS Care, 15, 263-274.

Alonzo, A. A., \& Reynolds, N. R. (1995). Stigma, HIV and AIDS: An exploration and elaboration of stigma trajectory. Social Science \& Medicine, 41, 303-315.

Anon. (2001). Outbreak of syphilis among men who have sex with men - Southern California, 2000. Morbidity and Mortality Weekly Report, 50, 117-120.

Anon. (2002). Primary and secondary syphilis among men who have sex with men - New York City, 2001. Morbidity and Mortality Weekly Report, 451, 853-856.

Ajzen, I. (1991). The theory of planned behavior. Organizational Behavior and Human Decision Processes, 50, 179-211.

Ajzen, I., \& Fishbein, M. (1970). The prediction of behavior from attitudinal and normative variables. Journal of Experimental Social Psychology, 6, 466-487.

Albarracín, D., Fishbein, M., Johnson, B. T., \& Muellerleile, P. A. (2001). Theories of reasoned action and planned behavior as models of condom use: A meta-analysis. Psychological Bulletin, 127, 142-161.

Aspinwall, L. G. (2001). Dealing with adversity: Self-regulation, coping, adaptation, and health. In A. Tesser \& N. Schwartz (Eds.), Blackwell handbook of social psychology: Intraindividual processes (pp. 591-614). Oxford, UK: Blackwell Publishers.

Baarda, D. B., De Goede, M. P. M., \& Teunissen, J. (2000). Kwalitatief onderzoek. Praktische handleiding voor het opzetten en uitvoeren van kwalitatief onderzoek. [Qualitative research. Practical guidebook for conducting qualitative research.]. Groningen: Stenfert Korese.

Bandura, A. (1986). Social foundations of thought and action: A social cognitive theory. Englewood Cliffs, NJ: Prentice-Hall.

Bandura, A. (1997). Self-efficacy: The exercise of control. New York: Freeman.

Bandura, A. (2005). The primacy of self-regulation in health-promotion. Applied Psychology: An International Review, 54, 245-254.

Baron, R. M., \& Kenny, D. A. (1986). The moderator-mediator variable distinction in social psychological research: Conceptual, strategic, and statistical considerations. Journal of Personality and Social Psychology, 51, 1173-1182.

Barosso, J. (1997). Reconstructing my life: Becoming a long-term survivor of AIDS. Qualitative Health Research, 7, 57-74.

Bartholomew, L. K., Parcel, G.S., Kok, G., \& Gottlieb, N. (2001). Intervention Mapping: Designing theory-and evidence-based health promotion programs. Mountain View, CA: Mayfield.

Bartholomew, L. K., Parcel, G. S., Kok, G., \& Gottlieb, N. H. (2006). Planning health promotion programs; an Intervention Mapping approach. San Francisco, CA: Jossey-Bass.

Bartholomew, L. K., Shegog, R., Parcel, G. S., Gold, R. S., Fernandez, M., Czyzewski, D. I., Sockrider, M. M., \& Berlin, N. (2000). Watch, Discover, Think, and Act: A model for patient education program development. Patient Education and Counseling, 39, 253268.

Batson, C. D. (1991). The altruism question: Toward a social-psychological answer. Hillsdale, NY: Erlbaum.

Batson, C. D., Early, S., \& Salvarani, G. (1997). Perspective taking: Imagining how another feels versus imagining how you would feel. Personality and Social Psychology Bulletin, 23, 751-758. 
Bayer, R. (1996). AIDS prevention. Sexual ethics and responsibility. The New England Journal of Medicine, 334, 1540-1542.

Belcher, L., Kalichman, S., Topping, M., Smith, S., Emshoff, J., Norris, F., \&\& Nurss, J. (1998). A randomized trial of a brief HIV risk reduction counseling intervention for women. Jounal of Consulting and Clinical Psychology, 66, 856-861.

Bingman, C. R., Marks, G., \& Crepaz, N. (2001). Attributions about one's infection and unsafe sex in seropositive men who have sex with men. AIDS and Behavior, 5, 283 289.

Black, J. S., Stern, P. C., \& Elworth, J. T. (1985). Personal and contextual influences on household energy adaptations. Journal of Applied Psychology, 70, 3-2l.

Blackard, J. T., Cohen, D. E., \& Mayer, K. H. (2002). Human immunodeficiency virus superinfection and recombination: Current state of knowledge and potential clinical consequences. Clinical Infectious Diseases, 34, 1108-1114.

Blagys, M. D., \& Hilsenroth, M. J. (2002). Distinctive activities of cognitive-behavioral therapy. A review of the comparitive psychotherapy process literature. Clinical Psychology Review, 22, 671-706.

Blower, S. M., Gershengorn, H. B., \& Grant, R. M. (2000). A tale of two futures: HIV and antiretroviral therapy in San Francisco. Science, 287, 650-654.

Boersma, S.N., Maes, S., Joekes, K., \& Dusseldorp, E. (2006). Goal processes in relation to goal attainment. Predicting health-related quality of life in myocardial infarction patients. Journal of Health Psychology, 11, 927-941

Bogart, L. M., Catz, S. L., Kelly, J. A., Gray-Bernhardt, M. L., Hartmann, B. R., Otto-Salaj, L. L., Hackl, K. L., \& Bloom, F. R. (2000). Psychosocial issues in the era of new AIDS treatments from the perspective of persons living with HIV. Journal of Health Psychology, 5, 500-516.

Bolding, G., Davis, M., Hart, G., Sherr, L., \& Elford, J. (2005). Gay men who look for sex on the Internet: Is there more HIV/STI risk with online partners? AIDS, 19, 961-968.

Bolding, G., Davis, M., Sherr, L., Hart, G., \&e Elford, J. (2004). Use of gay internet sites and views about online health promotion among men who have sex with men. AIDS Care, 16, 993-1001.

Bos, A. E. R. (2001). HIV stigma and social interaction. Examining strategies to influence perceiver's emotional and behavioral reaction in initial encounters. Unpublished doctoral dissertation, Universiteit Maastricht, Maastricht.

Brashers, D. E., Neidig, J. L., Cardillo, L. W., Dobbs, L. K., Russell, J. A., \& Haas, S. M. (1999). 'In an important way, I did die': Uncertainty and revival in persons living with HIV or AIDS. AIDS Care, 11, 201-219.

Brooks, R. A., Etzel, M. A., Hinojos, E., Henry, C. L., \& Perez, M. (2005). Preventing HIV among Latino and African American gay and bisexual men in a context of HIVrelated stigma, discrimination, and homophobia: Perspectives of providers. AIDS Patient Care and STDs, 19, 737-744.

Brown, L., Macintyre, K., \& Trujillo, L. (2003). Interventions to reduce HIV/AIDS stigma: What have we learned? AIDS Education and Prevention, 15, 49-69.

Browning, M. R., Blackwell, A. I., \& Joynson, D. H. (2000). Increasing gonorrhoea reports - not only in London. Lancet, 355, 1908-1909.

Cachay, E., Mar-Tang, M., \& Mathews, W. C. (2004). Screening for potentially transmitting sexual risk behaviors, urethral sexually transmitted infection, and sildenafil use among males entering care for HIV infection. AIDS Patient Care and STDs, 18, 349-354.

Cairo, I., Fennema, J. S. A., \& Maruanaya, W. M. (2001). Geslachtsziektebestrijding. Jaarverslag 2000. [STD prevention. Annual report 2000.]. Amsterdam: GG\&GD. 
Cameron, D. W., Heath-Chiozzi, M., Danner, S., Cohen, C., Kravcik, S., \& Maurath, C., et al. (1998). Randomised placebo-controlled trial of ritonavir in advanced HIV-1 disease. The Advanced HIV Disease Ritonavir Study Group. Lancet, 351, 543-549.

Cash, T. F., \& Pruzinsky, T. (1990). Body images: Development, deviance, and change. New York: Guilford Press.

Catalán, J., Klimes, I., Bond, A., \& Day, A. (1992). The psychosocial impact of HIV infection in men with heamophilia: Controlled investigation and factors associated with psychiatric morbidity. Journal of Psychosomatic Research, 36, 409-416.

Catalán, J., \& Meadows, J. (2000). Sexual dysfunction in gay and bisexual men with HIV infection: Evaluation, treatment and implications. AIDS Care, 12, 279-286.

Catalán, J., Burgess, A., \& Klimes, I. (1995). Psychological medicine of HIV infection. Oxford: Oxford University Press.

Catania, J. A., Gibson, D. A., Chitwood, D. D., \& Coates, T. L. (1990). Methodological problems in AIDS behavioral research: Influences on measurement error and participation bias in studies of sexual behavior. Psychological Bulletin, 108, 339-362.

CDC. (2003). Increases in HIV diagnoses - 29 states, 1999-2000. Morbidity and Mortality Weekly Report, 52, 1145-1148.

CDC. (2004). High-risk sexual behavior by HIV-positive men who have sex with men - 16 sites, United States, 2000 - 2002. Morbidity and Mortality Weekly Report, 53, 891-894.

Chen, S. Y., Gibson, S., Katz, M. H., Klausner, J. D., Dilley, J. W., Schwarcz, S. K., Kellogg, T. A., \& McFarland, W. (2002). Continuing increases in sexual risk behavior and sexually transmitted diseases among men who have sex with men: San Francisco, Calif, 1999-2001, USA. American Journal of Public Health, 1387-1388.

Chen, S. Y., Gibson, S., Weide, D., \& McFarland, W. (2003). Unprotected anal intercourse between potentially HIV-serodiscordant men who have sex with men, San Francisco. Journal of Acquired Immune Deficiency Syndromes, 33, 166-170.

Chesney, M. A., Morin, M., \& Sherr, 1. (2000). Adherence to HIV combination therapy. Social Science \& Medicine, 50, 1599-1605.

Chesney, M. A., \& Smith, A. W. (1999). Critical delays in HIV testing and care. The potential role of stigma. American Behavioral Scientist, 42, 1162-1174.

Clark, N. M., \& Zimmerman, B. J. (1990). A social cognitive view of self-regulated learning about health. Health Education Research, 5, 371-379.

Coates, T. J., McKusick, L., Kuno, R., \& Stites, P. (1989). Stress reduction training changed number of sexual partners but not immune function in men with HIV. American Journal of Public Health, 79, 885-887.

Colfax, G., \& Dawson-Rose, C. S. (2006). Integrating HIV prevention into the care of people with HIV In L. Peiperl \& P. A. Volberding (Eds.), HIV InSite Knowledge Base [textbook online].

Colfax, G. N., Guzman, R., Wheeler, S., Mansergh, G., Marks, G., Rader, M., \& Buchbinder, S. P. (2004). Beliefs about HIV reinfection (superinfection) and sexual behavior among a diverse sample of HIV-positive men who have sex with men. Journal of Acquired Immune Deficiency Syndromes, 36, 990-992.

Colfax, G. N., Mansergh, G., Guzman, R., Vittinghoff, E., Marks, G., Rader, M., \& Buchbinder, S. (2001). Drug use and sexual risk behavior among gay and bisexual men who attend circuit parties: A venue-based comparison. Journal of Acquired Immune Deficiency Syndromes, 28, 371-379.

Conner, M., \& Armitage, C. J. (1998). Extending the theory of planned behavior: A review and avenues for further research. Journal of Applied Social Psychology, 28, 1429-1464. 
Cooper, M. L., Shapiro, C. M., \& Powers, A. M. (1998). Motivations for sex and risky sexual behavior among adolescents and young adults: A functional perspective. Journal of Personality and Social Psychology, 75, 1528-1558.

Cove, J., \& Petrak, J. (2004). Factors associated with sexual problems in HIV-positive gay men. International Journal of STD \& AIDS, 15, 732-736.

Cox, J., Beauchemin, J., \& Allard, R. (2004). HIV status of sexual partners is more important than antiretroviral treatment related perceptions for risk taking by HIV positive MSM in Montreal, Canada. Sexually Transmitted Infections, 80, 518-523.

Crepaz, N., Hart, T. A., \& Marks, G. (2004). Highly active antiretroviral therapy and sexual risk behavior. Journal of the American Medical Association, 14, 224-236.

Crepaz, N., Lyles, C. M., Wolitski, R. J., Passin, W. F., Rama, S. M., Herbst, J. H., Purcell, D. W., Malow, R. M., \& Stall, R. (2006). Do prevention interventions reduce HIV risk behaviours among people living with HIV? A meta-analytic review of controlled trials. AIDS, 20, 143-157.

Crepaz, N., \& Marks, G. (2002). Towards an understanding of sexual behavior in people living with HIV: A review of social, psychological and medical findings. AIDS, 16, 135-149.

Crosby, R., DiClemente, R. J., \& Mettey, A. (2003). Correlates of recent unprotected anal sex among men having sex with men attending a large sex resort in the South. Sexually Transmitted Diseases, 30, 909-913.

Crowther, M. A., \& Zeiss, A. M. (1999). Cognitive-behavior therapy in older adults: A case involving sexual functioning. Journal of Clinical Psychology, 55, 961-975.

Cullen, K. W., Bartholomew, L. K., Parcel, G. S., \& Kok, G. (1998). Intervention Mapping: Use of theory and data in the development of a fruit and vegetable nutrition program for girl scouts. Journal of Behavioral Medicine, 21, 241-254.

Cusick, L., \& Rhodes, T. (1999). The process of disclosing positive HIV status: Findings from qualitative research. Culture, Health $\mathrm{S}$ Sexuality, 1, 3-18.

Danish, S. J. (1997). Going for the goal: A life skills program for adolescents. In G. W. Albee (Ed.), Primary prevention works (Vol. 6, pp. 291-312). Thousand Oaks, CA: Sage.

Davis, M., Baranowski, T., Resnicow, K., Baranowski, J., Doyle, C., Smith, M., Lin, L., Wang, D. T., \& Yaroch, A. L. (2000). Gimme 5 fruit and vegetables for fun and health: Process evaluation. Health Education \& Behavior, 27, 167-176.

Deci, E. L., Eghrari, H., Patrick, B., \& Leone, D. (1994). Facilitating internalization: The self-determination theory perspective. Journal of Personality, 62, 119-142.

Deci, E. L., \& Ryan, R. M. (2000). The 'what' and 'why' of goal pursuits: Human needs and the self-determination of behavior. Psychological Inquiry, 11, 227-268.

De Cremer, D., \& Van Dijk, E. (2002). Perceived criticality and contributions in public good dilemmas: A matter of feeling responsible to all? Group Processes e Intergroup Relations, 5, 319-332.

Denning, P. H., \& Campsmith, M. L. (2005). Unprotected anal intercourse among HIVpositive men who have sex with a steady male sex partner with negative or unknown HIV serostatus. American Journal of Public Health, 95, 152-158.

Díaz, R. M. (1998). Latino gay men and HIV: Culture, sexuality and risk behavior. New York: Routledge.

Dijker, A. J., Koomen, W., \& Kok, G. (1997). Interpersonal determinants of fear of people with AIDS: The moderating role of predictable behavior. Basic and Applied Social Psychology 19, 61-79

Donovan, B., Bodsworth, N. J., Rohrheim, R., McNulty, A., \& Tapsall, J. W. (2000). Increasing gonorrhoea reports-not only in London. Lancet, 355, 1908. 
Dukers, N. H. T. M., Goudsmit, J., De Wit, J. B. F., Prins, M., Weverling, G. J., \& Coutinho, R. A. (2001). Sexual risk behaviour relates to the virological and immunological improvements during highly active antiretroviral therapy in HIV-l infection. AIDS, 15, 369-378.

Dukers, N. H. T. M., Stolte, I. G., Albrecht, N., Coutinho, R. A., \& De Wit, J. B. (2001). The impact of experiencing lipodystrophy on the sexual behavior and well-being among HIV-infected homosexual men. AIDS, 15, 369-378.

Dunn, C., Deroo, L., \& Rivara, F. P. (2001). The use of brief interventions adapted from motivational interviewing across behavioral domains: A systematic review. Addiction, 96, 1725-1742.

Elford, J. (2006). Changing patterns of sexual behaviour in the era of highly active antiretroviral therapy. Current Opinion in Infectious Diseases, 19, 26-32.

Elford, J., Bolding, G., Davis, M., Sherr, L., \& Hart, G. (2004a). Trends in sexual behavior among London homosexual men 1998-2003: Implications for HIV prevention and sexual health promotion. Sexually Transmitted Infections, 80, 451-454.

Elford, J., Bolding, G., Davis, M., Sherr, L., \& Hart, G. (2004b). Web-based behavioral surveillance among men who have sex with men: A comparison of online and offline samples in London, UK. Journal of Acquired Immune Deficiency Syndromes, 35 , 421-426.

Elford, J., Bolding, G., Maguire, M., \& Sherr, L. (2000). Combination therapies for HIV and sexual risk behavior among gay men. Journal of Acquired Immune Deficiency Syndromes, 23, 266-271.

Elford, J., Bolding, G., Maguire, M., \& Sherr, L. (2001). HIV positive and negative homosexual men have adopted different strategies for reducing the risk of HIV transmission. Sexually Transmitted Infections, 77, 224-225.

Elford, J., Bolding, G., \& Sherr, L. (2002). High-risk sexual behavior increases among London gay men between 1998 and 2001: What is the role of HIV optimism? AIDS, $16,1537-1544$.

Ellis, A. (1975). The rational-emotive approach to sex therapy. The Counseling Psychologist, 5 , 14-21.

Evans, R. I., Raines, B. E., \& Hanselka, L. (1985). Developing data-based communications in social psychological research: Adolescent smoking prevention. Journal of Applied Social Psychology, 14, 289-295.

Fideli, U. S., Allen, S. A., Musonda, R., Trask, S., Hahn, B. H., Weiss, H., Mulenga, J., Kasolo, F., Vermund, S. H., \& Aldrovandi, G. H. (2001). Virologic and immunologic determinants of heterosexual transmission of human immunodefieciency virus type 1 in Africa. AIDS Reserch and Human Retroviruses, 17, 901-910.

Finucane, M. L., Alhakami, A., Slovic, P., \& Johnson, S. M. (2000). The affect heuristic in judgments of risks and benefits. Journal of Behavioral Decision Making, 13, 1-17.

Fishbein, M., \& Ajzen, I. (1975). Belief, attitude, intention, and behavior: An introduction into theory and behavior. Reading, MA: Addison-Wesley.

Fishbein, M., Triandis, H. C., Kanfer, F. H., Becker, M., Middlestadt, S. E., \& Eichler, A. (2001). Factors influencing behavior and behavior change. In A. Baum, T.

A. Revenson, \& J. E. Singer (Eds.), Handbook of Health Psychology (pp. 727-746). Mahwah, NJ: Lawrence Erlbaum Associates, Inc.

Fisher, J. D., Fisher, W. A., Cornman, D. H., Amico, R. K., Bryan, A., \& Friedland, G. H. (2006). Clinician-delivered intervention during routine clinical care reduces unprotected sexual behavior among HIV-infected patients. Journal of Acquired Immune Deficiency Syndromes, 41, 44-52. 
Fisher, J. D., Willcuts, D. L. K., Misovich, S. J., \& Weinstein, B. (1998). Dynamics of sexual risk behavior in HIV-infected men who have sex with men. AIDS and Behavior, 2, 101-113.

Flowers, P., Marriott, C., \& Hart, G. (2000). 'The bars, the bogs, and the bushes': The impact of locale on sexual cultures. Culture, Health e Sexuality, 2, 69-86.

Flowers, P., Sheeran, P., Beail, N., \& Smith, J. A. (1997). The role of psychosocial factors in HIV risk-reduction among gay and bisexual men: A quantitative review. Psychology and Health, 12, 197-230.

Frankis, J., \& Flowers, P. (2005). Men who have sex with men (MSM) in public sex environments (Pses): A systematic review of quantitative literature. Aids Care, 17, 273-288.

Glasgow, R. E., \& Rosen, G. M. (1978). Behavioral bibliotherapy: A review of self-help behavior therapy manuals. Psychological Bulletin, 85, 1-23.

Gochros, H. L. (1992). The sexuality of gay men with HIV infection. Social Work, 37, 105109.

Godin, G., \& Kok, G. (1996). The theory of planned behavior: A review of its applications to health-related behaviors. The Science of Health Promotion, 11, 87-98.

Godin, G., Savard, J., Kok, G., Fortin, C., \& Boyer, R. (1996). HIV seropositive gay men: Understanding adoption of safe sexual practices. AIDS Education and Prevention, 8 , 529-545.

Gollwitzer, P. M. (1999). Implementation intentions: Strong effects of simple plans. American Psychologist, 54, 493-503.

Gollwitzer, P. M., \& Sheeran, P. (2006). Implementation intentions and goal achievement: A meta-analysis of effects and processes. Advances in Experimental Social Psychology, 38, 249-268.

Gould, R. A., \& Clum, G. A. (1993). A meta-analysis of self-help treatment approaches. Clinical Psychological Review, 1, 1-20.

Gras, L., Van Sighem, A., Zaheri, S., \& De Wolf, F. (2005). Scientific report 2005. Monitoring of Human Immunodeficiency Virus (HIV) infection in the Netherlands. Amsterdam: HIV Monitoring Foundation.

Green, G., \& Smith, R. (2004). The psychosocial and health care needs of HIV-positive people in the United Kingdom: A review. HIV Medicine, 5 5-46.

Green, G., \& Sobo, E. (2000). The endangered self: Managing the social risks of HIV. London: Routledge.

Greenberg, J. B., Johnson, W. D., \& Fichtner, R. R. (1996). A community support group for HIV-seropositive drug users: Is attendance associated with reductions in risk behavior? AIDS Care, 8, 529 - 540

Gregoire, A. (1999). ABC of sexual health. British Medical Journal, 318, 245-247.

Guttman, N. (2000). Public health communication interventions. Values and ethical dilemmas. Thousand Oaks: Sage Publications.

Guttman, N., \& Ressler, W. H. (2001). On being responsible: Ethical issues in appeals to personal responsibility in health campaigns. Journal of Health Communication, 6, 117136.

Halkitis, P. N., Green, K. A., Remien, R. H., Stirratt, M. J., Hoff, C. C., Wolitski, R. J., \& Parsons, J. T. (2005). Seroconcordant sexual partnerings of HIV-seropositive men who have sex with men. AIDS, 19, S77-S86.

Halkitis, P. N., \& Parsons, J. T. (2003). Intentional unsafe sex (barebacking) among HIVpositive gay men who seek sexual partners on the Internet. AIDS Care, 15, 367-378. 
Halkitis, P. N., Parsons, J. T., \& Wilton, L. (2003). Barebacking among gay and bisexual men in New York City: Explanations for the emergence of intentional unsafe behavior. Archives of Sexual Behavior, 32, 351-357.

Halkitis, P. N., Wilton, L., Parsons, J. T., \& Hoff, C. (2004). Correlates of sexual risktaking behaviour among HIV seropositive gay men in concordant primary partner relationships. Psychology, Health $\sim$ Medicine, 9, 99-113.

Hankins, C., Gendron, S., Tran, T., Lamping, D., \& Lapointe, N. (1997). Sexuality in Montreal women living with HIV. Aids Care, 9, 261-271.

Harland, P., Staats, H., \& Wilke, H. A. M. (1999). Explaining pro-environmental intention and behavior by personal norms and the theory of planned behavior. Journal of Applied Social Psychology, 29, 2505-2528.

Hart, T. A., Wolitski, R. J., Purcell, D. W., Gomez, C., \& Halkitis, P. (2003). Sexual behavior among HIV positive men who have sex with men. Journal of Sex Research, 40, 197-188.

Heany, C. A., \& Israel, B. A. (2002). Social networks and social support. In K. Glanz \& B. K. Rimer \& M. L. Frances (Eds.), Health behavior and health education. Theory, research and practice (pp. 185-209). San Francisco, CA: Jossey-Bass.

Heinen, M. M., Bartholomew, L. K., Wensing, M., Van de Kerkhof, P., \& Van Achterberg, T. (2006). Supporting adherence and healthy lifestyles in leg ulcer patients: Systematic development of the Lively Legs program for dermatology outpatient clinics. Patient Education and Counseling, 61, 279-291.

Herbst, J. H., Sherba, R. T., Crepaz, N., Deluca, J. B., Zohrabyan, L., Stall, R. D., \& Lyles, C. M. (2005). A meta-analytic review of HIV behavioral interventions for reducing sexual risk behavior of men who have sex with men. Journal of Acquired Immune Deficiency Syndromes, 39, 228-241.

Herek, G. M. (1999). AIDS and Stigma. American Behavioral Scientist, 42, 1106-1116.

Hickson, F., Weatherburn, P., \& Reid, D. (2002). Vital Statistics Scotland 2001:Findings from the gay men's sex survey. London: Sigma research.

Hickson, F., Weatherburn, P., Reid, D., \& Stephens, M. (2003). Out and about: Findings from the United Kingdom gay men's sex survey. London: Sigma research.

Higgens, S. P., Sukthankar, A., Mahto, M., Jarvis, R. R., \& Lacey, H. B. (2000). Syphilis increases in Manchester, UK. Lancet, 355, 1908.

Hirshfield, S., Remien, R. H., Humberstone, M., Walavalkar, I., \& Chiasson, M. A. (2004). Substance use and high-risk sex among men who have sex with men: A national online study in the USA. AIDS Care, 16, 1036-1047.

Hobbis, I. C. A., \& Sutton, S. (2005). Are techniques used in cognitive behaviour therapy applicable to behaviour change interventions based on the theory of planned behaviour? Journal of Health Psychology, 10, 7-18.

Hoff, C. C., Gomez, C., Faigeles, B., Purcell, D. W., Halkitis, P. N., Parsons, J. T., \& Remien, R. H. (2004). Serostatus of primary partner impacts sexual behavior inside and outside the relationship: A description of HIV-positive MSM in primary relationships. Journal of Psychology and Human Sexuality, 16, 77-95.

Hogeweg, J., \& Hospers, H. J. (2000). Monitoronderzoek 2000 [Monitor research 2000]. Maastricht: Maastricht University.

Hopper, J. R., \& Nielsen, J. M. (1991). Recycling as altruistic behavior: Normative and behavioral strategies to expand participation in a community recycling program. Environment and Behavior, 23, 195-220.

Hospers, H., \& Blom, C. (1998). HIV prevention activities for gay men in the Netherlands 1983-93. In T. Sandfort (Ed.), The Dutch response to HIV: Pragmatism and consensus (pp. 40-60). London: UCL Press. 
Hospers, H. J., Dörfler, T. T., \& Zuilhof, W. (2004). Monitoronderzoek Amsterdam 2004 [Monitoring Study Amsterdam 2004]. Amsterdam: Schorer.

Hospers, H. J., Dörfler, T., \& Zuilhof, W. (2006). Schorermonitor 2006 [Dutch Gay and Lesbian Health Foundation Monitoring Study 2006]. Amsterdam: Schorer.

Hospers, H. J., \& Kok, G. (1995). Determinants of safe and risk-taking sexual behavior among gay men: A review. AIDS Education and Prevention, 7, 74-96.

Hospers, H. J., Kok, G., Harterink, P., \& De Zwart, O. (2005). A new meeting place: Chatting on the internet, e-dating and sexual risk behavior among Dutch men who have sex with men. AIDS, 19, 1097-1101.

Hull, P., Van de Ven, P., Prestage, G., Rawstorne, P., Gruhlich, A., Crawford, J., Kippax, S., Madeddu, D., McGuigan, D., \& Nicholas, A. (2003). Gay community periodic survey: Sydney 1996-2002. Sydney: National Centre in HIV Social Research.

International HIV/AIDS Alliance. (2003). Positive Prevention: Prevention strategies for people with HIV/AIDS: International HIV/AIDS Alliance.

Johnson, B. T., Carey, M. P., Chaudoir, S., \& Reid, A. E. (2006). Sexual risk reduction for persons living with HIV: Research synthesis of randomized controlled trials, 1993 to 2004. Journal of Acquired Immune Deficiency Syndromes, 41, 642-650.

Jones, M., Klimes, I., \& Catalan, J. (1994). Psychosexual problems in people with HIV infection: Controlled study of gay men and men with haemophilia. AIDS Care, 6, 587-593.

Jost, S., Bernard, M. C., Kaiser, L., Yerly, S., Hirschel, B., Samri, A., Autran, B., Goh, L. E., $\&$ Perrin, L. (2002). A patient with HIV-1 superinfection. New England Journal of Medicine, 347, 731-736.

Kalichman, S. C. (1998). Preventing AIDS: A sourcebook for behavioral interventions, Mahwah, NJ: Lawrence Erlbaum Associates.

Kalichman, S. C. (2000). HIV transmission risk behaviors of men and women living with HIV-AIDS: Prevalence, predictors, and emerging clinical interventions. Clinical Psychology: Science and Practice, 7, 32-46.

Kalichman, S. C., Carey, M. P., \& Johnson, B. T. (1996). Prevention of sexually transmitted HIV infection: A meta-analytic review of the behavioral outcome literature. Annals of Behavioral Medicine, 18, 6-15.

Kalichman, S. C., \& Nachimson, D. (1999). Self-efficacy and disclosure of HIV-positive serostatus to sex partners. Health Psychology, 18, 281-287.

Kalichman, S. C., Rompa, D., \& Cage, M. (2000). Sexually transmitted infections among HIV seropositive men and women. Sexually Transmitted Infections, 76, 350-354.

Kegeles, S. M., \& Hart, G. J. (1998). Recent HIV-prevention interventions for gay men: Individual, small-group and community-based studies. AIDS, 12, s209-s215.

Kelly, J. A. (1991). Changing the behavior of an HIV-seropositive man who practices unsafe sex. Hospital and Community Psychiatry, 42, 239-240.

Kelly, J. A. (2000). HIV prevention interventions with gay or bisexual men and youth. AIDS, 14, s34-s39.

Kelly, J. A., St.Lawrence, J. S., Stevenson, L. Y., Houth, A. C., Kuliehman, S. C., Diaz, Y. E., Brasfield, T. L., Koob, J. J., \& Morgan, M. G. (1992). Community AIDS/HIV risk reduction: The effects of endorsements by popular people in three cities. American Journal of Public Health, 82, 1483-1489.

Keogh, P., Weatherburn, P., \& Stephens, M. (1999). Relative safety. Risk and unprotected anal intercourse among gay men diagnosed with HIV. London: Sigma Research.

King-Spooner, S. (1999). HIV prevention and the positive population. International Journal of STD \& AIDS, 10, 141-150. 
Kok, G. (1999). Targeted prevention for people with HIV/AIDS: Feasible and desirable? Patient Education and Counseling, 36, 239-246.

Kools, M. (2006). Get the picture? A cognitive-psychological approach to systematic health education materials design. Unpublished doctoral dissertation, Universiteit Maastricht, Maastricht.

Kools, M., Ruiter, R. A. C., Van de Wiel, M., \& Kok, G. (in press). Testing the usability of access structures in a health education brochure. British Journal of Health Psychology.

Kotses, H., Lewis, P., \& Creer, T. L. (1990). Environmental control of asthma selfmanagement. Journal of Asthma, 27, 375-384.

Lamba, H., Goldmeier, D., Mackie, N. E., \& Scullard, G. (2004). Antiretroviral therapy is associated with sexual dysfunction and with increased serum oestradiol levels in men. International Journal of STD $\sim$ AIDS, 15, 234-237.

Latané, B., \& Darley, J. M. (1970). The unresponsive bystander: Why doesn't he help? New York: Appleton-Century-Crofts.

Laumann, E. O., Paik, A., \& Rosen, R. C. (1999). Sexual dysfunction in the United States. Prevalence and predictors. Journal of American Medical Association, 281, 537-544.

Lee, Y. J., De Young, R., \& Marans, R. W. (1995). Factors influencing individual recycling behavior in office settings: A study of office workers in Taiwan. Environment and Behavior, 27, 380-403.

Little, S. J., Holte, S., Routy, J. P., Daar, E. S., Markowitz, M., Collier, A. C., Koup, R. A., Mellors, J. W., Connick, E., Conway, B., Kilby, M., Wang, L., Whitcomb, J. M., Hellmann, N. S., \& Richman, D. D. (2002). Antiretroviral drug resistance among patients recently infected with HIV. New England Journal of Medicine, 374, 385-394.

Locke, E. A., \& Latham, G. P. (1991). A theory of goal setting and task performance. Englewood Cliffs, NJ: Prentice Hall.

Lupton, D. (1995). The imparative of health. Public health and the regulated body. London: Sage.

Maes, S., \& Karoly, P. (2005). Self-regulation assessment and interventions in physical health and illness: A review. Applied Psychology An International Review, 54, 267-299.

Mansergh, G., Marks, G., Colfax, G. N., Guzman, R., Rader, M., \& Buchbinder, S. (2002). 'Barebacking' in a diverse sample of men who have sex wih men. AIDS, 16, 653-659.

Manstead, S. R. (2000). The role of moral norm in the attitude-behavior relation. In D. J. Terry \& M. A. Hogg (Eds.), Attitudes, behavior and social context. The role of norms and group membership. Mahwah, NJ: Lawrence Erlbaum.

Marks, G., Burris, S., \& Peterman, T. A. (1999). Reducing sexual transmission of HIV from those who know they are infected: The need for personal and collective responsibility. AIDS, 13, 267-306.

Marks, G., Richardson, L. R., \& Maldonado, N. (1991). Self-disclosure of HIV infection to sexual partners. American Journal of Public Health, 81, 1321-1322.

Masters, W. H., \& Johnson, V. E. (1970). Human sexual inadequacy. Boston: Little, Brown.

Mattison, A. M., Ross, M. W., Wolfson, T., \& Franklin, D. (2001). Circuit party attendance, club drug use, and unsafe sex in gay men. Journal of Substance Abuse, 13, 119-126.

Mayer, K. H., Safren, S. A., \& Gordon, C. M. (2004). HIV care providers and prevention. Opportunities and challenges. Journal of Acquired Immune Deficiency Syndromes, 37 , sl30-sl32.

McConnell, J. J., Grant, R. M., \& Greenwood, G. (2002). Concerns about HIV superinfection and the sexual practices of seroconcordant couples. [Abstract C10929]. Paper presented at the XIV International AIDS Conference, Barcelona. 
McPherson-Baker, S., Malow, R. M., Penedo, F., Jones, D. L., Schneiderman, N., \& Klimas, N. G. (2000). Enhancing adherence to combination antiretroviral therapy in nonadherent HIV-positive men. AIDS Care, 12, 399-404.

Messick, D. M., \& Brewer, M. B. (1983). Solving social dilemmas, Review of Personality and Social Psychology (Vol. 4, pp. 11-44). Beverly Hills, CA: Sage.

Meyer-Bahlburg, H. F. L., Exner, T. M., Lorenz, G., Gruen, R. S., Gorman, J. M., \& Ehrhardt, A. A. (1991). Sexual risk behavior, sexual functioning, and HIV-disease progression in gay men. Journal of Sex Research, 28, 3-27.

Michie, S., \& Abraham, C. (2004). Interventions to change health behaviors: Evidencebased or evidence inspired? . Psychology $\sim$ Health, 19, 29-49.

Mikolajczak, J., Hospers, H. J., \& Kok, G. (2007). The effects of HIV-testing and counseling on sexual risk behavior: A systematic review of published articles between 1996 - 2006. Unpublished manuscript.

Miller, M., Meyer, L., Boufassa, F., Persoz, A., Sarr, A., Robain, M., \& Spira, A. A. (2000). Sexual behavior changes and protease inhibitor therapy. AIDS, 14, F33-F39.

Miller, W. R., \& Rollnick, S. (1991). Motivational interviewing: Preparing people to change addictive behavior. New York: The Guilford Press.

Miller, W. R., \& Rollnick, S. (2002). Motivational interviewing: Preparing people for change. New York: The Guilford Press.

Miller, W. R., Toscova, R. T., Miller, J. H., \& Sanchez, V. (2000). A theory-based motivational approach for reducing alcohol/drug problems in college Health Education and Behavior, 27, 744-759.

Monga, U. (2002). Sexual Functioning in Cancer Patients Sexuality and Disability, 20, 277295.

Montano, D. E., \& Kasprzyk, D. (2002). The theory of reasoned action and the theory of planned behavior. In K. Glanz, B. K. Rimer, \& F. M. Lewis (Eds.), Health behavior and health education. Theory, research, and practice (pp. 67-98). San Francisco, CA: Jossey-Bass.

Murphy, G., Charlett, A., Brown, A. E., Gill, O. N., \& Parry, J. V. (2004). Is HIV incidence increasing in homo/bisexual men attending GUM clinics in England, Wales and Northern Ireland? Communicable Disease and Public Health, 7, 11-14.

Nelissen, R., Dijker, A., \& De Vries, N. (in press). Emotions and goals: Assessing relations between values and emotions. Cognition \& Emotion.

Nimmons, D. (1998). In this together: The limits of prevention based on self-interest and the role of altruism in HIV safety. Journal of Psychology and Human Sexuality, 10, 75-87.

Nimmons, D., \& Folkman, S. (1999). Other-sensitive motivation for safer sex among gay men: Expanding paradigms for HIV prevention. AIDS and Behavior, 3, 313-324.

Offir, J. T., Fisher, J. D., Williams, S. S., \& Fisher, W. A. (1993). Reasons for inconsistent AIDS-preventive behaviors among gay men. The Journal of Sex Research, 30, 62-69.

O'Leary, A., Wolitski, R. J., Remien, R. H., Woods, W. J., Parsons, J. T., Moss, S., \& Lyles, C. M. (2005). Psychosocial correlates of transmission risk behavior among HIVseropositive gay and bisexual men. AIDS, 19, S67-S75.

Op de Coul, E., Van Sighem, A., \& Van de Laar, M. (2006a). Schatting van het aantal volwassenen met HIV/aids in Nederland in 2005 [National estimate of people living with HIV/AIDS in 2005 in the Netherlands]. Infectieziekte bulletin, 17, 398-403.

Op de Coul, E. L. M., De Boer, I. M., \& Van Sighem, A. I. (2006b). Soa en hiv in Nederland in 2006 [STDs and HIV in the Netherlands in 2005]. SOA AIDS Magazine on-line, 3.

Orbell, S., \& Sheeran, P. (1998). 'Inclined abstainers': A problem for predicting health behaviour. British journal of social psychology, 37, 151-166. 
Orr, G., Catalan, J., \& Longstaff, C. (2004). Are we meeting the psychological needs of heterosexual men with HIV disease? A retrospective case controlled study of referrals to a psychological medicine unit in London, UK. AIDS Care, 16, 586 - 593.

Ostrow, D. G. (1999). Practical prevention issues. In D. G. Ostrow \& S. C. Kalichman (Eds.), Psychosocial and public health impacts of new hiv therapies (pp. 151-169). New York: Kluwer Academic/Plenum Publishers.

Ostrow, D. E., Fox, K. J., Chmiel, J. S., Silvestre, A., Visscher, B. R., Vanable, P. A., Jacobson, L. P., \& Strathdee, S. A. (2002). Attitudes toward highly active antiretroviral therapy are associated with sexual risk taking among HIV-infected and uninfected homosexual men. AIDS, 16, 775-780.

Ostrow, D. G., \& Kalichman, S. C. (1999). Psychosocial and public health impacts of new HIV therapies. New York: Kluwer Academic/Plenum Publishers.

Parker, D., West, R., Stradling, S., \& Manstead, A. S. R. (1995). Extending the theory of planned behaviour: The role of personal norm. British Journal of Social Psychology, 34, $127-137$.

Parsons, J. T., \& Halkitis, P. N. (2002). Sexual and drug-using practices of HIV-positive men who frequent public and commercial sex environments. AIDS Care, 14, 815-826.

Parsons, J. T., Halkitis, P. N., Wolitski, R. J., \& Gómez, C. A. (2003). Correlates of sexual risk behaviors among HIV-positive men who have sex with men. AIDS Education and Prevention, 15, 383-400.

Parsons, J. T., Schrimshaw, E. W., Wolitski, R. J., Halkitis, P., Purcell, D. W., Hoff, C. C., \& Gómez, C. A. (2005). Sexual harm reduction practices of HIV-seropositive gay and bisexual men: Serosorting, strategic positioning, and withdrawal before ejaculation. AIDS, 19, S13-S25.

Penner, L. A., Dovidio, J. F., Piliavin, J. A., \& Schroeder, D. A. (2005). Prosocial behavior: Multilevel perspectives. Annual Review of Psychology, 56, 365-392.

Perry, S. W., Card, C. A. L., Moffatt, M., Ashman, T., Fishman, B., \& Jacobsberg, L. B. (1994). Self-disclosure of HIV infection to sexual partners after repeated counseling. AIDS Education and Prevention, 6, 403-411.

Persson, A., Race, K., \& Wakeford, E. (2003). HIV health in a context: Negotiating medical technology and lived experience. Health, 7, 397-415.

Piliavin, J. A., Dovidio, J., Gaertner, S. L., \& Clark, R. D. I. (1992). Responsive bystanders: the process of intervention. In V. Derlega \& J. Grzelak (Eds.), Cooperation and helping behavior: Theories and research. New York: Academic Press.

Pomazal, R. J., \& Jaccard, J. J. (1976). An informational approach to altruistic behavior. Journal of Personality and Social Psychology, 33, 317-326.

Poppen, P. J., Reisen, C. A., Zea, M. C., Bianchi, F. T., \& Echeverry, J. J. (2005).

Serostatus disclosure, seroconcordance, partner relationship, and unprotected anal intercourse among HIV-positive Latino men who have sex with men. AIDS Education and Prevention, 17, 227-237.

Prestage, G., Van de Ven, P., Grulich, A., Kippax, S., McInnes, D., \& Hendry, O. (2001). Gay men's casual sex encounters: Discussing HIV and using condoms. AIDS Care, $13,277-284$.

Prieur, A. (1990). Norwegian gay men: reasons for continued practice of unsafe sex. AIDS Education and Prevention, 2, 109-115.

Prochaska, J. O., DiClemente, C. C., \& Norcoss, J. C. (1997). In search of how people change: Applications to addictive behaviors. In G. Marlatt \& G. R. Van den Bos (Eds.), Addictive behaviors: Reading on etiology, prevention, and treatment. Washington, DC: American Psychological Association. 
Prochaska, J. O., Redding, C. A., \& Evers, K. E. (2002). The transtheoretical model and stages of change. In K. Glanz, B. K. Rimer, \& F. M. Lewis (Eds.), Health behavior and health education. Theory, research and practice (pp. 99-120). San Francisco, CA: JosseyBass.

Quadland, M. C. (1992). Sexual issues in psychotherapy for people with HIV/AIDS. Siecus Report, 20, 4-11.

Quinn, T. C., Wawer, M. J., Sewankambo, N., Serwadda, D., Li, C., Wabwire-Mangen, F., Meehan, M. O., Lutalo, T., \& Gray, R. H. (2000). Viral load and heterosexual transmission of human immunodeficiency virus type 1 in vivo. The New England Journal of Medicine, 342, 921-929.

Ramos, A., Hu, D. J., Nguyen, L., Phan, K. O., Vanichseni, S., Promadej, N., Choopanya, K., Callahan, M., Young, N. L., McNicholl, J., Mastro, T. D., Folks, T. M., \& Subbarao, S. (2002). Intersubtype Human Immunodeficiency Virus Type 1 Superinfection following Seroconversion to Primary Infection in Two Injection Drug Users Journal of Virology, 76(7444-7452).

Remor, E. A., \& Ulla, S. (2002). Sexuality, perceived illness, and quality of life in Spanish gay and bisexual men living with HIV. Journal of the Gay and Lesbian Medical Association 6, 41-45.

Richard, R., De Vries, N. K., \& Van der Pligt, J. (1998). Anticipated regret and precautionary sexual behavior. Journal of Applied Social Psychology, 28, 1411-1428.

Richard, R., Van der Pligt, J., \& De Vries, N. (1995). Anticipated affective reaction and the prevention of AIDS. British Journal of Social Psychology, 34, 9-21.

Richelle, M. (1993). Skinner. A reappraisal. London: Lawrence Erlbaum Associates.

Richman, D. D., Bozette, S., Morton, S., Wrin, C. T., Dawson, N., \& Hellmann, N. (2001, December 16-19). The prevalence of antiretroviral drug resistance in the U.S. [abstract LB-17]. Paper presented at the 4lst Interscience Conference on Antimicrobial Agents and Chemotherapy, Chicago, IL.

Ritchie, J., Lewis, J., \& Elam, G. (2003). Designing and selecting samples. In J. Ritchie \& J. Lewis (Eds.), Qualitative research practice: A guide for social science students and researchers (pp. 77-108). London Sage.

Rhodes, T., \& Cusick, L. (2002). Accounting for unprotected sex: Stories of agency and acceptability. Social Science \& Medicine, 55, 211-226.

Rogers, T. (1995). Diffusion of innovations. New York: Free Press.

Rollnick, S., Mason, P., \& Butler, C. (1999). Health behavior change. A guide for practitioners. Edinburgh: Churchill Livingstone.

Rollnick, S., \& Miller, W. R. (1995). What is motivational interviewing? Behavioural and Cognitive Psychotherapy 23, 325-334.

Rosen, R. C., \& Leiblum, S. R. (1995). Treatment of sexual disorders in the 1990s: An integrated approach. Journal of Consulting and Clinical Psychology, 63.

Rosen, R. C., Leiblum, S. R., \& Spector, I. (1994). Psychologically based treatment for male erectile disorder: A cognitive interpersonal model. Journal of Sex and Marital Therapy, 20, 67-85.

Rosenburg, M. (1965). Society and the adolescent self-image. Princeton, NJ: Princeton University Press.

Rosenburg, M. (1979). Conceiving the self. New York: Basic Books.

Rosengarten, M., Race, K., \& Kippax, S. (2000). “Touch wood, everything will be ok.” Gay men's understandings of clinical markers in sexual practice. Sydney: National Centre in HIV Social Research. 
Ross, M. W., \& Schonnesson, L. N. (2000). HIV/AIDS and sexuality. In F. Muscarella \& L. Szuchman (Eds.), Psychological perspectives in human sexuality (pp. 383-415). New York: John Wiley \& Sons.

Ross, M. W., Mattison, A. M., \& Franklin, D. R. (2003). Club drugs and sex on drugs are associated with different motivations for gay circuit party attendance in men. Substance Use \& Misuse, 38, 1173-1183.

Rotheram-Borus, M. J., Lee, M., Murphy, D. A., Futterman, D., Duan, N., Birnbaum, J. M., $\&$ Lightfoot, M. (2001). Efficacy of a preventive intervention for youths living with HIV. American Journal of Public Health, 91, 400-405.

Rotheram-Borus, M. J., Murphy, D. A., Wight, R. G., Lee, M. B., Lightfoot, M., Swendeman, D., Birnbaum, J. M., \& Wright, W. (2001). Improving the quality of life among young people living with HIV. Evaluation and Program Planning, 24, 227237.

Rottingen, J. A., Cameron, D. W., \& Garnett, G. P. (2001). A systematic review of the epidemiologic interactions between classic sexually transmitted diseases and HIV: How much really is known? Sexually Transmitted Diseases, 28, 579-597.

Rubenstein, L. V., Mittman, B. S., Yano, E. M., \& Mulrow, C. D. (2000). From understanding health care provider behavior to improving health care: The QUERI framework for quality improvement. Medical Care, 38, I129-Il41.

Rutledge, S. E., Roffman, R. A., Mahoney, C., Picciano, J. F., Berghuis, J. P., \& Kalichman, S. C. (2001). Motivational enhancement counseling strategies in delivering a telephone-based brief hiv prevention intervention. Clinical Social Work Journal, 29, 291-306.

Rye, B. J., Fisher, W. A., \& Fisher, J. D. (2001). The theory of planned behavior and safer sex behaviors of gay men. AIDS and Behavior, 5, 307-317.

Schiltz, M. A., \& Sandfort, T. G. M. (2000). HIV-positive people, risk and sexual behavior. Social Science \& Medicine, 50, 1571-1588.

Schippers, J., \& Van Kesteren, N. M. C. (2004). Hiv en seks. Een zelfhulpgids voor hiv-positieve homoseksuele mannen [HIV and sex. Self-help guide for HIV-positive gay men]. Amsterdam: Schorerstichting.

Schroeder, D. A., Penner, L. A., Dovidio, J. F., \& Piliavin, J. A. (1995). The psychology of helping and altruism. Problems and puzzles. New York: McGraw-Hill.

Schwartz, S. H. (1973). Normative explanations of helping behavior: A critique, proposal, and empirical test. Journal of Experimental Social Psychology, 9, 349-364.

Schwartz, S. H. (1977). Normative influences on altruism. In L. Berkowitz (Ed.), Advances in experimental social psychology (Vol. 10, pp. 221-279). New York: Academic press.

Schwartz, S. H., \& Howard, J. A. (1981). A normative decision-making model of altruism. In J. P. Rushton \& R. M. Sorrentino (Eds.), Altruism and helping behavior: Theories and research (pp. 327-353). New York: Academic Press.

Schwartz, S. H., \& Howard, J. A. (1982). Helping and cooperation: A self-based motivational model. In V. J. Derlega \& J. Grzelak (Eds.), Cooperation and helping behavior: theories and research (pp. 327-353). New York: Academic Press.

Schwartz, S. H., \& Howard, J. A. (1984). Internalized values as motivators of altruism. In E. Staub \& D. CBar-Tal \& J. Karylowski \& J. Reykowski (Eds.), Development and maintenance of prosocial behavior. New York: Plenum.

Schwartz, S. H., \& Tessler, R. C. (1972). A test of a model for reducing measured attitudebehavior discrepancies. Journal of Personality and Social Psychology, 24, 225-236.

Semans, J. H. (1956). Premature ejaculation: A new approach. Southern Medical Journal, 49, 353-358. 
Semple, S. J., Patterson, T. L., \& Grant, I. (2000a). Partner type and sexual risk behavior among HIV-positive gay and bisexual men: Social cognitive correlates. AIDS Education and Prevention, 12, 340-356.

Semple, S. J., Patterson, T. L., \& Grant, I. (2000b). Psychosocial predictors of unprotected anal intercourse in a sample of HIV positive gay men who volunteer for a sexual risk reduction intervention. AIDS Education and Prevention, 12, 416-430.

Semple, S. J., Patterson, T. L., \& Grant, I. (2000c). The sexual negotiation behavior of HIV-positive gay and bisexual men. Journal of Consulting and Clinical Psychology, 68, 934-937.

Semple, S. J., Patterson, T. L., \& Grant, I. (2003a). Binge use of methamphetamine among HIV-positive men who have sex with men: Pilot data and HIV prevention implication. AIDS Education and Prevention, 15, 133-147.

Semple, S. J., Patterson, T. L., \& Grant, I. (2003b). HIV-positive gay and bisexual men: Predictors of unsafe sex. AIDS Care, 15, 3-15.

Semple, S. J., Patterson, T. L., \& Grant, I. (2004). Psychosocial characteristics and sexual of HIV+ men who have anonymous sex partners. Psychology and Health, 19, 71-87.

Serovich, J. (2001). A test of two HIV disclosure theories. AIDS education and prevention, 13, $355-364$.

Sheeran, P. (2002). Intention-behavior relations: A conceptual and empirical review. In W. Stoebe \& M. Hewstone (Eds.), European Review of Social Psychology (Vol. 12, pp. 1-36). Chichester, UK: John Wiley \& Sons.

Sheeran, P., Abraham, C., \& Orbell, S. (1999). Psychosocial correlates of heterosexual condom use: A meta-analysis. Psychological Bulletin, 125, 90-132.

Sherbourne, C. D., \& Stewart, A. L. (1991). The MOS social support survey. Social Science e Medicine, 32, 705-714.

Sherr, L. (1995). Coping with psychosexual problems in the context of HIV infection. Sexual and Marital Therapy, 10, 307-319.

Silverberg, L. I. (2003). Bibliotherapy: The therapeutic use of didactic and literary texts in treatment, diagnosis, prevention, and training. Journal of American Osteopathic Association, 103, 131-135.

Smit, P. (2002). Juridische bommen en granaten onder de HIV-preventie [Legal bombs and grenades in HIV-prevention]. HIVnieuws, 78, 24-27.

Snape, D., \& Spencer, L. (2003). The foundations of qualitative research. In J. Ritchie \& J. Lewis (Eds.), Qualitative research practice: A guide for social science students and researchers (pp. 1-23). London: Sage.

Sniehotta, F. F., Scholz, U., Schwarzer, R., Behr, H., Fuhrmann, B., Kiwus, U., \& Völler, H. (2005). Long-term effects of two psychological interventions on physical exercise and self-regulation after coronary rehabilitation. International Journal of Behavioral Medicine, 12, 244-255.

Sniehotta, F. F., Schwarzer, R., Scholz, U., \& Schüz, B. (2005). Action planning and coping planning for long-term lifestyle change: Theory and assessment. European Journal of Social Psychology, 35, 565-576.

SOA AIDS Nederland (2004). Penitentie of preventie. Amsterdam: Bestuurscommissie Aidsbeleid \& Strafrecht, http://www.aidsfonds.nl/folders/strafrecht.pdf

Stall, R., \& Purcell, D. W. (2000). Intertwining epidemics: A review of research on substance use among men who have sex with men and its connection to the AIDS epidemic. AIDS and Behavior, 4, 181-192. 
Steckler, A., Goodman, R. M., \& Kegler, M. C. (2002). Mobilizing organizations for health enhancement: Theories of organizational change. In K. Glanz \& B. K. Rimer \& M. L. Frances (Eds.), Health behavior and healtheducation. Theory, research and practice (pp. 312-334). San Francisco, CA: Jossey-Bass.

Stein, M. D., \& Samet, J. H. (1999). Disclosure of HIV status. AIDS Patient Care and STDs, 13, 265-267.

Sterling, T., Chaisson, R., \& Moore, R. (2001, October 25-28). Initiation of high active antiretroviral therapy (HAART) at CD4+ levels 350 : Assessment of disease progression, and drug failure, toxicity and resistance [abstract 687]. Paper presented at the 39th Annual Meeting of the Infectious Diseases Society of America, San Francisco, CA.

Stephenson, J. M., Imrie, J., Davis, M. M. D., Mercer, C., Copas, A. J., Hart, G. J., Davidson, O. R., \& Williams, I. G. (2002). Is use of antiretroviral therapy among homosexual men associated with increased risk of transmission of HIV infection? Sexually Transmitted Infections 79, 7-10.

Stolte, I. G., Dukers, N. H., De Wit, J. B., Fennema, J. S., \& Coutinho, R. A. (2001). Increase in sexually transmitted infections among homosexual men in Amsterdam in relation to HAART. Sexually Transmitted Infections, 77, 184-186.

Stolte, I. G., De Wit, J. B. F., Van Eeden, A., Coutinho, R. A., \& Dukers, N. H. T. M. (2004). Perceived viral load, but not actual HIV-1-RNA load, is associated with sexual risk behaviour among HIV-infected homosexual men. AIDS, 18, 1943-1949.

Suarez, T., \& Kauth, M. R. (2001). Assessing basic HIV transmission risks and the contextual factors associated with HIV risk behavior in men who have sex with men. Journal of Clinical Psychology, 57, 655-669.

Swanborn, P. G. (2002). Basisboek sociaal onderzoek [Textbook social research]. Meppel: Boom.

Swearingen, S. G., \& Klausner, J. D. (2005). Sildenafil use, sexual risk behavior, and risk for sexually transmitted diseases, including HIV infection. The American Journal of Medicine, 118, 571-577.

Taleporos, G., \& McGabe, M. P. (2002). The impact of sexual esteem, body esteem, and sexual satisfaction on psychological well-being in people with disability. Sexuality and Disability, 20, 177-123.

Tan, G., Waldman, K., \& Bostick, R. (2002). Psychosocial issues, sexuality, and cancer. Sexuality and Disability, 20, 297-317.

Tangney, J. P., \& Dearing, R. L. (2002). Shame and guilt. New York: The Guilford Press.

Theodore, P. S., Durán, R. E. F., Antoni, M. H., \& Fernandez, M. I. (2004). Intimacy and sexual behavior among HIV-positive men-who-have-sex-with-men in primary relationships. AIDS and Behavior, 8, 321-331.

Thoresen, C. E., \& Kirmil-Gray, K. (1983). Self-management psychology and the treatment of childhood asthma. Journal of Allergy and Clinical Immunology, 72, 596-606.

Tortolero, S. R., Markham, C. M., Parcel, G. S., Peters, R. J., Escobar-Chaves, S. L., BasenEngquist, K., \& Lewis, H. L. (2005). Using Intervention Mapping to adapt an effective HIV, Sexually Transmitted Disease, and pregnancy prevention program for high-risk minority youth. Health Promotion Practice, 6, 286-298.

Vanable, P. A., Ostrow, D. G., \& McKirnan, D. J. (2003). Viral load and HIV treatment attitudes as correlates of sexual risk behavior among HIV-positive gay men. Journal of Psychosomatic Research, 54, 263-269.

Vanable, P. A., Ostrow, D. G., McKirnan, D. J., Taywaditep, K. J., \& Hope, B. A. (2000). Impact of combination therapies in HIV risk perceptions and sexual risk among HIV-positive and HIV-negative gay and bisexual men. Health Psychology, 19, 134-145.

Van de Laar, M. J. W., \& Op de Coul, E. L. M. (2004). HIV and Sexually Transmitted Infections in the Netherlands in 2003. Bilthoven: Rijksinstituut voor Volksgezondheid en Milieu. 
Van den Hoek, C., Kok, G., Van Kesteren, N. M. C., Hospers, H. J., \& De Zwart, O. (2005). De waaghals en de prins. Een onderbouwde interventie voor HIV/soa preventie bij homojongens [The daredevil and the prince. A planned intervention for the prevention of HIV/STD among young men having sex with men]. TSG: Tijdschrift voor Gezondheidswetenschappen, 83, 159-165.

Van de Ven, P., Kippax, S., Crawford, J., Rawstorne, P., Prestage, G., Gruhlich, A., \& Murphy, D. (2002). In a minority of gay men, sexual risk practice indicates strategic positioning for perceived risk reduction rather than unbridled sex. AIDS Care, 14, 471-480.

Van de Ven, P., Prestage, G., Crawford, J., Gruhlich, A., \& Kippax, S. (2000). Sexual risk behavior increases and is associated with HIV optimism among HIV-negative and HIV-positive gay men in Sydney over the 4 year period to February 2000. AIDS, 14, 2951-2953.

Van Empelen, P., \& Kok, G. (2006). Condom use in steady and casual sexual relationships: Planning, preparation and willingness to take risks among adolescents. Psychology \& Health, 21, 165-181.

Van Empelen, P., Kok, G., Jansen, M. W. J., \& A., H. C. J. P. (2001). The additional value of anticipated regret and psychopathology in explaining intended condom use among drug users. AIDS Care, 13, 309-318.

Van Empelen, P., Kok, G., Schaalma, H., \& Bartholomew, L. K. (2003). An AIDS risk reduction program for Dutch drug users: An intervention mapping approach to planning. Health Promotion Practice, 4, 402-412.

Van Empelen, P., Kok, G., Van Kesteren, N. M. C., Van den Borne, B., Bos, A., \& Schaalma, H. P. (2003). Effective methods to change sex-risk among drug users: A review of psychosocial interventions. Social Science and Medicine, 57, 1593-1608.

Van Empelen, P., Schaalma, H. P., Kok, G., \& Jansen, M. W. J. (2001). Predicting condom use with casual and steady sex partners among drug users. Health Education Research, 16, 293-305.

Van Kesteren, N.M.C., \& De Wildt, W. (2004). Hiv en seks. Gespreksprotocol voor hiv-positieve homoseksuele mannen gebaseerd op de principes van motiverende gespreksvoering. [HIV and sex. Counseling protocol for HIV-positive MSM based on motivational interviewing]. Maastricht: Universiteit Maastricht.

Van Kesteren, N. M. C., Hospers, H. J., \& Kok, G. (2007). Sexual risk behavior in HIVpositive men who have sex with men: A literature review. Patient Education and Counseling, 65, 5-20.

Van Kesteren, N. M. C., Hospers, H. J., Kok, G., \& Van Empelen, P. (2005). Sexuality and sexual risk behavior among HIV-positive men who have sex with men. Qualitative Health Research, 15, 145-168.

Van Kesteren, N. M. C., Hospers, H. J., Van Breukelen, G., \& Kok, G. (2007). Evaluation of a self-help and motivational enhancement intervention to promote sexual health in HIV-positive men who have sex with men. Unpublished manuscript.

Van Kesteren, N. M. C., Hospers, H. J., Van Empelen, P., Van Breukelen, G., \& Kok, G. (2007). Sexual decision-making in HIV-positive men who have sex with men: How moral concerns and sexual motives guide intended condom use with steady and casual sex partners. Archives of Sexual Behavior, 36, 437-449.

Van Kesteren, N. M. C., Kok, G., Hospers, H. J., Schippers, J., \& De Wildt, W. (2006). Systematic development of a self-help and motivational enhancement intervention to promote sexual health in HIV-positive men who have sex with men. AIDS Patient Care and STDs, 20, 858-875. 
Van Lankveld, J. J. D. M. (1998). Bibliotherapy in the treatment of sexual dysfunctions: A meta-analysis. Journal of Consulting and Clinical Psychology, 66, 702-708.

Van Liere, K. D., \& Dunlap, R. E. (1978). Moral norms and environmental behavior: An application of Schwartz's norm-activation model to yard burning. Journal of Applied Social Psychology, 8, 174-188.

Van Riemsdijk, A., \& Van Kesteren, N. M. C. (2004). Adoption and implementation of HIV-prevention for HIV-positive men who have sex with men: HIV nurses' perceived facilitating and hindering factors. Unpublished manuscript.

Verdult, F. (2005). Tevredenheidsmeting zorg aan mensen met HIV. Een positieve testuitslag [Assessment of satisfaction with care to people with HIV. A positive diagnosis]. Hivnieuws, 93, 14-17.

Vittinghoff, E., Douglas, J., Judson, F., McKirnan, D., MacQueen, K., \& Buchbinder, S. (1999). Per-contact risk of human immunodeficiency virus transmission between male sexual partners American Journal of Epidemiology, 150, 306-311.

Vroege, J. A. (1998). Elf vragen over het seksueel functioneren [Eleven questions on sexual function]. Leiden: Rijksuniversiteit Leiden.

Walters, A. S., \& Williamson, G. M. (1998). Sexual satisfaction predicts quality of life: A study of adult amputees. Sexuality and Disability, 16, 103-115.

Weatherburn, P., Anderson, W., Reid, D., \& Henderson, L. (2002). What do you need? Findings from a national survey of people living with HIV. London: Sigma Research.

Weiner, B. (1986). An attributional theory of motivation and emotion. New York: Springer.

Weinhardt, L. S., Carey, M. P., Johnson, B. T., \& Bickman, N. L. (1999). Effects of HIV counseling and testing on sexual risk behavior: A meta-analytic review of published research, 1985-1997. American Journal of Public Health, 89, 1397-1405.

Wenger, N. S., Kusseling, F. S., Beck, K., \& Shapiro, M. F. (1994). Sexual behavior of individuals infected with the human immunodefieciency virus. The need for intervention. Archives of International Medicine, 154, 1849-1854.

Wenzel, L., Glanz, K., \& Lerman, C. (2002). Stress, coping, and health behavior. In K. Glanz \& B. K. Rimer \& F. M. Lewis (Eds.), Health behavior and health education. Theory, research, and practice (pp. 210-239). San Francisco, CA: Jossey-Bass.

Whittington, W. L. H., Collis, T., Dithmer-Schreck, D., Hansfield, H. H., Shalit, P., Wood, R. W., Holmes, K. K., \& Celum, C. L. (2002). Sexually transmitted diseases and human immunodeficiency virus - discordant partnerships among men who have sex with men. Clinical Infectious Diseases, 35, 1010-1017.

Williams, C. (2001). Use of written cognitive-behavioral therapy self-help materials to treat depression. Advances in Psychiatric Treatment, 7, 233-240.

Wolitski, R. J., Bailey, C. J., O’Leary, A., Gómez, C. A., \& Parsons, J. T. (2003). Selfperceived responsibility of HIV-seropositive men who have sex with men for preventing HIV transmission. AIDS and Behavior, 7, 363-372.

Wolitski, R. J., \& Branson, B. M. (2002). "Gray area behaviors" and partner selection strategies. In A. O'Leary (Ed.), Beyond condoms. Alternative approaches to HIV prevention (pp. 173-198). New York: Kluwer Academic/Plenum Publishers.

Wolitski, R. J., Gómez, C. A., \& Parsons, J. T. (2005). Effects of a peer-led behavioral intervention to reduce HIV transmission and promote serostatus disclosure among HIV-seropositive gay and bisexual men. AIDS, 19, S99-S110. 


\section{Summary}

The present thesis describes the development, implementation, and evaluation of a theory-and evidence-based HIV-preventive intervention for HIV-positive men who have sex with men (MSM). Although many of those who learn that they are HIV-positive subsequently modify their sexual behavior, behavioral studies have consistently shown that a significant number of HIV-positive MSM engage in unprotected anal intercourse (UAI). The potential health consequences of UAI for MSM are serious, regardless of HIV-status. HIV-negative men run the risk not only of initial HIV infection, but also of HIV infection with a drug-resistant virus, which might have major consequences for subsequent treatment. HIV-positive MSM run the risk of HIV superinfection and other sexually transmitted diseases (STDs), possibly resulting in accelerated progress to full-blown AIDS and death. As the introduction of combination therapy in 1996, also known as highly active antiretroviral therapy (HAART), has led to beneficial results, such as a prolonged life expectancy and increased quality of life among HIV-infected individuals, new HIV infections are increasingly being associated with MSM who are known HIV-positive and participate in UAI. To prevent further spread of HIV and STDs reducing sexual risk behavior among HIV-positive MSM is an important public health challenge.

Chapter 1 provides an overview of the entire research project and developmental process that is reported in chapter 2 to 6 of this thesis. It starts with an overview of the reasons why behavioral programs developed for HIV-positive populations have lagged behind those developed for HIV-negative or status unknown target populations. Next, Intervention Mapping is being introduced as a tool for systematically developing theory-and evidence-based health promotion programs, describing six fundamental steps: (1) conducting a needs assessment (analysis of health problem, health behavior, environment and determinants of health behavior and environment); (2) preparing matrices of change objectives; (3) selecting theoryinformed intervention methods and practical strategies; (4) producing program components and materials; (5) planning program adoption, implementation, and sustainability; and (6) planning for evaluation. Further three core processes for Intervention Mapping can be used by the professional health educator: searching the literature for empirical findings, finding and using theories, and collecting new data. The present research project can be divided into four phases: the needs assessment (Intervention Mapping Step 1; Chapter 2 to 4); the developmental phase of the intervention (Intervention Mapping Steps 2 to 4; Chapter 5); implementation of the intervention (Intervention Mapping Step 5; Chapter 5); and evaluation of the effects (Intervention Mapping Step 6; Chapter 6). Finally, the main conclusions and the implications for future research and for HIV prevention practice are discussed.

In developing an HIV-preventive intervention for HIV-positive MSM more insight is needed in the behavioral factors underlying the health problem. Therefore, 
Chapter 2 presents a literature review in which the prevalence of UAI in HIVpositive MSM was studied more closely. In order to get a broad overview of what has been published, 53 published studies were included that reported on UAI in cross-sectional and longitudinal surveys of HIV-positive MSM and MSM of mixed HIV status. Although the studies varied greatly in design, sampling and measurement of sexual risk behavior, which make comparisons extremely difficult, the findings indicate high levels of UAI among HIV-positive MSM. In fact, based on the studies incorporated in this review, evidence suggests that up to two in five HIV-positive MSM reported engaging in UAI, and that much of this risky behavior occurs with partners who are HIV-negative or whose status is unknown. In addition, the review study showed that the prevalence of sexual risk behavior is significantly higher among HIV-positive MSM than among MSM who are HIV-negative or whose HIV status is unknown. Furthermore, the prevalence of UAI among HIV-positive MSM has increased in recent years. Thus, the review underlines the importance of addressing HIV-positive MSM as an especially important target group for HIV prevention.

Chapter 3 examines the psychological processes pertaining to sexuality and sexual risk behavior among HIV-positive MSM. Transcripts of 30 semi-structured interviews were analysed using QRS NUDIST 4.0. Results suggested that many HIVpositive MSM suffer from sexual problems after being diagnosed with HIV, including a temporary cessation of sexual activity and overall impairment in sexual function. Despite the impact of HIV on sexual life, over time most participants found a way to express their sexuality. Nevertheless, sexuality was dominated by fear of transmitting HIV to sex partners and feelings of personal responsibility for safer sex, especially within the context of steady relationships. Although most participants felt personally responsible to protect their sex partners from HIV, contextual factors (e.g., partner variables and social norms) determined whether or not their perceived norms of personal responsibility were translated into behavior. Moreover, a substantial number of men seemed to lack the skills to effectively communicate their own health interests, negotiate condom use and resist pressure to engage in sexual risk behavior.

Chapter 4 present a study that was undertaken to provide insight in the determinants of HIV-positive MSM intention to use condoms for anal intercourse with steady and casual sex partners $(\mathrm{N}=296)$. Given the proposition that safer sex behavior among HIV-positive people is a form of prosocial behavior, the present study extended the general framework of the Theory of Planned Behavior with Schwartz's norm-activation theory and tested the assumption that personal norms would mediate the effects of other psychosocial factors on intended condom use for anal sex. In addition, it was hypothesized that, depending on the context in which sex occurs, specific motives for unprotected anal sex may have a negative influence on intended condom use and, as such, undermine a prosocial tendency to practice safer sex. Therefore, we also investigated the influence of sexual motives for unprotected 
anal sex on intended condom use with steady and casual sex partners. Results indicated that the Theory of Planned Behavior adequately predicted condom use intentions (for casual sex partners and steady sex partners the explained variance was respectively 52\% and 53\%). However, our proposed model of sexual decisionmaking significantly improved the prediction of behavioral intentions. For steady and casual sex partners, the assumption of the mediating role of personal norms on condom use intention was confirmed empirically. Additionally, sexual motives for unprotected anal sex exerted, as expected, a direct, negative effect on condom use intention with casual sex partners.

Thus, the result of the first step of Intervention Mapping is a thorough identification of the needs of the target population, which provided the starting point for intervention development. Chapter 5 describes the application of Intervention Mapping 2 to 6 to developing a theory-and evidence-based intervention to promote sexual health in HIV-positive MSM. In Intervention Mapping Step 2, the focus was on the improvement of two health-promoting behaviors: satisfactory sexual functioning and safer sexual behavior. These behaviors were then linked with selected personal and external determinants, such as attitudes and social support, to produce a set of proximal program objectives. In Intervention Mapping Step 3, theory-informed intervention methods were identified to influence the change objectives and were translated into practical strategies. Although theory-informed intervention methods were derived from various theories, self-regulation theory and a cognitive behavioral model of change provided the main framework for selecting the intervention methods. The main strategies chosen were bibliotherapy (i.e., the use of written material to help people solve problems or change behavior) and motivational interviewing. In Intervention Mapping Step 4, the theoretical methods and practical strategies were applied in a program that comprised a self-help guide, a motivational interviewing session and a motivational interviewing telephone call, both delivered by specialist nurses in HIV treatment centers. In Intervention Mapping Step 5, implementation was anticipated by developing a linkage group to ensure involvement of program users in the planning process and conducting additional research to better understand how to implement our program. In Intervention Mapping Step 6, program evaluation was anticipated based on the planning process from the previous Intervention Mapping steps.

Chapter 6 reports on the effectiveness of the self-help and motivational enhancement intervention to promote sexual health in HIV-positive MSM. A total of 162 participants from 15 HIV treatment centers participated in the study. Data collection took place at baseline and three-month follow-up. Evaluation was based on $135(83.3 \%)$ participants who completed the 3-month follow-up survey. Participants included 50 (79.4\%) in the intervention group and 85 (85.9\%) in the waiting list control group. In this study, it was hypothesized that the self-help and motivational enhancement intervention would lead to significantly less sexual dysfunction and 
fewer sexual risk behaviors with steady and casual sex partners (primary outcomes). In addition, it was hypothesized that the self-help and motivational enhancement intervention would exhibit to increased preparatory behaviors to actual practice safer sex behaviors (e.g., buying condoms, carrying condoms and communicating about condoms) and action control (i.e., self-regulatory effort in implementing and maintaining behavior). Other secondary outcomes were psychosocial determinants of condom use with steady and casual sex partners, self-esteem, appearance evaluation, and social support. The three months follow-up results showed that the hypotheses regarding the positive effects of our intervention were not confirmed. The lack of significant effects of the intervention is disappointing, especially because a lot of effort was put in systematic program development. Process data helped partially explain why the program was not successful in meeting its program goals. The results showed that the HIV-positive MSM positively evaluated program components. However, implementation of the program was moderate. Additional research is needed to establish why the intervention showed no effect and to find ways to promote sexual health in HIV-positive MSM. 


\section{Samenvatting}

Dit proefschrift beschijft de planmatige ontwikkeling, implementatie en evaluatie van een hiv-preventieve interventie voor hiv-positieve mannen die seks hebben met mannen (MSM). Hoewel de meeste mensen die te horen krijgen dat zij hivpositief zijn veiliger gaan vrijen, toont onderzoek eveneens aan dat een aanzienlijke minderheid van hiv-positieve MSM onbeschermde anale seks heeft. De mogelijke negatieve effecten van onbeschermde anale seks op de gezondheid van MSM (ongeacht hiv-status) zijn groot. Zo lopen niet-geïnfecteerde mannen niet alleen risico geïnfecteerd te raken met hiv, zij lopen ook risico op een infectie met een hivresistente virusstam, wat de mogelijkheden voor effectieve behandeling nadelig kan beïnvloeden. Hiv-positieve mannen lopen het risico op andere seksueel overdraagbare aandoeningen (soa) en hiv-superinfectie, wat kan resulteren in een versnelde ontwikkeling van AIDS en vroegtijdige dood. Aangezien de introductie van 'Highly Active AntiRetroviral Therapy' (HAART) in 1996 bij het merendeel van de hivgeïnfecteerden heeft geleid tot substantiële winst in levensduur en -kwaliteit, worden nieuwe hiv-infecties in toenemende mate geassocieerd met MSM die bekend hivpositief zijn en onbeschermde anale seks hebben. Om verdere verspreiding van hiv en soa te voorkomen is het terugdringen van seksueel risicogedrag onder hiv-positieve MSM van groot belang.

Hoofdstuk 1 beschrijft het onderzoeks- en ontwikkelingsproces dat gerapporteerd wordt in hoofdstuk 2 tot en met 6 van dit proefschrift. Naast een uiteenzetting van de redenen waarom in de hiv-preventie de aandacht pas recentelijk uitgaat naar mensen met hiv, wordt Intervention Mapping geïntrocudeerd als leidraad voor de systematische ontwikkeling van op theorie- en onderzoeksgebaseerde voorlichtingsprogramma's. Volgens Intervention Mapping bestaat dit proces uit zes fundamentele stappen: 1) uitvoeren van een 'needs assessment' (analyse van het gezondheidsprobleem, gedrag, omgeving en determinanten van gedrag en omgeving); 2) voorbereiden van matrices van veranderdoelen; 3 ) selecteren van theoretische interventiemethodieken en praktische strategieën; 4) produceren van programma componenten en materialen; 5) plannen van programma adoptie, implementatie en behoud; en 6) plannen van evaluatie. Verder worden in alle stappen de volgende drie basisvaardigheden systematisch toegepast: uitvoeren van literatuuronderzoek, toepassen van theorieën en het doen van aanvullend kwantitatief en kwalitatief onderzoek. Het proefschrift bestaat uit vier delen. In het eerste deel (Intervention Mapping Stap 1; hoofdstuk 2 tot en met 4) gaat de aandacht uit naar de 'needs assessment'. Het tweede deel (Intervention Mapping Stap 2 tot en met 4; hoofdstuk 5) beschrijft de ontwikkeling van een hiv-preventieve interventie. Het derde deel (Intervention Mapping Stap 5; hoofdstuk 5) gaat in op programma-implementatie, terwijl het vierde deel (Intervention Mapping Stap 6; hoofdstuk 6) gericht is op de korte termijn effecten van de hiv-preventieve interventie. Het hoofdstuk wordt 
afgesloten met de belangrijkste conclusies en aanbevelingen voor de praktijk van de hiv-preventie.

Bij de ontwikkeling van een hiv-preventieve interventie voor hiv-positive MSM is het allereerst van belang om meer inzicht te hebben in de gedragsfactoren die ten grondslag liggen aan het gezondheidsprobleem. Daarom beschrijft hoofdstuk 2 de resultaten van een literatuuronderzoek naar de prevalentie van onbeschermde anale seks onder hiv-positieve MSM. In totaal werden 53 studies geïncludeerd die rapporteren over onbeschermde anale seks in crossectionele en longitudinale surveys onder alleen hiv-positieve MSM en MSM met een verschillende hiv-status. Ondanks dat de variatie in design, steekproeftrekking, en de wijze waarop seksueel risicogedrag gemeten wordt vergelijk bemoeilijkte, werden aanzienlijke percentages van onbeschermde anale seks gevonden. Naar voren kwam dat twee op de vijf hivpositieve MSM participeren in onbeschermde anale seks en dat dit vaak voorkomt met sekspartners met een hiv-negatieve of onbekende hiv-status. In aanvulling hierop bleek de prevalentie van onbeschermde anale seks onder hiv-positieve MSM hoger dan onder hiv-negatieve MSM of MSM met een onbekende hiv-status. Bovendien bleek de prevalentie van onbeschermde anale seks onder hiv-positive MSM te zijn toegenomen in de afgelopen jaren. Geconcludeerd werd dat hiv-preventie voor hiv-positieve MSM ter ondersteuning van adoptie en behoud van veiliger seks geïntensiveerd moet worden.

Hoofdstuk 3 geeft meer inzicht in de psychologische processen die ten grondslag liggen aan de beleving van seksualiteit en seksueel risicogedrag onder hiv-positieve MSM. Ten behoeve hiervan werden transcripten van 30 semi-gestructureerde interviews geanalyseerd met QRS NUDIST 4.0. De resultaten van deze studie toonden aan dat hiv-positieve mannen een verscheidenheid aan veranderingen rapporteren in hun seksueel gedrag na kennisname van hun hiv-positieve diagnose. Voorbeelden van deze veranderingen zijn tijdelijke onderbreking in hun seksuele activiteiten en een algemene verslechtering van seksueel functioneren. De meeste mannen bleken na verloop van tijd hun seksleven weer te hervatten. Echter, het merendeel van de mannen gaf aan dat seksualiteit gedomineerd wordt door angst om het hiv-virus over te dragen aan sekspartners en door gevoelens van persoonlijke verantwoordelijkheid voor veiliger seks, met name binnen vaste relaties. Hoewel alle mannen een duidelijke visie bleken te hebben over persoonlijke verantwoordelijkheid voor veiliger seks, bepalen contextuele factoren (zoals partnerkarakteristieken en sociale normen) of deze normen over verantwoordelijkheid voor veiliger seks daadwerkelijk worden omgezet in gedrag. Bovendien bleek een groot aantal mannen niet over de vaardigheiden te beschikken om effectief te communiceren over hun eigen gezondheidsbelangen, te onderhandelen over condoomgebruik en druk te weerstaan om te participeren in seksueel risicogedrag.

Hoofdstuk 4 presenteert een studie naar de determinanten van de intentie tot condoomgebruik voor anale seks met vaste en losse sekspartners. In totaal namen 296 
hiv-positieve MSM verspreid door heel Nederland aan deze studie deel. Gebaseerd op de veronderstelling dat veiliger seks onder hiv-positieven een vorm is van prosociaal gedrag, werd de theorie van gepland gedrag van Ajzen uitgebreid met de normactivatie theorie van Schwarz. In deze studie werd de veronderstelling getoetst dat persoonlijke normen de effecten van de andere psychosociale determinanten zouden mediëren op de intentie tot condoomgebruik voor anale seks. In aanvulling hierop werd de hypothese getoetst dat, afhankelijk van de context waarin de seks plaatsvindt, seksuele motieven (ofwel de behoefte aan onbeschermde anale seks vanwege fysieke of emotionele bevrediging) voor onbeschermde anale seks een negatieve invloed hebben op de intentie tot condoomgebruik, en als zodanig de prosociale tendens om veiliger te vrijen ondermijnen. De resultaten toonden aan dat de theorie van gepland gedag de intentie tot condoomgebruik voor anale seks adequaat voorspelde (voor losse en vaste sekspartners was de verklaarde variantie respectievelijk 52\% en 53\%). Echter, het door ons voorgestelde model van seksuele besluitvorming verbeterde de voorspelling van intentie tot condoomgebruik aanzienlijk. Daarnaast werd de mediërende rol van persoonlijke normen op intentie tot condoomgebruik aangetoond voor zowel vaste als losse sekspartners. Bovendien bleken seksuele motieven - zoals voorspeld - de intentie tot condoomgebruik negatief te beïnvloeden met losse sekspartners, maar niet met vaste sekspartners.

Dus, het resultaat van Intervention Mapping stap 1 is een grondige analyse van de behoeften van de doelgroep, wat de basis vormde voor de ontwikkeling van een hiv-preventieve interventie voor hiv-positieve MSM. In hoofdstuk 5 wordt dit ontwikkelingsproces beschreven, waarbij Intervention Mapping stap 2 tot en met 6 centraal staan. In Intervention Mapping stap 2 ging de aandacht uit naar de volgende twee gezondheidsbevorderende gedragingen: een bevredigend seksueel functioneren en veiliger seks (primair condoomgebruik). Vervolgens werden deze gezondheidsbevorderende gedragingen gekoppeld aan een selectie van persoonlijke en externe determinanten, zoals attitude en sociale steun, wat resulteerde in matrices voor het formuleren van veranderdoelen. In Intervention Mapping stap 3 werden theoretische methodieken geselecteerd die kunnen bijdragen aan de verwezenlijking van de veranderdoelen. Hoewel deze methodieken afkomstig waren uit verschillende theorieën, hebben we ons met name laten inspireren door theorieën over zelfregulatie en cognitieve gedragstherapie. De theoretische methodieken werden vervolgens vertaald in de volgende twee praktische voorlichtingstechnieken: 1) bibliotherapie (het gebruik van geschreven materiaal met als doel mensen te helpen bij het oplossen van problemen of het veranderen van gedrag); en 2) motiverende gespreksvoering. Het doel van Intervention Mapping stap 4 is het samenvoegen van de praktische voorlichtingstechnieken in een coherent voorlichtingsprogramma. Besloten werd een programma te ontwikkelen, dat bestond uit een zelfhulpgids en twee counselingsessies (één 'face-to-face' en één telefonische afspraak) gebaseerd op motiverende gespreksvoering, dat zou worden 
geïmplementeerd door hiv-consulenten in hiv-behandelcentra. In Intervention Mapping stap 5 werd geanticipeerd op programma-implementatie door het samenstellen van verbindingsgroep gericht op het vergroten van de participatie van de programmagebruikers en de doelgroep tijdens het ontwikkelings-en verspreidingsproces. Om er zeker van te zijn dat het programma zo goed mogelijk zou passen binnen de context waarbinnen het programma zou worden geïmplementeerd, werd eveneens aanvullend onderzoek gedaan bij de programmagebruikers ofwel hivconsulenten. Intervention Mapping biedt niet alleen een basis voor de ontwikkeling van een interventie, maar ook voor de evaluatie van een interventie. Daarom werd in Intervention Mapping stap 6 geanticipeerd op programma-evaluatie door het ontwikkelen van een gedetailleerd evaluatieplan op basis van de voorafgaande Intervention Mapping stappen.

In hoofdstuk 6 worden de resultaten gepresenteerd van een studie naar de effectiviteit van de door ons ontwikkelde hiv-preventieve interventie voor hiv-positieve MSM. In totaal namen 162 participanten afkomstig uit 15 hivbehandelcentra deel aan deze studie. Dataverzameling vond plaats voorafgaand aan en drie maanden na start van de interventie. De evaluatie was gebaseerd op 135 (83.3\%) participanten die de schriftelijke nameting invulden, waarvan $50(79.4 \%)$ in de interventie conditie en 85 (85.9\%) in de wachtlijst-controle conditie. Wij verwachtten dat de door ons ontwikkelde interventie zou leiden tot minder seksuele problemen en minder seksueel risicogedrag met vaste en losse sekspartners (primaire uitkomstmaten). Daarnaast was onze verwachting dat de interventie zou leiden tot meer voorbereidende gedragingen voor daadwerkelijk condoomgebruik (kopen, bij je hebben en communiceren over condoomgebruik) en actiecontrole (zogenaamde inspanning voor zelfregulatie van implementatie en behoud van (nieuw) gedrag). Andere secundaire uitkomstmaten waren psychosociale determinanten van condoomgebruik met vaste en losse sekspartners, zelfwaardering, evaluatie van uiterlijk en sociale steun. Drie maanden na de start van de interventie konden de voorspelde positieve effecten noch op de primaire noch op de secundaire uitkomstmaten worden aangetoond. Het gebrek aan significante interventieeffecten is teleurstellend, zeker gelet op alle energie die gestoken is in planmatige programmaontwikkeling. De procesevaluatie bood tot op zekere hoogte inzicht in het ontbreken van significante interventie-effecten. Hoewel de verschillende programma-componenten positief werden beoordeeld door de participanten, bleek de implementatie van het programma matig. Aanvullend onderzoek is noodzakelijk voor het verkrijgen van meer inzicht in het gebrek aan effectiviteit van de interventie en voor het ontwikkelen van effectieve manieren om de seksuele gezondheid van hivpositieve MSM te bevorderen. 


\section{Curriculum vitae}

Nicole van Kesteren werd op 29 augustus 1972 geboren in Zevenaar. In 1990 behaalde zij het VWO diploma aan het Mollerlyceum in Bergen op Zoom. In 1990 startte zij haar studie Gezondheidswetenschappen aan de Universiteit Maastricht. In december 1996 behaalde zij het doctoraal diploma van zowel de afstudeerrichting Gezondheidvoorlichting als de afstudeerrichting Beleid en Beheer van de Gezondheidszorg. Zij volgde eveneens het keuzetracé Vrouwenstudies. In mei 1997 werd zij aangenomen als onderzoeker bij de capaciteitsgroep Gezondheidsvoorlichting van de Universiteit Maastricht, waar zij werkte op het gebied van energiebesparing en hiv-preventie onder migrantenvrouwen. Daarna werkte zij van februari 2000 tot oktober 2006 als Assistent In Opleiding (AIO)/ docent bij de capaciteitsgroep Experimentele Psychologie van de Universiteit Maastricht. Deze aanstelling mondde uit in het schrijven van dit proefschrift. Sinds december 2006 heeft zij een aanstelling als wetenschappelijk medewerker bij de sector Gezondheidsbevordering van TNO Kwaliteit van Leven in Leiden. 